\title{
Advanced Sorbent Development Program \\ Development of Sorbents for Moving-Bed and Fluidized-Bed Applications
}

Volume I: Development of Sorbents for Moving-Bed Applications

Final Report

By

R.E. Ayala

V.S. Venkataramani

September 1998

Work performed under Contract No.: DE-AC21-94MC31089 -02

September 30, 1994 to September 30, 1998

For

U.S. Department of Energy

Federal Energy Technology Center

Morgantown, West Virginia

By

GE Corporate Research and Development

P.O. Box 8

Schenectady, New York 12301

E-mail: Raul.Ayala@crd.ge.com 


\section{DISCLAIMER}

This report was prepared as an account of work sponsored by an agency of the United States Government. Neither the United States Government nor any agency thereof, nor any of their employees, makes any warranty, express or implied, or assumes any legal liability or responsibility for the accuracy, completeness, or usefulness of any information, apparatus, product, or process disclosed, or represents that its use would not infringe privately owned rights. Reference herein to any specific commercial product, process, or service by trade name, trademark, manufacturer, or otherwise does not necessarily constitute or imply its endorsement, recommendation, or favoring by the United States Government or any agency thereof. The views and opinions of authors expressed herein do not necessarily state or reflect those of the United States Government or any agency thereof. 


\begin{abstract}
The integrated gasification combined cycle (IGCC) power system using high-temperature coal gas cleanup is one of the most promising advanced technologies for the production of electric power from coal in an environmentally acceptable manner. Unlike conventional low-temperature cleanup systems that require costly heat exchangers, high-temperature coal gas cleanup systems can be operated near $482-538^{\circ} \mathrm{C}\left(900-1000^{\circ} \mathrm{F}\right)$ or higher, conditions that are a closer match with the gasifier and turbine components in the IGCC system, thus resulting is a more efficient overall system.
\end{abstract}

GE is developing a moving-bed, high-temperature desulfurization system for the IGCC power cycle in which zinc-based regenerable sorbents are currently being used as desulfurization sorbents. Zinc titanate and other proprietary zinc-based oxides are being considered as sorbents for use in the Clean Coal Technology Demonstration Program at Tampa Electric Co.'s (TECo) Polk Power Station. Under cold startup conditions at TECo, desulfurization and regeneration may be carried out at temperatures as low as $343^{\circ} \mathrm{C}\left(650^{\circ} \mathrm{F}\right)$, hence a versatile sorbent is desirable to perform over this wide temperature range. A key to success in the development of high-temperature desulfurization systems is the matching of sorbent properties for the selected process operating conditions, namely, sustainable desulfurization kinetics, high sulfur capacity, and mechanical durability over multiple cycles. Additionally, the sulfur species produced during regeneration of the sorbent must be in a form compatible with sulfur recovery systems, such as sulfuric acid or elemental sulfur processes.

The overall objective of this program is to develop regenerable sorbents for hydrogen sulfide removal from coal-derived fuel gases in the temperature range $343-538^{\circ} \mathrm{C}\left(650-1000^{\circ} \mathrm{F}\right)$. Two categories of reactor configurations are being considered: moving-bed reactors and fluidized-bed (bubbling and circulating) reactors. In addition, a cost assessment and a market plan for large-scale fabrication of sorbents were developed. As an optional task, long-term bench-scale tests of the best moving-bed sorbents were conducted.

Starting from thermodynamic calculations, several metal oxides were identified for potential use as hot gas cleanup sorbents using constructed phase stability diagrams and laboratory screening of various mixed-metal oxide formulations. Modified zinc titanates and other proprietary metal oxide formulations were evaluated at the bench scale and many of them found to be acceptable for operation in the target desulfurization temperature range of $370^{\circ} \mathrm{C}\left(700^{\circ} \mathrm{F}\right)$ to $538^{\circ} \mathrm{C}\left(1000^{\circ} \mathrm{F}\right)$ and regeneration temperatures up to $760^{\circ} \mathrm{C}\left(1400^{\circ} \mathrm{F}\right)$. Further work is still needed to reduce the batch-to-batch repeatability in the fabrication of modified zinc titanates for larger scale applications.

The information presented in this Volume 1 report contains the results of moving-bed sorbent development at General Electric's Corporate Research and Development (GE-CRD). A separate Volume 2 report contains the results of the subcontract on fluidized-bed sorbent development at the Institute of Gas Technology (IGT). 


\section{ACKNOWLEDGMENTS}

Special thanks to all the people who, over the years, contributed in one way or another to the fruitful completion of this multiyear contract. Our sincere appreciation to all those who provided technical insights and managerial guidance at various points in the program. At the risk of forgetting to acknowledge individually each and all of the contributors, the help of the following individuals was particularly appreciated:

- E. Gal and S. Bevan at GE Environmental Services, Inc. (GEESI), and S.G. Kimura, D. Najewicz, and N. Shilling, at GE-CRD who reviewed the project through the years and gave useful advice and guidance.

- T. Chuck and K. McEvoy, who diligently performed most of the tests in the laboratory at GE-CRD. Also A.H. Furman, A. Feitelberg and the technical staff of the GE-CRD pilot plant, who collaborated in the pilot plant and gathered data on the performance of zinc titanates during the 200-hr Test 8 in 1996.

- J. Swisher, E\&A Associates, and the Illinois Clean Coal Institute for providing GE-CRD with the samples of ICCI-2C sorbent for bench evaluation within this program

- M. Wise and W. Goyette of Chemetals, Inc., who provided samples of zinc-manganese sorbents for evaluation at GE-CRD.

- R. Gupta and the technical staff at Research Triangle Institute, who performed the independent 50cycle long-term testing of GE-UCI zinc titanate sorbents in their bench-reactor facilities.

- The authors also acknowledge the helpful discussions with Mr. D. Cicero, DOE's Program Contracting Office Representative, for the support and review of this contract work over the years, as well as the rest of the staff at the U.S. Dept. of Energy, Federal Energy Technology Center, who funded this project under Contract DE-AC21-94MC31089. 


\section{TABLE OF CONTENTS}

ABSTRACT

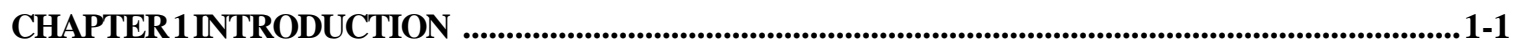

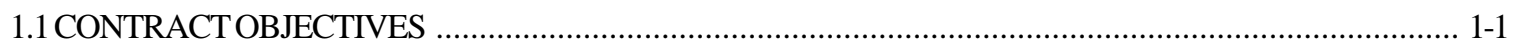

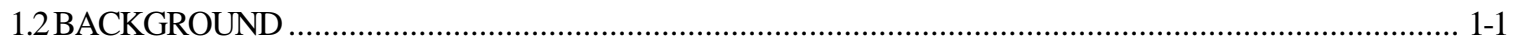

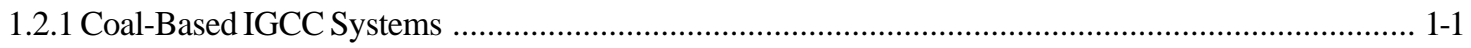

1.2.2 High-Temperature Desulfurization Systems …................................................................ 1-3

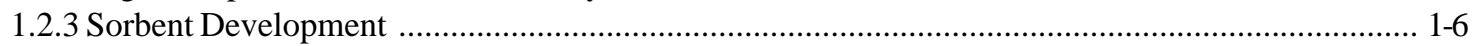

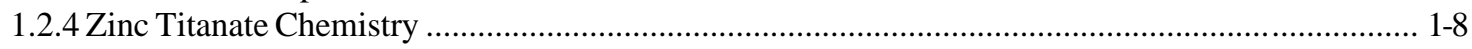

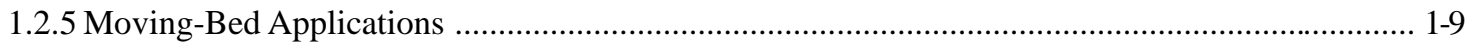

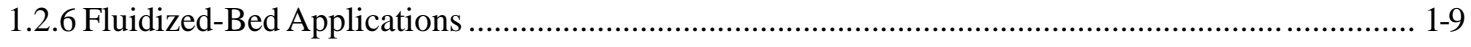

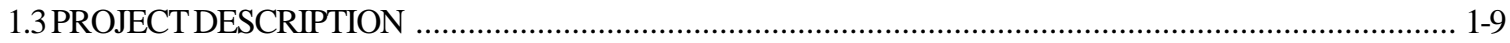

CHAPTER 2 EXPERIMENTAL PROCEDURES ...............................................................................2 2-1

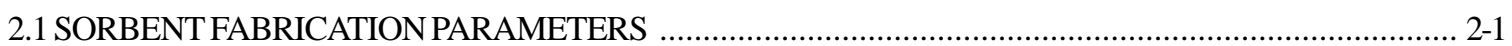

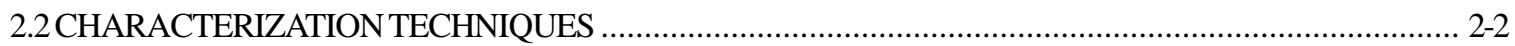

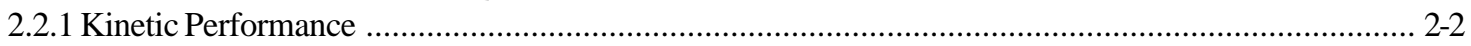

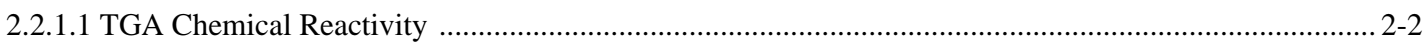

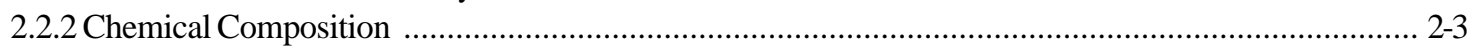

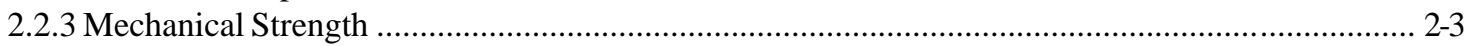

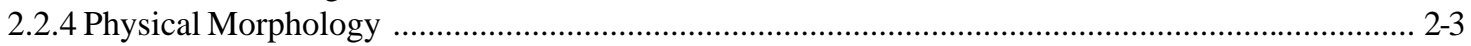

2.2.4.1 Pore Size Distribution by Mercury Porosimetry ...................................................................... 2-3

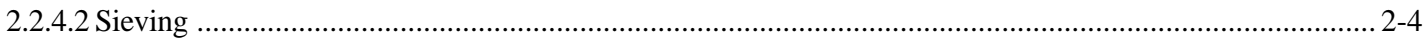

2.3 PROVISION OF BENCH-SCALE REACTOR (TASK 3) ................................................................... $2-4$

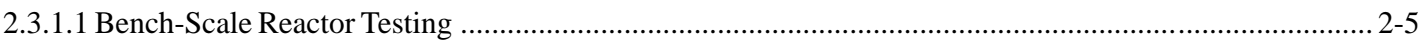

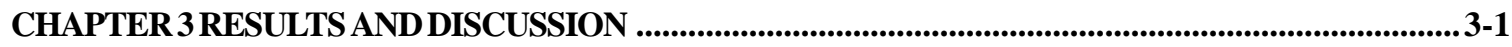

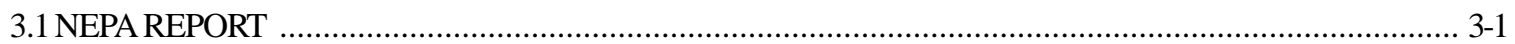

3.2 EVALUATION OF METAL OXIDES AS REGENERABLESORBENTS .......................................... 3-1

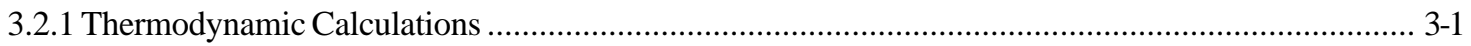

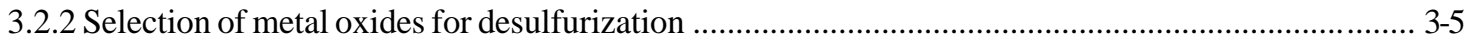

3.3 SORBENT PREPARATION AND BENCH REACTOR TESTING ................................................... 3-7

3.3.1 Testing of UCI-GE Zinc Titanate Sorbents ..................................................................... 3-7

3.3.2 Screening of Sorbents Containing Mixed-Metal Oxides ..................................................... 3-7

3.3.3 Evaluation of Molybdenum-Containing Zinc Titanate Sorbents ........................................... 3-9

3.3.3.1 Screening of laboratory formulations at GE-CRD ....................................................................... 3-9

3.3.3.2 50-cycle of Bench Test at Research Triangle Institute .............................................................. 3-11

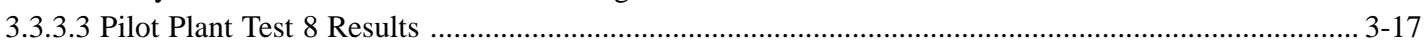

3.3.3.4 Zinc titanate structure determination after sulfidation/regeneration cycles ........................................ 3-20 
3.3.3.5 Regeneration of Mo-doped zinc titanate formulations at higher pressure and

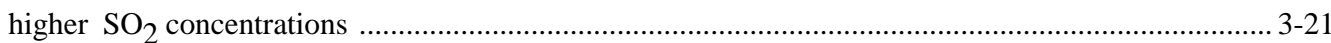

3.3.4 Modified Zinc Titanates (MZT's) with additives ................................................................ 3-27

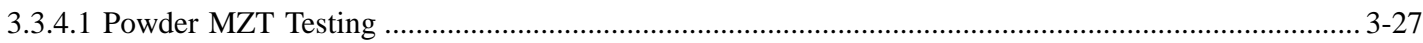

3.3.4.2 Pelletized MZT Sorbent Testing ….................................................................................... 3-31

3.3.4.2.1 Mechanical durability of fresh pelletized sorbents .............................................................. 3-31

3.3.4.2.2 Desulfurization and regeneration characteristics ............................................................... 3-32

3.3.4.2.3 Sulfate formation during regeneration ........................................................................... 3-36

3.3.4.2.4 Temperature range of desulfurization of single pellets ....................................................... 3-36

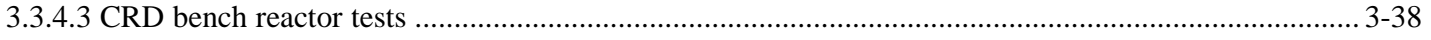

3.3.4.3.1 Mechanical durability of cycled formulations .................................................................. 3-43

3.3.4.3.2 Bench-scale extended multicycle tests at GE-CRD ............................................................ 3-45

3.3.4.3.3 Desulfurization and Regeneration performance at $371^{\circ} \mathrm{C}\left(700{ }^{\circ} \mathrm{F}\right)$ temperatures ....................... 3-48

3.3.4.4 RTI's Independent Bench Evaluation ................................................................................ 3-51

3.3.5 Evaluation of Chemetals Manganese Oxide Sorbents ............................................................ 3-54

3.3.6 Evaluation of ICCI-2C Zinc Titanate Sorbent ................................................................... 3-62

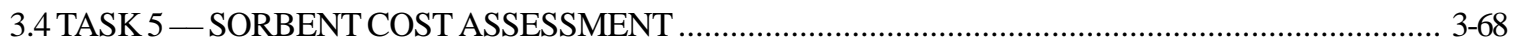

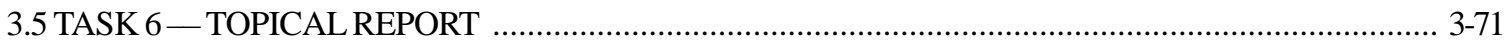

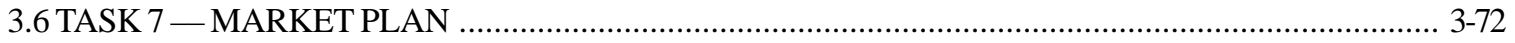

CHAPTER 4 CONCLUSIONS

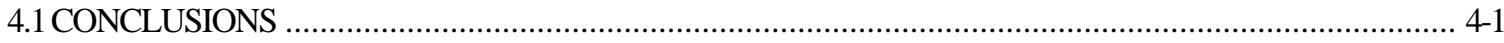

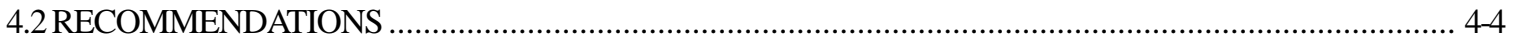




\section{LIST OF TABLES}

Table 2-1 Gas Compositions (vol \%) used in TGA tests .................................................................2-2

Table 2-2 Simulated Coal Gas Composition for Bench-Scale Testing ..............................................2-6

Table 3-1 List of metal components for sorbent screening …................................................ 3-6

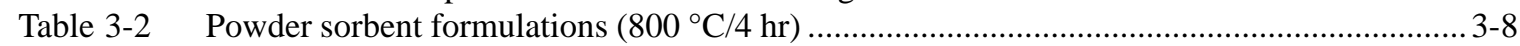

Table 3-3 Zinc/titanium formulations with various additives ...................................................... 3-8

Table 3-4 Powder mixed-metal oxides formulations .............................................................. 3-9

Table 3-5 Gas compositions for 50-cycle test ................................................................. 3-13

Table 3-6 Target test conditions during absorption ........................................................ 3-13

Table 3-7 Sulfur loading of zinc titanate sorbent ........................................................... 3-15

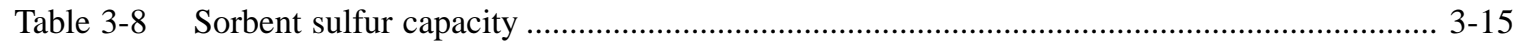

Table 3-9 Attrition results of zinc titanate bench tests at RTI .................................................... 3-17

Table 3-10 Major structure of Mo-doped zinc titanate by XRD ...................................................... 3-20

Table 3-11 GE Modified Zinc Titanate Formulations .................................................................. 3-27

Table 3-12 Properties of the first round of pelletized fresh samples ............................................. 3-31

Table 3-13 Mechanical properties of the second round of zinc titanate formulations ...................... 3-32

Table 3-14 Target test conditions during absorption in bench tests ......................................... 3-38

Table 3-15 Test conditions in the GE-CRD reactor system during quadrant bench tests .................... 3-39

Table 3-16 Formulations loaded into bench quadrant tests at GE-CRD ....................................... 3-40

Table 3-17 Attrition and sulfur results on 5th regeneration samples from quadrant bench test \#1 ...... 3-43

Table 3-18 Attrition and sulfur results on 5th regeneration samples from quadrant bench test \#2 ....... 3-44

Table 3-19 Bench-Scale Extended testing of MZT-I1 ....................................................... 3-47

Table 3-20 Preliminary results of screening tests at RTI on MZT-R1 .......................................... 3-53

Table 3-21 XRD Analysis of CST939 sorbent …....................................................................... 3-56

Table 3-22 Bench-Scale Test Parameters for Chemetals CST-939 Sorbent ........................................ 3-60

Table 3-23 Residual sulfur of ICCI-2C samples after bench-scale testing at GE-CRD ........................ 3-60

Table 3-24 Relative cost of metal oxides for sorbent fabrication .................................................... 3-68

Table 4-1 List of metal components for sorbent screening ......................................................... 


\section{LIST OF FIGURES}

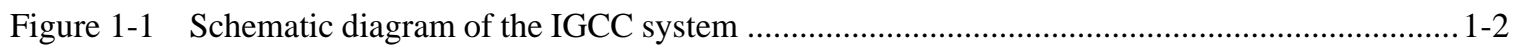

Figure 1-2 Schematic diagram of the GE-CRD pilot plant ................................................................... 1-4

Figure 2-1 Schematic diagram of the gas flow system in the bench-scale reactor ...................................2-5

Figure 3-1 $\mathrm{H}_{2} \mathrm{~S}$ equilibrium concentration in fuel gas (Texaco) with various oxides ...............................3-3

Figure 3-2 $\mathrm{H}_{2} \mathrm{~S}$ equilibrium concentration in fuel gas (U-GAS) with various oxides ..............................3-3

Figure 3-3 Phase stability diagrams for Zn-S-O, Mo-S-O, Cu-S-O, and Mn-S-O systems ......................... 3-4

Figure 3-4 Phase stability diagrams for Co-S-O, Fe-S-O, W-S-O, and Ce-S-O systems ............................. 3-5

Figure 3-5 $\mathrm{H}_{2} \mathrm{~S}$ breakthrough curve for the simultaneous bench reactor testing of four formulations

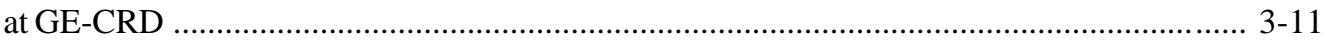

Figure 3-6 Envelope of breakthrough curves for zinc titanate screening at GE-CRD .......................... 3-11

Figure 3-7 ASTM attrition results on sorbents after the 20th regeneration in bench screening

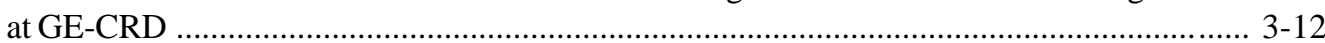

Figure 3-8 Pellet distribution after ASTM attrition test (20th. regeneration) ....................................... 3-12

Figure 3-9 TGA sulfur capacity of sorbents after 20-cycles ........................................................ 3-12

Figure 3-10 $\mathrm{H}_{2} \mathrm{~S}$ breakthrough curves for 50-cycle test of zinc titanate at RTI .................................... 3-14

Figure 3-11 Envelope of breakthrough curves for zinc titanate testing at RTI ................................... 3-14

Figure 3-12 TGA sulfur capacity of powdered samples after 50 cycles of testing at RTI ....................... 3-16

Figure 3-13 TGA reactivity of T-3121 zinc titanate pellets after 50 cycles of bench tests at RTI ........ 3-16

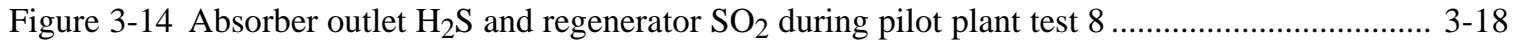

Figure 3-15 TGA reactivity of T-2594M zinc titanate pellets after 200 hours of pilot plant Test 8

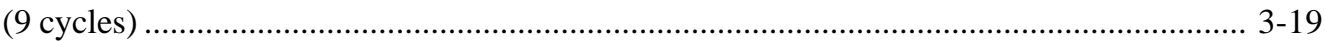

Figure 3-16 $\mathrm{H}_{2} \mathrm{~S}$ breakthrough curves for T-2594M when regeneration under regeneration with $\mathrm{SO}_{2}$

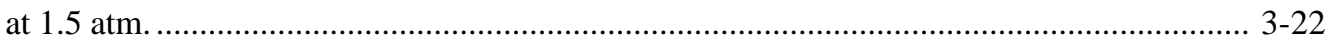

Figure 3-17 Envelope of $\mathrm{H}_{2} \mathrm{~S}$ breakthrough curves for T-2594M when regenerating under $\mathrm{SO}_{2}$

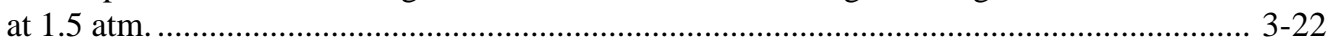

Figure 3-18 $\mathrm{H}_{2} \mathrm{~S}$ breakthrough curves for T-2594M with regeneration performed with $\mathrm{SO}_{2}$ at 3 atm. . 3-23

Figure 3-19 Envelope of $\mathrm{H}_{2} \mathrm{~S}$ breakthrough curves for T-2594M with regeneration performed with $\mathrm{SO}_{2}$ at $3 \mathrm{~atm}$.

Figure 3-20 $\mathrm{H}_{2} \mathrm{~S}$ breakthrough curves for T-2594M with regeneration performed with $\mathrm{SO}_{2}$ at $5 \mathrm{~atm}$ and $704{ }^{\circ} \mathrm{C}$ (cycles $\left.1-5\right)$ or $760^{\circ} \mathrm{C}\left(1400{ }^{\circ} \mathrm{F}\right)($ cycles 6-8) ............................................... 3-24

Figure 3-21 Envelope of $\mathrm{H}_{2} \mathrm{~S}$ breakthrough curves for T-2594M with regeneration performed with $\mathrm{SO}_{2}$ at $5 \mathrm{~atm}$ and $704{ }^{\circ} \mathrm{C}\left(1300{ }^{\circ} \mathrm{F}\right)$ (cycles 1-5) or $760{ }^{\circ} \mathrm{C}\left(1400{ }^{\circ} \mathrm{F}\right)$ (cycles 6-8) ...... 3-24

Figure 3-22 $\mathrm{H}_{2} \mathrm{~S}$ breakthrough curves for T-2594M with regeneration performed with $\mathrm{SO}_{2}$ at $5 \mathrm{~atm}$

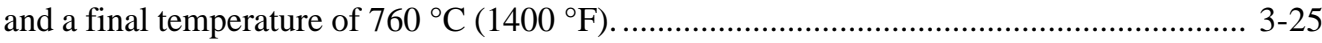

Figure 3-23 Envelope of $\mathrm{H}_{2} \mathrm{~S}$ breakthrough curves for T-2594M with regeneration performed with $\mathrm{SO}_{2}$ at 5 atm and a final $\mathrm{N}_{2}$ decomposition temperature of $760{ }^{\circ} \mathrm{C}\left(1400{ }^{\circ} \mathrm{F}\right)$............ 3-25

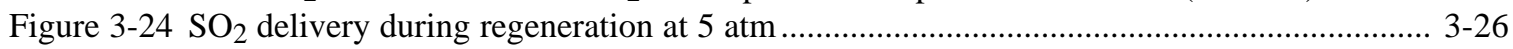

Figure 3-25 TGA chemical reactivity of ZT9607 zinc titanate ........................................................... 3-29

Figure 3-26 TGA Chemical reactivity of ZT9603 zinc titanate without stabilizer ................................ 3-29

Figure 3-27 TGA reactivity of a zinc titanate with a phase stabilizer ................................................ 3-30

Figure 3-28 TGA reactivity of powder modified zinc titanates at $482{ }^{\circ} \mathrm{C}, 3 \% \mathrm{H}_{2} \mathrm{~S}$, and $1 \mathrm{~atm}$............ 3-30

Figure 3-29 TGA Reactivity of PP4114 zinc titanate at $482^{\circ} \mathrm{C}\left(900^{\circ} \mathrm{F}\right)$......................................... 3-33

Figure 3-30 TGA Reactivity of PP4118 zinc titanate at $482{ }^{\circ} \mathrm{C}\left(900{ }^{\circ} \mathrm{F}\right)$........................................ 3-33

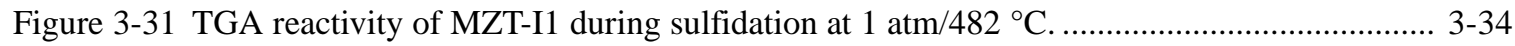

Figure 3-32 TGA reactivity of MZT-O1 during sulfidation at $1 \mathrm{~atm} / 492{ }^{\circ} \mathrm{C}$..................................... 3-34

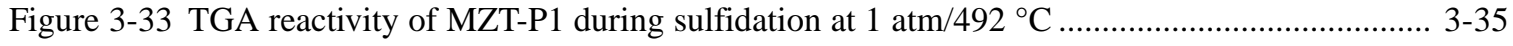

Figure 3-34 TGA reactivity of MZT-R1 during sulfidation at $1 \mathrm{~atm} / 492{ }^{\circ} \mathrm{C}$........................................ 3-35

Figure 3-35 TGA reactivity of MZT-G1 during sulfidation at $1 \mathrm{~atm} / 492{ }^{\circ} \mathrm{C}$...................................... 3-36

Figure 3-36 TGA weight gain due to sulfate formation during regeneration of the pelletized modified zinc titanates at $1 \mathrm{~atm}$ and $718^{\circ} \mathrm{C}\left(1325^{\circ} \mathrm{F}\right)$................................................... 3-37

Figure 3-37 TGA reactivity of MZT-R1 zinc titanate as a function of temperature ............................... 3-37 
Figure 3-38 Breakthrough curves during absorption for the modified zinc titanate sorbents

(Quadrant Bench Test \#1) .................................................................................... 3-40

Figure 3-39 Temperatures profiles for the four sorbents tested under the Quadrant Bench Test \#1........ 3-41

Figure 3-40 Temperatures profiles for the four sorbents tested under the Quadrant Bench Test \#1 ........ 3-42

Figure 3-41 Breakthrough curves for T-2594M zinc titanate with regeneration at 5 atm and $8 \% \mathrm{SO}_{2}$ in the regeneration gas

Figure 3-42 Outlet $\mathrm{H}_{2} \mathrm{~S}$ concentration from the pilot plant absorber using T-2594M during Test 8 (1995)

Figure 3-43 Attrition resistance ratios of zinc titanate formulations after 5 cycles of bench-scale testing (Quadrant Bench Test \#1) .................................................................................... 3-44

Figure 3-44 Breakthrough curves of MZT-I1 for the first 10 cycles of screening ................................. 3-45

Figure 3-45 Breakthrough curves of MZT-I1 after the first 10 cycles of screening .............................. 3-46

Figure 3-46 Envelope of the breakthrough curves at $120 \mathrm{~min}$ of absorption for MZT-I1 ...................... 3-46

Figure 3-47 $\mathrm{H}_{2} \mathrm{~S}$ breakthrough curves for absorption by MZT-R1 at $371^{\circ} \mathrm{C}\left(700^{\circ} \mathrm{F}\right)$.......................... 3-48

Figure 3-48 Temperature profiles during regeneration of MZT-R1 at $371{ }^{\circ} \mathrm{C}\left(700{ }^{\circ} \mathrm{F}\right)$

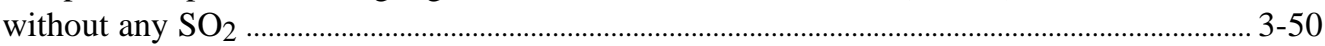

Figure 3-49 Temperature profiles during regeneration of MZT-R1 at $371{ }^{\circ} \mathrm{C}\left(700{ }^{\circ} \mathrm{F}\right)$ with $10 \% \mathrm{SO}_{2}$ added $3-50$

Figure 3-50 Breakthrough curves for MZT-R1 sorbent for 5-cycles in screening bench tests performed at RTI

Figure 3-51 Breakthrough curves for MZT-I1 sorbent for 5-cycles in screening bench tests performed at RTI

Figure 3-52 Breakthrough curves for MZT-I1 sorbent for 13 cycles in screening bench tests performed at RTI

Figure 3-53 Mechanical Strength of Chemetals Sorbents $3-54$

Figure 3-54 First sulfidation on CST 939 manganese oxide sorbent in a TGA .................................... 3-55

Figure 3-55 TGA regeneration profile of CST-939 sorbent powder at $1350{ }^{\circ} \mathrm{F}$ and $2 \% \mathrm{O}_{2} \ldots \ldots \ldots \ldots \ldots \ldots \ldots . . . . . . . .3-56$

Figure 3-56 Equilibrium diagram for the system Mn-O-S at $550{ }^{\circ} \mathrm{C}\left(1022^{\circ} \mathrm{F}\right)$................................... 3-57

Figure 3-57 Second TGA absorption of CST-939 sorbent powder at $100{ }^{\circ} \mathrm{F}$ and $3 \% \mathrm{H}_{2} \mathrm{~S}$.

Reductive regeneration started at $\sim 50$ min. $\mathrm{H}_{2} \mathrm{~S}$ introduced at 125 minutes .................... 3-57

Figure 3-58 First absorption of CST 10255-171-3 sorbent .......................................................... 3-58

Figure 3-59 Chemetals CST-939 breakthrough curves .................................................................. 3-61

Figure 3-60 Sulfur species evolved during Reductive Regeneration \#1 ............................................... 3-61

Figure 3-61 Sulfur species evolved during Reductive Regeneration \#2 ............................................... 3-62

Figure 3-62 Breakthrough curves of ICCI-2C during bench testing at GE-CRD .................................. 3-63

Figure 3-63 Envelope of the breakthrough curves for bench testing of ICCI-2C at GE-CRD ............... 3-64

Figure 3-64 TGA Reactivity of ICCI-2C samples from the gas inlet location ....................................... 3-65

Figure 3-65 TGA Reactivity of ICCI-2C samples from the gas outlet location ..................................... 3-65

Figure 3-66 Temperature history of ICCI-2C during bench-scale absorptions and regenerations ......... 3-66

Figure 3-67 Sorbent makeup cost versus percent sorbent makeup ........................................................... 3-69 


\section{EXECUTIVE SUMMARY}

\section{BACKGROUND}

The integrated gasification combined cycle (IGCC) power system using high-temperature coal gas cleanup is one of the most promising advanced technologies for the production of electric power from coal in an environmentally acceptable manner. Unlike conventional low-temperature cleanup systems that require costly heat exchangers, high-temperature coal gas cleanup systems can be operated near $482-538^{\circ} \mathrm{C}\left(900-1000{ }^{\circ} \mathrm{F}\right)$ or higher, conditions that are a closer match with the gasifier and turbine components in the IGCC system, thus resulting in a more efficient overall system.

GE is developing a moving-bed, high-temperature desulfurization system for the IGCC power cycle in which zinc-based regenerable sorbents are currently being used as desulfurization sorbents. Zinc titanate and other proprietary zinc-based oxides are being considered as sorbents for use in the Clean Coal Technology Demonstration Program at Tampa Electric Co.'s (TECo) Polk Power Station. Under cold startup conditions at TECo, desulfurization and regeneration may be carried out at temperatures as low as $343^{\circ} \mathrm{C}\left(650^{\circ} \mathrm{F}\right)$; hence a versatile sorbent is desirable to perform over this wide temperature range. A key to success in the development of high-temperature desulfurization systems is the matching of sorbent properties for the selected process operating conditions, namely, sustainable desulfurization kinetics, high sulfur capacity, and mechanical durability over multiple cycles. Additionally, the sulfur species produced during regeneration of the sorbent must be in a form compatible with sulfur recovery systems, such as sulfuric acid or elemental sulfur processes.

\section{OBJECTIVES}

The overall objective of this program is to develop regenerable sorbents for hydrogen sulfide removal from coal-derived fuel gases in the temperature range $343-538^{\circ} \mathrm{C}\left(650-1000{ }^{\circ} \mathrm{F}\right)$. Two categories of reactor configurations are being considered: moving-bed reactors and fluidized-bed (bubbling and circulating) reactors. In addition, a cost assessment and a market plan for large-scale fabrication of sorbents were developed. As an optional task, long-term bench-scale tests of the best moving-bed sorbents were conducted.

The information presented in this Volume 1 report contains the results of moving-bed sorbent development at General Electric's Corporate Research and Development (GE-CRD). A separate Volume 2 report contains the results of the subcontract on fluidized-bed sorbent development at the Institute of Gas Technology (IGT). 


\section{ACCOMPLISHMENTS}

- Thermodynamic equilibrium calculations were performed for metal oxides under desulfurization conditions to determine the predicted desulfurization efficiency from coal gases in the temperature range $343-538^{\circ} \mathrm{C}$. Phase stability diagrams were constructed for oxidative regeneration conditions of the same metal oxides. From an initial list of twenty metal oxides, the number of viable candidates was reduced to six desulfurization and three structural components for laboratory evaluation. This work complements previous thermodynamic calculations of desulfurization at temperatures from $500{ }^{\circ} \mathrm{C}$ to $800{ }^{\circ} \mathrm{C}$ available in the literature.

- Evaluation of molybdenum-containing zinc titanate was performed from laboratory and bench scale to pilot plant $(4500 \mathrm{~kg})$ to correlate desulfurization reactivity and mechanical durability of sorbents and determine operating costs after scale up. The optimized formulation achieved $99 \% \mathrm{H}_{2} \mathrm{~S}$ removal from coal gas in the pilot plant and produced $8 \% \mathrm{SO}_{2}$ in the regeneration gas stream over 200 hours of operation.

- To expand the temperature operating window of zinc titanates from $482^{\circ} \mathrm{C}$ down to $343^{\circ} \mathrm{C}$, metal additives were used to produce various formulations, such as MZT-R1, which are capable of desulfurization and regeneration without preconditioning at least down to $371^{\circ} \mathrm{C}\left(700^{\circ} \mathrm{F}\right)$, conditions that are representative of cold startup at TECo's Polk Power Station HGCU demonstrationscale system.

- Two types of proprietary sorbents supplied by external vendors (ICCI-2C sorbent from E\&A Associates/Illinois Clean Coal Institute, and various zinc-manganese sorbents from Chemetals) were evaluated at GE-CRD's bench reactor to qualify for additional long-term testing.

- Sorbent operating costs for a commercial power plant using a moving-bed HGCU system were calculated. Guidelines for raw materials cost, fabrication costs, and replacement or makeup costs were calculated using a sorbent total operating cost of $0.16-0.2$ cents/ $/ \mathrm{kWh}$ for a typical $250 \mathrm{MW}$ IGCC power plant. A market plan, including recommendations for sorbent fabrication in commercial scale and identification of various vendors for the fabrication of the identified zinc titanate and proprietary sorbents, was established.

\section{RESULTS AND CONCLUSIONS}

The following results and conclusions were drawn from the evaluation of metal oxides from thermodynamic and kinetic principles in order to identify sorbent formulations suitable for fabrication and laboratory evaluation:

- A literature review of past work and screening thermodynamic calculations of metal oxides identified twenty metal oxides that had the potential for use in hot gas desulfurization systems in the temperature range of 343 to $538^{\circ} \mathrm{C}$. These were considered for further experimental evaluation.

- Thermodynamic equilibrium diagrams of $\mathrm{H}_{2} \mathrm{~S}_{(\mathrm{g})}$ over metal oxides were constructed as a function of temperature to determine the maximum sulfur removal possible at the given temperature range. Two 
coal gas fuel compositions were chosen: oxygen-blown, entrained-flow gasifier and air-blown, fluidized-bed gasifier. Of the twenty metal oxides initially considered, manganese, molybdenum, cobalt, zinc, and copper oxides were identified as having the low equilibrium $\mathrm{H}_{2} \mathrm{~S}$ and the required kinetic rates to desulfurize coal gas to the target of less than $25 \mathrm{ppm}_{2} \mathrm{~S}$.

- Corresponding phase stability diagrams of the metal sulfides in oxidative regeneration gases were also constructed to identify the regeneration capabilities of the promising desulfurization metal oxides. Zinc, copper, iron and molybdenum among others were the metals that thermodynamically and kinetically exhibited promising characteristics for regeneration at temperatures compatible with the desulfurization range chosen. Manganese required a higher temperature of regeneration than the others but still could be considered for evaluation.

- Three categories of metal oxides were considered for evaluation: (1) main components for desulfurization, (2) secondary components for desulfurization, chemical stability additives, or porosity modifiers, and (3) structural components to maintain mechanical durability of the pellets.

- The following table summarizes the metal oxides that were identified in each of the three categories as potential candidates for laboratory fabrication and evaluation.

\section{List of metal components for sorbent screening.}

\begin{tabular}{ccc}
\hline Main Component & Secondary Component & Structural Component \\
\hline $\mathrm{Zn}$ & $\mathrm{Fe}, \mathrm{Cu}, \mathrm{Mo}, \mathrm{Co}$ & $\mathrm{Ti}, \mathrm{Zr}, \mathrm{Ce}$ \\
$\mathrm{Fe}$ & $\mathrm{Cu}$ & $\mathrm{Ti}, \mathrm{Zr}$ \\
$\mathrm{Ce}$ & $\mathrm{Mo}$ & $\mathrm{Ti}, \mathrm{Zr}$ \\
$\mathrm{Cu}$ & $\mathrm{Mn}$ & $\mathrm{Ti}, \mathrm{Zr}$ \\
\hline
\end{tabular}

The following conclusions can be drawn from the sorbent fabrication and experimental evaluation of UCI-GE zinc titanates:

- Molybdenum-containing zinc titanate (at 2\% equivalent molybdenum oxide) exhibited a good combination of chemical and mechanical properties during laboratory testing at GE-CRD. Further testing at RTI's facilities during 1996 showed that requirements at that time for chemical reactivity and sulfur loading were exceeded at the target levels of $50 \%$ of theoretical. The mechanical ASTM attrition loss was well below the target level for the fresh material ( $0.7 \%$ vs. $4 \%$ target) although the same ASTM attrition loss after 50 cycles was higher at $7.4 \%$ versus the target of $5 \%$. Higher levels of attrition resistance would be required ultimately for this sorbent to be economically viable in commercial systems.

- The same molybdenum-containing formulation studied in the laboratory was also tested for 200 hours of continuous operation in the GE-CRD pilot plant under Test 8 in September 1998 to determine the correspondence in performance between bench-scale conditions in the laboratory and pilot plant operation. The pilot plant makeup losses were measured at 1.7 and $0.3 \%$ for the 200 -hr cycled sorbent under conditions of two different mesh sizes of the vibrating screen that 
removes the sorbent fines. These results are better than the 7.4\% ASTM attrition loss measured after 50 cycles in the laboratory, indicating that the large-scale operation is less severe and the cost of sorbent replacement or makeup in the pilot plant is less than predicted from ASTM tests. With respect to desulfurization performance in the GE-CRD pilot plant, close to $99 \%$ sulfur removal (30-40 ppm dry residual $\mathrm{H}_{2} \mathrm{~S}$ in the clean gas) was obtained while simultaneously achieving the target sulfur loading on the sorbent for TECo and $\mathrm{SO}_{2}$ production during regeneration. The results at the three levels of testing indicate that the flow of information and technology transfer from laboratory to pilot plant is technically consistent and prediction of larger pilot-plant scale operation is possible from laboratory and bench test results.

- Several formulations of modified zinc titanates (MZT's) were pelletized to aim at improvements in mechanical durability over the previously tested molybdenum-containing zinc titanate formulations. Two rounds of formulations containing additives were prepared. Although the first round of formulations was disappointingly weak in mechanical strength, the second round of pelletization included two formulations, MZT-I1 and MZT-R1, which exhibited improved characteristics. Both presented better mechanical durability with negligible degradation with respect to the fresh formulation, but only MZT-R1 was capable of meeting the requirements of sulfur loading of $0.11 \mathrm{~g}$ of sulfur $/ \mathrm{cm}^{3}$ of bed $\left(6.7 \mathrm{lb} / \mathrm{ft}^{3}\right)$ at the low temperatures of operation $\left(370^{\circ} \mathrm{C}, 700^{\circ} \mathrm{F}\right)$.

- Batch-to-batch repeatability in the fabrication of MZT's, however, is still an issue. ASTM attrition loss of different batches of fresh MZT-R1 prepared for testing at GE-CRD and RTI ranged from 0.7 to $2.0 \%$. This batch-to-batch variability in the attrition resistance of fresh samples is large compared to the corresponding changes in attrition loss, typically less than $1 \%$, that occur over repetitive testing. Further refinements to the formulation of MZT compositions will require better control in the pelletization procedures.

- Testing at RTI for 13 cycles at bench-scale conditions showed that the two MZT sorbents considered (MZT-R1 and MZT-I1) can desulfurize and regenerate at conditions resembling those encountered at the TECo plant, namely, desulfurization in the range $373-482^{\circ} \mathrm{C}\left(700-900^{\circ} \mathrm{F}\right)$ and regeneration up to $760^{\circ} \mathrm{C}\left(1400^{\circ} \mathrm{F}\right)$. In spite of these positive results, more work is needed to circumvent the impending degradation of the pellets over a higher number of cycles.

The following conclusions can be drawn from the testing of proprietary sorbents in the GE-CRD pressurized bench-scale reactor system:

- Several formulations of zinc oxide/manganese oxide sorbents provided by Chemetals (Baltimore, Maryland) were evaluated at GE-CRD for mechanical durability (attrition and crush strength) and chemical reactivity.

- Evaluation of Chemetals manganese-containing zinc-based sorbents suggested that improvements in mechanical strength can be brought about by the manganese component to the sorbent. Given that manganese by itself cannot remove $\mathrm{H}_{2} \mathrm{~S}$ to as low levels as zinc-based sorbents can, the combination gives a synergistic advantage of deep desulfurization and added mechanical strength. However, improvements in the fabrication procedures aimed at increasing attrition resistance of the manganese-zinc pellets are necessary to compete against other zinc-containing sorbents in durability.

- Evaluation of ICCI-2C sorbent was carried out at GE-CRD with the purpose of evaluating the reactivity and durability of the sorbent in pelletized forms. ASTM attrition losses after 13 cycles of bench testing (range 1.89-2.09\%) were comparable to that of the fresh sorbent (2.16\%), suggest- 
ing that this sorbent is a potential candidate for long-term use. All testing was performed at $482{ }^{\circ} \mathrm{C}$ for absorption and regeneration; evaluation at lower temperatures is still needed to confirm suitability for low-temperature operation down to $343^{\circ} \mathrm{C}$.

- ICCI-2C is capable of operating under pilot plant conditions (1.5-atm regeneration) provided an activation step of three to five cycles is carried out in the absence of $\mathrm{SO}_{2}$ during regeneration. Evaluation at higher generation pressures (i.e., 7 atm), as in the TECO demonstration plant, will require additional bench-scale testing before confirming the suitability of the sorbent for those conditions.

- With respect to the economics of operating a moving-bed HGCU system, a reasonable target for the sorbent operating cost to a utility company is 0.1 to 0.2 cents $/ \mathrm{kWh}$. To operate below this target and be commercially viable, the sorbent makeup rate must be less than 0.16 to $0.2 \%$ at a sorbent purchase price of \$3-5/lb to make the moving-bed HGCU systems feasible. Higher sorbent prices or higher make-up rates make the HGCU system commercially less attractive. Currently, sorbent manufacturers consider these sorbent sale prices achievable in commercial quantities.

\section{RECOMMENDATIONS}

The development of zinc titanates, whether in the form of molybdenum-added formulations or modified zinc titanates (MZT's), has reached a level of understanding that makes them suitable for commercial applications. Evaluation of desulfurization reactivity at the laboratory, bench-scale, and pilot-plant facilities has shown that zinc titanates and proprietary sorbents can easily meet the target levels of $99 \%$ desulfurization of coal gases in the temperature range of 343 to $538^{\circ} \mathrm{C}$.

A significant issue that still remains with the use of zinc titanates is the capability to control the fabrication procedures that result in predictable sorbent mechanical properties, particularly the ASTM attrition resistance. To date, variations from batch to batch have a spread that is comparable to the changes observed during testing over five to fifteen cycles. It is recommended that a program be undertaken with commercial sorbent suppliers aimed at understanding and minimizing the variability in the physical morphology and mechanical properties of the pelletized sorbents.

For the case of Chemetals manganese-zinc sorbents, given that addition of zinc oxide decreased the attrition resistance of the pure manganese sorbents, a study of the production methods and mixing variability is also needed.

For the case of ICCI-2C sorbents, a study is needed on the operability of the sorbent at temperatures in the range 343 to $482^{\circ} \mathrm{C}$ to determine if the chemical reactivity is sufficient to operate a commercial system at the desired sulfur loadings. In addition, methods should be investigated that decrease the level of conditioning or activation that is currently required over the first three to five cycles.

Overall the technology of manufacturing pelletized sorbents for desulfurization in moving-bed applications has reached a high level of maturity that makes it possible to assess current sorbent performance in laboratory and bench-scale systems and correlate with pilot-scale performance. Extrapolation of these performance parameters is still necessary when going to commercial scale systems, since no data have been generated at these scales. 


\section{Chapter 1 INTRODUCTION}

\subsection{CONTRACT OBJECTIVES}

The overall objective of this program is to develop regenerable sorbents for hydrogen sulfide removal from coal-derived fuel gases in the temperature range $343-538^{\circ} \mathrm{C}\left(650-1000{ }^{\circ} \mathrm{F}\right)$. Two categories of reactor configurations are being considered: fixed-bed/moving-bed reactors and fluidized-bed (bubbling and circulating) reactors. In addition, a cost assessment and a market plan for large-scale fabrication of sorbents will be developed. As an optional task, long-term bench-scale tests (up to 100 cycles) of the best fixed-bed/moving-bed and fluidized-bed sorbents will be conducted.

The sorbents must have chemical characteristics that permit cyclic regeneration over many cycles without a drastic loss of activity. They must also have physical characteristics that are compatible with the selected reactor (e.g., moving bed vs. fluidized bed), and which remain acceptable during absorption and regeneration. The sorbents must be capable of reducing the hydrogen sulfide level in the fuel gas to less than $20 \mathrm{ppmv}$ in the specified temperature range and pressures in the range of 1 to 20 atmospheres.

\subsection{BACKGROUND}

\subsubsection{Coal-Based IGCC Systems}

Global power generation markets have shown a steady penetration of gas turbine/combined cycle technology into oil- and gas-fired applications as the technology has matured. The low cost, improved reliability, and efficiency advantages of combined cycles can now be used to reduce the cost of electricity and meet environmental acceptance of fuels other than natural gas such as coal, heavy oil, petroleum coke, and waste products.

According to Holt, ${ }^{1}$ coal and lignite account for approximately 3400 gigatons of oil equivalents (Gtoe), or $76 \%$, of the total recoverable fossil fuel reserves in the world, which is estimated at 4400 Gtoe. In contrast, natural gas is only 220 Gtoe or $5 \%$ of the total recoverable fossil fuel reserves. Unconventional oils (including heavy crudes, natural bitumen, and oil shale) account for $14 \%$ of the total, while conventional oil represents an additional 5\%. From these figures, it is clear that coal and lignites account for a large percentage of total recoverable fossil fuel reserves in the world and, as such, will have an important role in the future of energy usage and power generation worldwide.

Several technologies have been proposed to convert coal to electricity, including combustion (atmospheric and pressurized), liquefaction, and gasification. Several reviews of gasification are available in the literature ${ }^{2,3}$ that provide details on the status of various technologies for coal utilization. Within gasification, the Integrated Gasification Combined-Cycle (IGCC) is now 
moving towards being a commercial technology. In the global marketplace, this shift is being demonstrated using various gasification technologies to produce a clean fuel for the combined cycle. Early plants in the 1980's demonstrated the technical/environmental features and suitability for power generation. Economics, however, were disappointing until advances in gas turbine technology were first used in the early 1990's. Since 1993, a number of IGCC projects have taken off for commercial application in the mid- to late-1990's. These applications utilize seven different gasification technologies to meet specific project needs. ${ }^{4}$

In power generation technology, the combined cycle consists of the gas turbine cycle (Brayton cycle) and the steam turbine cycle (Rankine cycle). The combination of the two results in a more efficient configuration than either of the two cycles taken separately.

The major components of the coal-based IGCC cycle, shown in schematic form in Figure 1-1, are:

- Coal handling and gasification

- Gas cleanup

- Gas turbine cycle

- Steam turbine cycle (including the heat recovery steam generator, HRSG)

In practice there are many other sub-elements of the IGCC configuration that support the operation of the major components enumerated above.

When integrating gas cleanup systems with the gasification cycle it is necessary to match conditions of the gasifier exit coal gas with the operating conditions of downstream equipment (i.e., gas cleanup systems and gas turbine fuel inlet conditions). With respect to gas cleanup systems for IGCC operation, two temperature regions have been reported ${ }^{3}$ : the low-temperature region below $300{ }^{\circ} \mathrm{C}$ and the high-temperature region above $300{ }^{\circ} \mathrm{C}$.

In the low-temperature cleanup (LTCU) range, also called cold gas cleanup (CGCU), the gas coming from the gasifier is typically cleaned of particulate matter and sulfur species such as $\mathrm{H}_{2} \mathrm{~S}$,

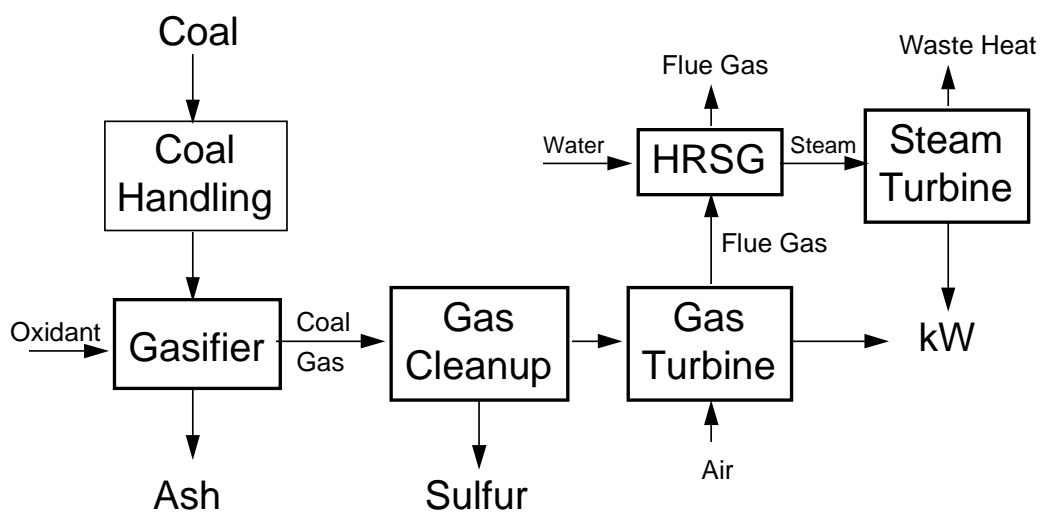

Figure 1-1. Schematic diagram of the IGCC system 
$\mathrm{COS}$, and $\mathrm{CS}_{2}$, at temperatures below $300{ }^{\circ} \mathrm{C}$. Generally, CGCU systems operate around 20$100{ }^{\circ} \mathrm{C}$, with some that include cryogenic stages that require sub-zero temperatures. CGCU systems are proven technologies and commercially available. The main limitation is that they are energy intensive, and are parasitic processes to the high cycle efficiencies desired from IGCC or any other system.

In the high-temperature cleanup (HTCU) range, also called hot gas cleanup (HGCU), the gas from the gasifier is cleaned of particulate matter, sulfur species, and other contaminants at temperatures above $400{ }^{\circ} \mathrm{C}$. HGCU technologies are at various stages of development or in the early stages of commercialization. High-temperature desulfurization is typically accomplished using throwaway calcium-based sorbents or regenerable mixed-metal oxide sorbents. Cost, removal efficiency, and operability determine the advantages of one type of sorbent over the other. The performance of regenerable mixed-metal oxide sorbents for HGCU desulfurization will be solely discussed in this report.

IGCC power systems using HGCU are one of the most promising advanced technologies for the production of electric power from coal in an environmentally acceptable manner. In conventional cleanup systems, costly heat exchangers are necessary to cool down the gases for cleaning. Unlike these conventional low-temperature cleanup systems, where the coal gas from the gasifier has to be cooled down from $500-1100{ }^{\circ} \mathrm{C}\left(932-2012^{\circ} \mathrm{F}\right)$ to below $149^{\circ} \mathrm{C}\left(300{ }^{\circ} \mathrm{F}\right)$, hightemperature coal gas cleanup systems can be operated at near $482-538{ }^{\circ} \mathrm{C}\left(900-1000{ }^{\circ} \mathrm{F}\right)$ or higher, i.e., at conditions compatible with the gasifier and turbine components in the IGCC system. The result is a more efficient overall system. ${ }^{5-7}$ A review of high-temperature desulfurization technology has been given by Thambimuthu ${ }^{3}$, and economic analyses and optimization in various gas stream cleanup systems have been published by Buchanan. ${ }^{8}$

Coal gas desulfurization to sufficiently low levels at elevated temperatures is now recognized as crucial to efficient and economic coal utilization in Integrated Gasification-Combined Cycle (IGCC) systems. The implementation of hot coal gas desulfurization heavily relies on the development of regenerable sorbent materials that have high sulfur capacity and can efficiently remove $\mathrm{H}_{2} \mathrm{~S}$ (from several thousand ppmv levels down to a few ppmv) over many cycles of sulfidation/regeneration. Structural stability and good mechanical strength are also desirable features in a sorbent. Not surprisingly, only a few metal oxides can meet these stringent requirements.

A recent international conference ${ }^{9}$ focused on new developments of coal-based IGCC systems and high-temperature desulfurization systems. A review of the status of application of IGCC technology to power generation throughout the world ${ }^{10}$ and an assessment of coal gasification processes as related to sorbent development ${ }^{4}$ are given in the conference proceedings.

\subsubsection{High-Temperature Desulfurization Systems}

The research and development for high-temperature desulfurization of fuel gases has been sponsored primarily by the Federal Energy Technology Center (FETC, formerly Morgantown Energy Technology Center, METC) of the United States Department of Energy (U.S. DOE). ${ }^{11}$ Fixed-bed systems, fluidized-bed systems, moving-bed systems, and transport reactor systems for 
hot gas desulfurization are being pursued under DOE/FETC contracts and are described in the literature. $^{12}$

Fluidized-bed systems ${ }^{13,77}$ are also under development with DOE/FETC sponsorship. They have an advantage over fixed-bed systems in that better temperature control can be achieved during regeneration because of better gas-solid mixing. However, sorbents are subject to higher levels of attrition in a fluidized bed, and stronger sorbent materials are necessary. A variation of the fluidized bed concept is being pursued by the transport reactor design of M.W. Kellogg. ${ }^{14}$

GE is developing a moving-bed, high-temperature desulfurization system for integrated gasification combined-cycle (IGCC) power systems in which zinc-based regenerable sorbents are currently being used as desulfurization sorbents. ${ }^{15-18}$ Design and analysis of moving-bed reactors has been pursued over several years ${ }^{19,20}$ based on mathematical analyses available in the literature. ${ }^{21}$ Zinc titanates and various other zinc-based oxides are being considered as sorbents for use in the Clean Coal Technology Demonstration Program at Tampa Electric Co.'s Polk Power Station. A key to success in the development of high-temperature desulfurization systems is the matching of sorbent properties for the selected process operating conditions, namely, sustainable desulfurization kinetics, sulfur capacity, and mechanical durability over multiple cycles.

A schematic of the GE-CRD pilot plant, or Process Evaluation Facility (PEF), is shown in Figure 1-2. The GE/Lurgi fixed bed, pressurized air-/steam-blown gasifier is shown on the left. The lowBtu coal gas is directed from the gasifier to the primary cyclone located immediately downstream of the gasifier (to collect entrained particles), through a circulating fluidized bed (CFB) hydrogen chloride removal vessel, then to the HGCU system.

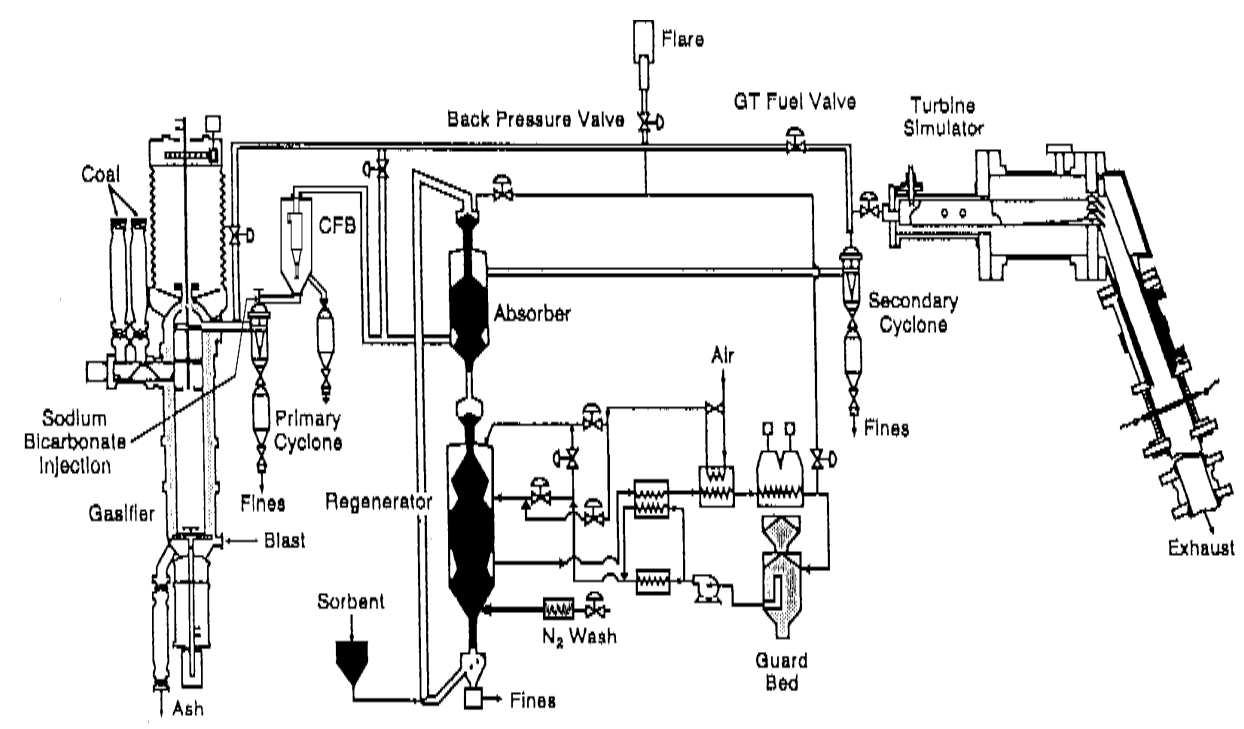

Figure 1-2. Schematic diagram of the GE-CRD pilot plant. 
The HGCU system consists of high-efficiency cyclones to collect entrained particles, a movingbed absorber containing the metal oxide sorbent to remove sulfur compounds, a moving-bed regenerator to oxidize the sulfided sorbent back to its original oxide form, a regenerator gas recycle system, and a solids transport system. A secondary cyclone is located downstream of the absorber, and the cleaned fuel can be directed either to the combustion test stand or to the system flare.

In GE's moving-bed, HGCU system configuration zinc-based metal oxide sorbents are currently being used as regenerable desulfurization sorbents. During normal operation, the sorbent moves by gravity across the absorber and in countercurrent direction to the flow of gases. In the process, the sulfur species in the coal gas are removed to very low levels (approximately 10-50 ppmv) while the sorbent reacts to form metal sulfides. The sulfided sorbent moves down by gravity slowly and leaves the bottom of the absorber vessel through a lockhopper and continues to move down by gravity to the regenerator, which is also a slow moving bed. The sulfided sorbent is then regenerated at nearly atmospheric pressure in three stages of varying oxygen concentrations with the evolution of $\mathrm{SO}_{2}$.

The ability to regenerate and recycle the sorbent is essential for economically viable hot coal gas desulfurization. The regeneration step is a highly exothermic oxidation process requiring careful temperature control. Too high a temperature (above $800{ }^{\circ} \mathrm{C}$ ) sinters and destroys the sorbent structure and reduces its ability to absorb sulfur in consecutive absorption steps. Low temperature, high $\mathrm{SO}_{2}$ and $\mathrm{O}_{2}$ result in sulfate formation and a lower sulfur removal efficiency. In order to effectively control the reaction and achieve a complete regeneration, the regenerator reactor is divided into three zones or stages. As the sorbent proceeds in a controlled atmosphere with varying oxygen concentrations, $\mathrm{SO}_{2}$ is evolved. Sorbent movement in the regenerator is controlled by a rotary valve at its bottom.

The moving-bed regeneration produces an off-gas with a high enough $\mathrm{SO}_{2}$ concentration (up to $10-12 \%$ ) suitable for direct production of sulfuric acid or elemental sulfur. The regeneration gas recycle loop is designed as an internal diluent that reduces the oxygen concentration in the air to the desired levels without the use of costly externally provided diluents such as steam or nitrogen. Using recycle rather than external inert diluent also enriches the $\mathrm{SO}_{2}$ concentration of the product stream. The heat exchangers in the recycle loop are designated to control the temperature of the regenerator inlet streams. The gas cooler removes the heat generated during the regeneration reaction by cooling the recycle gas stream. In a commercial system, the gas cooler will be replaced by a steam generator.

GE has patented the moving-bed process to utilize mixed metal oxide sorbents to remove sulfur from a high-temperature fuel gas stream and regenerate the sorbent for reuse while producing a byproduct stream suitable for the recovery of sulfur ${ }^{22,23}$.

Mixed-metal oxide sorbents have been studied quite extensively in the past, including various types of zinc titanates (e.g., $\mathrm{Zn}_{2} \mathrm{TiO}_{4}$ and $\left.\mathrm{Zn}_{2} \mathrm{Ti}_{3} \mathrm{O}_{8}\right)^{24-27,13}$ or as combinations of other metal oxides such as nickel, copper, manganese, cobalt, tin, and others; see for instance. ${ }^{28-32}$ Proprietary zinc-based sorbents, such as Phillips Petroleum Company's Z-Sorb ${ }^{\mathrm{TM}}$ III sorbent and METC sorbents, have also been tested both in the laboratory as well as in pilot-plant scale. ${ }^{33-35}$ 


\subsubsection{Sorbent Development}

Over the last two decades a number of studies have been reported on high-temperature $\mathrm{H}_{2} \mathrm{~S}$ removal, primarily using various transition metal oxides as regenerable sorbents. ${ }^{36-42}$ The sorbent most intensively studied in the 1980's was iron oxide, which yields equilibrium $\mathrm{H}_{2} \mathrm{~S}$ concentrations in the few hundred ppm range for a composition representative of low-Btu coalderived gas and temperatures of above $500{ }^{\circ} \mathrm{C}$. While the sulfidation kinetics of iron oxide are very good, ${ }^{38}$ this sorbent cannot be used for single-stage coal gas desulfurization to reduce the $\mathrm{H}_{2} \mathrm{~S}$ content of the fuel gas down to a few ppm of sulfur.

Zinc oxide has been used as a non-regenerable sorbent in "guard beds" protecting catalyst beds from trace sulfur impurities. More recently, zinc oxide has also been investigated as a regenerable sorbent. ${ }^{39-46}$ The thermodynamic equilibrium for sulfidation of $\mathrm{ZnO}$ is quite favorable, yielding desulfurization down to a few $\mathrm{ppm} \mathrm{H}_{2} \mathrm{~S}$. The sulfidation kinetics of $\mathrm{ZnO}$, however, are slower ${ }^{47}$ compared to those of pure iron oxide, and the regenerability of $\mathrm{ZnO}$ is restricted above $700{ }^{\circ} \mathrm{C}$ by the loss of surface area and the formation of zinc sulfate at low regeneration temperatures.

In the late 1980's, it was shown that certain mixed oxides have superior properties compared to single oxides for hot gas cleanup. ${ }^{43-45,48-54}$ A compound of zinc and iron oxides, zinc ferrite, $\mathrm{ZnFe}_{2} \mathrm{O}_{4}$, developed by DOE/METC was tested at the pilot stage for desulfurization of low-Btu gases. ${ }^{55-57}$ Physical durability of the zinc ferrite sorbent in long-term testing precluded further use at that time, but recent work suggests that improved performance can be obtained with new preparation techniques. ${ }^{58}$

Because of the apparent limitations of the zinc ferrite sorbent, many investigators have been conducting research to develop a superior mixed metal oxide sorbent. ${ }^{42-45,59-63}$

Earlier experimental studies that pioneered the use of mixed-metal oxides were performed at the Massachusetts Institute of Technology (MIT), ${ }^{64-66}$ Research Triangle Institute (RTI), ${ }^{67} 68$ Electrochem, ${ }^{69}$ U.S. Dept. of Energy/Morgantown Energy Technology Center (DOE/METC), ${ }^{70}$ (now Federal Energy Technology Center, FETC) and the Institute of Gas Technology (IGT). ${ }^{71}$ Mixed-metal oxide sorbents have been studied in the past both as straight zinc titanates, (e.g., $\mathrm{Zn}_{2} \mathrm{TiO}_{4}$ and $\left.\mathrm{Zn}_{2} \mathrm{Ti}_{3} \mathrm{O}_{8}\right)^{72}$ or as combinations of oxides of vanadium, copper, manganese, cobalt, and others; see for instance. ${ }^{65}$

Work on zinc titanates such as $\mathrm{ZnTiO}_{3}, \mathrm{Zn}_{2} \mathrm{TiO}_{4}$, and $\mathrm{Zn}_{2} \mathrm{Ti}_{3} \mathrm{O}_{8}{ }^{44},{ }^{45}$ has shown that titanium oxide is a better alternative to iron oxide additives in terms of the higher stability of the titanates over the ferrite compounds of zinc, and their similar sulfidation equilibria. With zinc titanates, the sulfidation temperature has been shown to extend to $700{ }^{\circ} \mathrm{C}$, and sintering of the $\mathrm{ZnO}$ was greatly reduced. Although zinc titanate has also shown better attrition resistance than zinc ferrite in pilot tests, this sorbent also suffers gradual loss of reactivity in long-term cyclic operation, resulting in high fresh sorbent makeup rate to maintain the desired level of desulfurization. ${ }^{73,74}$ Other mixed metal oxides such as copper-based and cobalt-based sorbents have also been investigated ${ }^{75-78}$ however, the research has been limited to laboratory-scale equipment. 
Although higher temperature application offers better overall process efficiency, the stringent requirement for sulfur removal efficiency at temperatures above $538{ }^{\circ} \mathrm{C}\left(1000{ }^{\circ} \mathrm{F}\right)$ limits the choice of the sorbents to a few metal oxides (based on thermodynamic equilibrium), that have been shown to have other limitations as described earlier. The thermodynamic equilibria of many metal oxides significantly improve as the temperature decreases, making many metal oxide sorbents suitable for hot gas cleanup application in the temperature range of $343-538{ }^{\circ} \mathrm{C}(650$ $\left.1000^{\circ} \mathrm{F}\right)$. Although the initial chemical reactivities of the sorbents generally decrease with decreasing temperature, the lower thermal stress incurred can lead to better sorbent reactivity after a large number of cycles, reducing the sorbent replacement cost. In general, the benefit to be gained by lower temperature application may outweigh the slight loss of efficiency, resulting in lower overall cost of electricity. However, no extensive study has been done on the development of advanced sorbents for the lower temperature application. The reactions occurring during desulfurization of coal gases and regeneration of the sulfided sorbents have been

described before in many sources. ${ }^{13-79}$ More recent studies of sorbent development can be found in the literature. ${ }^{12}$

Outside of the United States, work on sorbent development has been very prolific, particularly in western European countries such as the Netherlands, ${ }^{80,81}$ England, and Spain. ${ }^{82}$

In order for a metal oxide to be considered suitable for high-temperature desulfurization, the material must exhibit desirable properties in the following areas:

1. Rate of $\mathrm{H}_{2} \mathrm{~S}$ absorption and low equilibrium $\mathrm{H}_{2} \mathrm{~S}$ achievable in the gas phase

2. Ease of regeneration of the sulfide species formed during absorption

3. Likelihood of sulfate formation and ease of sulfate decomposition

4. Metal/sorbent evaporation and temperature of incipient evaporation

5. Formation of low-melting eutectic phases

6. Reduction to metal during absorption due to highly reducing coal gases

7. Interactions between active metal oxide, stabilizers, and support with other components and contaminants in coal gas (e.g., $\mathrm{H}_{2}$, alkali metals, halogens)

8. Sulfur loading of metal oxide and sulfur loading capacity limitations

9. Disposal of spent sorbent metals and deleterious effects of volatilized sorbent metals to other IGCC components (e.g., turbine)

10. Cost of support and/or cost of active metal oxide

The feasibility of operating a moving-bed high-temperature desulfurization system in an economically competitive and technically feasible manner currently restricts its use to a temperature window between $400-750{ }^{\circ} \mathrm{C}\left(752-1472{ }^{\circ} \mathrm{F}\right)$ and pressures above 10 atmospheres 
during absorption. Operation below $400{ }^{\circ} \mathrm{C}$ does not take full advantage of higher system efficiency compared to low-temperature cleanup systems, while operation above $750{ }^{\circ} \mathrm{C}$ requires a tradeoff between more sophisticated material properties/higher capital costs and reliability of process operation. Although this window of operation may expand in the future, these current boundaries of operation are considered realistic.

Preliminary to the preparation of mixed-metal oxide sorbents under this program, a review of the literature was done to identify pure metal oxides and combinations of metal oxides that had been evaluated in the past for high-temperature desulfurization of coal gases. ${ }^{27}$ Given the degree of advanced development of zinc-based sorbents and the need to minimize secondary undesired reactions (as described in items 1-10 above), it was decided to focus first on the optimization of zinc titanate sorbents.

\subsubsection{Zinc Titanate Chemistry}

When calcining mixtures of $\mathrm{ZnO}$ and $\mathrm{TiO}_{2}$ powders at high temperature, three crystalline structures of zinc titanate may form depending on the ratio of zinc to titanium: $\mathrm{ZnTiO}_{3}$, $\mathrm{Zn}_{2} \mathrm{Ti}_{3} \mathrm{O}_{8}$, or $\mathrm{Zn}_{2} \mathrm{TiO}_{4}$. The highest zinc-to-titanium molar ratio zinc titanate, $\mathrm{Zn}_{2} \mathrm{TiO}_{4}$, would be the most desired crystalline phase from the point of view of its higher sulfur capacity. For this case, the overall reaction occurring during $\mathrm{H}_{2} \mathrm{~S}$ absorption from coal gases is as follows:

$$
\mathrm{Zn}_{2} \mathrm{TiO}_{4}+2 \mathrm{H}_{2} \mathrm{~S} \Rightarrow 2 \mathrm{ZnS}+\mathrm{TiO}_{2}+2 \mathrm{H}_{2} \mathrm{O}
$$

A secondary reaction that may take place during desulfurization is the reduction of zinc titanate by hydrogen and carbon monoxide to zinc metal, with the subsequent loss of $\mathrm{Zn}$ caused by evaporation. Zinc metal evaporation becomes significant if desulfurization above $732{ }^{\circ} \mathrm{C}$ $\left(1350{ }^{\circ} \mathrm{F}\right)$ under dry conditions (i.e., low $\mathrm{H}_{2} \mathrm{O}$ content in the coal gas) is desired ${ }^{68}$ Since the GE moving-bed system carries out $\mathrm{H}_{2} \mathrm{~S}$ absorption around $482-538^{\circ} \mathrm{C}\left(900-1000{ }^{\circ} \mathrm{F}\right)$, zinc metal evaporation is not a concern. When regeneration is carried out under dry conditions in the presence of diluted air, the following reaction takes place:

$$
2 \mathrm{ZnS}+\mathrm{TiO}_{2}+3 \mathrm{O}_{2} \Rightarrow \mathrm{Zn}_{2} \mathrm{TiO}_{4}+2 \mathrm{SO}_{2}
$$

In addition to the regeneration reaction, zinc sulfate formation may occur during regeneration, favored below $650{ }^{\circ} \mathrm{C}\left(1200^{\circ} \mathrm{F}\right)$, and at high $\mathrm{O}_{2}$ and $\mathrm{SO}_{2}$ concentrations.

$$
\mathrm{ZnO}+\mathrm{SO}_{2}+\frac{1}{2} \mathrm{O}_{2} \Rightarrow \mathrm{ZnSO}_{4}
$$

Zinc sulfate formation is undesirable because the sulfate occupies more volume than the sulfides in the pores (producing internal pellet stresses) and decomposes during subsequent absorption, releasing $\mathrm{SO}_{2}$. Zinc sulfate thermally decomposes in the range of $600{ }^{\circ} \mathrm{C}\left(1112{ }^{\circ} \mathrm{F}\right)^{83}$ to $740{ }^{\circ} \mathrm{C}$ $\left(1364^{\circ} \mathrm{F}\right) .^{84}$ These decomposition temperatures increase at higher concentrations of $\mathrm{SO}_{2}$ and $\mathrm{O}_{2}$. Hence, a regeneration scheme in which the temperature is appropriate to minimize zinc sulfate formation or maximize decomposition is desired. 


\subsubsection{Moving-Bed Applications}

Moving-bed systems have been developed by GE. ${ }^{85}$ Although the sorbent materials move slowly between the absorber and regenerator vessels, the level of deterioration at process conditions requires the material to be mechanically durable. Sorbent formulations prepared for moving-bed systems must have mechanical durability and exhibit satisfactory desulfurization kinetics at 538 ${ }^{\circ} \mathrm{C}\left(1000{ }^{\circ} \mathrm{F}\right) ;{ }^{34}$ however, larger-scale demonstration systems such as the Tampa Electric Co.'s Polk Station will operate at lower temperatures, close to $482{ }^{\circ} \mathrm{C}\left(800-900{ }^{\circ} \mathrm{F}\right)$. Hence, development of sorbents with reactivity in this middle temperature range of 343 to $538^{\circ} \mathrm{C}(650$ $1000^{\circ} \mathrm{F}$ ) is important for moving-bed systems.

\subsubsection{Fluidized-Bed Applications}

Although the fixed-bed approach using metal oxides has been shown to reduce the $\mathrm{H}_{2} \mathrm{~S}$ content of the cleaned gas to very low levels, the operation is not continuous. It also suffers from operational problems and requires large-scale high temperature valves. To overcome these problems, US DOE has sponsored fluidized-bed as well as moving-and fixed-bed hot gas desulfurization research in recent years. The fluidized-bed approach offers advantages over the moving- and fixed-bed reactors because of its ability to control the reactor temperature during the highly exothermic regeneration step.

The key characteristic of concern in the fluidized-bed application is maintenance of the physical integrity of the sorbent during the chemical transformations associated with absorptionregeneration. Testing appears to verify that excessive attrition results primarily from the changes in composition during transformation and not from mechanical forces. ${ }^{7374}$ The extreme temperature and severe chemical conditions of air/steam regeneration are deleterious to many inorganic support materials and sorbent compounds. A sorbent suitable for fluidized-bed application must, therefore, have both good thermodynamic equilibrium and initial chemical reactivity in the range of $343{ }^{\circ} \mathrm{C}-538^{\circ} \mathrm{C}$, as well as acceptable long-term physical and chemical durability with a reasonable cost of production.

The application of fluidized beds to hot gas desulfurization will be dealt with in detail in the second volume of this report which summarizes the subcontract program developed at the Institute of Gas Technology.

\subsection{PROJECT DESCRIPTION}

The proposed program is divided into several tasks:

Task 1 - NEPA Report

Task 2 - Sorbent Preparation

Task 3 - Provision of Bench Unit 
Task 4 - Bench Testing

Task 5 - Sorbent Cost Assessment

Task 6 - Topical Report

Task 7 - Market Plan

Task 8 - Long-Term Testing (option)

In Task 1, the information required for preparation of a NEPA report by DOE was provided. In Task 2, several sorbents suitable for fixed-/moving-, and fluidized-bed applications were fabricated. Three classes of materials were used: zinc-based materials (e.g., zinc titanates), advanced metal oxide (non-zinc) materials, and proprietary materials from external vendors. Selection of non-proprietary materials was based on thermodynamic and laboratory evaluation of powder materials. GE-CRD, IGT, and Prof. M. Flytzani-Stephanopoulos (consultant, Tufts University) were involved in identifying and screening the chemical compositions of the sorbents. Pelletization (for moving/fixed beds) and granulation (for fluidized beds) was conducted on the promising materials using suitable binders and pore formers. Standard techniques (extrusion and calcination) were used to modify the morphology of the formed materials. GE-CRD focused on moving/fixed-bed applications, while IGT focused on fluidizedbed applications.

Commercial sorbent and catalyst developers pelletized or agglomerated the final formulations for bench testing according to recommendations by GE-CRD and IGT. In Task 3, the moving/fixedbed bench reactor at GE-CRD and the fluidized-bed reactor at IGT were refurbished for use. In Task 4, the eight most promising sorbents that passed screening under Task 2 were tested for ten cycles of absorption and regeneration each in the GE-CRD moving/fixed-bed bench reactor and IGT fluidized-bed reactor, and the properties of the used materials were compared against those of the fresh sorbents. In Task 5, a sorbent cost assessment was performed to determine costs and sensitivity of costs for raw materials, fabrication, disposal, or recycle. In Task 6, a Topical Report was prepared summarizing the results obtained in the program. In Task 7, a Market Plan was considered jointly with the commercial sorbent manufacturers and users to develop a strategy for commercialization and benefits to IGCC technologies.

Finally as an optional task, Task 8 was proposed for testing of a minimum of two formulations, one for moving/fixed-bed systems and the other for fluidized-bed systems for extended number of cycles (up to 100 cycles) to assess durability and chemical reactivity in the corresponding bench-scale reactor configurations.

The information presented in this Volume 1 report details the results on moving-bed sorbent development at GE-CRD. The work performed at IGT on fluidized-bed sorbents under a subcontract from GE-CRD will be presented under Volume 2 of this final contract report. 


\section{REFERENCES: CHAPTER 1}

${ }^{1}$ Holt, N. 1995. World Market: A Survey of Opportunities for Advanced Coal-Fired Systems. In Proceedings of the Coal-Fired Power Systems 95 - Advances in IGCC and PFBC Review Meeting, p. 5. DOE/METC-95/1018. NTIS/DE95009732. Springfield, Va.: National Technical Information Service.

${ }^{2}$ Takematsu, T. and Maude, C. 1991. Coal Gasification for IGCC Power Generation. IEACR/37. IEA Coal Research, London, 1991.

${ }^{3}$ Thambimuthu, K.V. 1993. Gas Cleaning for Advanced Coal-Based Power Generation. IEACR/53, March 1993. IEA Research, London.

${ }^{4}$ Ayala, R.E. 1996. Assessment of Coal Gasification Processes - Relevance to Sorbent Development. In Desulfurization of Hot Coal Gas. Proceedings of the NATO/Advanced Study Institute Conference - Desulfurization of Hot Coal Gas with Regenerable Metal Oxide Sorbents: New Developments, KuLadasi, Turkey, July 7-19 1996. A. Atimtay (ed.) NATO ASI Series. Series G Ecological Sciences Vol. 42. pp. 41-56. Springer Verlag, Berlin. August 1998. ISBN 3-540-64726-0.

${ }^{5}$ Rath, L.K., G.T. Lee, and P.H. Le. 1994. IGCC System Studies. In Proceedings of the Coal-Fired Power Systems 94 - Advances in IGCC and PFBC Review Meeting, p. 66. DOE/METC-94/1008. NTIS/DE94012252. Springfield, Va.: National Technical Information Service.

${ }^{6}$ Droog, H.A., A. Delwel, and R. Assink. 1993. Comparison of High-Temperature Gas Treatment Options with LowTemperature Gas Treatment in IGCC's following Entrained Flow Gasification. In Proceedings 12th EPRI Conference on Gasification Power Plants.San Francisco, CA, Oct 27-29, 1993

${ }^{7}$ Corman, J.C. 1986. System Analysis of Simplified IGCC Plants, Topical Report. U.S. Dept of Energy, DOE/ET/14928-2233.

${ }^{8}$ Buchanan, T.L., H.T. Chen, M.G. Klett, M.D. Rutkowski, and R. Zaharchuk. 1994. Optimization of Gas Stream Cleanup in Three IGCC Systems. Final Report to the U.S. Department of Energy/Morgantown Energy Technology Center by Gilbert/Commonwealth, Inc. Contract DE-AC01-88FE61660. March 1994.

9 Atimtay, A. (ed.) Proceedings of the NATO/Advanced Study Institute Conference - Desulfurization of Hot Coal Gas with Regenerable Metal Oxide Sorbents: New Developments, Kusadasi, Turkey, July 7-19, 1996. NATO ASI Series. Series G Ecological Sciences Vol. 42. Springer Verlag, Berlin. August 1998. ISBN 3-540-64726-0.

${ }^{10}$ Ayala, R.E. Application of IGCC Technology to Power Generation. In Proceedings of the NATO/Advanced Study Institute Conference - Desulfurization of Hot Coal Gas with Regenerable Metal Oxide Sorbents: New Developments, Kusadasi, Turkey, July 7-19, 1996. NATO ASI Series. Series G Ecological Sciences Vol. 42. pp. 75-102. Springer Verlag, Berlin. August 1998. ISBN 3-540-64726-0.

${ }^{11}$ Bossart, S.J., D.C. Cicero, C.M. Zeh, and R.C. Bedick. 1990. Gas Stream Cleanup. Technology Status Report. DOE/METC-91/0273. NTIS/DE91002037. Springfield, Va.: National Technical Information Service.

${ }^{12}$ McDaniel, H.M, D.J. Mollot, and V.K. Venkataraman. 1995. editors. In Proceedings of the Advanced Coal-Fired Power Systems '95 Review Meeting, Vol I and II. DOE/METC-95/1018. NTIS/DE95009732. Springfield, Va.: National Technical Information Service.

${ }^{13}$ Gangwal, S.K., and R.P. Gupta, 1993. Enhanced Durability of Desulfurization Sorbents for Fluidized-Bed Applications. In Proceedings of the Coal-Fired Power Systems 93 - Advances in IGCC and PFBC Review Meeting, p. 146-157. DOE/METC-93/6131. NTIS/DE93000289. Springfield, Va.: National Technical Information Service.

${ }^{14}$ Gangwal, S.K., R.P. Gupta, W.M. Campbell, G.B. Henningsen . 1995. Zinc Titanate tests in Transport Reactor. In Proceedings of the Advanced Coal-Fired Power Systems '95 Review Meeting, Vol I, p 215. DOE/METC95/1018. NTIS/DE95009732. Springfield, Va.: National Technical Information Service.

${ }^{15}$ Furman, A.H., R. Ayala, A. Feitelberg, M. Lacey, and S. Bevan. 1998. Integrated Operation of a Pressurized Fixed-Bed Gasifier and Hot Gas Desulfurization System. CD ROM. Final Report to the U.S. Department of Energy/Federal Energy Technology Center, Morgantown, WV, under contract DE-AC21-87MC23170. March 1998. 
${ }^{16}$ Bevan, D.J. Najewicz, R.E. Ayala, A. Feitelberg, and A. Furman. 1995. Integrated Operation of a Pressurized Gasifier, Hot Gas Desulfurization System and Turbine Simulator. In Proceedings of the Advanced Coal-Fired Power Systems '95 Review Meeting, Vol I , pp. 187-201. DOE/METC-95/1018. NTIS/DE95009732. Springfield, Va.: National Technical Information Service.

${ }^{17}$ Bevan, S., D.J. Najewicz, E. Gal, A.H. Furman, R. Ayala, and A. Feitelberg. 1994. Integrated Operation of a Pressurized Gasifier, Hot Gas Desulfurization System and Turbine Simulator. In Proceedings of the Coal-Fired Power Systems 94 - Advances in IGCC and PFBC Review Meeting, p. 222. DOE/METC-94/1008. NTIS/DE94012252. Springfield, Va.: National Technical Information Service.

${ }^{18}$ Cook, C.S., R. Hamilton, E. Gal, A.H. Furman, and R. Ayala. 1991. Integrated Operation of a Pressurized FixedBed Gasifier and Hot Gas Desulfurization System. In Proceedings of the Eleventh Annual Gasification and Gas Stream Cleanup Systems Contractors Review Meeting, ed. V.K. Venkataraman, L.K. Rath, J.W. Martin, and R.C. Bedick. Vol 1.p. 45. DOE/METC-91/6123. NTIS/DE92001102. Springfield, Va.: National Technical Information Service.

${ }^{19}$ R.E. Ayala and B.M. Kim, "Modeling and Analysis of Moving-Bed Hot-Gas Desulfurization Processes," Environ. Prog., 8, 19 (1989).

${ }^{20}$ Ayala, R.E. 1991. Enhanced Durability of High Temperature Desulfurization Sorbents for Moving-Bed Applications. Base Program: Development and Testing of Zinc Ferrite Sorbents. Topical Report. DOE/MC/250033045. NTIS/DE92001121. Springfield, Va.: National Technical Information Service.

${ }^{21}$ Westerterp, K.R., W.P.M van Swaaij, and A.A.C.M. Beenackers. 1984. Chemical Reactor Design and Operation. Wiley, New York.

${ }^{22}$ Gal, E. 1991. System for Removal of Sulfur Compounds from Gases and for Regenerating Spent Sorbents, U.S. patent 5,026,528, June 25, 1991. Also U.S. patent 4,857,285, August 1989.

${ }^{23}$ Ayala, R.E. and E. Gal. 1995. Process and Apparatus for Generating Elemental Sulfur and Reusable Metal Oxide from Spent Metal Sulfide Sorbents, U.S. patent 5,401,475, March 28, 1995.

${ }^{24}$ Ayala, R.E., V.S. Venkataramani, J. Abbasian, and A.H. Hill. 1995b. Advanced Low-Temperature Sorbents. In Proceedings of the Advanced Coal-Fired Power Systems '95 Review Meeting, Vol I, pp 407-416. DOE/METC95/1018 Vol. 1. NTIS/DE95009732. Springfield, Va.: National Technical Information Service.

${ }^{25}$ Ayala, R.E. T.L. Chuck, and R.P. Gupta. 1995a. . Moving-Bed Sorbents. In Proceedings of the Advanced CoalFired Power Systems '95 Review Meeting, Vol II , pp 591-600. DOE/METC-95/1018 Vol 2. NTIS/DE95009733. Springfield, Va.: National Technical Information Service.

${ }^{26}$ Ayala, R.E., T. Chuck, E. Gal, and R.P. Gupta. 1994. Development of High Temperature Desulfurization Sorbents for Moving-Bed Systems. In Proceedings of the Coal-Fired Power Systems 94 -Advances in IGCC and PFBC Review Meeting, p. 637. DOE/METC-94/1008. NTIS/DE94012252. Springfield, Va.: National Technical Information Service.

${ }^{27}$ Ayala, R.E. 1993. Enhanced Durability of High-Temperature Desulfurization Sorbents for Moving-Bed Applications. Option 2 Program: Development and Testing of Zinc Titanate Sorbents. Contract DE-AC2188MC25003. Topical Report. Springfield, Va.: National technical Information Service.

${ }^{28}$ Gasper-Galvin, L.D., J.H. Swisher, and K Hammerbeck. 1994. Characterization and Fixed-Bed Testing of a Nickel-Based Hot Gas Desulfurization Sorbent. In Proceedings of the Coal-Fired Power Systems 94 -Advances in IGCC and PFBC Review Meeting, p. 308. DOE/METC-94/1008. NTIS/DE94012252. Springfield, Va.: National Technical Information Service.

${ }^{29}$ Gasper-Galvin, L.D., and A.T. Atimtay. 1989. Novel Supported Hot Gas Desulfurization Sorbents: Zinc Oxide on Zeolite. In Proceedings of the Ninth Annual Gasification and Gas Stream Cleanup Systems Contractor's Review Meeting. ed. R.A. Johnson, and T.P. Dorchak. Vol 2, pp 563. DOE/METC-89/6107. NTIS/DE89011707. Springfield, Va.: National Technical Information Service. 
${ }^{30}$ Gasper-Galvin, L.D., and A.T. Atimtay. 1991. Zeolite Supported Copper Sorbents for Hot Gas Desulfurization. Paper 82f presented at the 1991 AIChE Summer National Meeting, Pittsburgh, PA, August. 18-21, 1991.

${ }^{31}$ Hepworth, M.T., and R. Ben-Slimane. 1994. Hot Gas Desulfurization with Manganese-Based Sorbents. In Proceedings of the Coal-Fired Power Systems 94 - Advances in IGCC and PFBC Review Meeting, p. 337. DOE/METC-94/1008. NTIS/DE94012252. Springfield, Va.: National Technical Information Service.

${ }^{32}$ Karpuk, M.E, R.J. Copeland, D. Feinber, D. Wickham, B. Windecker, and J. Yu. 1994. High Temperature Hydrogen Sulfide Removal with Stannic Oxide. In Proceedings of the Coal-Fired Power Systems 94 -Advances in IGCC and PFBC Review Meeting, p. 444. DOE/METC-94/1008. NTIS/DE94012252. Springfield, Va.: National Technical Information Service.

${ }^{33}$ Everitt, C.E., and S.J. Monaco. 1994. Data Summary Report for M.W. Kellogg Z-Sorb Sorbent Tests (Z-Sorb-01, Z-Sorb-02, Z-Sorb-03). Final Topical Report. Contract DE-AC21-90MC26328. Report No. 33FF-R93-003.

${ }^{34}$ Gangwal, S.K., R.P. Gupta, G.P. Khare, G.A. Delzer, and D.H. Kubicek. 1994. Fluidization Studies using Phillips Z-SORB Sorbent. In Proceedings of the Coal-Fired Power Systems 94 -Advances in IGCC and PFBC Review Meeting, p. 654. DOE/METC-94/1008. NTIS/DE94012252. Springfield, Va.: National Technical Information Service.

${ }^{35}$ Siriwardane, R.V., U. Grimm, J. Poston, and S. Monaco. 1994. Desulfurization Sorbent Development at the Morgantown Energy Technology Center. In Proceedings of the Coal-Fired Power Systems 94 -Advances in IGCC and PFBC Review Meeting, p. 662. DOE/METC-94/1008. NTIS/DE94012252. Springfield, Va.: National Technical Information Service.

36 "MERC — Hot Gas Cleanup Process," Final Report, MERC/SP-78/2, Morgantown, W.V., 1978.

${ }^{37}$ Joshi, D., Olson, T. H., Hayes, M. L. and Shah, "Hot Low-Btu Producer Gas Desulfurization in Fixed-Bed of Iron Oxide-Fly Ash," APCI Final Report to DOE, Contr. No. FE-77-2757-3, 1979.

${ }^{38}$ Tamhankar, S. S., Hasatani, M. and Wen, C. Y., Chem. Eng. Sci. 36, 1181-1191 (1981).

${ }^{39}$ Grindley, T. and Steinfeld, G., "Development and Testing of Regenerable Hot Coal Gas Desulfurization Sorbents," Final Report No. DOE/MC/16545-1125, 1981.

${ }^{40}$ Jalan, V. and Wu, D., "High Temperature Desulfurization of Fuel Gases for Molten Carbonate Fuel Cell Power Plants," Paper presented at the National Fuel Cell Seminar, San Diego, CA, July 14-16, 1980.

${ }^{41}$ In Proceedings of the Advanced Coal-Based and Environmental Systems '96 Review. CD ROM. U.S. Dept. of Energy, Morgantown Energy Technology Center (METC). Morgantown, WV.

${ }^{42}$ In Proceedings of the Advanced Coal-Based and Environmental Systems '97 Conference. CD ROM. U.S. Dept. of Energy, Federal Energy Technology Center. Pittsburgh, PA 15236.

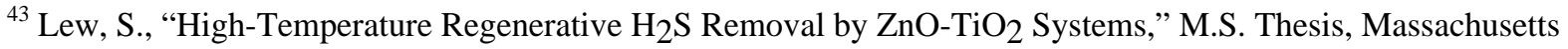
Institute of Technology, January 1987.

${ }^{44}$ Flytzani-Stephanopoulos, M. et al., Final Report to DOE, DOE/MC22193-2582, October 1987.

${ }^{45}$ Lew, S., Jothimurugesan, K. and Flytzani-Stephanopoulos, M., Ind. Eng. Chem. Res. 28,535 (1989).

${ }^{46}$ Siriwardane, R.V., J.A. Poston, and K. Hammerbeck. Testing and Analysis of METC10 Sorbent. In Proceedings of the Advanced Coal-Based and Environmental Systems '97 Conference. CD ROM. U.S. Dept. of Energy, Federal Energy Technology Center. Pittsburgh, PA 15236.

${ }^{47}$ Westmoreland, P. R., Gibson, J. B. and Harrison, D. P., Env. Sci. Tech. 11 (5), 488-491 (1977).

${ }^{48}$ Grindley, T. and Steinfeld, G., "Zinc Ferrite as Hydrogen Sulfide Absorbent," 3rd Ann. Contr. Mtg. on Contaminant Control in Coal-Derived Gas Streams, Rp. No. DOE/METC/84-6, 1983. 
${ }^{49}$ Anderson, G. L. et al., "Development of Hot Gas Cleanup System for Integrated Coal Gasification/Molten Carbonate Fuel Cell Plants," Final Report, No. DOE/MC/19403-1816, 1985.

${ }^{50}$ Flytzani-Stephanopoulos, M., Tamhankar, S. S., Sharma, P. K. and Gavalas, G. R., "Novel Sorbents for HighTemperature Regenerative $\mathrm{H}_{2} \mathrm{~S}$ Removal," Jet Propulsion Laboratory Final Report No. DOE/MC/20417-1898, October 1985.

${ }^{51}$ Tamhankar, S. S., Bagajewicz, M., Gavalas, G. R., Sharma, P. K. and Flytzani-Stephanopoulos, M., Ind. Eng. Chem. Proc. Des. Dev. 25, 429-437 (1986).

${ }^{52}$ Flytzani-Stephanopoulos, M. et al., High-Temperature Regenerative Removal of $\mathrm{H}_{2} \mathrm{~S}$ by Porous Mixed Oxide Sorbents, ACS Div. Fuel Chem. Preprints 30, 16-25 (1985).

${ }^{53}$ Flytzani-Stephanopoulos, M., Lew, S. and Sarofim, A. F., "Mechanistic and Kinetic Studies of High-Temperature Coal Gas Desulfurization Sorbents," Quarterly Report to DOE/PETC, DOE/PC88927-1, December 1988.

${ }^{54}$ Focht, G. D., Ranade, P. V., Harrison, D. P., "High-Temperature Desulfurization Using Zinc Ferrite: Reduction and Sulfidation Kinetics," Chemical Engineering Science, 43, (11) 3005-3013, 1988.

55 Smith, K. J., Haldipur, G. B. and Lucas, J. L., "KRW Process Development Coal Gasification/Hot Gas Cleanup," Proceedings, 7th Ann. Gasification and Gas Stream Cleanup Systems Contr. Rev. Mtg. DOE/METC-87/6079, 2, 668, June 1987.

${ }^{56}$ Wu, T. C., Kassman, J. S. and Robin, A. M., "Integration and Testing of Hot Desulfurization and Entrained Flow Gasification for Power Generation Systems," Proceedings of 9th Ann. Gasification and Gas Stream Cleanup Systems Contr. Rev. Mtg., Morgantown, WV, June 1989, DOE/METC-89/6107, 1, 25-36.

${ }^{57}$ Cook, C.S., E. Gal, A.H. Furman, and R.E. Ayala. Integrated Operation of a Pressurized Fixed-Bed Gasifier and Hot Gas Desulfurization System. In Proceedings of the Twelfth Annual Gasification and Gas Stream Cleanup Systems Contractors Meeting. U.S. Department of Energy, Morgantown Energy Technology Center, Morgantown, WV. DOE/METC-92/6128 (DE93000228).

${ }^{58}$ Copeland, R.J., M. Cesario, D.A. Feinberg, J. Sibold, and B. Windecker. Highly Attrition Resistant Moving-Bed Zinc Ferrite (Titanate) Sorbent. In Proceedings of the Advanced Coal-Based and Environmental Systems '97 Conference. CD ROM. U.S. Dept. of Energy, Federal Energy Technology Center. Pittsburgh, PA 15236.

${ }^{59}$ Gavalas, G. R., Patrick, U., Jothimurugeson, Kandaswami, Flytzani-Stephanopoulas, Maria, "High-Temperature

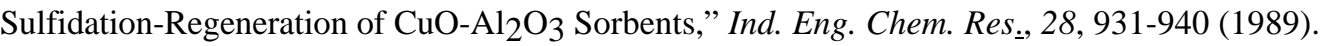

${ }^{60}$ Gangwal, S. K., Harkins, W. M., Stronger, J. M., Bossart, S. J., “Testing of Novel Sorbents for H2 Removal From Coal Gas," Environmental Progress, 8, (1) 26 (1989).

${ }^{61}$ Portzer, J.W., A.S. Damle, and S.K. Gangwal. Hot-Gas Desulfurization with Sulfur Recovery. In Proceedings of the Advanced Coal-Based and Environmental Systems '97 Conference. Paper CD ROM. U.S. Dept. of Energy, Federal Energy Technology Center. Pittsburgh, PA 15236.

${ }^{62}$ Flytzani-Stephanopoulos, M., Lew, S. and Sarofim, A. F., "Hot Gas Desulfurization by Zinc Oxide-Titanium Dioxide Regenerable Sorbents," ACS - Division of Fuel Chemistry Preprints of Papers. Presented at 199th ACS Nat'l Mtg., Boston, MA, Vol. 35 (1), p. 77, April 1990.

${ }^{63}$ Patrick, V., Gavalas, G. R., Flytzani-Stephanopoulos, M. and Jothimurugesan, K., Ind. Eng. Chem. Res. 28, $931-$ $940,1989$.

${ }^{64}$ Flytzani-Stephanopoulos, G.R. Gavalas, and S.S. Tamhankar. 1984. Novel Sorbents for High Temperature Regenerative $\mathrm{H}_{2} \mathrm{~S}$ Removal. Topical Report prepared by Jet Propulsion Laboratory, California Institute of Technology, Pasadena, CA, to U.S Dept. of Energy. DOE/MC-87/20407-2. JPL F-1750. July 1984.

${ }^{65}$ Flytzani-Stephanopoulos, M, K. Johtimurugesan, S. Lew, G.R. Gavalas, and V. Patrick. 1987. Detailed Studies of Novel Regenerable Sorbents for High-Temperature Coal-Gas Desulfurization. In Proceedings of the Seventh Annual Gasification and Gas Stream Cleanup Systems Contractor's Review Meeting. ed. M. Ghate, K. Markel, L. 
Jarr, S. Bossart, Vol 1, p. 726. DOE/METC-87/6079. NTIS/DE87006496. Springfield, Va.: National Technical Information Service.

${ }^{66}$ Lew S., M, K. Johtimurugesan, and Flytzani-Stephanopoulos. 1989. High-Temperature $\mathrm{H}_{2} \mathrm{~S}$ Removal from Fuel Gases by Regenerable Zinc Oxide-Titanium Dioxide Sorbents. Ind. Eng. Chem. Res. 28, 535 (1989).

${ }^{67}$ Gangwal, S.K., and Harkins, S.M. 1987. Bench-Scale Testing of Novel High-Temperature Desulfurization Sorbents. In Proceedings of the Seventh Annual Gasification and Gas Stream Cleanup Systems Contractor's Review Meeting. ed. M. Ghate, K. Markel, L. Jarr, S. Bossart, Vol 2, p. 749. DOE/METC-87/6079. NTIS/DE87006496. Springfield, Va.: National Technical Information Service.

${ }^{68}$ Gangwal, S.K., and Harkins, S.M. 1988. Bench-Scale Testing of Novel High-Temperature Desulfurization Sorbents. In Proceedings of the Eighth Annual Gasification and Gas Stream Cleanup Systems Contractor's Review Meeting. ed. V.P. Kothari, J.R. Longanbach, Vol 1, pp 103. DOE/METC-88/6092. NTIS/DE88010253. Springfield, Va.: National Technical Information Service.

${ }^{69}$ Jalan, V., M. Desai, and F. Brown. 1989. Copper-Based Sorbents for Hot Gas Cleanup. In Proceedings of the Ninth Annual Gasification and Gas Stream Cleanup Systems Contractor's Review Meeting. ed. R.A. Johnson, and T.P. Dorchak. Vol 2, pp 541. DOE/METC-89/6107. NTIS/DE89011707. Springfield, Va.: National Technical Information Service.

${ }^{70}$ Grindley, T. 1991. Lab-Scale Sorbent Development. In Proceedings of the Eleventh Annual Gasification and Gas Stream Cleanup Systems Contractor's Review Meeting. ed. V.K. Venkataraman, L.K. Rath, J.W. Martin, and R.C. Bedick. Vol 2, p. 516. DOE/METC-91/6123. NTIS/DE92001102. Springfield, Va.: National Technical Information Service.

${ }^{71}$ Anderson, G.L., and F.O. Berry. 1987. Development of a Hot Gas Cleanup System. In Proceedings of the Seventh Annual Gasification and Gas Stream Cleanup Systems Contractors Review Meeting, Vol 2. p. 642. DOE/METC87/6079. NTIS/DE87006496. Springfield, Va.: National Technical Information Service.

${ }^{72}$ Woods, M.C., K.E. Leese, S.K. Gangwal, D.P. Harrison, and K. Jothimurugesan. 1989. Reaction Kinetics and Simulation Models for Novel High-Temperature Desulfurization Sorbents. Final report. DOE/METC/24160-2671. NTIS/DE89000950. Springfield, Va.: National Technical Information Service.

73 "Desulfurization of Hot Coal Gas in Fluidized-Bed With Regenerable Sorbents," J. Abbasian, K. Salo and W. Mojtahedi. Paper submitted for publication in Fuel Processing Technology, 1993.

74 "High Temperature Fuel Gas Desulfurization in Fluidized-Bed With Zinc Titanate," W. Mojtahedi, K. Salo, J. Abbasian, J. R. Wangerow and F. S. Lau. Paper presented at the AIChE Annual Meeting, St. Louis, 1993.

${ }^{75}$ Abbasian, J., Hill, A. H., and Wangerow, J. R., "Development of Novel Copper Based Sorbent for Hot Gas Cleanup," Final Technical Report, September 1, 19909-August 31, 1992, prepared by Institute of Gas Technology for Center for Research on Sulfur in Coal.

${ }^{76}$ Abbasian, J., Rehmat, A., Stephanopoulous, M.F., and Hu, Z., "Development of Novel Copper-Based Sorbent for Hot Gas Cleanup." Paper presented at the 1992 AIChE Spring National Meeting, New Orleans, LA.

${ }^{77}$ Abbasian, J., R.B. Slimane, J.R. Wangerow, and M.K. Zarnegar, Advanced Low-Temperature Sorbents for FluidBed Applications. CD ROM. U.S. Dept. of Energy, Federal Energy Technology Center. Pittsburgh, PA 15236.

${ }^{78}$ Anderson, G. A., et. al., "Development of a Hot Gas Cleanup System for Integrated Coal Gasification/Molten Carbonate Fuel Cell Power Plant,” Final Report Prepared by Institute of Gas Technology for U.S. DOE/METC.

${ }^{79}$ Westmoreland, P.W., and D. P. Harrison. 1976. Evaluation of Candidate Solids for High-Temperature Desulfurization of Low-Btu Gases. Env. Sci. Tech., 10, 659 (1976).

${ }^{80}$ Moulijn, J.A.; W.J.W. Bakker, J.C.P. van Rossen, and J.P. Janssens. 1996. Sulfiding Mechanisms in Absorption of $\mathrm{H}_{2} \mathrm{~S}$ by Solids. Also Performance Analysis of Manganese-Based Sorbents in Hot Gas Desulfurization. In Proceedings of the NATO/Advanced Study Institute Conference - Desulfurization of Hot Coal Gas with Regenerable Metal Oxide Sorbents: New Developments, KuEadasi, Turkey, July 7-19, 1996. 
${ }^{81}$ Van der Ham, A.G.J. van der Ham, R.H. Venderbosch, W. Prins, and W.P.M. van Swaaij. Desulfurization Processes of Fue Gas and Stage-wise Desulfurization. Also Effect of Reactor Parameters on Sulphidation/Regeneration Performance. In Proceedings of the NATO/Advanced Study Institute Conference Desulfurization of Hot Coal Gas with Regenerable Metal Oxide Sorbents: New Developments, Ku乏adasi, Turkey, July 7-19, 1996

${ }^{82}$ García, E; C. Ibarra, J.V. Cilleruelo, M. Pineda, and J.M. Palacios. 1997. Kinetic Study of High Temperature Removal of $\mathrm{H}_{2} \mathrm{~S}$ by Novel Metal Oxide Sorbents. Ind. Eng. Chem. Res., 1997, 36, 846-853.

${ }^{83}$ Wheast, R.C., and M.J. Astle, 1978. CRD Handbook of Chemistry and Physics. CRD Press, Inc. West Palm Beach, Florida, 33409.

${ }^{84}$ Perry, H.R., and C.H. Chilton. 1973. Chemical Engineer's Handbook. 5th. Edition. McGraw-Hill, New York.

${ }^{85}$ Ayala, R.E., V.S. Venkataramani, and T.L. Chuck. Hot Gas Desulfurization using Moving-Bed Reactor. In Proceedings of the Advanced Coal-Based and Environmental Systems ' 97 Conference. CD ROM. U.S. Dept. of Energy, Federal Energy Technology Center. Pittsburgh, PA 15236. 


\section{Chapter 2 \\ EXPERIMENTAL PROCEDURES}

\subsection{SORBENT FABRICATION PARAMETERS}

Two different types of sorbents were evaluated for moving-bed applications in the current program:

- Zinc-based sorbents, particularly zinc titanates

- Non-zinc sorbents, particularly proprietary formulations

Testing of zinc-based sorbents included zinc titanates prepared for GE by United Catalysts, Inc. (UCI), and ICCI zinc titanates prepared by UCI for E\&A Associates and the Illinois Clean Coal Technology Institute (ICCI). Non-zinc sorbents included manganese-based Chemetals Inc. sorbents. Because of the proprietary nature of the preparation procedures for most sorbents, the fabrication parameters for the formulations tested in this program will not be presented here.

Zinc titanate sorbents prepared for GE by United Catalysts, Inc., (UCI) were rounded 3-5-mm pellets. The rounded pellets were used to screen a number of chemical formulations for chemical performance in desulfurization to achieve a desired balance of mechanical properties (crush strength and attrition resistance) and chemical properties. The details of the preparation procedure are proprietary to UCI, but in general, the procedure involves mixing of the metal oxide powders followed by forming into shape and calcining at high temperature so that the mixed-metal oxide structure is created by solid-state reactions. The rounding procedure, when used in addition to extrusion, produces stronger pellets and has been described before and shown to aid in the preparation of sorbents more suitable for moving-bed applications. ${ }^{1,2}$.

For all zinc titanate formulations, calcination time and temperature were varied as necessary to achieve the best combination of chemical and mechanical properties. Pellet size was held constant at $5 \mathrm{~mm}$ whenever comparisons of reactivity were being made. When calcining mixtures of $\mathrm{ZnO}$ and $\mathrm{TiO}_{2}$ powders at high temperature, three crystalline structures of zinc titanate may form depending on the ratio of zinc to titanium: $\mathrm{ZnTiO}_{3}, \mathrm{Zn}_{2} \mathrm{Ti}_{3} \mathrm{O}_{8}$, or $\mathrm{Zn}_{2} \mathrm{TiO}_{4}$. The highest zincto-titanium molar ratio zinc titanate, $\mathrm{Zn}_{2} \mathrm{TiO}_{4}$, would be the most desired crystalline phase for its higher sulfur capacity. However, other phases could also be desirable in principle if they provide higher strength to the calcined sorbent pellet.

More information on the properties of the sorbents will be given in the results section for each sorbent.

Several guidelines were used to assess sorbent performance and to identify superior formulations for moving-bed systems. Among the guidelines, a formulation had to meet mechanical strength requirements (crush strength and attrition resistance), chemical reactivity requirements (as measured by single-pellet thermo-gravimetric analysis, (TGA)), and pellet physical morphology requirements (size, shape, and pore structure). 


\subsection{CHARACTERIZATION TECHNIQUES}

\subsubsection{Kinetic Performance}

\subsubsection{TGA Chemical Reactivity}

Chemical reactivity of single-pellet sorbent samples was determined by measuring pellet sulfur capacity and regenerability in a thermogravimetric analyzer (TGA). The rate of sulfidation or regeneration was determined indirectly by relating pellet weight gained or lost as a function of time. Details of the procedure have been described before ${ }^{1}$.

The TGA is a Perkin Elmer balance having a capacity of up to $100 \mathrm{~g}$, and capable of measuring weight changes with an accuracy of $\pm 1 \mu \mathrm{g}$. Typical gas compositions used for sulfidation and regeneration are shown in Table 2-1. The sulfidation gas compositions could simulate oxygenblown, entrained-bed gasifier gas or air-blown, fixed-bed gasifier gas; the regeneration gas composition did not include purposely any $\mathrm{SO}_{2}$ in the feed in order to achieve the highest level of regeneration and measure the true regeneration to oxide in the absence of zinc sulfate formation. The test procedure consists of a 30-minute reduction at $482-538^{\circ} \mathrm{C}\left(900-1000{ }^{\circ} \mathrm{F}\right)$ in clean reducing gas (i.e., no $\mathrm{H}_{2} \mathrm{~S}$ ) prior to each sulfidation. Sulfidation is then conducted at the selected temperature with $3 \% \mathrm{H}_{2} \mathrm{~S}$ for both the half-cycle (i.e., sulfidation) runs and the $1 \frac{1}{2}$-cycle (i.e., sulfidation-regeneration-sulfidation) runs. Tests are conducted for a minimum of three hours or until no weight change occurs.

After full sulfidation, oxidative regeneration is carried out at $677^{\circ} \mathrm{C}\left(1250{ }^{\circ} \mathrm{F}\right)$ with $4 \% \mathrm{O}_{2}$ in $\mathrm{N}_{2}$. At this point the run is interrupted, if necessary, to remove one pellet from the screen for characterization of pore size distribution. The remaining pellets are then subjected to a second reduction and sulfidation prior to termination of the run. All tests were conducted at $1 \mathrm{~atm}$ pressure, except for a few conducted at higher pressure elsewhere to cross-correlate results via partial pressures of $\mathrm{H}_{2} \mathrm{~S}$. All of the sample pellets for testing were selected to be of nearly equivalent size so that the comparison of reaction rates would be meaningful.

Table 2-1. Gas Compositions (vol \%) used in TGA tests

\begin{tabular}{lccc}
\hline & $\begin{array}{l}\text { Simulated } \\
\text { air-blown } \\
\text { gasifier gas }\end{array}$ & $\begin{array}{l}\text { Simulated } \\
\mathrm{O}_{2} \text {-blown } \\
\text { gasifier gas }\end{array}$ & Regeneration gas \\
\hline $\mathrm{H}_{2}$ & 15.0 & 25.1 & \\
$\mathrm{CO}$ & 8.0 & 60.9 & \\
$\mathrm{CO}_{2}$ & 11.0 & 3.0 & \\
$\mathrm{H}_{2} \mathrm{O}$ & 30.0 & 3.0 & \\
$\mathrm{H}_{2} \mathrm{~S}$ & 3.0 & 3.0 & \\
$\mathrm{~N}_{2}$ & 33.0 & 5.0 & 96.0 \\
$\mathrm{O}_{2}$ & & & 4.0 \\
\hline
\end{tabular}




\subsubsection{Chemical Composition}

Chemical composition analyses were conducted on both fresh sorbents and sorbents extracted from the bench-scale reactor system after multicycle testing. Analyses concentrated on the determination of the elemental composition, solid crystalline phase composition, and microstructure.

The crystalline phase composition of the sorbent was determined using x-ray diffraction (XRD). The instrument used for analysis is a Rigaku $\theta / \theta$ automated diffractometer with a 43-position sample changer. The lower detection limit for most constituents is of the order of $1 \%$ to $3 \%$. Quantitative average elemental analysis of whole pellets was determined by inductively coupled plasma (ICP) atomic emission spectroscopy; qualitative and quantitative elemental analyses for whole pellets was determined by $\mathrm{x}$-ray fluorescence (XRF) spectrometry. The average content of total carbon and total sulfur in single pellets was determined by total carbon and total sulfur analyses by Commercial Testing and Engineering, Co. (CTE, South Holland, Illinois) using a LECO induction furnace analyzer. Sulfate sulfur was also determined at CTE following the ASTM D2492 procedure.

\subsubsection{Mechanical Strength}

The mechanical strength of sorbents, crush strength, and attrition resistance were measured at GE-CRD or at the sorbent supplier site. Crush strength is defined as the maximum dead-weight load a pellet withstands on compression prior to fracture; for rounded pellets, the crush strength is presented as force per pellet since the contact area between the flat plates and the ellipsoidal pellet is not easily measured and varies depending on the pellet aspect ratio. Crush strength (i.e., deadweight load) was measured by subjecting single pellets to an increasing load between two plates in an Instrom tester until breakage occurred, and the measured force was averaged over a minimum of 20 pellets.

Attrition tests were performed at ambient temperature in a rotating cylinder, and the weight loss of sorbent on attrition was measured according to a modified ASTM D4058-81 method, "Attrition and Abrasion of Catalysts and Catalysts Carriers." Modifications of the test apparatus to withstand high temperature have been described previously. ${ }^{3}$ In this study, attrition resistance

is defined as $100 \%$ minus the ASTM percent loss on attrition. Percent loss on attrition is defined in the above ASTM D4058-81 method by calculating the percent difference in measured weight of the sample retained in a No. $20(850 \mu \mathrm{m})$ ASTM sieve before and after rotating the cylinder at $60 \mathrm{rpm}$ for 30 minutes. The word attrition will be used in this report as being equivalent to the definition of percent loss on attrition, as defined in the ASTM D4058-81 method.

\subsubsection{Physical Morphology}

\subsubsection{Pore Size Distribution by Mercury Porosimetry}

Pellet pore size distributions, including the calculation of median pore diameter (MPD) (i.e., diameter at 50\% intrusion) and specific pore volume (SPV) (i.e., pore or void volume per unit 
mass of sorbent), were determined using a Micromeritics (Model AutoPore 9220II) mercury porosimeter or equivalent. Measurement of pore size distributions for selected formulations are presented in this report. This information is not given for proprietary sorbents.

\subsubsection{Sieving}

Sieving was performed using ASTM standard sieves in order to determine the size distribution of solids before and after attrition tests. Pellet size classification was divided into three categories: whole pellets, broken pellets, or aggregates (i.e., those particles or pellet pieces larger than 20 mesh but smaller than whole pellets), and fines (i.e., powder material below $850 \mu \mathrm{m}$, or 20 mesh). This classification allowed us to quantify the degree of degradation that whole pellets had experienced by fracture or other means even if not resulting in the formation of fines less than 20 mesh as defined by the ASTM D4058-81 test.

\subsection{PROVISION OF BENCH-SCALE REACTOR (TASK 3)}

Relatively minor hardware modifications were made to the reactor system at GE-CRD under Task 3. The bench reactor had been commissioned and tested under a previous DOE-sponsored sorbent development contract. ${ }^{2}$ Figure 2-1 shows the gas flow system of the bench reactor. Most changes or enhancements were in the automation of data acquisition, handling, and analysis. A significant change attempted in the gas flowing system was the addition of a recirculation loop (shown as a dashed line). The purpose was to simulate the recycling of regeneration gases, which concentrates the $\mathrm{SO}_{2}$ to $8-10 \%$. High $\mathrm{SO}_{2}$ levels are beneficial for sulfur recovery systems, such as sulfuric acid production, because the production then runs without external heat input. Unfortunately, the recirculation pump was not capable of delivering the desired flow rate at the temperatures $\left(400{ }^{\circ} \mathrm{C}\right.$ or higher) and pressures $(5 \mathrm{~atm})$ of interest. After many attempts, the recirculation loop operation was still unreliable and we reverted back to a single-pass regeneration system where the $\mathrm{SO}_{2}$ is introduced directly into the feed stream.

In addition, the bench-scale reactor system was also modified to automate the data acquisition module. In particular, the acquisition and logging of direct readings of thermocouple temperature were switched from a central VAX computer system to a personal computer running the software LabView for Windows. All PC hardware and software additions to the bench unit were provided by GE from internal funding at no charge to the government contract. Data from temperature and flow rate measuring instrumentation is processed in the PC and stored in the hard disk for future

off-line analysis using spreadsheet programs. Previously, retrieval of temperature data during the run required mounting of a disk tape, downloading it as ASCII files, and then importing the data into a PC. 


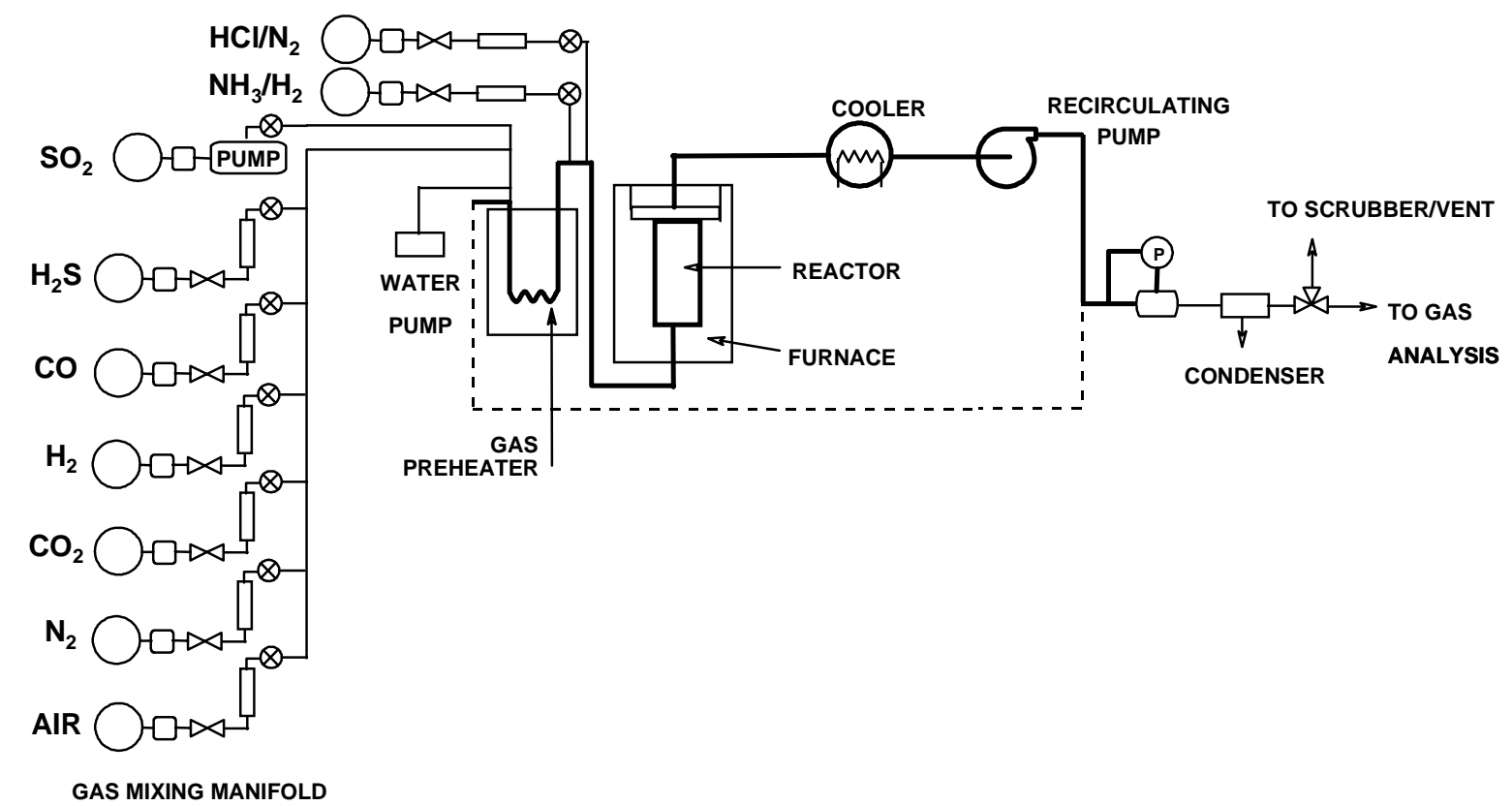

Figure 2-1. Schematic diagram of the gas flow system in the bench-scale reactor

\subsubsection{Bench-Scale Reactor Testing}

In addition to TGA tests, chemical reactivity was also determined by measuring sorbent sulfur loading (defined as grams of sulfur absorbed per $100 \mathrm{~g}$ of fresh sorbent) in fresh and in cycled (i.e., spent) samples from the bench-scale reactor. Only formulations that exhibited a good balance of chemical and mechanical performance as fresh pellets were selected for further cyclic testing in a bench-scale reactor system.

The important aspect of the bench-scale testing is that both absorption and regeneration are conducted in a packed-bed reactor simulating the time/temperature environment in which the sorbent would be exposed in a typical full-scale moving-bed system. Absorption was carried out at $482{ }^{\circ} \mathrm{C}\left(900^{\circ} \mathrm{F}\right)$ using the gas composition shown in Table 2-2, which is similar to that of an oxygen-blown gasifier. The $1 \% \mathrm{H}_{2} \mathrm{~S}$ concentration used is artificially high in order to accelerate the rate of sulfur loading and reduce testing time. 


\section{Table 2-2. Simulated Coal Gas Composition for Bench-Scale Testing}

\begin{tabular}{ll}
\hline Component & $(\%)$ \\
\hline $\mathrm{CO}$ & 39 \\
$\mathrm{CO}_{2}$ & 10 \\
$\mathrm{H}_{2}$ & 30 \\
$\mathrm{H}_{2} \mathrm{O}$ & 20 \\
$\mathrm{H}_{2} \mathrm{~S}$ & 1 \\
$\mathrm{~N}_{2}$ & 0 \\
\hline
\end{tabular}

The oxidative regeneration was carried out between $343-538{ }^{\circ} \mathrm{C}\left(700-1000{ }^{\circ} \mathrm{F}\right)$, depending on the test, up to $677^{\circ} \mathrm{C}\left(1250^{\circ} \mathrm{F}\right)$ or higher. Oxygen concentration was between $1-8 \%$ oxygen during the early phases of regeneration in order to keep the peak temperatures below $760{ }^{\circ} \mathrm{C}\left(1400{ }^{\circ} \mathrm{F}\right)$ during the final phase of regeneration. This scheme of regeneration was intended to simulate the temperature rise of the sorbent bed (triggered by the exothermic oxidation reaction) in the largescale system. Several variations of the bench reactor test procedures were depending on the test. More details of the test conditions are provided in the results section so that the reader can follow the procedural information closer to the test results.

\section{REFERENCES: CHAPTER 2}

\footnotetext{
${ }^{1}$ Ayala, R.E. 1993.Enhanced Durability of High-Temperature Desulfurization Sorbents for Moving-Bed Applications. Option 2 Program: Development and Testing of Zinc Titanate Sorbents. Topical Report, Contract DEAC21-88MC25003 US Department of Energy, Morgantown Energy Technology Center. Morgantown, West Virginia.

${ }^{2}$ Ayala, R.E and T.L. Chuck. 1996. Enhanced Durability of High-Temperature Desulfurization Sorbents for Moving-Bed Applications. Option 3 Program: Development and Testing of Additional Zinc Titanate Sorbents. Topical Report, Contract DE-AC21-88MC25003 US Department of Energy, Morgantown Energy Technology Center. Morgantown, West Virginia.

${ }^{3}$ Ayala, R.E. 1991.Enhanced Durability of High-Temperature Desulfurization Sorbents for Moving-Bed Applications. Base Program: Development and Testing of Zinc Ferrite Sorbents. Topical Report, DOE/MC/250033045. NTIS/DE920001121. Contract DE-AC21-88MC25003 US Department of Energy, Morgantown Energy Technology Center. Morgantown, West Virginia.
} 


\section{Chapter 3}

\section{RESULTS AND DISCUSSION}

Results are being presented in each of the following sections according to technical topic (e.g., testing of modified zinc titanates) rather than by program task (as described in Section 1.3 Project Description). The task to which each of the technical topics belongs is referenced within the text. This approach was taken since it is more logical for the reader to follow from beginning to end a technical topic (e.g., development of a given sorbent) that was carried out across several tasks rather than to follow simultaneously several topics presented in sequential task order.

\subsection{NEPA REPORT}

The information necessary for the DOE to prepare a National Environmental Program Assessment (NEPA) report was submitted by GE-CRD and the subcontractor IGT to DOE as per contract requirements. The NEPA information fulfilled the requirements for completion of Task 1. The reports included, as a minimum, detailed information on the environmental impact that the execution of the experimental tasks would have on the environment in the areas of:

- land use

- air quality

- water resources/water quality

- solid waste and hazardous materials

- other areas (energy requirements, noise level, impact on vegetation and animals, visual resources, historical/cultural resources

\subsection{EVALUATION OF METAL OXIDES AS REGENERABLE SORBENTS}

\subsubsection{Thermodynamic Calculations}

Before undertaking the actual preparation of new sorbent formulations under Task 2-Sorbent Preparation and Characterization, it was deemed necessary to review the literature and perform thermodynamic equilibrium calculations for $\mathrm{H}_{2} \mathrm{~S}$ removal by metal oxides in equilibrium with the corresponding sulfided solid phases. The literature review was previously summarized in Section 1.2, Background. The thermodynamic calculations were performed as part of Task 2 - Sorbent Preparation and Characterization.

Results were evaluated in view of the program objectives considering that most of these previous studies concentrated in the temperature range $538-704^{\circ} \mathrm{C}\left(1000-1300^{\circ} \mathrm{F}\right)$ for sulfidation, rather than in the range of $343-538^{\circ} \mathrm{C}\left(650-1000^{\circ} \mathrm{F}\right)$. Consequently, some materials that were considered by previous authors to be of secondary importance in the upper temperature range may show reasonable reactivity and absence of secondary undesired reactions to be competitive in the lower temperature range.

Model calculations of equilibrium between $\mathrm{H}_{2} \mathrm{~S}_{(\mathrm{g})}$ and metal sulfides had been performed in the past by Westmoreland et al. ${ }^{1}$ with emphasis on desulfurization at temperatures above $500{ }^{\circ} \mathrm{C}$. In this program, the emphasis is on desulfurization at below $538^{\circ} \mathrm{C}\left(1000^{\circ} \mathrm{F}\right)$ using two particular coal gasifier gas 
compositions: an oxygen-blown, entrained-flow gasifier (similar to Texaco gasifier being used at the Tampa Electric Co.'s Polk Power Station), and an air-blown, fluidized-bed gasifier gas (such as the UGas gasifier). Calculations on oxygen-blown, entrained flow gasifier coal gas were performed at GECRD since the Tampa Electric Co.'s Polk Plant uses a Texaco gasifier and a moving-bed HGCU system. On the other hand, those for an air-blown, fluidized bed U-Gas gasifier were performed by the subcontractor IGT with the end goal of coupling the gasifier with a fluidized bed desulfurization system.

The thermodynamic $\mathrm{H}_{2} \mathrm{~S}$ equilibrium concentrations in simulated fuel gases (Texaco and U-GAS gasifiers) for a number of potential metal oxides were calculated at elevated temperatures (i.e., $350^{\circ}$ $550^{\circ} \mathrm{C}$ ) and pressure (20 bar). Calculations were performed on a personal computer using the thermodynamic calculation package and database HSC Chemistry for Windows software. Calculations were based on the minimization of the Gibbs free energy of formation and suppressing secondary reactions that change the gas composition (e.g., solid carbon deposition, and methane formation equilibria for the case of coal gases). The metal oxides considered for this analysis included copper, zinc, iron, nickel, tin, cobalt, molybdenum, manganese, and tungsten. The number of moles of the fuel gas and the solid oxides was selected to correspond to $50 \%$ sorbent conversion during sulfidation. Based on the available data, certain restrictions were imposed on formation of a number of species (such as carbon deposition) so as to better simulate the actual environment of a dynamic, kinetically constrained equilibria coal gasifier.

The results of these analyses are presented in Figure 3-1 for the Texaco fuel gas. Better $\mathrm{H}_{2} \mathrm{~S}$ removal (i.e., lower equilibrium $\mathrm{H}_{2} \mathrm{~S}$ concentrations) can be obtained by all of the metal oxides considered at lower temperatures. For this program, a target of less than 25 ppm equilibrium $\mathrm{H}_{2} \mathrm{~S}$ is acceptable for HGCU sorbent development. For comparison, Figure 3-2 presents the corresponding results for UGAS fuel gas performed at IGT, indicating that calculated $\mathrm{H}_{2} \mathrm{~S}$ equilibrium concentrations are only slightly affected by the fuel gas composition of these two gasifiers. Furthermore, because of the lower temperature range (e.g., $350^{\circ}-550^{\circ} \mathrm{C}$ ) considered in this study, a large number of metal oxides are capable of reducing the $\mathrm{H}_{2} \mathrm{~S}$ level of the fuel gases to below $20 \mathrm{ppmv}$ for IGCC application. It should be noted that the $\mathrm{H}_{2} \mathrm{~S}$ equilibrium for copper oxide is the lowest (e.g., below $0.1 \mathrm{ppmv}$ ). If reduction to metallic copper is prevented while in the reduced form, metallic copper is still an acceptable candidate below $400^{\circ} \mathrm{C}$. On the other hand, kinetic considerations must also be included prior to selecting a metal oxide as being a superior desulfurization agent for HGCU development. The above argument is the reason for testing several types of sorbents in this program (e.g., modified zinc titanates and proprietary sorbents).

In addition to constructing $\mathrm{H}_{2} \mathrm{~S}$ equilibrium diagrams for reducing gases (i.e., coal gas), phase stability diagrams for oxidizing gas atmospheres (i.e., regeneration gases) were constructed using similar algorithms based on minimization of the Gibbs free energy of the system. The phase stability of metals under regeneration gases containing $\mathrm{SO}_{2}$ and $\mathrm{O}_{2}$ is important during regeneration because spalling and pellet deterioration occur more often as a result of metal sulfate formation. Figure 3-3 shows the stability of four metals as a function of the $\log$ partial pressure of $\mathrm{O}_{2}$ and $\mathrm{SO}_{2}$ (in atms). For gas compositions containing approximately 0.02 atm of $\mathrm{O}_{2}$ and 0.5 to 0.1 atm $\mathrm{SO}_{2}$ (typical of atmospheric regeneration gases in the moving-bed system), the thermodynamically stable phase of copper is copper sulfate, while the thermodynamically stable form of molybdenum is the oxide. For most pure oxides, including zinc oxide, the metal sulfate is the stable form under oxidizing gas conditions at temperatures around 500$700{ }^{\circ} \mathrm{C}$, depending on $\mathrm{SO}_{2}$ and $\mathrm{O}_{2}$ concentration. Of course, thermodynamic predictions do not take 


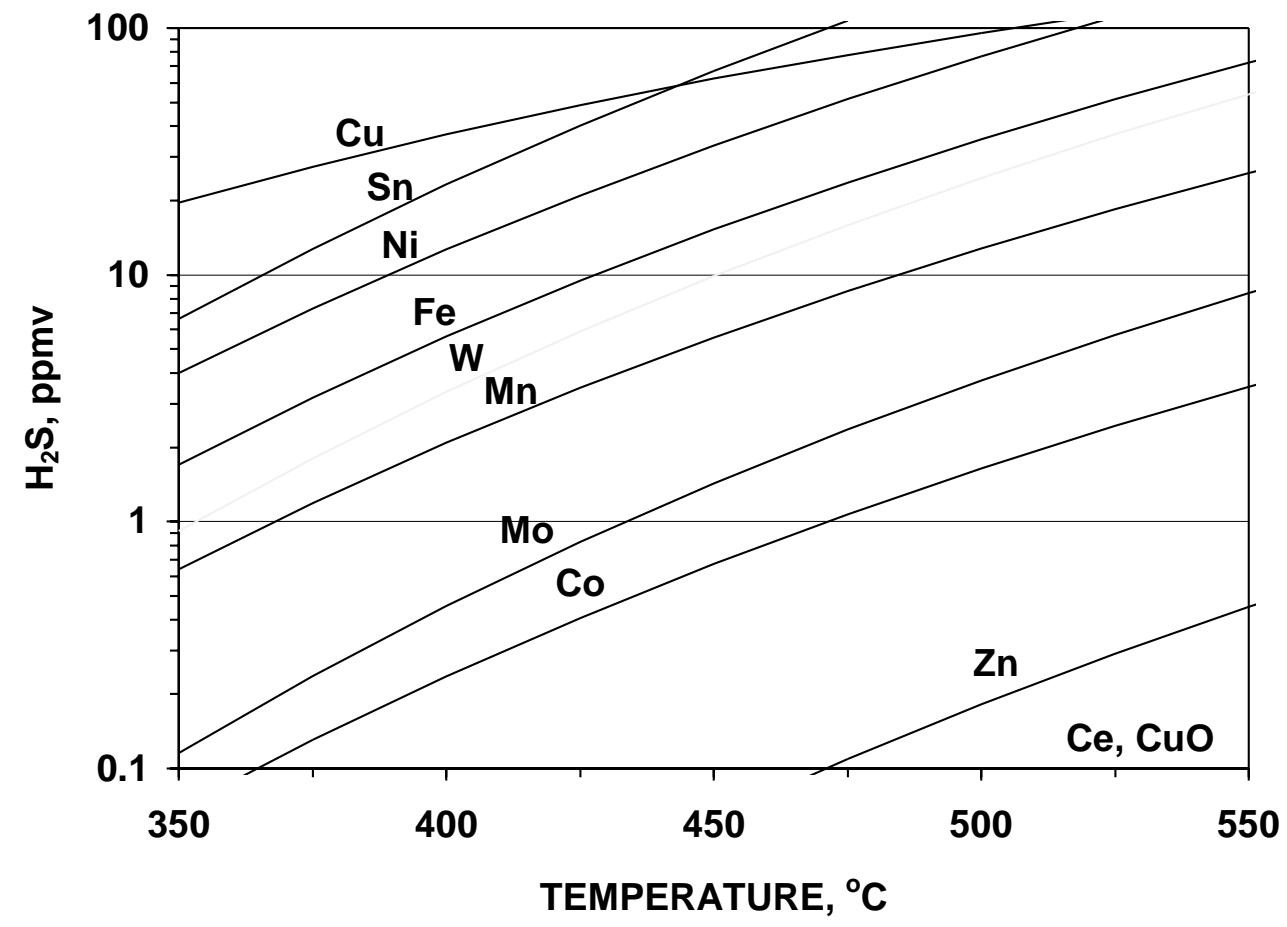

Figure 3-1. $\mathrm{H}_{2} \mathrm{~S}$ equilibrium concentration in fuel gas (Texaco) with various oxides

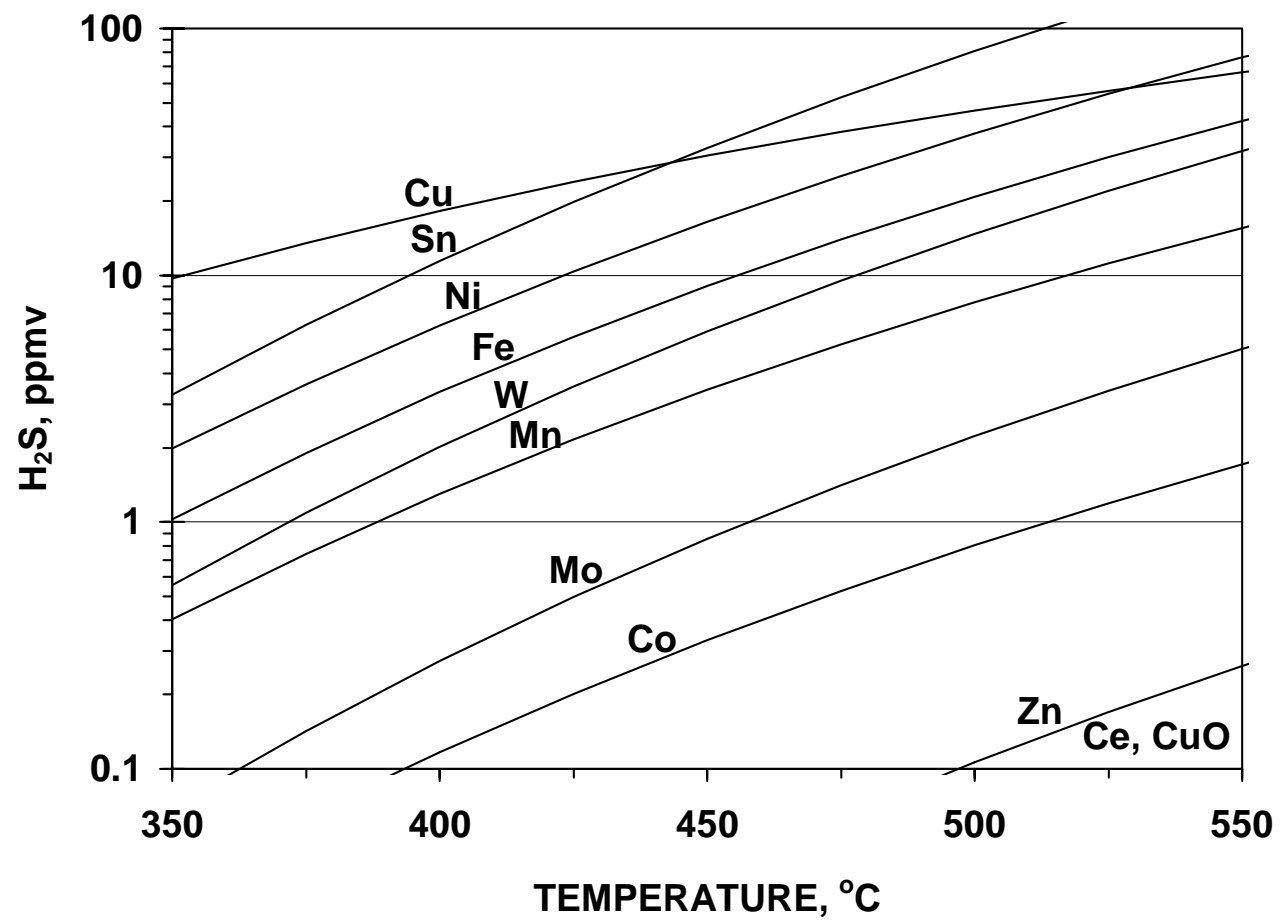

Figure 3-2. $\mathrm{H}_{2} \mathrm{~S}$ equilibrium concentration in fuel gas (U-GAS) with various oxides 

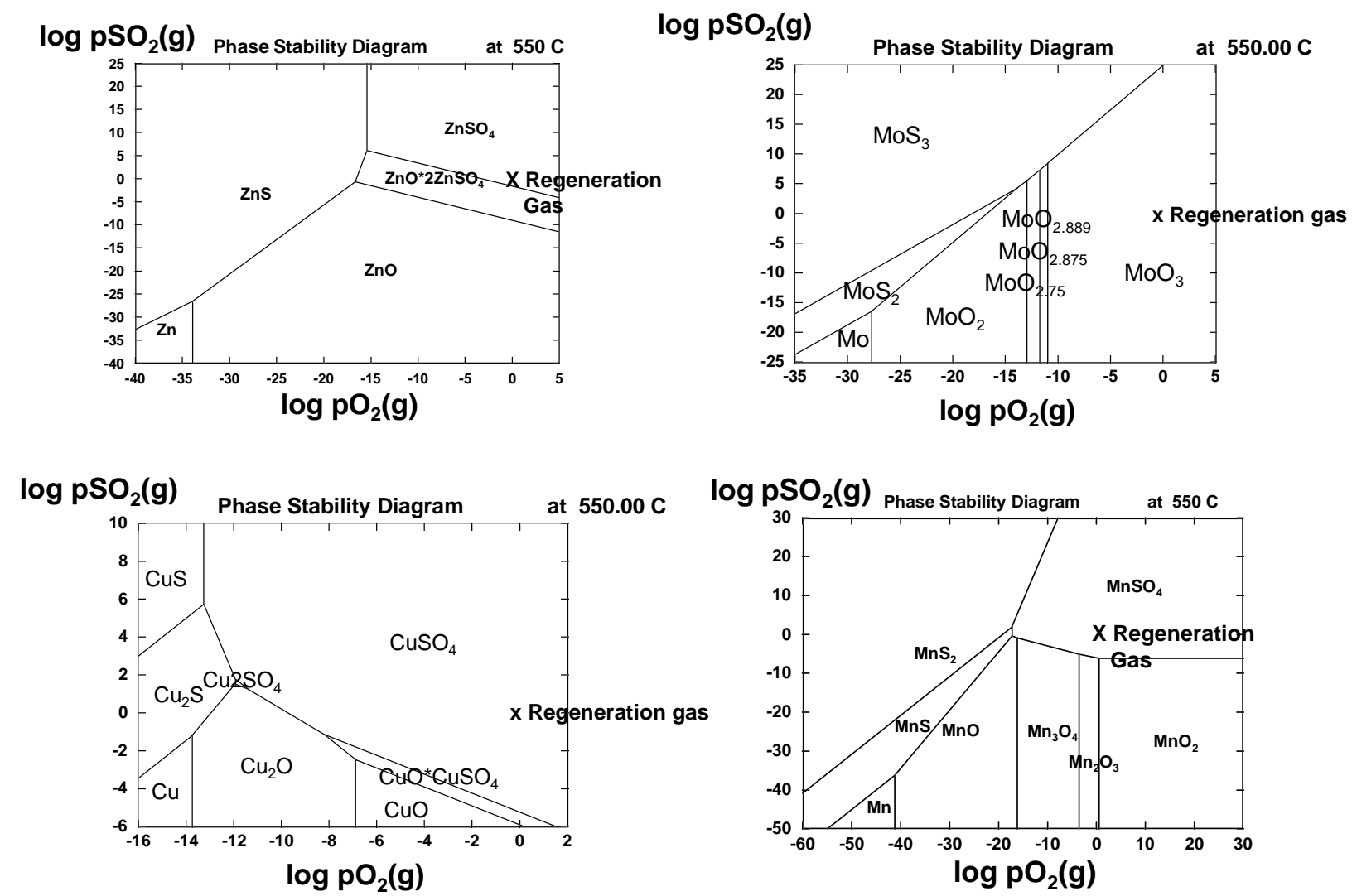

Figure 3-3. Phase stability diagrams for Zn-S-O (upper left), Mo-S-O (upper right), Cu-S-O (lower left), and Mn-S-O (lower right) systems.

into account the rate of approach to equilibrium (i.e., kinetic rates), and hence experimental data is still needed to confirm the extent of formation of the predicted species. Nevertheless, thermodynamics allows the investigator to determine if formation of certain compounds is infeasible. Other phase stability diagrams for cobalt, iron, tungsten, and cerium are presented below in Figure 3-4.

The diagram for zinc has been well studied in the literature and was used as a corroboration of the predictions of our calculation methodology. The diagram for cobalt is particularly interesting in that two cobalt sulfide species are possible, giving the sorbent a potential for several levels of sulfidation. 

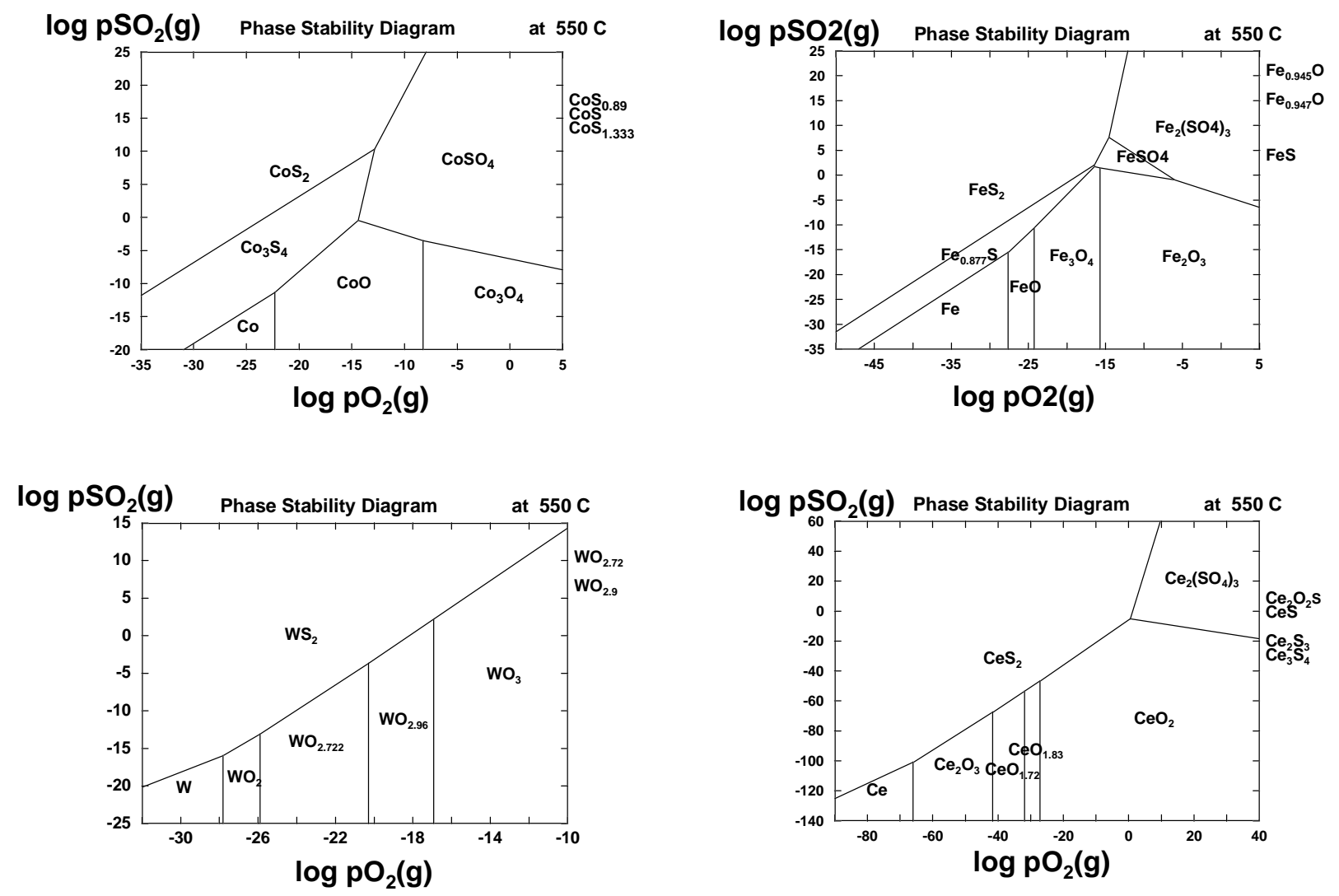

Figure 3-4. Phase stability diagrams for Co-S-O (upper left), Fe-S-O (upper right), W-S-O (lower left), and Ce-S-O (lower right) systems.

\subsubsection{Selection of Metal Oxides for Desulfurization}

Various meetings among the program participants were held to identify new sorbent formulations for the current program. The selection of metal oxides for sorbents fell under three categories:

- Zinc-based sorbents

- Non-zinc sorbents

- Proprietary formulations

The main criteria for selection were based on:

1. High desulfurization capability: thermodynamic equilibria and fast reaction kinetics in the temperature range of $343-538^{\circ} \mathrm{C}\left(650-1000^{\circ} \mathrm{F}\right)$.

2. Minimization of undesired reactions under reducing gas conditions (e.g., interactions with $\mathrm{HCl}$, $\mathrm{CO}$, and $\mathrm{H}_{2}$, catalysis of gas phase reactions).

3. Ease of regeneration capability: thermodynamic stability and fast reaction kinetics compatible with the desulfurization temperature range.

4. Minimization of undesired reactions under oxidizing gas conditions (e.g., sulfate formation, hydrothermal stability) 
From the initial screening of metals, the following metals were ruled out immediately: $\mathrm{Ba}, \mathrm{Ca}, \mathrm{Sr}$, and $\mathrm{V}$. The main reason was the lack of sulfidation of their oxide forms in the desired range of $340-550^{\circ} \mathrm{C}$ $\left(\sim 650-1000^{\circ} \mathrm{F}\right)$ or incompatibility with turbine operation (i.e., high-temperature corrosion by vanadium compounds).

The process of selection of metal oxides for desulfurization identified the following metals as being potentially useful for our study: $\mathrm{Zn}, \mathrm{Cu}, \mathrm{Co}, \mathrm{Fe}, \mathrm{Ce}, \mathrm{Mo}, \mathrm{Mn}, \mathrm{Sn}, \mathrm{W}, \mathrm{Ni}$. It was agreed that many of these metals have weaknesses when considered as pure metal oxides, but become useful when used in combination with others (e.g., $\mathrm{Cu}-\mathrm{Mo}$, and $\mathrm{Zn}$-Mo systems). $\mathrm{Zn}, \mathrm{Cu}, \mathrm{Fe}, \mathrm{Ce}$, and Mo were ranked as being the most useful, hence worth further evaluation. Sn and Ni were ranked as being less desirable than the others and probably will not be considered before the others. Sn has one of the highest $\mathrm{H}_{2} \mathrm{~S}$ vapor pressures and its sintering temperatures are relatively low, which may affect the regeneration process conditions, typically done from 500 to $700^{\circ} \mathrm{C}$. More information on thermodynamic properties is needed on the $\mathrm{W}$ system to proceed forward with an evaluation.

The next step was consideration of the relative compositions in formulations. The metals still considered as useful at that point were divided into three functional groups:

- Main components for desulfurization

- Secondary components for desulfurization, chemical stability, or porosity modifier

- Structural component to maintain mechanical durability

Given these characteristics, the following matrix was developed (Table 3-1) for consideration both at GE-CRD and at IGT. Up to this point, the selection of metal oxides is a general method that is equally applicable to moving beds as well as fluidized beds, transport beds or any other HGCU process configuration operating in the prescribed temperature regime.

$\mathrm{Zn}, \mathrm{Fe}, \mathrm{Ce}$, and $\mathrm{Cu}$ were selected to be the next generation of most promising metals for use as main components. Secondary components will be added to the main components to satisfy most of the evaluation criteria (criteria 1-4 in the previous page), and a structural component will be needed to maintain morphological and mechanical durability. The relative amounts of each component were outlined in a test matrix.

It is important to emphasize that the selection of useful metals was made keeping in mind both (1) shortterm goals (such as providing for support in the selection of the TECO sorbents in the next year) and (2) long-term goals (such as providing for laboratory evaluation of the next generation sorbents), where other larger scale systems may be scheduled for operation.

Table 3-1. List of metal components for sorbent screening

\begin{tabular}{ccc}
\hline Main Component & Secondary Component & Structural Component \\
\hline $\mathrm{Zn}$ & $\mathrm{Fe}, \mathrm{Cu}, \mathrm{Mo}, \mathrm{Co}$ & $\mathrm{Ti}, \mathrm{Zr}, \mathrm{Ce}$ \\
$\mathrm{Fe}$ & $\mathrm{Cu}$ & $\mathrm{Ti}, \mathrm{Zr}$ \\
$\mathrm{Ce}$ & $\mathrm{Mo}$ & $\mathrm{Ti}, \mathrm{Zr}$ \\
$\mathrm{Cu}$ & $\mathrm{Mn}$ & $\mathrm{Ti}, \mathrm{Zr}$ \\
\hline
\end{tabular}


The cost of purchasing raw materials was also considered in the evaluation of the relative merit of the various metal oxides. A more detailed analysis of cost of raw materials will be presented in Section 3.4-Sorbent Cost Assessment. Costs were kept in mind when developing formulations, but it was considered too early to make decisions whether to use or not to use an oxide just because of its price, since the relative amounts of secondary components may be too small (e.g., $<1 \%)$ to have a significant impact on the cost of the sorbent and yet have a tremendous impact on the durability of the material.

After the outline of the metal oxides suitable for desulfurization in the desired range of $343-538^{\circ} \mathrm{C}$ $\left(650-1000^{\circ} \mathrm{F}\right)$ was completed, the task of sorbent preparation in the laboratory was divided into moving-bed and fluidized-bed applications.

\subsection{SORBENT PREPARATION AND BENCH REACTOR TESTING}

\subsubsection{Testing of UCI-GE Zinc Titanate Sorbents}

UCI and GE have developed over the years several formulations of zinc titanate sorbents with additives that exhibit desirable properties for desulfurization and regeneration of fuel coal gases. In the following sections, a description of the results on molybdenum-containing zinc titanates (Section 3.3.3, Evaluation of Molybdenum-Containing Zinc Titanate Sorbents) and modified zinc titanates (MZT) (Section 3.3.4, Modified Zinc Titanates (MZT's) with additives) will be presented. Various aspects of the information contained within this report are subject to one or more patents issued in the name of the General Electric Company ${ }^{1-4}$ and are referenced in this report so that the reader can understand the technical background and framework for the development of HGCU moving-bed sorbents within this program.

\subsubsection{Screening of Sorbents Containing Mixed-Metal Oxides}

Once it was decided to start the experimental work on sorbent preparation and characterization, two objectives were defined for the moving-bed applications:

1. To develop an accelerated program of less than a year for screening molybdenum-containing zinc titanates in order to select a sorbent for testing in Run 8 of the GE pilot plant in September 1995.

2. To develop a longer-term program emphasizing development of mixed-metal oxides, including zinc titanates and other non-zinc sorbents, for moving-bed systems.

Phase diagrams of molybdenum in zinc titanate suggest that the presence of molybdenum lowers the minimum temperature needed for the formation of the zinc titanate structure from the zinc and titanium oxide components. Information available in the literature suggests that molybdenum is a good "fluxing" agent. For this reason, calcination temperature for zinc titanates containing molybdenum was explored in more detail (Table 3-2).

Additional samples of reformulated zinc titanate were prepared where the ratio of zinc to titanium, as well as the presence of bentonite binder, was varied (Table 3-3). The addition of zinc and titanium cations in various forms of starting materials was done with the purpose of substituting the cationic sites in tetrahedral and octahedral sites in the inverse spinel structure of zinc titanate that will add either mechanical strength to the lattice or resistance to overoxidation of zinc to zinc sulfate compounds during regeneration. 
Table 3-2. Powder sorbent formulations $\left(800^{\circ} \mathrm{C} / 4 \mathrm{hr}\right)$

\begin{tabular}{cc}
\hline Formulation ID & Chemical Structure \\
\hline GEMZT-1 & $\mathrm{Zn}_{2} \mathrm{Ti}_{0.983} \mathrm{Mo}_{0.017} \mathrm{O}_{4}$ \\
GEMZT-2 & $\mathrm{Zn}_{2} \mathrm{Ti}_{0.966} \mathrm{Mo}_{0.034} \mathrm{O}_{4}$ \\
GEMZT-3 & $\mathrm{Zn}_{2} \mathrm{Ti}_{0.9575} \mathrm{Mo}_{0.0425} \mathrm{O}_{4}$ \\
GEMZT-4 & $\mathrm{Zn}_{2} \mathrm{Ti}_{0.949} \mathrm{Mo}_{0.051} \mathrm{O}_{4}$ \\
GEMZT-5 & $\mathrm{Zn}_{2} \mathrm{Ti}_{0.915} \mathrm{Mo}_{0.0425} \mathrm{O}_{4}$ \\
GEMZT-6 & $\mathrm{Zn}_{2} \mathrm{Ti}_{0.93825} \mathrm{Mo}_{0.0425} \mathrm{O}_{4}$ \\
GEMZT-7 & $\mathrm{Zn}_{1.9575} \mathrm{Ti}_{0.9575} \mathrm{Mo}_{0.0425} \mathrm{O}_{4}$ \\
GEMZT-8 & $\mathrm{Zn}_{1.8725} \mathrm{Ti} \mathrm{Mo}_{0.0425} \mathrm{O}_{4}$ \\
GEMZT-9 & $\mathrm{Zn}_{2.0425} \mathrm{Ti}_{0.9120} \mathrm{Mo}_{0.0425} \mathrm{O}_{4}$ \\
\hline
\end{tabular}

Table 3-3. Zinc/Titanium formulations with various additives

\begin{tabular}{cc}
\hline Formulation ID & Chemical Structure \\
\hline MZT-23 & $(32.60 \%) \mathrm{ZnO}, 16 \% \mathrm{TiO}_{2},(0.97 \%) \mathrm{MoO}_{3} *$ \\
MZT-24 & $(50 \%) \mathrm{Zn}_{2} \mathrm{TiO}_{4}, 1 \% \mathrm{MoO}_{3}{ }^{*}$ \\
MZT-25 & $(50 \%) \mathrm{Zn}_{2} \mathrm{TiO}_{4}, 1 \% \mathrm{MoO}_{3}$ \\
MZT-26 & $(32.60 \%) \mathrm{ZnO}, 16 \% \mathrm{TiO}_{2},(1.12 \%) \mathrm{MoO}_{3} / \mathrm{ZnO}$ \\
MZT-27 & $(50 \%) \mathrm{Zn}_{2} \mathrm{TiO}_{4},(1.15 \%) \mathrm{MoO}_{3} / \mathrm{ZnO}$ \\
MZT-28 & $(32.60 \%) \mathrm{ZnO}, 16 \% \mathrm{TiO}_{2},(0.97 \%) \mathrm{MoO}_{3}$ \\
MZT-29 & $(16 \%) \mathrm{ZnO},(16 \%) \mathrm{TiO}_{2},(0.64 \%) \mathrm{MoO}_{3} *$ \\
\hline
\end{tabular}

All samples contain approximately $10 \%$ solution of polyvinyl alcohol for porosity enhancement. Samples marked with a * contain bentonite at around 1-1.5\% bentonite. Comparison of performance between samples containing bentonite and those without will provide indication of the effect on strength.

In addition to zinc titanate sorbents containing molybdenum additives, several other mixed-metal oxides have been prepared and calcined (Table 3-4). The replacement of zinc and titanium cations is being done with the purpose of substituting the cationic sites in tetrahedral and octahedral sites in the inverse spinel structure of zinc titanate with atoms $(\mathrm{Ce}, \mathrm{Cu}, \mathrm{Fe}$, etc.) that will add either mechanical strength to the lattice or resistance to overoxidation of zinc to zinc sulfate compounds. Results on the reactivity of these powder formulations was assessed by TGA tests. 
Table 3-4. Powder mixed-metal oxides formulations

\begin{tabular}{cc}
\hline Formulation ID & Chemical Structure \\
\hline MZT-1 & $\mathrm{Zn}_{2} \mathrm{TiO}_{4}$ \\
MZT-2 & $\mathrm{Zn}_{1.985} \mathrm{Ti}_{0.985} \mathrm{Fe}_{0.03} \mathrm{O}_{4}$ \\
MZT-3 & $\mathrm{Zn}_{1.97} \mathrm{Fe}_{0.03} \mathrm{TiO}_{4}$ \\
MZT-4 & $\mathrm{Zn}_{2} \mathrm{Fe}_{0.03} \mathrm{Ti}_{0.97} \mathrm{O}_{4}$ \\
MZT-5 & $\mathrm{Zn}_{2} \mathrm{Fe}_{0.03} \mathrm{Ti}_{0.97} \mathrm{O}_{4}$ \\
MZT-6 & $\mathrm{Zn}_{2} \mathrm{Sn}_{0.05} \mathrm{Ti}_{0.95} \mathrm{O}_{4}$ \\
MZT-7 & $\mathrm{Zn}_{1.97} \mathrm{Fe}_{0.05} \mathrm{TiO}_{4}$ \\
MZT-8 & $\mathrm{Zn}_{2} \mathrm{SnO}_{4}$ \\
MZT-9 & $\mathrm{Cu}_{2} \mathrm{SnO}_{4}$ \\
MZT-11 & $\mathrm{ZnCuTiO}_{4}$ \\
MZT-12 & $\mathrm{ZnCuSnO}_{4}$ \\
MZT-13 & $\mathrm{Ce}_{2} \mathrm{CuTiO}_{4}$ \\
\hline
\end{tabular}

\subsubsection{Evaluation of Molybdenum-Containing Zinc Titanate Sorbents}

Three levels of testing were performed on molybdenum-doped zinc titanate: laboratory screening at GECRD, long-term (50-cycle) bench-scale testing at RTI, and pilot plant testing (200-hr, Test 8) at the GE-CRD pilot plant. The purpose of the screening tests at GE-CRD was to improve the addition and composition of molybdenum in order to enhance performance in scheduled pilot plant tests (Test 8, September 1995). The laboratory work was performed in support of the DOE-sponsored Clean Coal Technology Program at Tampa Electric Co's (TECO) Polk Power Station, where a demonstrationscale moving-bed HGCU system has been built. Previous work had identified the usefulness of molybdenum-addition to zinc titanate for HGCU in moving-bed reactor configurations. For instance, the presence of molybdenum oxide in small quantities promotes quicker rearrangement and reconstitution of the zinc titanate structure over multiple cycles than in the case of straight zinc titanates.

\subsubsection{Screening of laboratory formulations at GE-CRD}

Several formulations of Mo-containing zinc titanate sorbents were extruded, rounded, and calcined by United Catalysts Inc. (UCI) during early 1995. From attrition test results, the most promising four formulations having higher attrition resistance were selected for bench-scale screening over twenty cycles. The screening for chemical reactivity over multiple cycles of absorption and regeneration of four molybdenum-doped zinc titanate formulations was performed using a the $7-\mathrm{cm}(2.75 \mathrm{in}$.) ID fixed-bed bench reactor at GE-CRD described previously in this report. One modification to the bench reactor was introduced for these tests: the cross sectional area of the reactor was divided into four quadrants, 
and each quadrant was filled with a different zinc titanate formulation. This modification allowed simultaneous testing of up to four formulations under identical conditions of time and gas flow rate.

The four formulations tested ranged in molybdenum content from $0 \%$ (formulation $\mathrm{A}$ ) to $1.5 \%$ (formulation B) to $2.0 \%$ (formulations $\mathrm{C}$ and D). Formulations $\mathrm{C}$ and $\mathrm{D}$ differed in the calcination history (i.e., calcination temperature and/or time). Absorption and regeneration were performed at 5 atm each, since the GE-CRD reactor does not have the capability to operate at $20 \mathrm{~atm}$. Absorption was performed at $482{ }^{\circ} \mathrm{C}$ using a simplified coal gas composition similar to that of an oxygen-blown gasifier with high $\mathrm{H}_{2} \mathrm{~S}$ $\left(39 \% \mathrm{CO}, 10 \% \mathrm{CO}_{2}, 30 \% \mathrm{H}_{2}, 20 \% \mathrm{H}_{2} \mathrm{O}, 1 \% \mathrm{H}_{2} \mathrm{~S}\right)$. Regeneration was performed between $482{ }^{\circ} \mathrm{C}$ and $760{ }^{\circ} \mathrm{C}$ using $1-4 \% \mathrm{O}_{2}$ in nitrogen. At the end of the 20 cycles, the sorbent bed was unloaded for chemical and reactivity analysis of the pellets.

Figure 3-5 shows the outlet $\mathrm{H}_{2} \mathrm{~S}$ concentration (i.e., the $\mathrm{H}_{2} \mathrm{~S}$ breakthrough curve) of the composite four-formulation test. The $\mathrm{H}_{2} \mathrm{~S}$ concentration prior to breakthrough was less than $200 \mathrm{ppm}$ (dry), indicating good desulfurization reactivity (i.e., $99.84 \%$ sulfur removal in 60 minutes) and well beyond the target desulfurization of $50 \mathrm{ppm}$ (dry) residual $\mathrm{H}_{2} \mathrm{~S}$ in the gas phase.

Figure 3-6 shows the envelope of breakthrough curves (at the 200 ppm outlet $\mathrm{H}_{2} \mathrm{~S}$ ) taking the highest breakthrough time ( $2 \mathrm{hr}$ for absorption 1$)$ as being $100 \%$ of initial sorbent performance. These resulting breakthrough measurements are the composite of the four formulations being tested in parallel in the same reactor (to make exposure conditions comparable). All absorptions showed $\mathrm{H}_{2} \mathrm{~S}$ levels below 20 ppm prior to breakthrough. The results were very promising, with about $80 \%$ capacity maintained from cycles ten to twenty. In addition, the convergence of the envelope of breakthrough curves as we went from 10 to 20 cycles suggests that the level of regeneration improved as we adjusted the operating conditions from each previous cycle's results. The four sorbents were unloaded, and pellet quality (absence of hairline cracks) was better when molybdenum was present.

Figures 3-7 through 3-9 show the properties of the fresh and cycled samples. Some conclusions that were drawn from those figures are:

- All formulations A, B, C, and D met the ASTM attrition test criterion for fresh pellets (i.e., <4\% ASTM attrition loss), but formulations B and D did not meet the ASTM attrition criterion for longterm operation (i.e., <5\% ASTM attrition) simulated moving-bed operation (Figure 3-7). Formulation $\mathrm{C}$ had the lowest ASTM attrition for both the fresh (0.7\%) and after 20 accelerated cycles $(2.2 \%)$.

- The distribution of broken pellets and whole pellets after the ASTM attrition tests in the 20th regeneration samples is shown in Figure 3-8. Formulation $\mathrm{C}$ again fares better than the other three formulations tested.

- Sulfur capacity of the pellets was compared as fresh and after 20 cycles (Figure 3-9). Formulation C comfortably exceeded the minimum sulfur capacity required for TECO: $6.7 \mathrm{lb}$ sulfur/ $\mathrm{ft}^{3}$ bed (107 kg sulfur $/ \mathrm{m}^{3}$ bed), or approximately $3.2 \% \mathrm{wt}$. gain on TGA sulfidation for a bulk density of $100 \mathrm{lb} / \mathrm{ft}^{3}\left(1603 \mathrm{~kg} / \mathrm{m}^{3}\right)$. Weight gain for formulation $\mathrm{C}$ was more than twice the minimum.

Overall, formulation C (containing $2 \%$ equivalent molybdenum oxide) exhibited the best combination of desired properties for long-term operation and was recommended for preparation and testing for longterm (50 cycles) at RTI's bench-scale reactor system and in the GE pilot plant Test 8. 


\subsubsection{50-Cycle Bench Test at Research Triangle Institute}

In support of the effort for the selection of sorbent for the Tampa Electric Co's Polk Station, a subcontract was issued by GE-CRD to Research Triangle Institute to conduct an independent 50-cycle benchscale test on one selected zinc titanate formulation for the screening tests at GE-CRD. The test would provide information on the long-term chemical reactivity and mechanical durability of the pelletized sorbent when operated at a pressure of 20 atm during absorption and 7 atm during regeneration. GECRD's bench reactor has capability only up to $7 \mathrm{~atm}$. The selected sorbent for 50 -cycle testing was

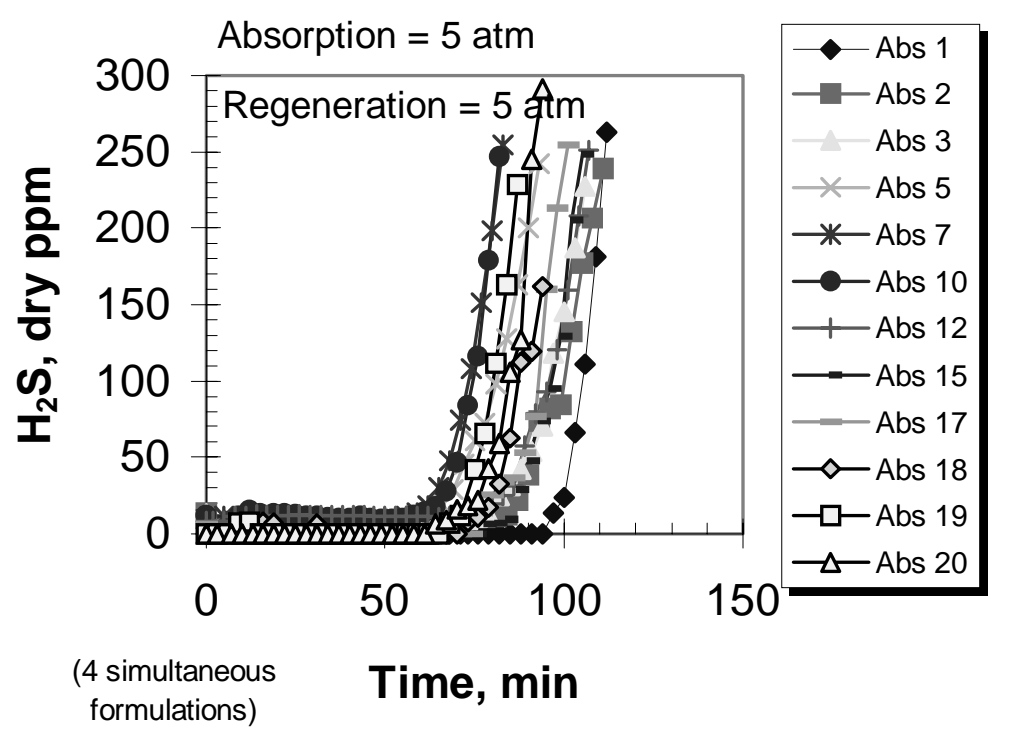

Figure 3-5. $\mathrm{H}_{2} \mathrm{~S}$ breakthrough curve for the simultaneous bench reactor testing of four formulations at GE-CRD

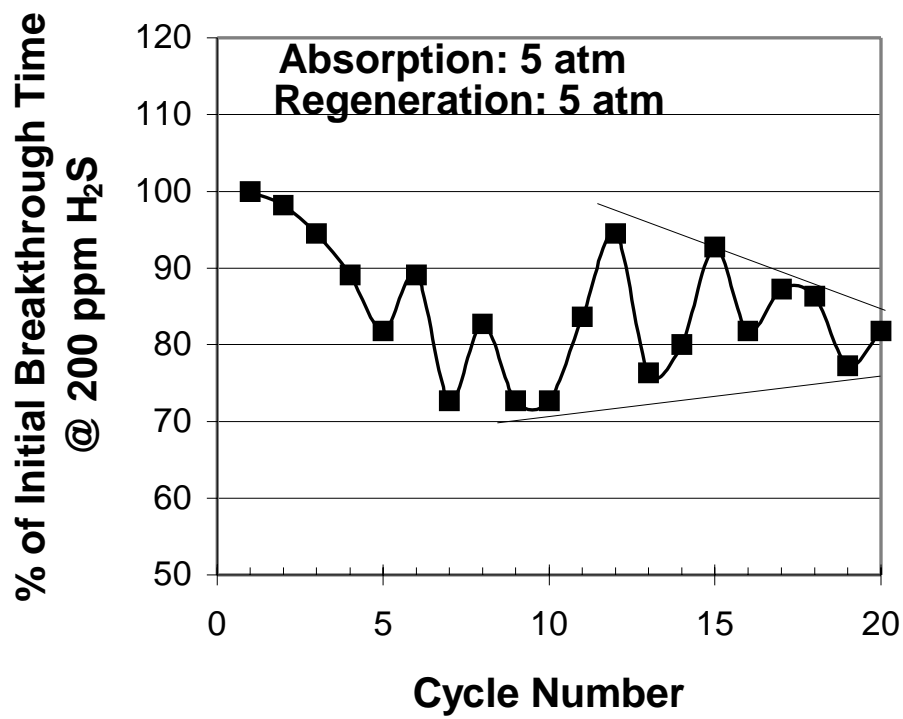

Figure 3-6. Envelope of breakthrough curves for zinc titanate screening at GE-CRD 


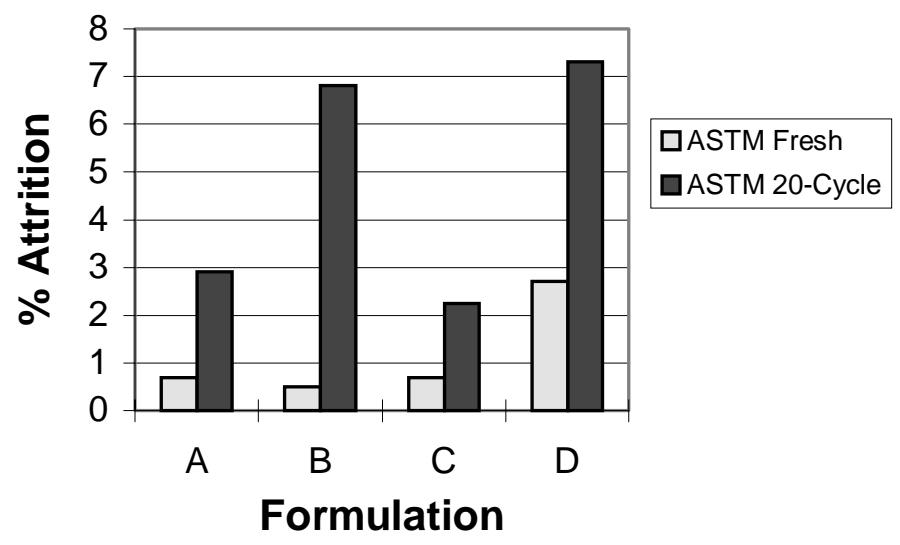

Figure 3-7. ASTM attrition results on sorbents after the 20th regeneration in bench screening at GE-CRD

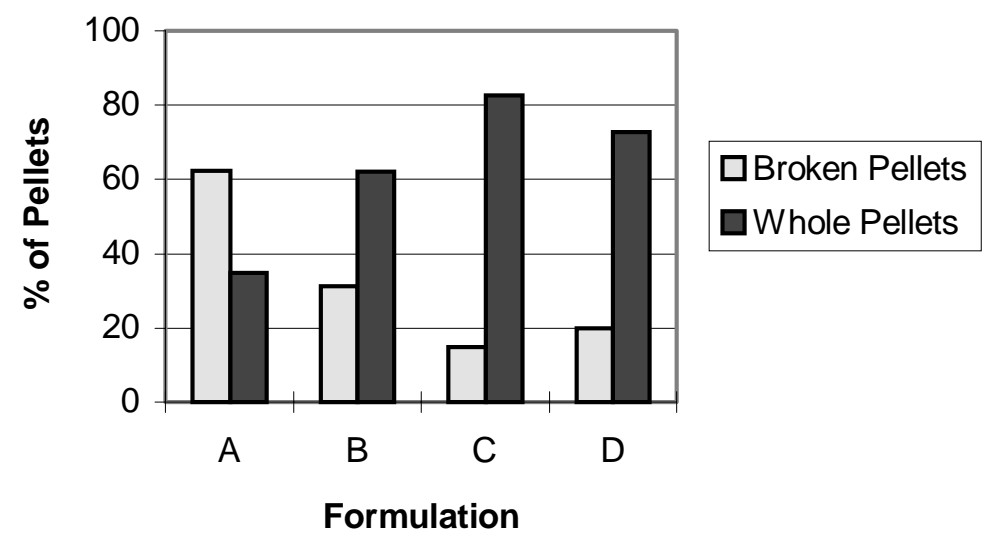

Figure 3-8. Pellet distribution after ASTM attrition test (20th regeneration)

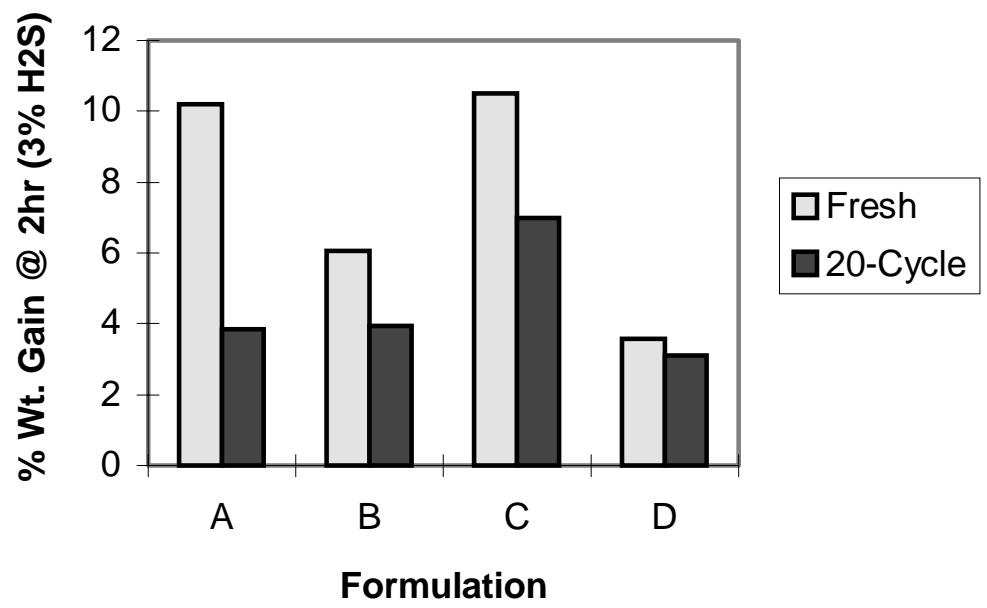

Figure 3-9. TGA sulfur capacity of sorbents after 20 cycles 
Formulation C, previously shown in Figures 3-7 and 3-8, which exhibited low ASTM attrition and high sulfur loading in the GE-CRD screening tests. The sorbent was fabricated again by UCI under similar calcinations conditions and designated as formulation PP2131. The testing at RTI proceeded according to the test protocol written at GE-CRD to provide uniformity in test procedures for the development of moving-bed sorbents. Conditions for the testing are shown in Table 3-5 and Table 3-6.

The bed volume was adjusted to obtain the desired gas space velocity, meet the requirement of sulfur loading at the gas inlet location, meet the $200 \mathrm{ppmv}$ breakthrough in a reasonable time $(<5 \mathrm{hr})$, and meet the test schedule for completion of the 50 cycles. Test conditions during absorption (Table 3-6) follow the TECO conditions, except for the reduced pressure (20 atm vs. $30 \mathrm{~atm}$ ) and definition of breakthrough (200 ppmv vs. less than $50 \mathrm{ppmv}$ ). The reduced pressure is a result of limitations in the existing hardware; the definition of breakthrough was selected for ease of measurement and for historical comparisons. Regeneration was conducted at 7 atm and between $482{ }^{\circ} \mathrm{C}$ and $760{ }^{\circ} \mathrm{C}$.

Figure 3-10 shows the raw data of the breakthrough curves for PP3121 zinc titanate. Pre-breakthrough $\mathrm{H}_{2} \mathrm{~S}$ concentrations were below the detection limit $\left(<5 \mathrm{ppm}_{2} \mathrm{~S}\right)$, suggesting good desulfurization kinetics and thermodynamics. Target desulfurization is less than 50 ppmv for the Polk Station hot gas cleanup system. A gradual decrease in reactivity that stabilizes at about 40 minutes is observed due to aging of the pellet structure.

Figure 3-11 shows the corresponding envelope of the breakthrough curves at the $200 \mathrm{ppm}$ level. The bed performance stabilizes to a constant level as the number of cycles increases. This result suggests that steady state operation can be achieved, and loss in bed capacity is not a linear process with number of cycles. Hence, extrapolation of bed performance to longer number of cycles is possible. In practice,

Table 3-5. Gas compositions for 50-cycle test

\begin{tabular}{l|cc}
\hline & Absorption & Regeneration \\
\hline $\mathrm{CO}$ & Balance & \\
$\mathrm{CO}_{2}$ & 10 & \\
$\mathrm{H}_{2}$ & 20 & \\
$\mathrm{H}_{2} \mathrm{O}$ & 20 & Balance \\
$\mathrm{N}_{2}$ & 16.3 & \\
$\mathrm{H}_{2} \mathrm{~S}$ & 2.0 & $0-4$ \\
$\mathrm{O}_{2}$ & & \\
\hline
\end{tabular}

Table 3-6. Target test conditions during absorption

\begin{tabular}{l|c}
\hline Parameter & Operating Condition \\
\hline Desired Sorbent Sulfur Loading & $\begin{array}{c}96.2 \mathrm{~g} \mathrm{~S} / \text { liter of bed }\left(6-7 \mathrm{lb} \mathrm{S} / \mathrm{ft}^{3} \text { of bed }\right) \\
\text { at the gas inlet location }\end{array}$ \\
$\mathrm{H}_{2} \mathrm{~S}$ Breakthrough point & $200 \mathrm{ppm}$ \\
Gas space velocity & $\geq 2000 \mathrm{hr}^{-1}(\mathrm{STP})^{*}$ \\
Pressure & $20 \mathrm{~atm}$ \\
Temperature & $482{ }^{\circ} \mathrm{C}\left(900{ }^{\circ} \mathrm{F}\right)$ \\
\hline
\end{tabular}

* STP (standard temperature and pressure is defined at $20^{\circ} \mathrm{C}$ and $1 \mathrm{~atm}$ ). 


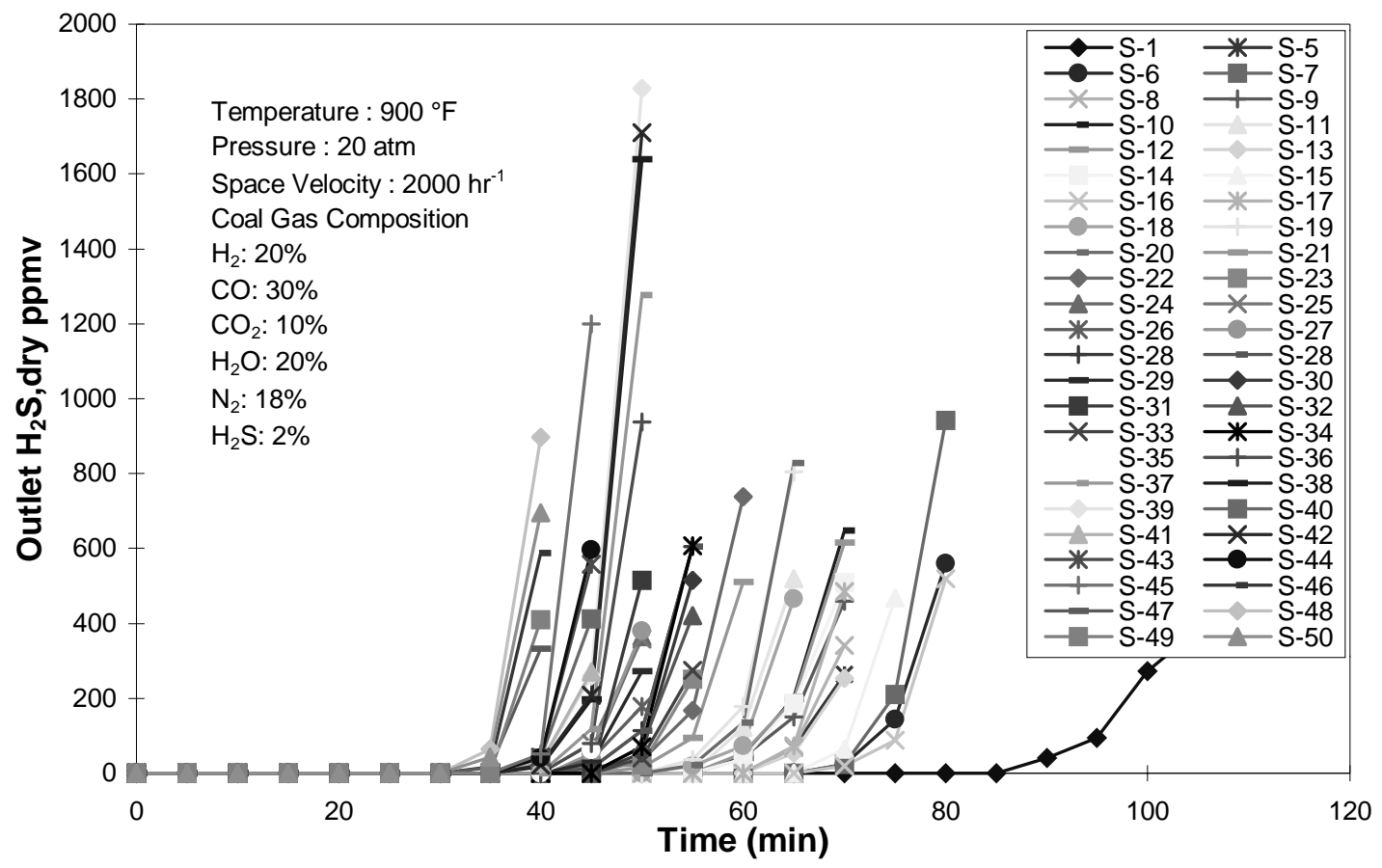

Figure 3-10. $\mathrm{H}_{2} \mathrm{~S}$ Breakthrough Curves for 50-Cycle Test of Zinc Titanate at RTI

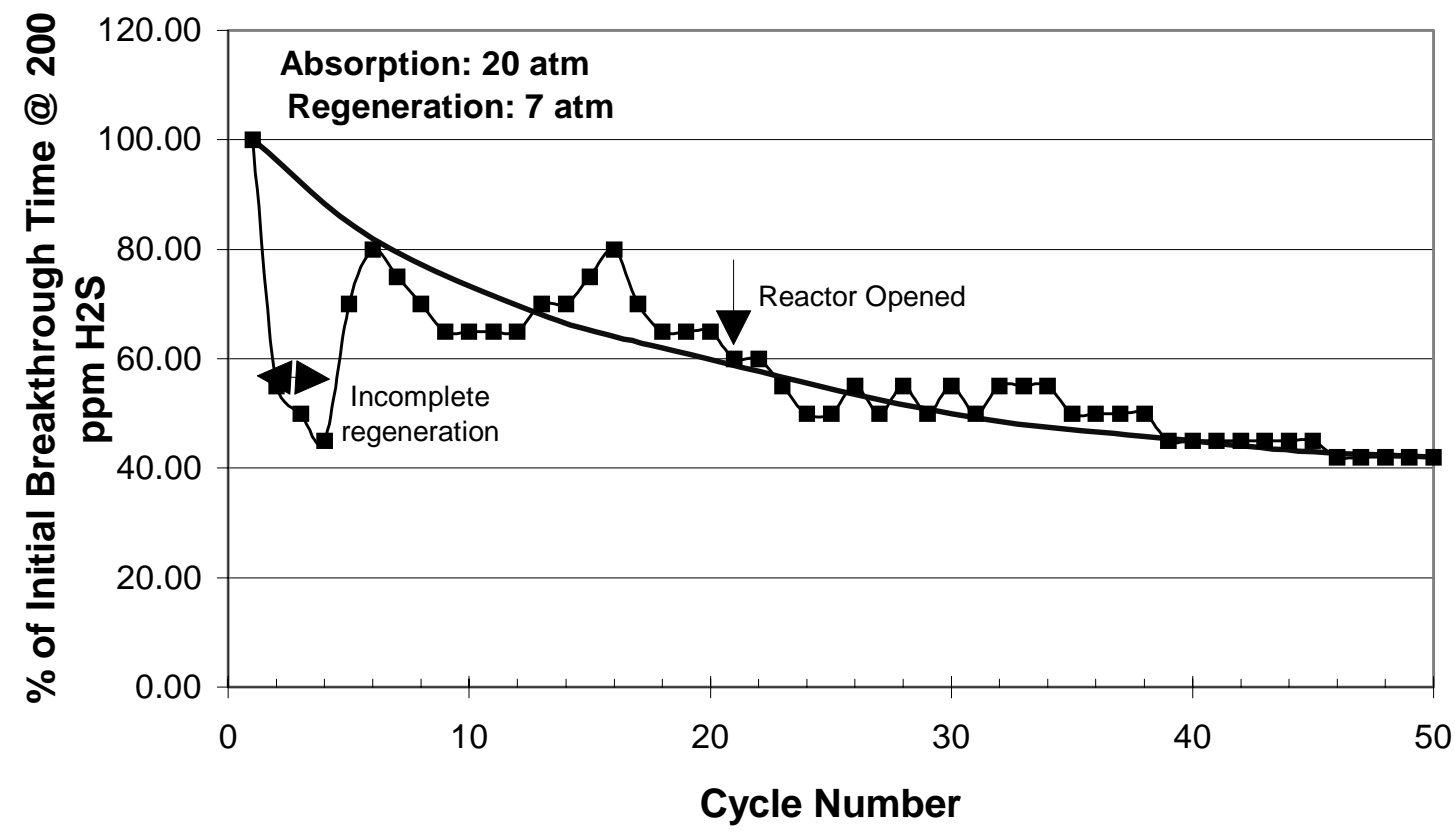

Figure 3-11. Envelope of breakthrough curves for zinc titanate testing at RTI 
the location of the y-axis stable point (as \% of initial breakthrough time) can be adjusted by modifying the actual operating conditions (e.g., temperature and flow rate).

Table 3-7 shows a comparison of sulfur loading for the fresh and cycled sorbents. The target sulfur loading depends on current bulk density as the sorbent densifies upon cycling. Sulfur loadings were measured by a thermogravimetric analyzer (TGA) as regenerable sulfide on gas inlet location samples. Sulfur measurements by the induction furnace (LECO) method were performed for reference and agreed with the TGA measurements.

Given that the 60-minute absorption at cycle 21 resulted in below target sulfur loading, the absorption time was increased to keep loading within target range. Overall, the target sulfur loading at the gas inlet location was maintained over the 50 cycle test.

In addition to the current sulfur loadings on the pelletized sorbent at the end of selected sulfidations, the measurement of total sulfur capacity available in the powder was also made by TGA, and is shown in Table 3-8 and in Figure 3-12. Samples were in powder form to determine the intrinsic reactivity of the oxide while minimizing pore diffusion mass transfer resistances across the pellets. Poisoning, sulfate accumulation, formation of inert zinc phases, and other chemical considerations could all contribute to the loss of chemical reactivity of the sorbent over a period of time, regardless of pellet pore structure or pellet integrity. A sorbent is considered acceptable for long-term operation if its sulfur capacity is retained at $50 \%$ or higher of its initial (i.e., theoretical) capacity -in other words, if the sorbent decreases its capacity by no more than a factor of two at the end of fifty cycles.

The rate of sulfur loading on the powder sorbents as a function of time is given by the TGA curves presented in Figure 3-12. A standard GE TGA test was performed at $1 \mathrm{~atm} / 538^{\circ} \mathrm{C} / 3 \% \mathrm{H}_{2} \mathrm{~S}$ for 2 hours.

Table 3-7. Sulfur loading of zinc titanate sorbent

\begin{tabular}{l|c}
\hline Bed Capacity & $\begin{array}{c}\text { \% Sulfur Capacity by GE TGA Test } \\
\text { (At 2-hr exposure) }\end{array}$ \\
\hline Target: as \% of theoretical after 50 cycles & $50 \%$ \\
Fresh & $95 \%$ \\
After 21 cycles & $60 \%$ \\
After 50 cycles & $55 \%$ \\
After 50 cycles (at 3-hr exposure) & $62 \%$ \\
\hline
\end{tabular}

Table 3-8. Sorbent sulfur capacity

\begin{tabular}{l|c}
\hline Bed Capacity & $\begin{array}{c}\text { \% Sulfur Capacity by GE TGA Test } \\
\text { (At 2-hr exposure) }\end{array}$ \\
\hline Target: as \% of theoretical after 50 cycles & $50 \%$ \\
Fresh & $95 \%$ \\
After 21 cycles & $60 \%$ \\
After 50 cycles & $55 \%$ \\
After 50 cycles (at 3-hr exposure) & $62 \%$ \\
\hline
\end{tabular}




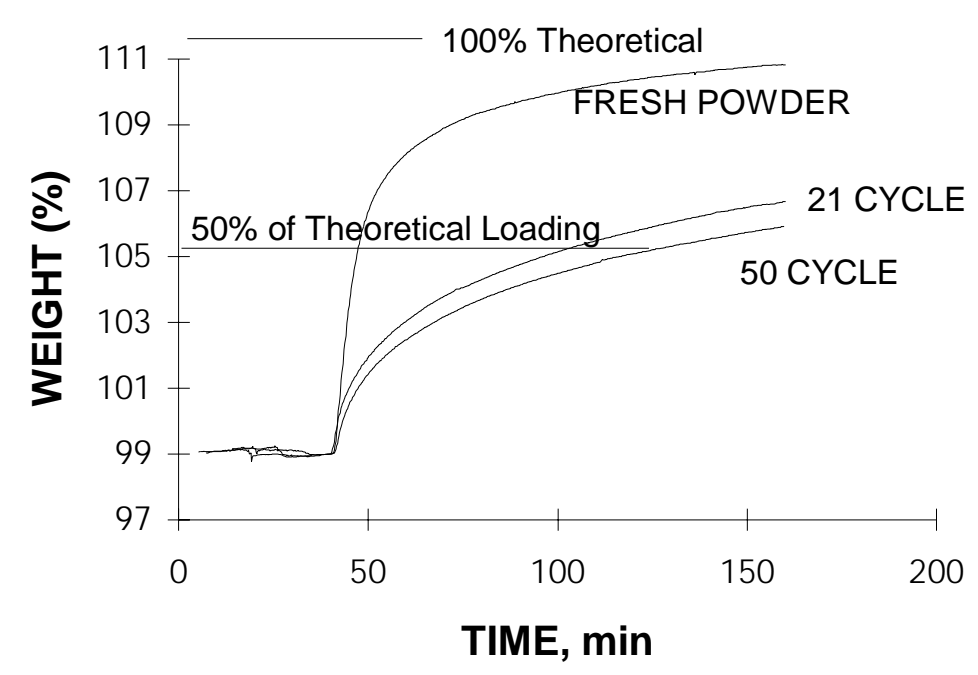

\section{Figure 3-12. TGA sulfur capacity of powdered samples after 50 cycles of testing at RTI}

After the standard 2-hr TGA test, the 50-cycle powder sample was allowed to sulfide for 1 additional hour to determine if sorbent was saturated at that point. The measured sulfur capacity was higher $(62 \%$ of theoretical) after one additional hour of sulfidation, confirming that the target sulfur loading requirement was exceeded comfortably and that further capacity was still available in the sorbent. All samples exceeded the acceptance requirement for sulfur capacity, as shown in Table 3-8.

A comparison of TGA reactivities between powder and pelletized samples would answer the question if the pellet porosity, or pellet integrity, was retained to a reasonable extent. Figure 3-13 shows the single-pellet TGA reactivity of the sorbent after 50-cycle bench tests at RTI . The drop in the weight gain due to sulfur absorption indicates a measurable decrease in the reactivity of the pelletized sorbent. The qualitative behavior in reactivity is similar between the powder and the pelletized samples after 50

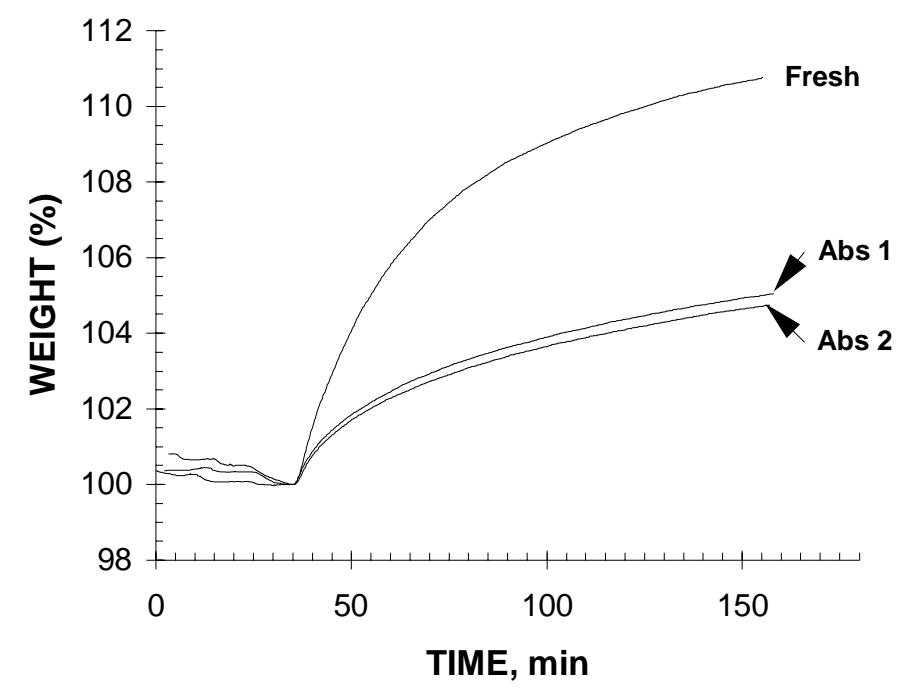

Figure 3-13. TGA reactivity of T-3121 zinc titanate pellets after 50 cycles of bench tests at RTI 
cycles of testing. This suggests that the loss in reactivity is a result of chemical degradation and not pore blinding in the pellets. The most likely reason for chemical degradation is, of course, zinc sulfate formation given that the regeneration at RTI was conducted at high pressure (i.e., $7 \mathrm{~atm}$ ).

In addition to measuring the chemical reactivity of the cycled sorbent, the mechanical performance was also measured by ASTM D4058-81 attrition tests (Table 3-9).

\section{Table 3-9. Attrition Results of Zinc Titanate Bench Tests at RTI}

\begin{tabular}{l|c}
\hline Sample Source & ASTM (D4058-81) Attrition Loss, \% \\
\hline Target: Fresh sorbent & $<4 \%$ \\
Fresh & $0.7 \%$ \\
After 50 cycles: Target & $<5 \%$ \\
After 50 cycles: gas inlet location & $8.0 \%$ \\
After 50 cycles: gas outlet location & $6.9 \%$ \\
After 50 cycles: average & 7.4 \\
\hline
\end{tabular}

The attrition loss for the fresh sorbent was well below the initial target of $4 \%$ by the ASTM method. The target for the fresh sorbent is as defined in the performance specifications for pilot plant sorbent procurement. The attrition loss for the 50-cycle sorbent was above the target value. Given the fact that the chemical reactivity was satisfactory and exceeded the minimum requirements but the attrition was above target, the performance suggests that the sorbent should be regenerated preferably below 7 atm, so that the rate of sulfate formation is minimized. Also, the sorbent should be calcined differently to further increase pellet strength at the expense of lower reactivity. As we have stated in the past, calcination conditions determine a balance of reactivity and strength: the higher the reactivity (because of higher pellet porosity) the lower the pellet strength and the higher the ASTM attrition.

Overall, the PP3121 molybdenum-containing zinc titanate sorbent formulation exceeded minimum specifications of reactivity, sulfur capacity, $\mathrm{H}_{2} \mathrm{~S}$ equilibrium removal levels, and initial attrition losses. An improvement in the attrition resistance at the 50th cycle (i.e., 50th regeneration) is still desirable for regeneration at $7 \mathrm{~atm}$ of pressure. Currently regeneration pressure should be conducted at $5 \mathrm{~atm}$ or below as the GE-CRD tests. In order to correlate any laboratory data with actual plant operation during evaluation of future sorbent formulations, a batch of this same zinc titanate composition was recommended for fabrication and testing at the GE-CRD pilot plant.

\subsubsection{Pilot Plant Test 8 Results}

Formulation PP3121, tested at RTI for fifty cycles, was again fabricated by UCI as a $6,400 \mathrm{~kg}$ batch $(\sim 14,000 \mathrm{lb})$ (designation T-2594M) for testing in the GE-CRD pilot plant during Test 8 in September 1995. From the point of view of sorbent development, the purpose of the pilot plant testing was to collect data on the scaling factors of chemical reactivity and sorbent mechanical durability between laboratory tests and larger-scale systems. A second objective was to measure the manufacturability of large sorbent batches given laboratory target specifications.

Figure 3-14 shows the absorber outlet $\mathrm{H}_{2} \mathrm{~S}$ during operation of the GE-CRD pilot plant (Test 8) using the zinc titanate sorbent developed in the current sorbent program. Complete results of the pilot plant 


\section{TEST 8: ABSORBER OUTLET $\mathrm{H}_{2} \mathrm{~S}$}

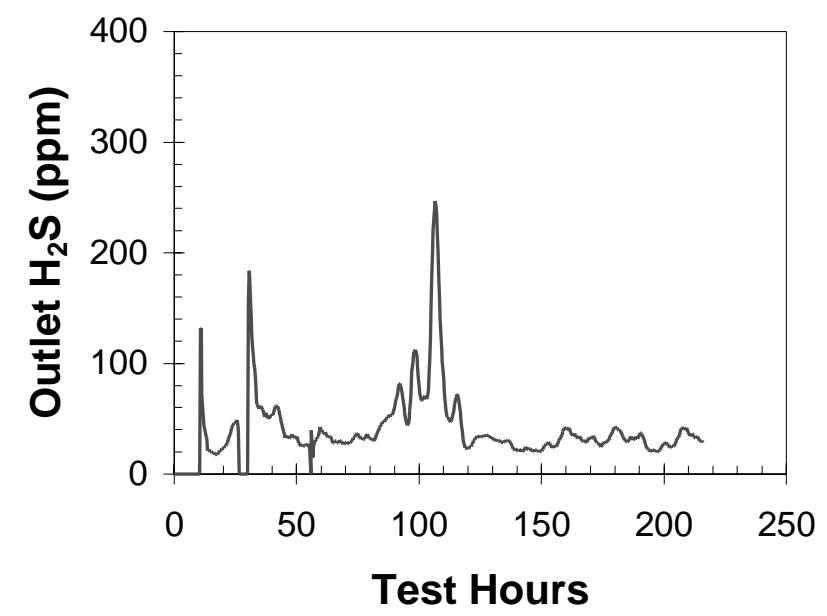

TEST 8 REGENERATOR $\mathrm{SO}_{2}$

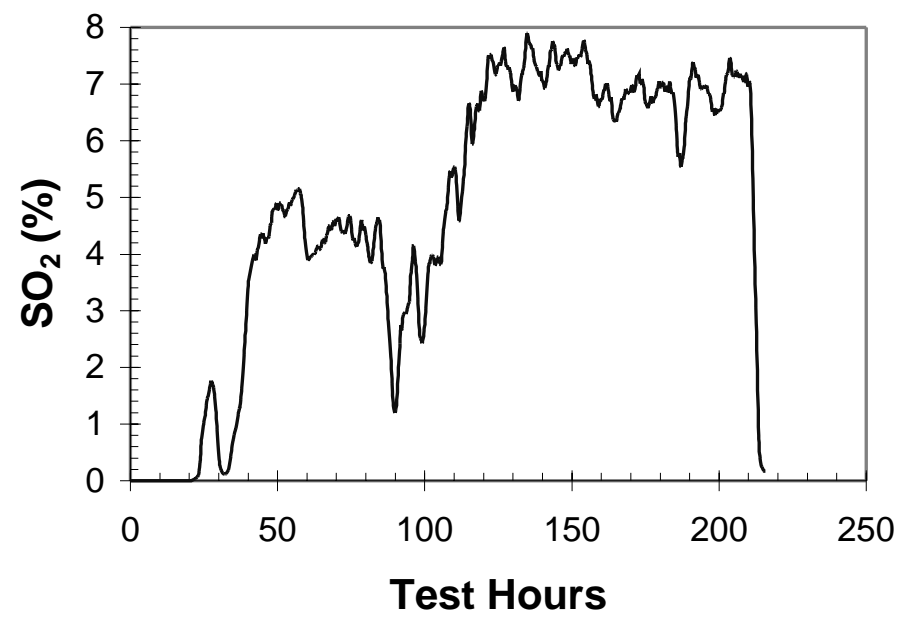

Figure 3-14. Absorber outlet $\mathrm{H}_{2} \mathrm{~S}$ and regenerator $\mathrm{SO}_{2}$ production during pilot plant test 8

Test 8 were presented in a separate GE report to DOE. ${ }^{5}$ Absorption was carried out at 20 atm and close to $480^{\circ} \mathrm{C}\left(\sim 900^{\circ} \mathrm{F}\right)$. After some initial excursions in the desulfurization performance during the first 100 hours, the sorbent and hardware were made to operate in integrated fashion, with close to $99 \% \mathrm{H}_{2} \mathrm{~S}$ removal (from $3500 \mathrm{ppmv}$ dry to $30-40 \mathrm{ppmv}$ dry), while simultaneously achieving desired sorbent net sulfur loading in the absorber and stable $\mathrm{SO}_{2}$ production in the regeneration loop. $\mathrm{SO}_{2}$ production was increased during the second half of the test by adjusting the regeneration operating conditions $\left(\mathrm{O}_{2}\right.$ concentration and bed temperature profiles). These encouraging pilot plant results proved the soundness of the scale-up method used from laboratory to pilot-plant tests. The attrition loss in the pilot plant test was measured at $1.7 \%$ under one set of conditions (i.e., a V-Wire screen in the regenerator fines separator) and $0.3 \%$ loss under another set of conditions after the test (i.e., a $1 \mathrm{~mm} \mathrm{x}$ $1 \mathrm{~mm}$ square mesh screen at the same location). These measured pilot plant attrition losses compare favorably with the ASTM attrition losses of approximately $7 \%$ measured in the laboratory, indicating 
that the large-scale operation is less severe and the cost of sorbent replenishment is less than predicted from ASTM tests alone. No corresponding scaling factors are currently available from pilot plant to the TECO demonstration plant, and these will have to be measured under comparable operating conditions of the vibrating screen at the outlet of the regenerator.

Figure 3-15 presents the reactivity of the pelletized T-2594M zinc titanate sorbent as fresh and after 200 hours of operation during Test 8 . The reactivity of the 200 -hr regenerated sample was somewhat lower than that of the fresh. Note that the reactivity of the fresh sorbent tested at RTI is different from that of the fresh sorbent tested under Test 8. The RTI material was made more reactive but less strong, and it was fabricated before the formulation T-2549M for the pilot plant test, when it was adjusted to correct some of the strength. Moreover, the loss in reactivity of the sorbent tested in the pilot plant Test 8 for $200 \mathrm{hr}$ ( 10 cycles, 1.5 -atm regeneration) was less than that measured for its corresponding formulation in the RTI tests (50 cycles, 7-atm regeneration).

Although the pilot plant batch T-2594M was not prepared at the same time and with the same scale equipment as the laboratory formulations screened at GE-CRD (formulations A-D) and RTI (PP3121), it was still encouraging that a formulation with lower performance in the laboratory performed acceptably in reactivity and initial attrition in the pilot plant operation.

In conclusion, three levels of testing were performed on molybdenum-doped zinc titanate: laboratory screening at GE-CRD, long-term (50-cycle) bench-scale testing at RTI, and pilot plant testing (200-hr, Test 8) at the GE-CRD pilot plant. The results indicate that the flow of information and technology transfer from laboratory to pilot plant is consistent and prediction of large-scale system operation is possible from laboratory and bench test results.

Test 8 in the pilot plant confirmed the acceptability of molybdenum-doped zinc titanate for desulfurization in a moving-bed system to target levels in commercial plants. Test 8 also suggested that higher levels of attrition resistance would be required for this sorbent to be economically viable during long-term use in commercial systems. To address some of these operational needs for Mo-doped zinc titanate, further efforts in the laboratory concentrated in several areas:

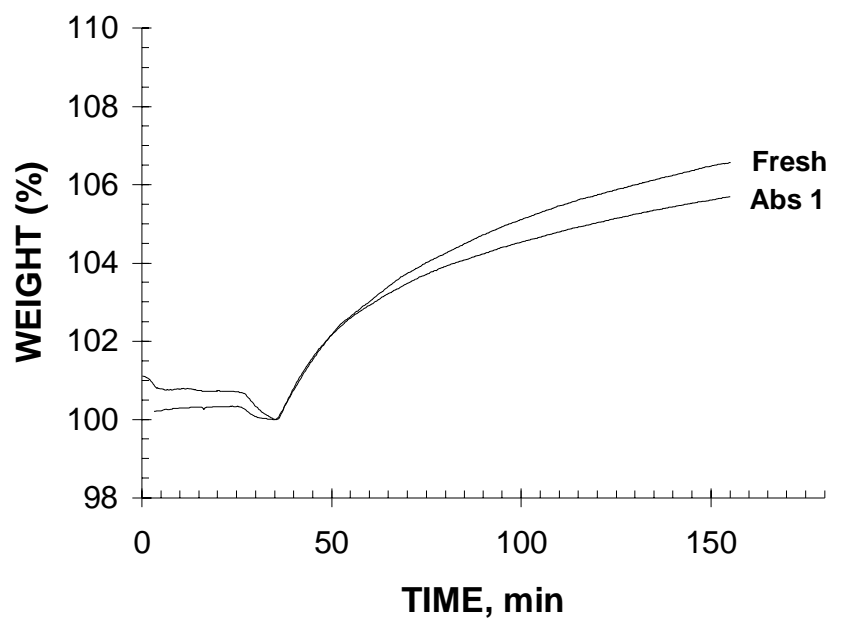

Figure 3-15. TGA reactivity of T-2594M zinc titanate pellets after 200 hours of pilot plant Test 8 ( 9 cycles) 
- Determination of the zinc titanate structure reconstitution after several sulfidation/regeneration cycles (Section 3.3.2.4, Zinc titanate structure determination after sulfidation/regeneration cycles).

- Regeneration of zinc titanate in the presence of $10 \% \mathrm{SO}_{2}$ in the regeneration gases at regeneration pressures of 1.5, 3, and 5 atm (Section 3.3.2.5, Regeneration of Mo-doped zinc titanate formulations at higher pressure and higher $\mathrm{SO} 2$ concentrations).

- Development of zinc titanate powder formulations containing additives for higher desulfurization rates below $482^{\circ} \mathrm{C}\left(900^{\circ} \mathrm{F}\right)$ and pelletized formulations for higher attrition resistance (Section 3.3.3, Modified Zinc Titanates (MZT's) with additives).

\subsubsection{Zinc titanate structure determination after sulfidation/regeneration cycles}

One of the practical questions that needs to be answered about the performance of zinc titanates with added mixed-metal oxide is whether the $\mathrm{Zn}_{2} \mathrm{TiO}_{4}$ crystal structure reforms after undergoing transformations between sulfided and regenerated states. In other words, whether there will be free zinc oxide and titanium dioxide phases present after repetitive cycling of the zinc titanate sorbents and, if so, whether this phenomenon is a potential source of weakening of the pellet mechanical structure. Several tests were conducted in the laboratory to study this question further.

X-ray diffraction patterns were taken from several zinc titanate sorbents after several levels of sulfidation to determine the extent of reconstitution of the zinc titanate, $\mathrm{Zn}_{2} \mathrm{TiO}_{4}$, structure after sulfidation. All regenerations were carried out at a maximum temperature of approximately $718^{\circ} \mathrm{C}\left(1325^{\circ} \mathrm{F}\right)$. Table 3-10 presents the results of sorbent regenerated in the laboratory Regardless of the prior level of sulfidation (e.g., 10, 25, 50, 75\%), zinc titanate always reconstitutes to $\mathrm{Zn}_{2} \mathrm{TiO}_{4}$ structure, at least above the level of detection by XRD ( 3-5 wt \%). Results of sulfided sorbent from the laboratory show that, in addition to $\mathrm{ZnS}$, there is the presence of the $\mathrm{ZnTiO}_{3}$ structure, suggesting that the sorbent never has free zinc oxide, $\mathrm{ZnO}$, available for reaction with $\mathrm{HCl}$ or $\mathrm{SO}_{2}$ during operation to form undesirable solid chlorides or sulfates. The pilot plant samples shown in Table 3-10 also show that the sorbent leaving the regenerator is not fully oxidized because there is some residual $\mathrm{ZnS}$ present, but the regenerated zinc is present in the form of $\mathrm{Zn}_{2} \mathrm{TiO}_{4}$, and the $\mathrm{ZnS}$ can be regenerated completely to $\mathrm{Zn}_{2} \mathrm{TiO}_{4}$.

Table 3-10. Major structure of Mo-doped zinc titanate by XRD

\begin{tabular}{lcc}
\hline Zinc titanate & $\begin{array}{c}\text { \% of Theoretical } \\
\text { Sulfidation }\end{array}$ & $\begin{array}{c}\text { Major Crystal } \\
\text { Structure }\end{array}$ \\
\hline 2nd. Regeneration sorbent & $10 \%$ & $\mathrm{Zn}_{2} \mathrm{TiO}_{4}$ \\
2nd. Regeneration sorbent & $25 \%$ & $\mathrm{Zn}_{2} \mathrm{TiO}_{4}$ \\
2nd. Regeneration sorbent & $50 \%$ & $\mathrm{Zn}_{2} \mathrm{TiO}_{4}$ \\
2nd. Regeneration sorbent & $75 \%$ & $\mathrm{Zn}_{2} \mathrm{TiO}_{4}$ \\
2nd. Sulfidation sorbent & $75 \%$ & $\mathrm{ZnS}^{\mathrm{ZnTiO}_{3}}$ \\
Pilot Plant Test 8 (sample 95-8R91, & $25 \%$ & $\mathrm{ZnS}+\mathrm{Zn}_{2} \mathrm{TiO}_{4}$ \\
200-hr regenerator) & & $\mathrm{Zn}_{2} \mathrm{TiO}_{4}$ \\
Above sample after TGA exposure & $25 \%$ & \\
to $\mathrm{O}_{2}$ at $704{ }^{\circ} \mathrm{C}\left(1300^{\circ} \mathrm{F}\right) / 1 \mathrm{hr}$ & & \\
\hline
\end{tabular}




\subsubsection{Regeneration of Mo-doped zinc titanate formulations at higher pressure and higher $\mathrm{SO}_{2}$ concentrations}

Work during the month of September focused on analyzing cyclic testing of zinc titanate in the presence of $10 \% \mathrm{SO}_{2}$ in the regeneration gases at pressures of $1.5,3$, and 5 atm and regeneration temperatures below $700{ }^{\circ} \mathrm{C}$. The objective of these tests was to determine the effect of sulfate accumulation or the rate of sulfide oxidation on the effective bed capacity during absorption and over multiple cycles.

In the following plots (Figure 3-16 to Figure 3-23) we will show the outlet $\mathrm{H}_{2} \mathrm{~S}$ concentrations versus time (i.e., the $\mathrm{H}_{2} \mathrm{~S}$ breakthrough curves) and the envelope of the breakthrough curves (at the $200 \mathrm{ppm}$ $\mathrm{H}_{2} \mathrm{~S}$ point) for each curve at $1.5,3$, and $5 \mathrm{~atm}$. Absorptions were performed at $900{ }^{\circ} \mathrm{F}$ with $1 \% \mathrm{H}_{2} \mathrm{~S}$ in simulated oxygen-blown gasifier coal gases. All regenerations were conducted in the presence of up to $12 \% \mathrm{SO}_{2}$ with no previous activation or preconditioning required. Regenerations were carried out until the $\mathrm{O}_{2}$ climbed to $0.1 \%$ or higher in the effluent gases. The maximum temperature during regeneration was maintained below $704^{\circ} \mathrm{C}\left(1300^{\circ} \mathrm{F}\right)$ and typically between $650-700^{\circ} \mathrm{C}$ except when otherwise noted. Hence, the bed performance at a given absorption is the result of either the residual sulfide or the sulfate formed and accumulated during previous regenerations.

As shown in Figure 3-16 and Figure 3-17, there is a gradual loss in bed capacity when regenerating at $1.5 \mathrm{~atm}$ and below $1300^{\circ} \mathrm{F}$ (cycles 1-4). When conditions were changed, i.e., temperature or regeneration time, the sulfur loading and the breakthrough time increased for the bed during absorption number 5 . This curve showed the effect of regeneration temperature on sulfate decomposition.

For the case of regeneration at 3 atm (Figure 3-18 and Figure 3-19), the loss of sulfur reactivity is less than in the case of regeneration at $1.5 \mathrm{~atm}$ during the first few cycles because the temperature at the gas outlet location of the bed had been monitored more closely and maintained near $700^{\circ} \mathrm{C}\left(1300^{\circ} \mathrm{F}\right)$, rather than near $650^{\circ} \mathrm{C}\left(1210^{\circ} \mathrm{F}\right)$. There is still a leveling off of the breakthrough time by the fifth absorption.

Similarly, Figure 3-20 and Figure 3-21 show the case of regeneration at 5 atm and demonstrate that regeneration below $704^{\circ} \mathrm{C}\left(1300^{\circ} \mathrm{F}\right)$ still results in a gradual loss of sulfur capacity in the bed (cycles 1-5). However, when the temperature of regeneration was increased to $760^{\circ} \mathrm{C}\left(1400^{\circ} \mathrm{F}\right)$, or slightly above $760^{\circ} \mathrm{C}$ as in cycles 6 to 8 , there was upward trend in the breakthrough times, suggesting that a steady level of performance had been achieved or that the sulfur capacity loss in previous cycles could be regained via zinc sulfate decomposition. This set of conditions is a good indicator that suggests pressurized regeneration at $5 \mathrm{~atm}$ can be achieved, but the level of control of regeneration may be very difficult.

Figure 3-22 and Figure 3-23 show the similar case when all the first five cycles were performed with regeneration temperatures as high as $760^{\circ} \mathrm{C}\left(1400^{\circ} \mathrm{F}\right)$. The downward trend is still present, but the trend stabilizes for cycles 5 and above. Samples were taken for sulfur analysis at the end of five cycles. The sulfur content of the sorbent, prior to the $\mathrm{N}_{2}$ sulfate decomposition step, indicated that there was a $2.16 \%$ residual sulfide (considered to be high) and a $1.28 \%$ sulfate sulfur (considered to be relatively low). The fact that there was residual sulfide suggests that the regeneration time was not long enough to complete regeneration in the presence of $\mathrm{SO}_{2}$, which is known to slow down the net oxidation rate of sulfide. The fact that the $\mathrm{O}_{2}$ was shut off at low levels of breakthrough $\left(<1 \% \mathrm{O}_{2}\right)$ during regeneration, as it will be shown later, confirms the supposition of incomplete oxidation. Hence, the regeneration at 
T2594M ZINC TITANATE

(Regeneration @ 1.5 Atm., >5\% SO2)

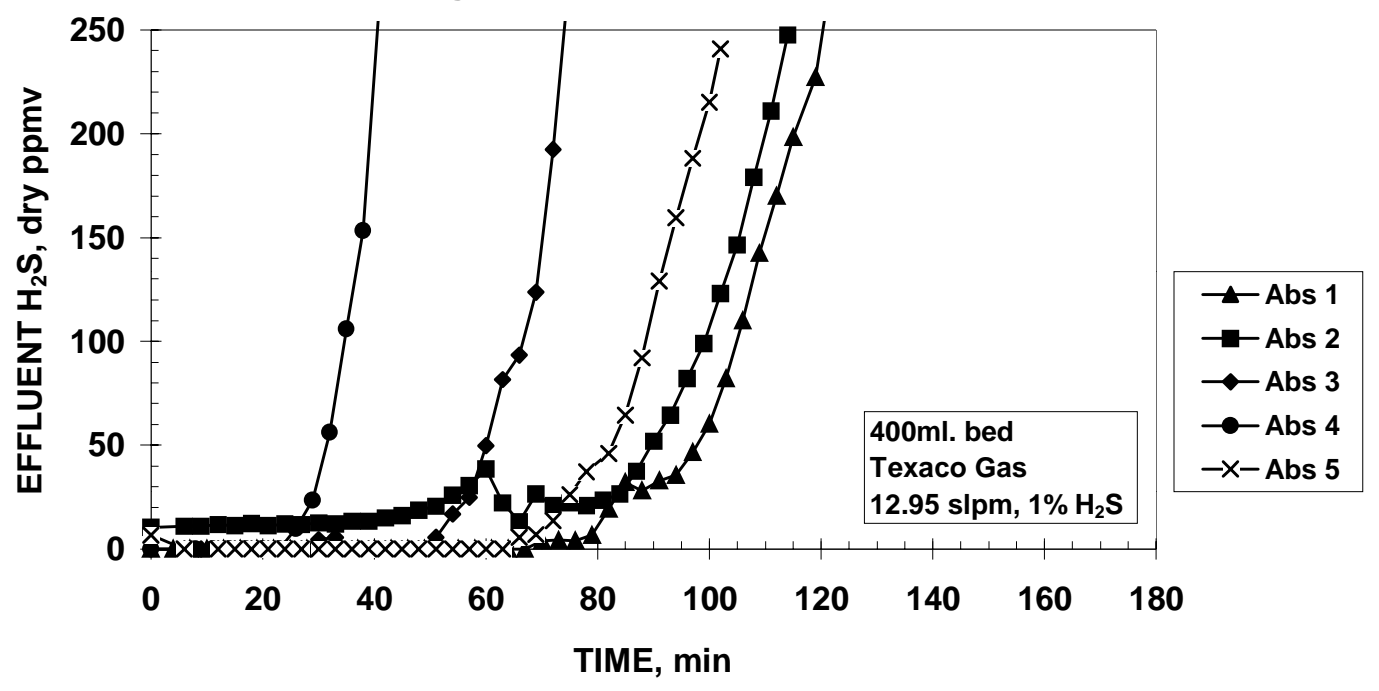

Figure 3-16. $\mathrm{H}_{2} \mathrm{~S}$ breakthrough curves for $\mathrm{T}-2594 \mathrm{M}$ when regeneration under regeneration with $\mathrm{SO}_{2}$ at 1.5 atm.

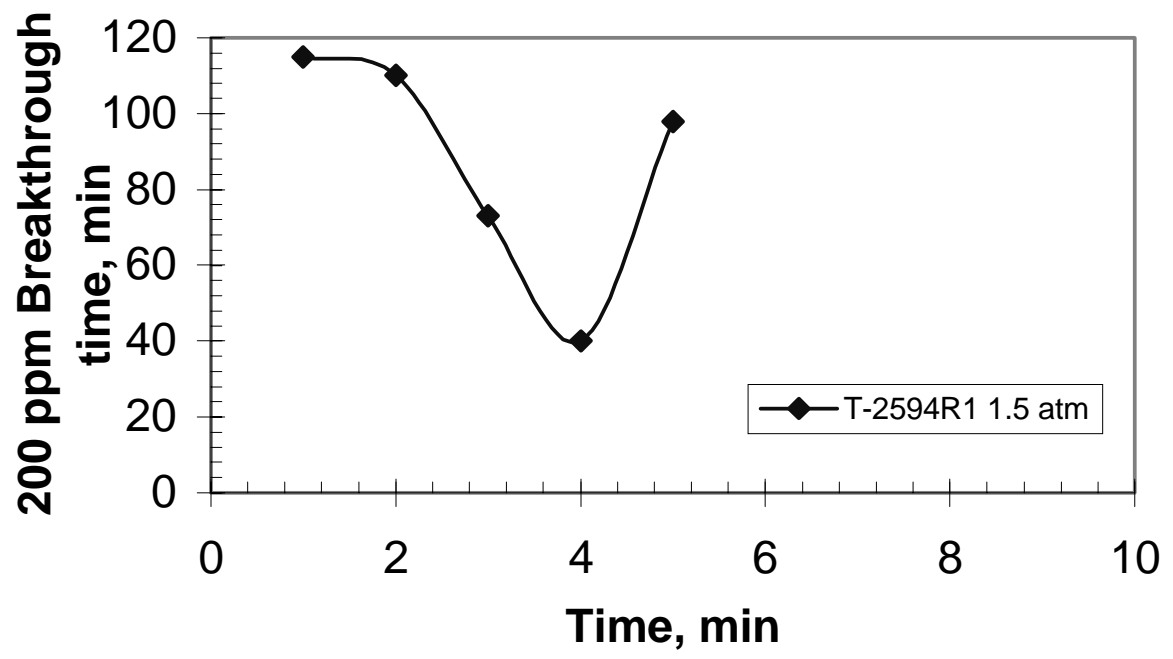

Figure 3-17. Envelope of $\mathrm{H}_{2} \mathrm{~S}$ breakthrough curves for T-2594M when regenerating under $\mathrm{SO}_{2}$ at $1.5 \mathrm{~atm}$. 
T2594M ZINC TITANATE

(Regeneration @ 3 Atm., >5\% SO2)

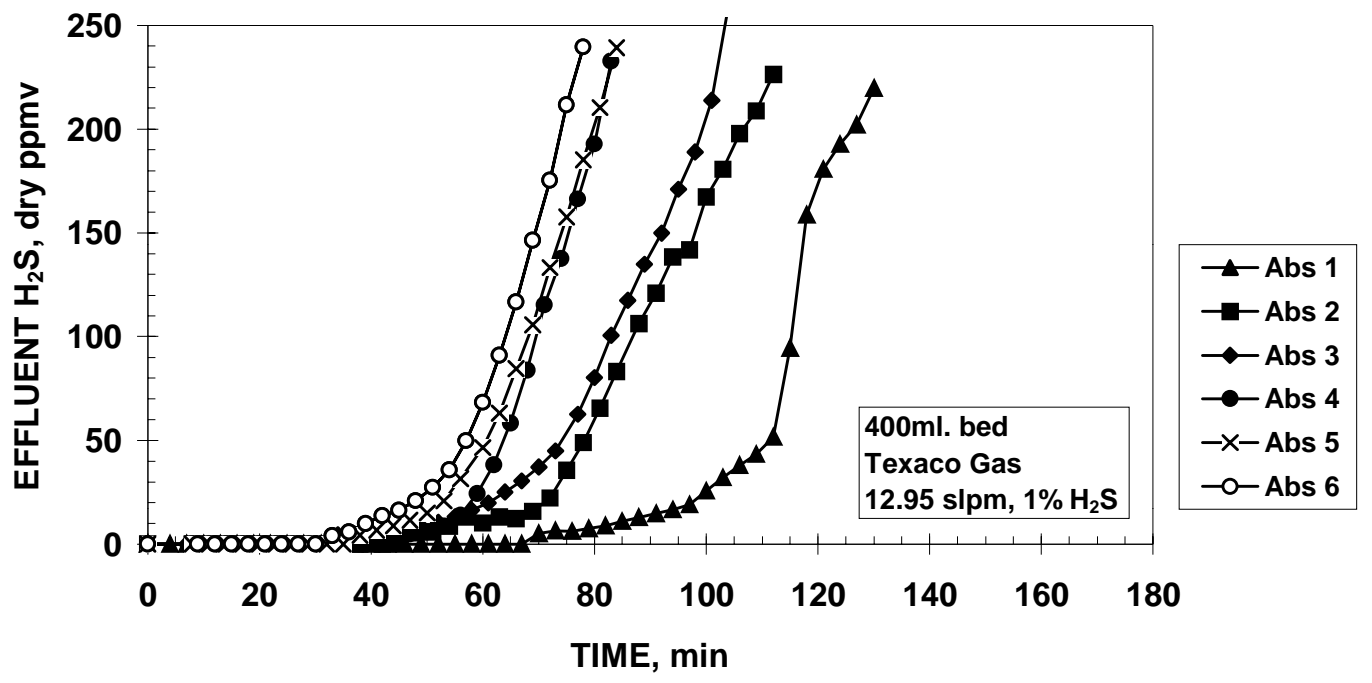

Figure 3-18. $\mathrm{H}_{2} \mathrm{~S}$ breakthrough curves for $\mathrm{T}-2594 \mathrm{M}$ with regeneration performed with $\mathrm{SO}_{2}$ at 3 atm.

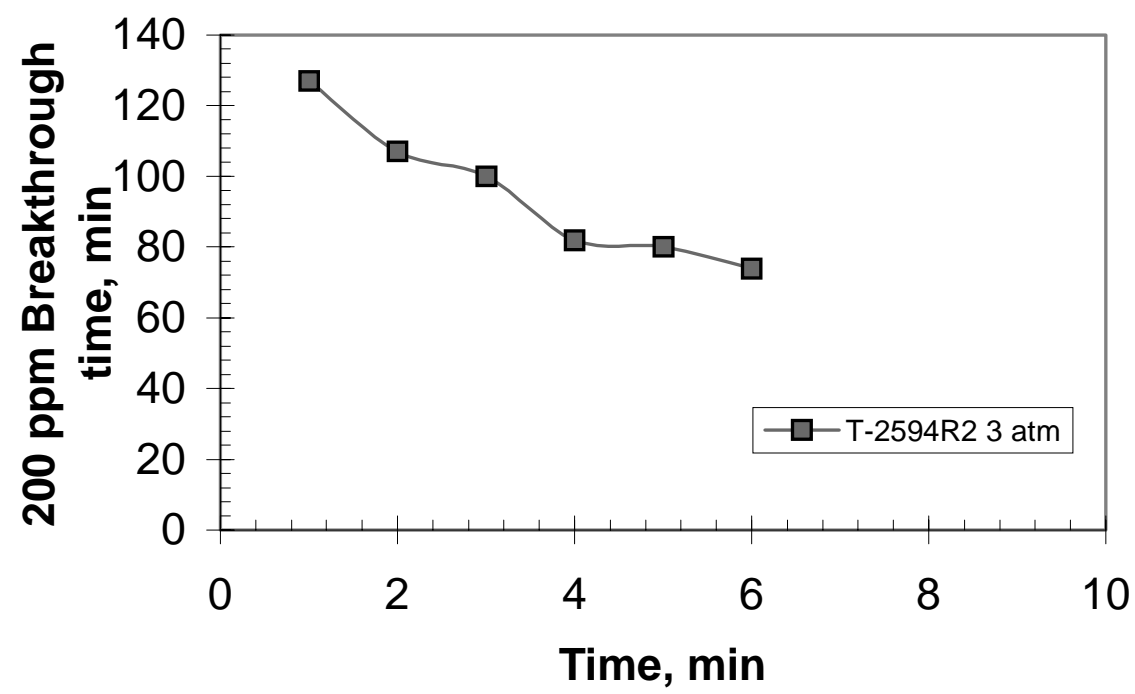

Figure 3-19. Envelope of $\mathrm{H}_{2} \mathrm{~S}$ breakthrough curves for T-2594M with regeneration performed with $\mathrm{SO}_{2}$ at 3 atm. 
T2594M ZINC TITANATE

(Regeneration @ 5.0 Atm., >5\% SO2)

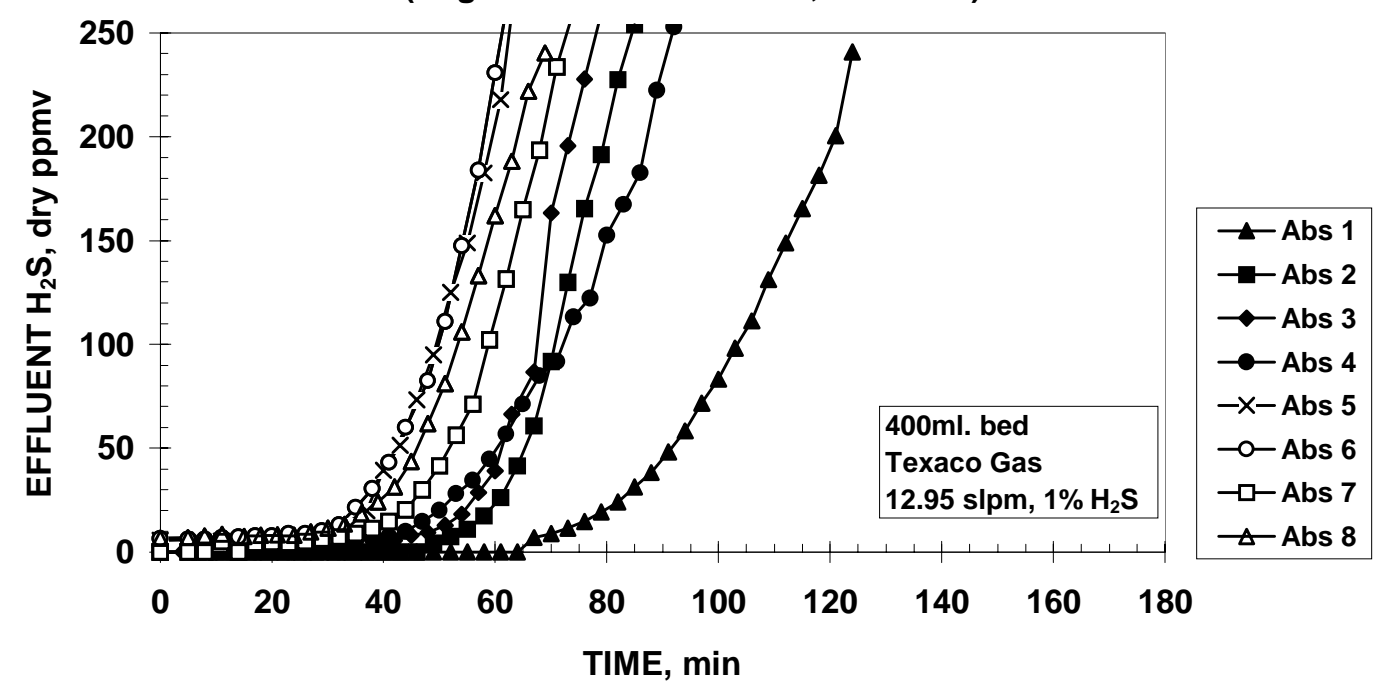

Figure 3-20. $\mathrm{H}_{2} \mathrm{~S}$ breakthrough curves for $\mathrm{T}-2594 \mathrm{M}$ with regeneration performed with $\mathrm{SO}_{2}$ at 5 atm and $704^{\circ} \mathrm{C}\left(\right.$ cycles 1-5) or $760{ }^{\circ} \mathrm{C}\left(1400{ }^{\circ} \mathrm{F}\right)($ cycles 6-8).

Envelope of Breakthrough times

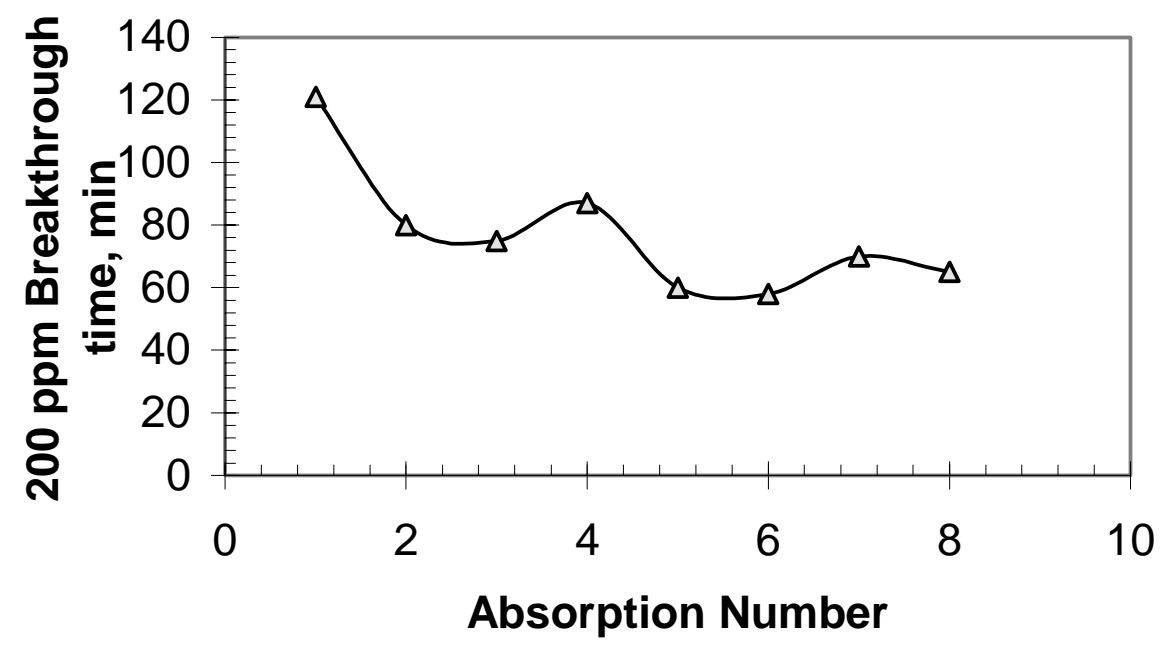

Figure 3-21. Envelope of $\mathrm{H}_{2} \mathrm{~S}$ breakthrough curves for T-2594M with regeneration performed with $\mathrm{SO}_{2}$ at 5 atm and $704^{\circ} \mathrm{C}\left(1300{ }^{\circ} \mathrm{F}\right)(\operatorname{cycles} 1-5)$ or $760{ }^{\circ} \mathrm{C}\left(1400{ }^{\circ} \mathrm{F}\right)$ (cycles 6-8). 


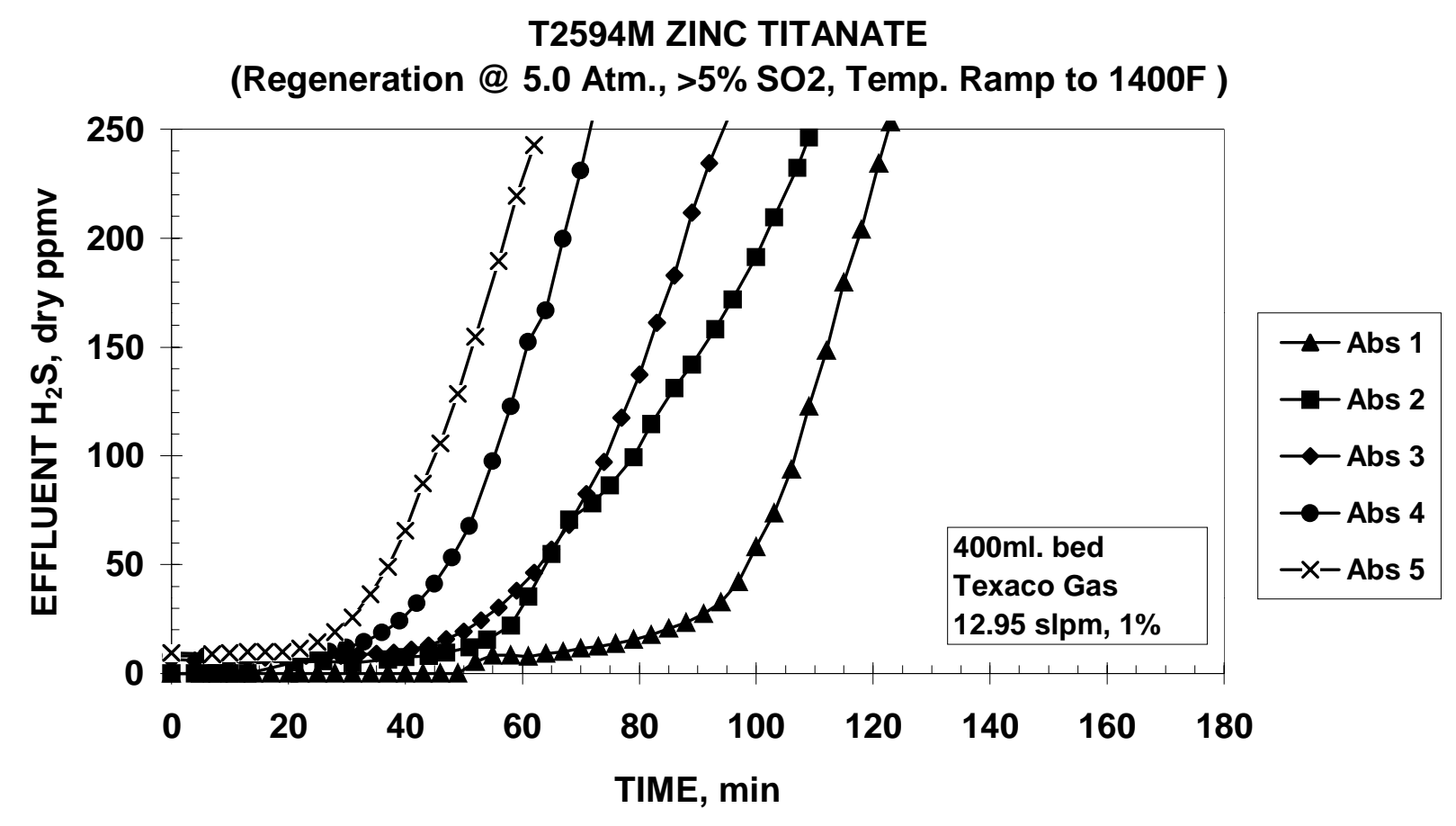

Figure 3-22. $\mathrm{H}_{2} \mathrm{~S}$ breakthrough curves for $\mathrm{T}-2594 \mathrm{M}$ with regeneration performed with $\mathrm{SO}_{2}$ at $5 \mathrm{~atm}$ and a final temperature of $760^{\circ} \mathrm{C}\left(1400{ }^{\circ} \mathrm{F}\right)$.

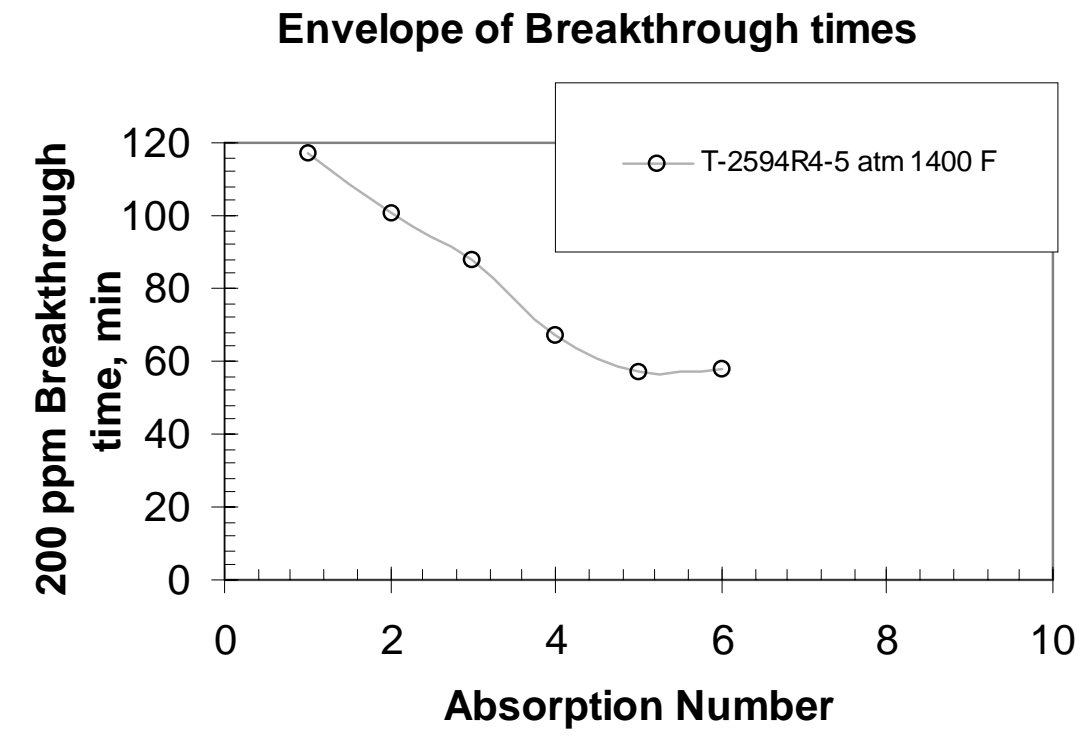

Figure 3-23. Envelope of $\mathrm{H}_{2} \mathrm{~S}$ breakthrough curves for $\mathrm{T}-2594 \mathrm{M}$ with regeneration performed with $\mathrm{SO}_{2}$ at $5 \mathrm{~atm}$ and a final $\mathrm{N}_{2}$ decomposition temperature of $760{ }^{\circ} \mathrm{C}\left(1400{ }^{\circ} \mathrm{F}\right)$. 
$704^{\circ} \mathrm{C}\left(1400^{\circ} \mathrm{F}\right)$ kept low sulfate levels in the sorbent, which is beneficial, but should have been carried out longer in the presence of $\mathrm{O}_{2}$ to complete the zinc sulfide oxidation.

Addition of $\mathrm{SO}_{2}$ from compressed gas cylinders to a pressurized bench-scale reactor system is somewhat complicated because at the high flow rates needed, only liquefied $\mathrm{SO}_{2}$ can be used. To show that the level of control maintained on regeneration experiments was acceptable, Figure 3-24 shows the $\mathrm{SO}_{2}$ concentrations delivered at $5 \mathrm{~atm}$ regeneration, as planned for TECO. The $\mathrm{SO}_{2}$ delivery system at pressure was able to keep up with the flow rate of sulfur dioxide needed for the bench reactor system and deliver $10 \% \mathrm{SO}_{2}$. In some other cases (not shown), however, the fluctuations in inlet $\mathrm{SO}_{2}$ were high (from $10 \pm 3 \%$ ) due to flashing of the liquid $\mathrm{SO}_{2}$ as it was delivered to the hot system. We have taken measures to minimize these fluctuations, and future tests will probably be within narrower limits of $\mathrm{SO}_{2}$ fluctuations. In general, it was easier to control the $\mathrm{SO}_{2}$ delivered at higher pressures than at lower pressures, where flashing and cavitation of the liquid $\mathrm{SO}_{2}$ pump were observed.

The same Figure 3-24 shows the outlet $\mathrm{O}_{2}$. A typical regeneration time was stopped at 200 minutes or less, when the oxygen concentration had broken through at the reactor exit from 0 to $0.5-0.7 \% \mathrm{O}_{2}$. Since the initial absorption times were around 120 minutes, the regeneration should perhaps have been carried out up to 240 minutes, or twice the absorption times to prevent sulfide accumulation.

REGENERATION \#2 @ 5 ATM.

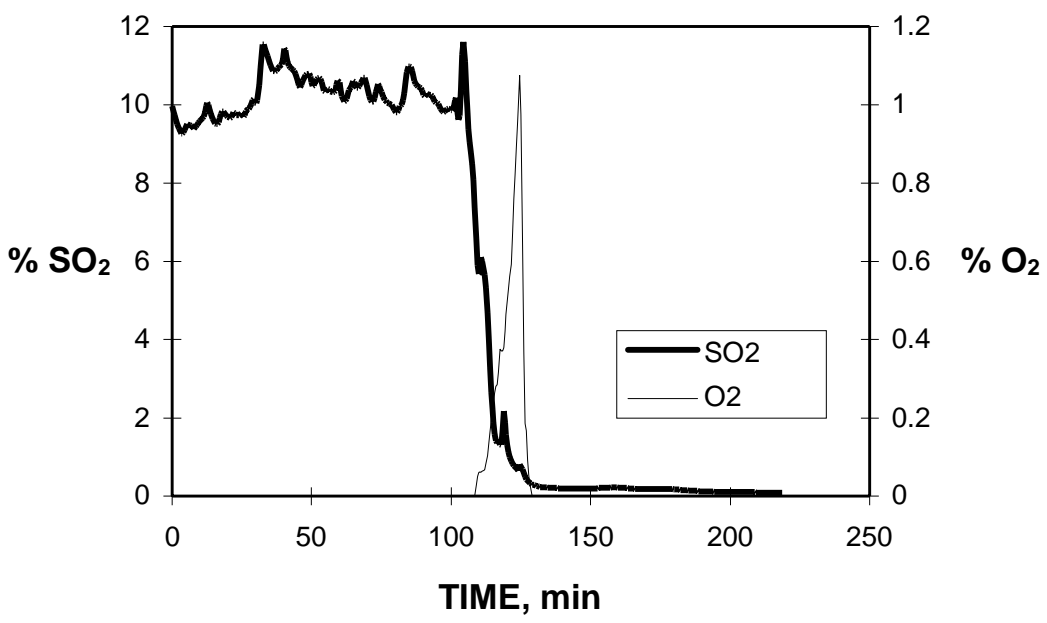

Figure 3-24. $\mathrm{SO}_{2}$ delivery during regeneration at 5 atm 


\subsubsection{Modified Zinc Titanates (MZT's) with Additives}

Introduction of additives other than molybdenum into the zinc titanate structure was also pursued at GECRD. These zinc titanates were called modified zinc titanates (MZT's). The tests were performed with two major objectives in mind:

1. To increase the strength of the $\mathrm{Zn}_{2} \mathrm{TiO}_{4}$ sorbent pellets, which in the past have exhibited various degrees of mechanical performance in long-term pilot plant tests (phase-stability modifiers)

2. To increase the lower limit of operation during desulfurization from $482{ }^{\circ} \mathrm{C}$ down towards $343^{\circ} \mathrm{C}$ (desulfurization-rate additives). This need for sustained reactivity at temperatures below $482^{\circ} \mathrm{C}$ $\left(900^{\circ} \mathrm{F}\right)$ exists because of the lower actual gasifier coal gas temperatures currently being delivered by the Texaco gasifier at the HGCU demonstration plant at TECO.

The initial tests on MZT's were performed using powders to ascertain that the presence of additives would not cause negative interactions with the desulfurization reactivity and sulfur removal capacity of $\mathrm{Zn}_{2} \mathrm{TiO}_{4}$. Once proper reactivity was determined, the existing powders were pelletized to obtain durable formulations to withstand operation over multiple cycles.

\subsubsection{Powder MZT Testing}

Evaluation of the modified zinc titanates (MZT) was first performed to ascertain that the presence of additives in powders would not have a negative effect on the desulfurization reactivity, sulfur removal capacity, and regenerability of zinc titanate. For instance, the structure in zinc titanate is less likely to form zinc chloride compounds during sulfidation than pure zinc oxide; however, additives to the zinc titanate could potentially react with $\mathrm{HCl}_{(\mathrm{g})}$ in the coal gas and promote formation of metal chlorides; these metal chlorides would be undesirable because they are carried to the regenerator where they decompose and are released as $\mathrm{HCl}_{(\mathrm{g})}$ during regeneration, affecting the sulfur recovery system. The second part of the testing involved pelletizing the formulations and assessing the mechanical characteristics (attrition and crush strength) of the fresh and reacted sorbents.

Approximately 30 powder formulations were prepared during 1996 to assess chemical reactivity. Table 3-11 presents the designation of a few of the powder formulations that were prepared with promising desulfurization and regeneration properties. Details of formulation compositions are covered in the GE patent literature reported in Section 3.3.1.

Table 3-11. GE modified zinc titanate formulations

\begin{tabular}{lll}
\hline $\begin{array}{l}\text { Formulation } \\
\text { Number }\end{array}$ & $\begin{array}{l}\text { GE } \\
\text { Designation }\end{array}$ & \multicolumn{1}{c}{ Comment } \\
\hline 1 & ZT9601 & reference plain zinc titanate \\
2 & ZT9602 & molybdenum additive \\
3 & ZT9603 & desulfurization additive \\
4 & ZT9606 & strengthening additive \\
5 & ZT9607 & phase stability additive \\
6 & ZT9608 & phase stability additive \\
7 & ZT9605 & phase stability additive \\
8 & ZT9604 & Mo + stabilizing additive \\
\hline
\end{tabular}


Formulations 1 and 2 are the standard plain zinc titanate $\left(\mathrm{Zn}_{2} \mathrm{TiO}_{4}\right)$ without additives and zinc titanate with molybdenum additive. These two were fabricated again to provide a comparison baseline. Formulation 3 contains additives to increase the desulfurization capability in the temperature range 343-482 ${ }^{\circ} \mathrm{C}$, which is currently the operating coal gas temperature of the Texaco gasifier coal gas at TECO. Formulation 4 contains an additive for strength. In the past (Test 8 of the pilot plant), the existing zinc titanate (as in formulation No. 2) performed very well in terms of reactivity, but the attrition rate was higher after $200 \mathrm{hr}$ of operation than commercially desired.

Chemical reactivity of sorbents was assessed using a thermogravimetric analyzer (TGA). In a TGA test, the weight of a powder or pellet sample hanging from the microbalance is monitored as a function of time. The weight gain is proportional to the extent of reaction in the sample. For pure zinc titanate $\left(\mathrm{Zn}_{2} \mathrm{TiO}_{4}\right)$, the complete sulfidation reaction (26\% wt/wt sulfur on the sorbent) corresponds to a weight gain of $12.6 \%$. Of course, addition of inerts and binders reduces the weight gain observed at saturation, but reproducibility of the weight changes through multiple cycles of absorption and regeneration is the key parameter in sorbent development. In a typical TGA reactivity test, the pellets are exposed to simulated clean coal gas (without $\mathrm{H}_{2} \mathrm{~S}$ ) for the first 30 minutes at 1 atm and $482{ }^{\circ} \mathrm{C}$ to establish a weight baseline. Then, $3 \% \mathrm{H}_{2} \mathrm{~S}$ is introduced during absorption (also called sulfidation) to check for weight changes during the reaction. A regeneration with 2-4\% $\mathrm{O}_{2}$ can follow the sulfidation, when the weight should return to its base value. Repetitive cycles of sulfidation and regeneration can be carried out in a multiple cycle test. A typical example of a TGA powder formulation with a phase stability additive (ZT9607) is shown in Figure 3-25, where no loss in reactivity is observed between the first and the second absorptions, indicating hydrothermal stability of the sorbent in the absence of confounding sulfidation weight changes. A horizontal baseline is measured in the first 30 minutes of each absorption, and essentially no loss in reactivity is observed between the first and the second absorptions. Standard conditions for TGA sulfidation tests at GE are $3 \% \mathrm{H}_{2} \mathrm{~S}$ in simulated coal gases at $482{ }^{\circ} \mathrm{C}$ and $1 \mathrm{~atm}$.

Figure 3-26 presents the reactivity of ZT9603 zinc titanate. This formulation has desulfurization additives and no phase stabilizers. Some initial loss in capacity is observed, either due to sulfate formation or structure densification (e.g., loss of surface area).

Figure 3-27 shows the performance of ZT9606 zinc titanate with a phase stabilizer. The fact that the two absorptions are very close together suggest that there is little surface area loss between cycles.

TGA tests show that the reactivity of the top five formulations is satisfactory during the initial screening, i.e., that the strengthening and desulfurization enhancing additives are not detrimental to the desulfurization and regeneration of the sorbents. Figure 3-28 shows the TGA curves for the first sulfidation of several of the formulations obtained at $482{ }^{\circ} \mathrm{C}, 1 \mathrm{~atm}$, and $3 \% \mathrm{H}_{2} \mathrm{~S}$ in the simulated coal gas. The theoretical capacity of the modified zinc titanate powders is between $10 \%$ and $12 \%$ weight gain, so all the curves exhibit a normal behavior of weight gain to close to saturation after the two hour test (theoretical for these zinc titanates is approximately $12.6 \%$ ). Differences in the total sulfur capacity among the sorbents are a result of differences in the zinc titanate initial concentration in the formulation. Also, none of the formulations lose or gain weight prior to introduction of $\mathrm{H}_{2} \mathrm{~S}$ ( 0 to 40 minutes), which indicates a (hydrothermally) stable crystal structure in the presence of $\mathrm{H}_{2}$ and $\mathrm{CO}$ in the simulated coal gas.

After completion of the reactivity tests on powder formulations, UCI was requested to pelletize these formulations to test their mechanical properties (attrition resistance and crush strength) at GE-CRD. 


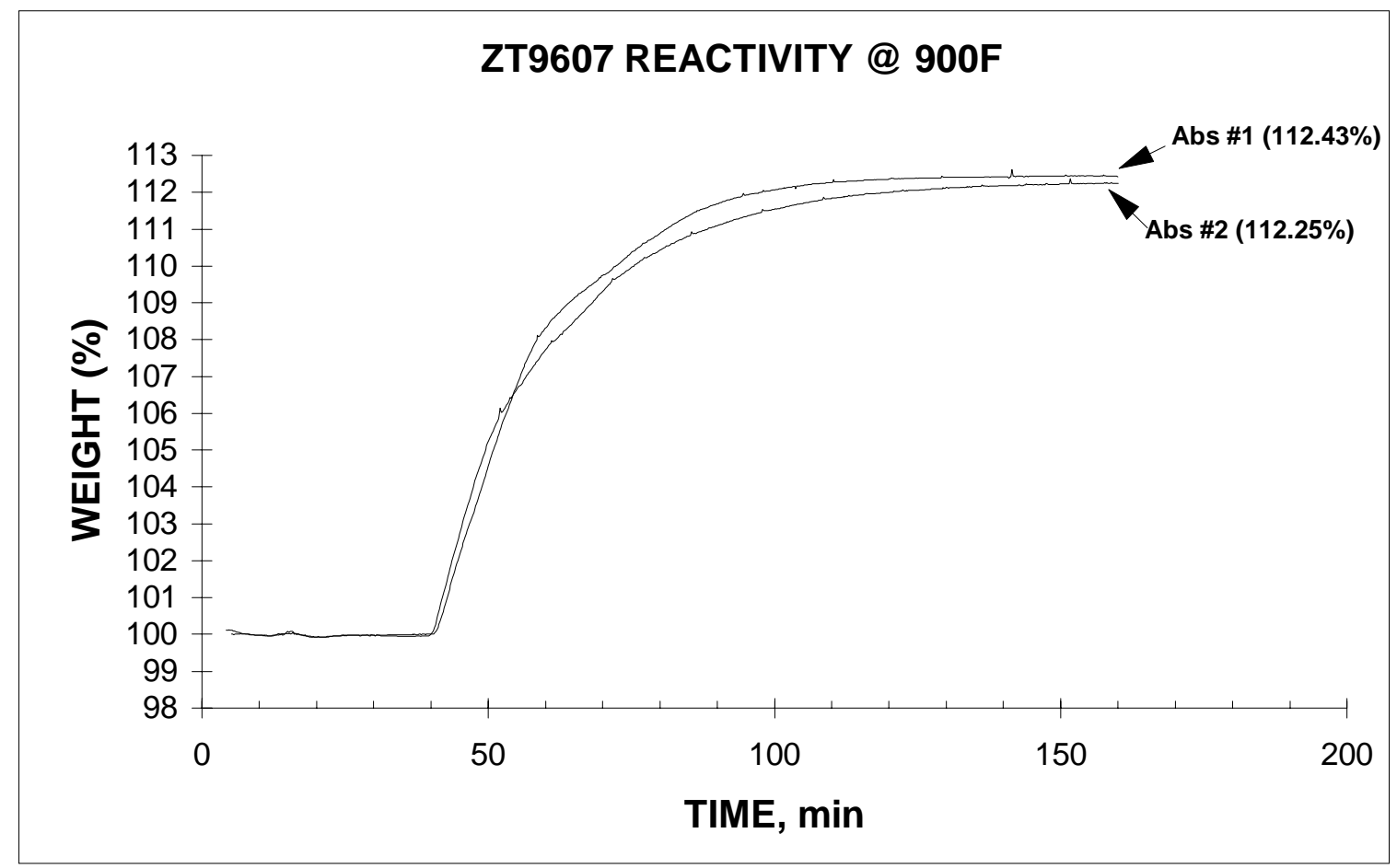

Figure 3-25. TGA Chemical reactivity of ZT9607 zinc titanate

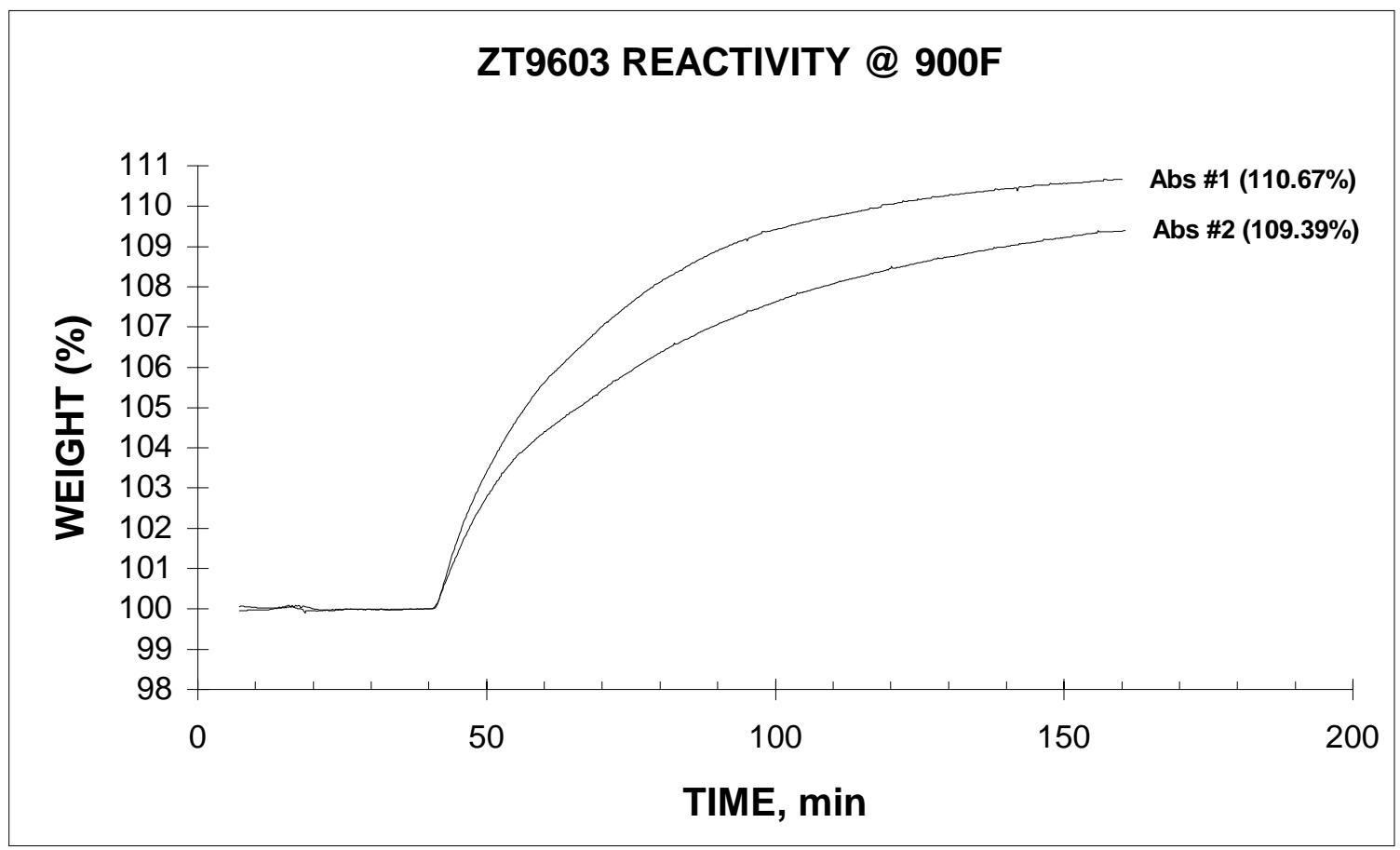

Figure 3-26. TGA Chemical reactivity of ZT9603 zinc titanate without stabilizer 


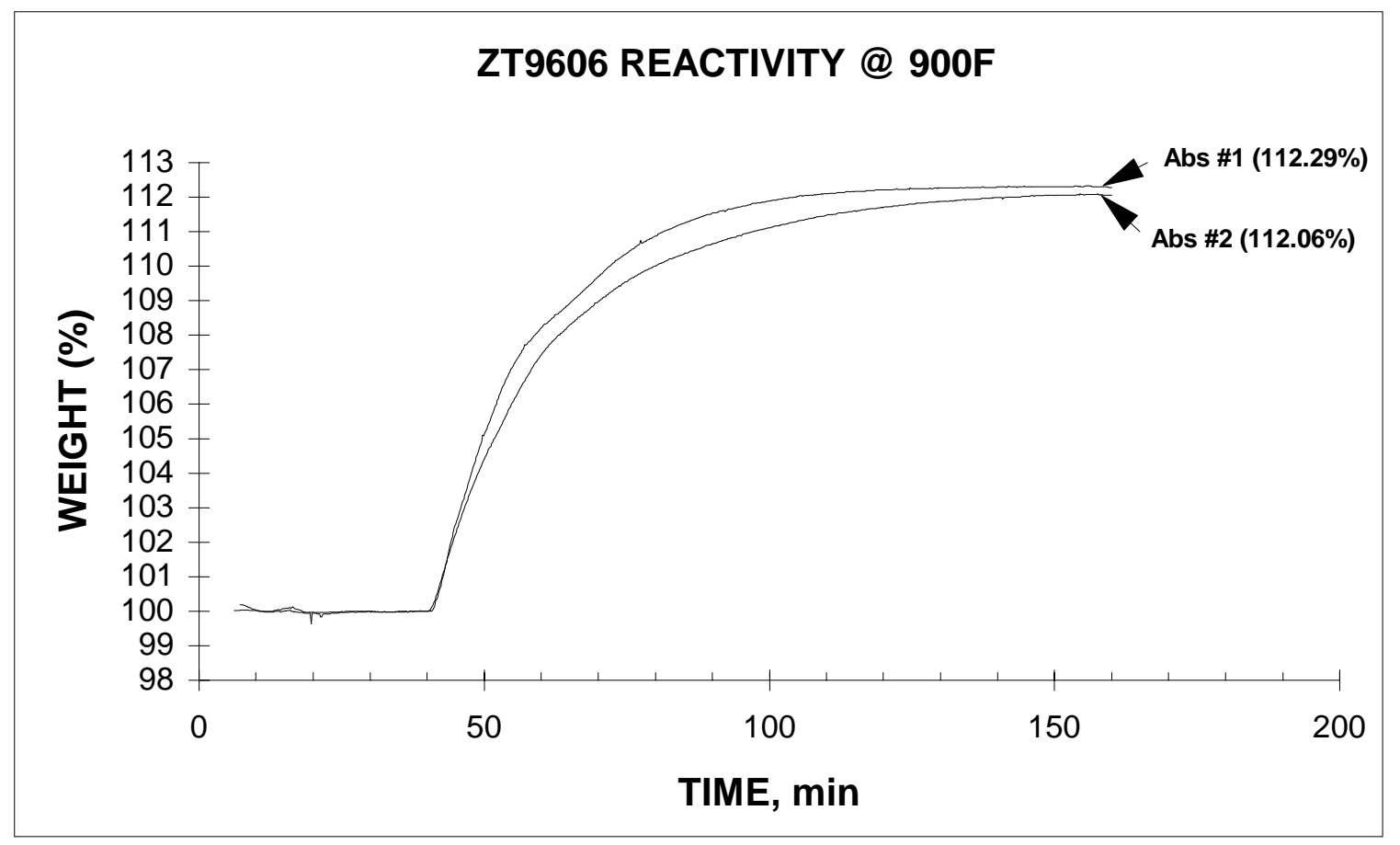

Figure 3-27. TGA reactivity of a zinc titanate with a phase stabilizer

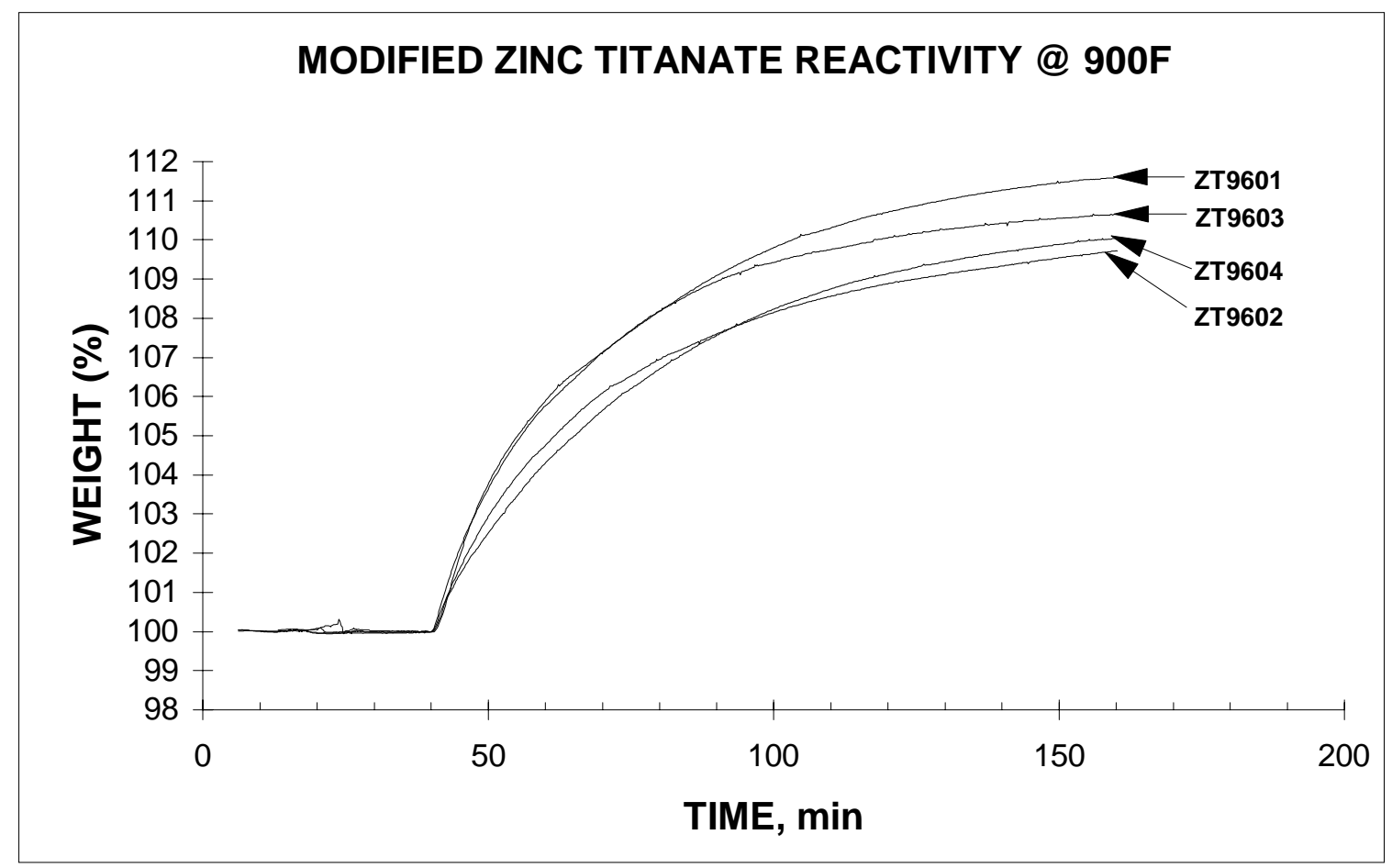

Figure 3-28. TGA reactivity of powder modified zinc titanates at $482{ }^{\circ} \mathrm{C}, 3 \% \mathrm{H}_{2} \mathrm{~S}$, and 1 atm. 


\subsubsection{Pelletized MZT Sorbent Testing}

Having evaluated the chemical performance of powder MZT sorbents, we proceeded to pelletize those formulations that exhibited satisfactory chemical performance. The purpose of the pelletization studies at UCI was to improve the mechanical durability of zinc titanate sorbent formulations by adjusting the pelletization conditions (i.e., time, temperature, pore modifiers, and binders) that would result in an improved overall (chemical and mechanical) performance of the previously tested powdered formulations. Typically, mechanically strong pellets have low reactivities, and highly reactive pellets tend to be soft. A balance between the two properties is usually necessary to achieve optimum performance in moving-bed applications.

The following key areas of sorbent performance were considered for comparison among pelletized formulations:

- mechanical durability (attrition and crush strength) of fresh and cycled sorbents

- desulfurization and regeneration characteristics during normal operation

- sulfate formation tendency during regeneration

- temperature range of desulfurization.

All modified zinc titanate formulations were tested as received from UCI. No interim conditioning or activation of the pellets was necessary prior to testing at GE-CRD. Pelletization procedures are proprietary to UCI.

\subsection{Mechanical durability of fresh pelletized sorbents}

Several formulations of modified zinc titanate sorbents were extruded, formed, and calcined by UCI. The resulting pellets had a 3-4 mm diameter and were ellipsoidal in shape. The first round of pelletized zinc titanate formulations was received for evaluation at GE-CRD in January 1997 (Table 3-12). Crush strength was acceptable (i.e., greater than $3 \mathrm{lb} /$ pellet or $1.36 \mathrm{~kg} / \mathrm{pellet}$ ) and TGA reactivity was also reasonable (discussed in the next section). However, ASTM attrition for most of the fresh formulations was above the target value of less than $4 \%$.

Given that pelletization of modified zinc titanates in the first round fell short of exceeding the target mechanical strength (i.e., ASTM attrition less than 4\%), preparation of a second round of formulations with the same compositions was undertaken again at UCI. This time, pelletization procedures were

Table 3-12. Properties of the first round of pelletized fresh samples

\begin{tabular}{lcccc}
\hline Formulation & $\begin{array}{c}\text { Density, } \\
\text { lb/ft } \\
\text { (sp. gravity) }\end{array}$ & $\begin{array}{c}\text { Crush Strength, } \\
\text { lb/pellet } \\
\text { (kg/pellet) }\end{array}$ & $\begin{array}{c}\text { ASTM Attrition, } \\
\%\end{array}$ & $\begin{array}{c}\text { Presence of broken } \\
\text { granules after ASTM } \\
\text { attrition tests }\end{array}$ \\
\hline PP-4114 & $83.1(1.33)$ & $6.5(2.9)$ & 1.32 & No \\
PP-4115 & $84.3(1.61)$ & $5.9(2.7)$ & 10.85 & No \\
PP-4116 & $88.4(1.42)$ & $5.1(2.3)$ & 16.15 & No \\
PP-4117 & $78.4(1.26)$ & $4.6(2.1)$ & 8.64 & Yes \\
PP-4118 & $80.3(1.29)$ & $3.9(1.8)$ & 5.22 & Yes \\
\hline
\end{tabular}


tailored to the particular extrusion characteristics of the formulations. The objective for preparation of a second round of formulations was to obtain $2 \%$ or less ASTM attrition loss, or half the maximum acceptable for a fresh sorbent.

Table 3-13 shows the physical properties of the second round of fresh sorbents. The crush strength values are higher than those measured in the first round (Table 3-12), and well above the minimum of 3 $\mathrm{lb} /$ pellet needed to prevent pellet crushing under its own bed weight. ASTM attrition loss values were lower than those in Table 3-12 and, except for formulation MZT-G1, achieved the internal target of less than or equal to $2 \%$, which is half of the $4 \%$ ASTM attrition loss target for evaluation in pilot plant operation.

Table 3-13. Mechanical properties of the second round of zinc titanate formulations

\begin{tabular}{lllcc}
\hline UCI ID & GE ID & $\begin{array}{l}\text { Density, lb./ft } \\
\text { (sp. gravity) }\end{array}$ & $\begin{array}{c}\text { Crush Strength, } \\
\text { lb/pellet } \\
\text { (Kg/pellet) }\end{array}$ & $\begin{array}{c}\text { ASTM Attrition \%, } \\
\text { (GE-CRD) }\end{array}$ \\
\hline PP-4195 & MZT-P1 & $64.0(1.03)$ & $8.3(3.8)$ & 1.0 \\
PP-4197 & MZT-R1 & $63.6(1.02)$ & $4.9(2.2)$ & 2.0 \\
PP-4198 & MZT-G1 & $61.5(0.99)$ & $4.8(2.2)$ & 2.5 \\
PP-4199 & MZT-I1 & $61.0(0.98)$ & $6.0(2.7)$ & 1.96 \\
PP-4248 & MZT-O1 & $65.2(1.04)$ & $5.4(2.4)$ & 0.91 \\
\hline
\end{tabular}

\subsection{Desulfurization and regeneration characteristics}

TGA chemical reactivity tests were conducted at GE-CRD on the pelletized sorbent formulations in two rounds of production by UCI. Typical reactivity performance of two of the formulations prepared during the first round of pelletization are shown in Figure 3-29 and Figure 3-30. TGA reactivity tests were conducted using the standard conditions at GE-CRD $\left(482{ }^{\circ} \mathrm{C}, 1 \mathrm{~atm}, 3 \% \mathrm{H}_{2} \mathrm{~S}\right.$ in simulated coal gases). A weight gain due to sulfur absorption of at least $5 \%$ in 2 hours is considered acceptable sulfur capture performance. The first 30-35 minutes correspond to exposure to simulated clean coal gas without $\mathrm{H}_{2} \mathrm{~S}$ (i.e., reductive regeneration) to establish a weight baseline. Note that the pellet weight is stable during the 30-minute reductive regeneration step, indicating that the metal oxides used in MZT's do not react with clean coal gas.

However, since the mechanical durability, attrition in particular, was low in these first round formulations, these formulations are considered weak and not as desirable for further testing.

Chemical reactivity of the pellets produced in the second round of formulations (previously shown in Table 3-13) was also tested. Figure 3-31 shows the typical weight gain during absorption for the first two cycles of MZT-I1, while Figure 3-32 shows the corresponding weight gain of MZT-O1. Again, the first 30 minutes correspond to exposure to simulated clean coal gas (without $\mathrm{H}_{2} \mathrm{~S}$ ) to establish a weight baseline. An acceptable weight gain is 5\% above the stable initial baseline in the first 2 hours. This weight gain corresponds to the operating point for the moving-bed system (i.e., $96 \mathrm{~g}$ of sulfur/liter of bed) for these formulations. Both formulations met this requirement. MZT-I1 is slightly more stable than MZT-O1 since the difference in sulfur loading against time for repetitive absorptions is more predictable. The difference in behavior between the two formulations is probably a result of different chemical compositions and preparation method. 


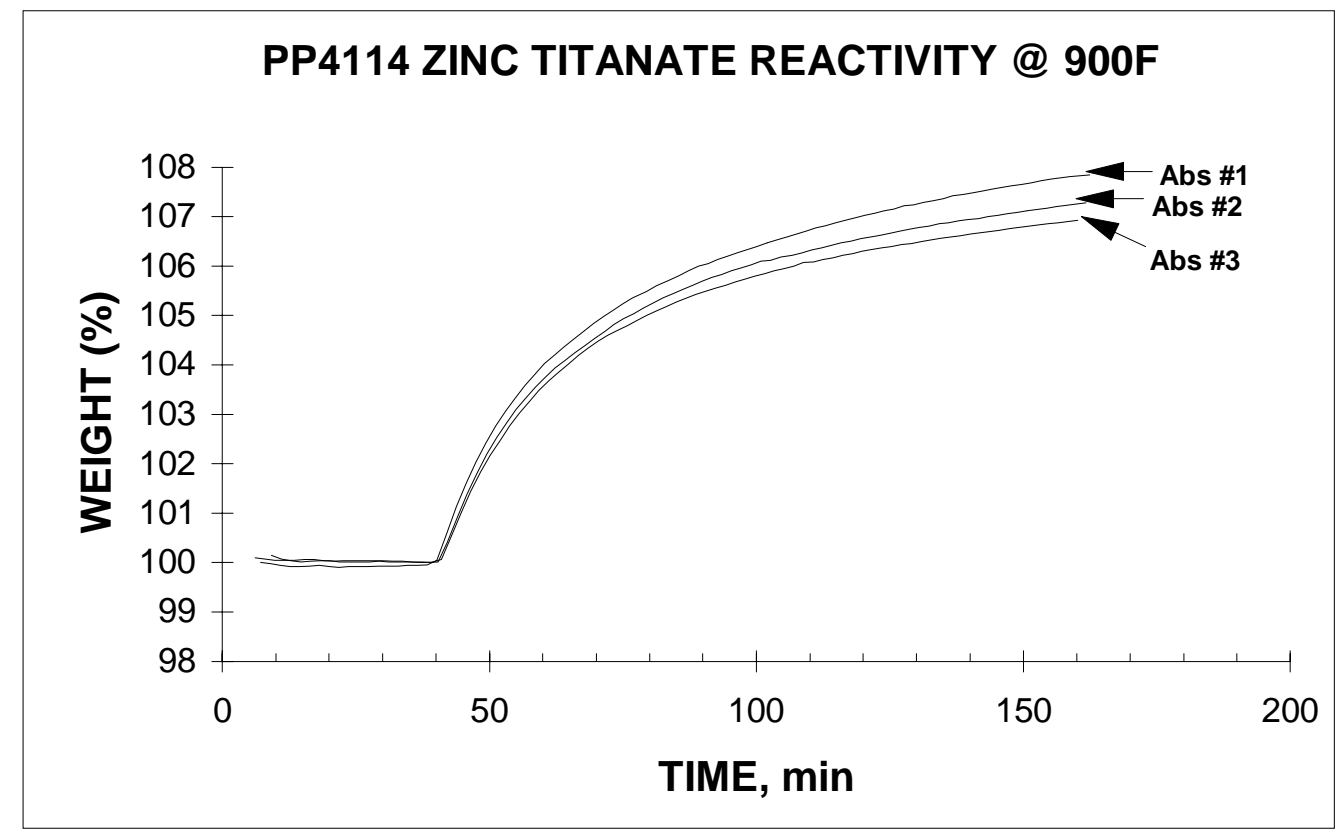

Figure 3-29. TGA Reactivity of PP4114 zinc titanate at $482{ }^{\circ} \mathrm{C}\left(900{ }^{\circ} \mathrm{F}\right)$

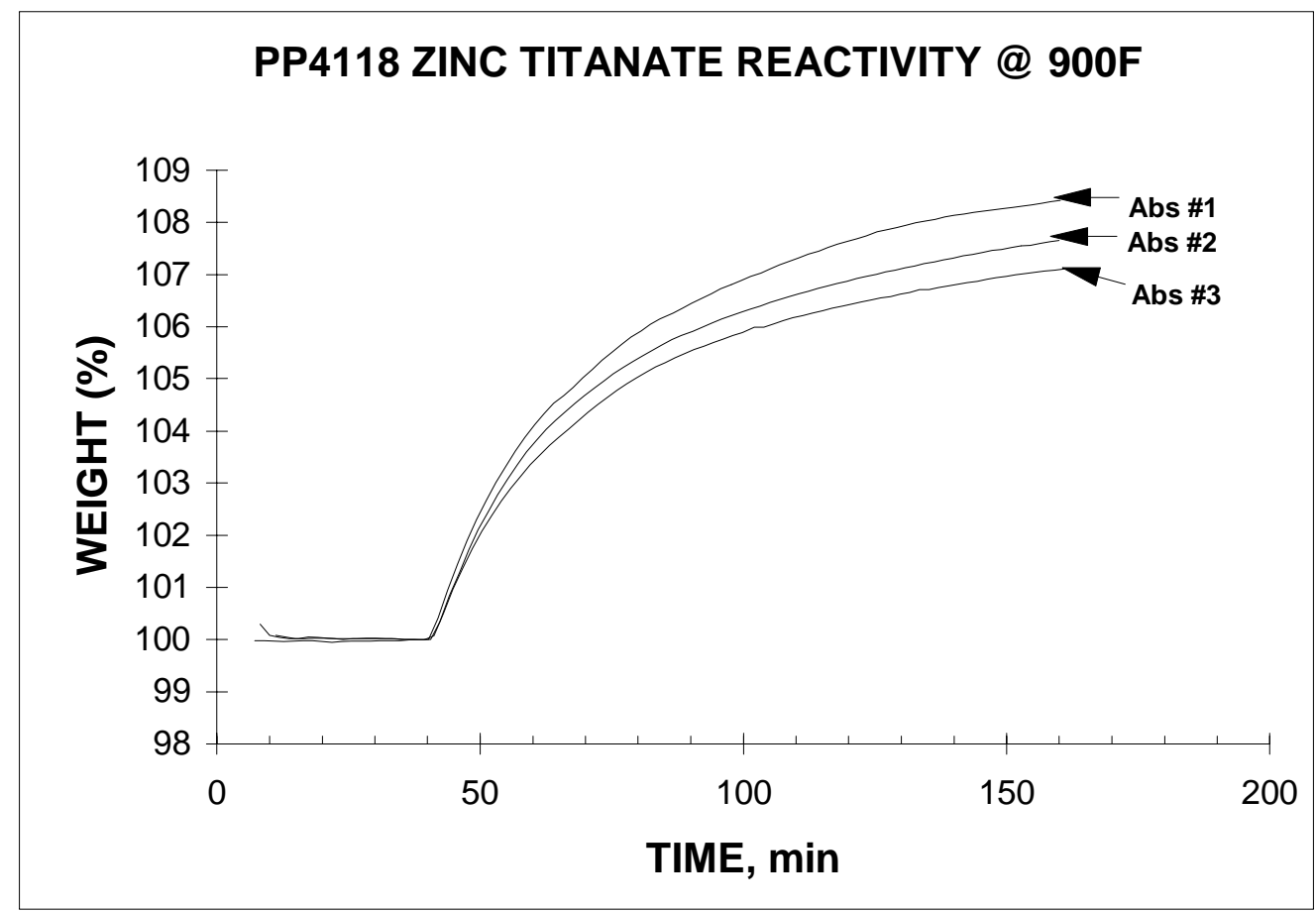

Figure 3-30. TGA Reactivity of PP4118 zinc titanate at $482{ }^{\circ} \mathrm{C}\left(900{ }^{\circ} \mathrm{F}\right)$ 


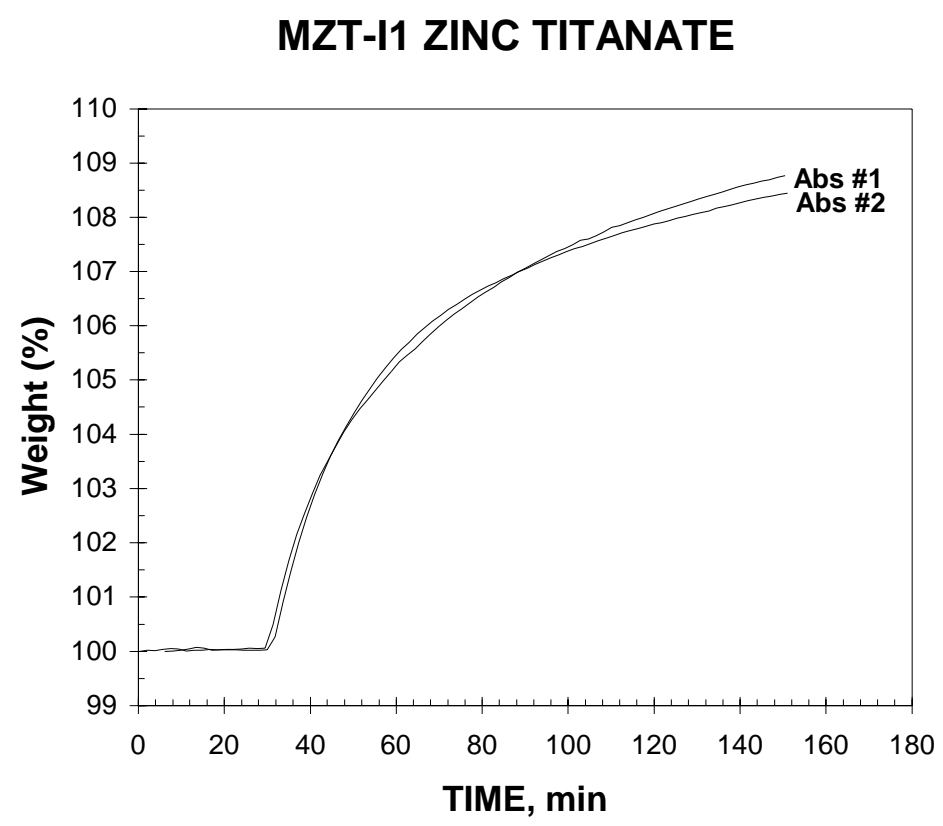

Figure 3-31. TGA reactivity of MZT-I1 during sulfidation at $1 \mathrm{~atm} / 482{ }^{\circ} \mathrm{C}$.

\section{MZT-01 ZINC TITANATE}

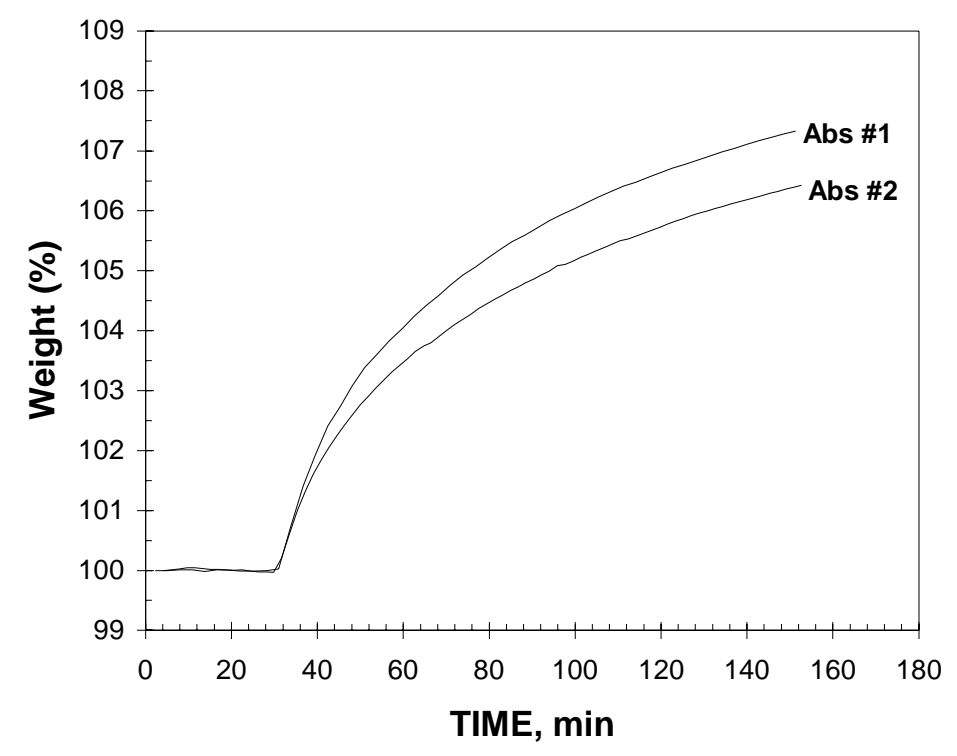

Figure 3-32. TGA reactivity of MZT-O1 during sulfidation at $1 \mathrm{~atm} / 492{ }^{\circ} \mathrm{C}$ 
Performance for the other formulations is shown in Figure 3-33 to Figure 3-35.

Overall, the chemical reactivity as well as the mechanical durability of the fresh MZT's prepared under the second round was acceptable for further testing in the bench-scale reactor.

\section{MZT-P1 ZINC TITANATE}

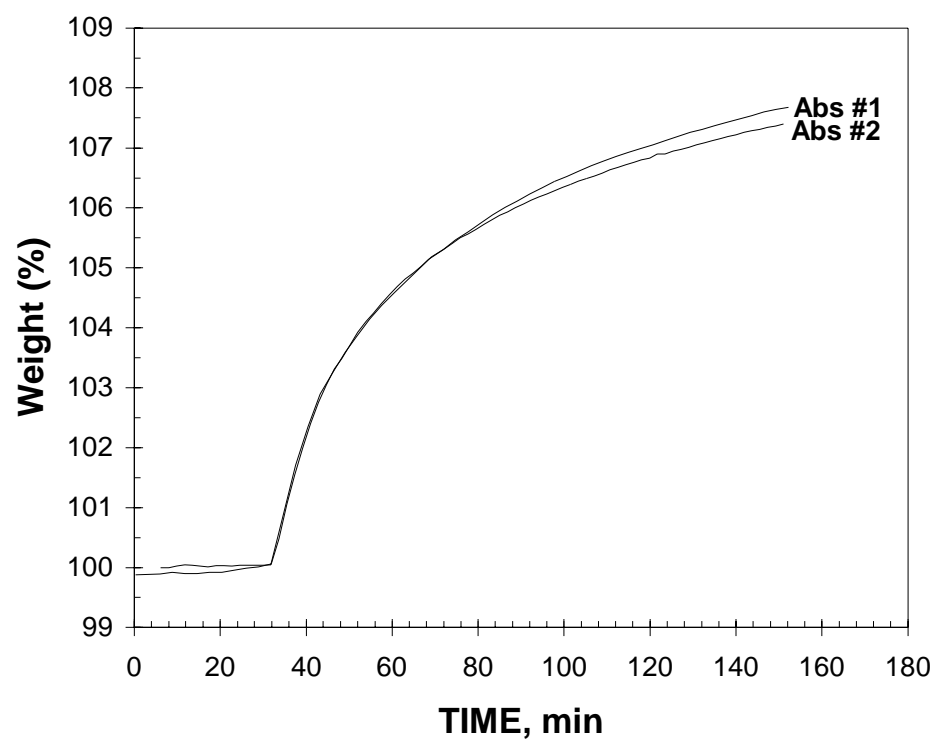

Figure 3-33. TGA reactivity of MZT-P1 during sulfidation at $1 \mathrm{~atm} / 492{ }^{\circ} \mathrm{C}$

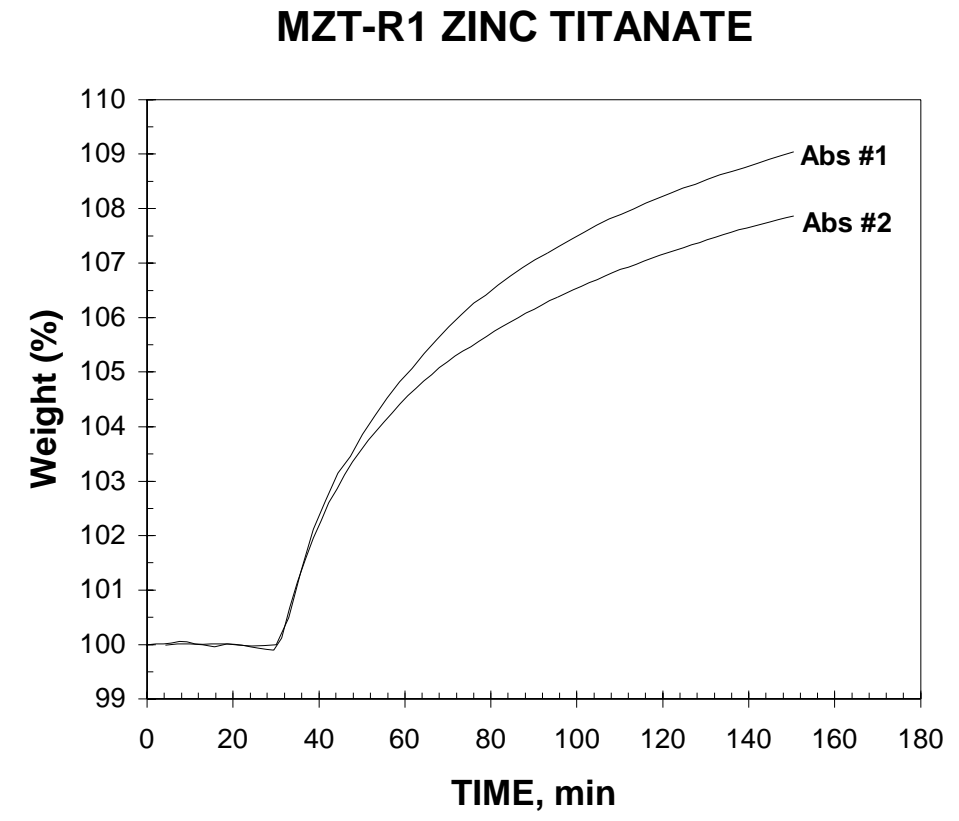

Figure 3-34. TGA reactivity of MZT-R1 during sulfidation at $1 \mathrm{~atm} / 492{ }^{\circ} \mathrm{C}$ 


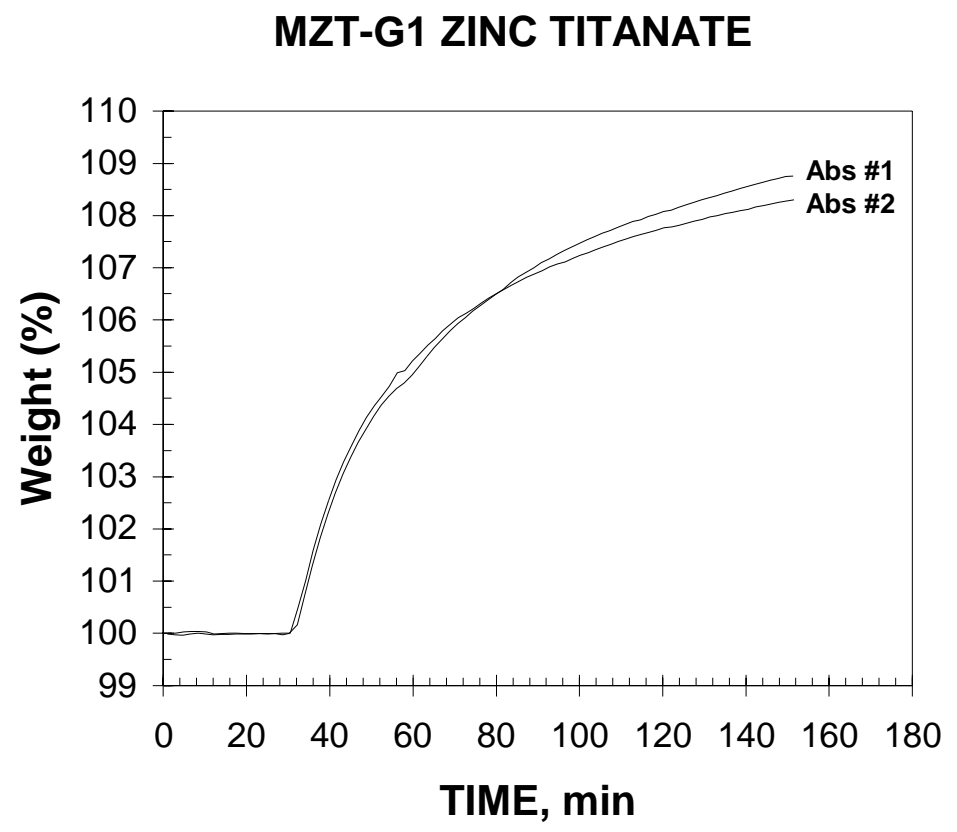

Figure 3-35. TGA reactivity of MZT-G1 during sulfidation at $1 \mathrm{~atm} / 492{ }^{\circ} \mathrm{C}$

\subsection{Sulfate formation during regeneration}

Dry regeneration of zinc-based sorbents with diluted air produces sulfur dioxide, which is used as a starting material for sulfuric acid production or elemental sulfur. However, sulfur species may remain in the sorbent as residual solid zinc sulfates. The presence of zinc sulfates is highly undesirable because it reduces the sulfur capacity of the sorbent in subsequent cycles and eventually cannot be removed from the sorbent even with thermal treatment. Accumulation of sulfates reduces porosity and future reactivity of the pellets. The TGA weight gain of the sorbent pellets due to sulfate formation in the presence of oxidizing regeneration gases is presented in Figure 3-36. After establishing a baseline steady weight of the sorbent at $718^{\circ} \mathrm{C}\left(1325^{\circ} \mathrm{F}\right)$ under nitrogen for twenty minutes, the sorbent was exposed to a gas containing $5 \% \mathrm{SO}_{2}, 2 \% \mathrm{O}_{2}$ at $718^{\circ} \mathrm{C}\left(1325^{\circ} \mathrm{F}\right)$ and $1 \mathrm{~atm}$. Higher weight gains are indicative of detrimental faster rates of sulfate formation for the sorbent in the 2 hour exposure time. Plain zinc titanate (MZT-P1) (i.e., zinc titanate with no additives) has the higher sulfate formation tendency, while those with additives have a reduced tendency. Lower zinc sulfate formation tendencies are beneficial because they minimize sorbent deterioration.

\subsection{Temperature range of desulfurization of single pellets}

In order for a sorbent to be useful in HGCU operation, it has to be able to desulfurize coal gas in reasonable times, i.e., have a chemical reactivity for sulfur species compatible with practical reactor size, not only at steady state but also during transient startup/shutdown operations. Typical startup and shutdown operations for an absorber require operation at lower temperatures (below 482 ${ }^{\circ} \mathrm{C}$ ). Off-design operation may also require operation at lower temperatures for extended periods of time. For these reasons, sulfur absorption tests were performed in the TGA to compare the rate of reaction of zinc titanate sorbents as a function of temperature. 


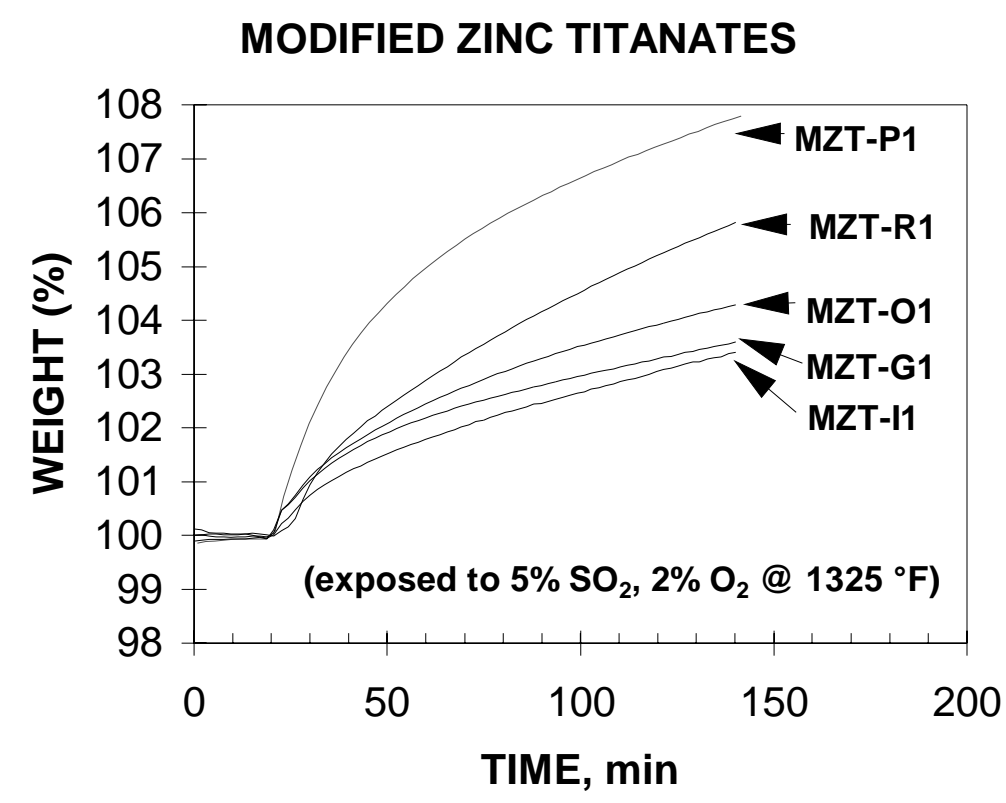

Figure 3-36. TGA weight gain due to sulfate formation during regeneration of the pelletized modified zinc titanates at $1 \mathrm{~atm}$ and $718^{\circ} \mathrm{C}\left(1325{ }^{\circ} \mathrm{F}\right)$

Figure 3-37 shows the TGA performance of MZT-R1 formulation in the range $371-482{ }^{\circ} \mathrm{C}(700-900$ $\left.{ }^{\circ} \mathrm{F}\right)$. After setting a baseline initial sample weight under simulated coal gases without $\mathrm{H}_{2} \mathrm{~S}$, the $\mathrm{H}_{2} \mathrm{~S}$ was started at 30 minutes. The desulfurization rate of the sorbent results in a weight gain as the zinc component of zinc titanate goes from the oxide form to the sulfide form. A typical normal operating condition (NOC) in a moving-bed reactor requires a sulfur loading of $96.2 \mathrm{~g}$ of sulfur/liter of bed. This target is shown as a horizontal line at the equivalent weight percentage versus time in Figure 3-37 and labeled TECo NOC. For the chosen TGA test (at $1 \mathrm{~atm}, 3 \% \mathrm{H}_{2} \mathrm{~S}$ ) to be a good predictor of sulfur loading in a moving-bed reactor, the target sulfur loading in the TGA must be accomplished in 2 hours of test time.

MZT-R1 ZINC TITANATE

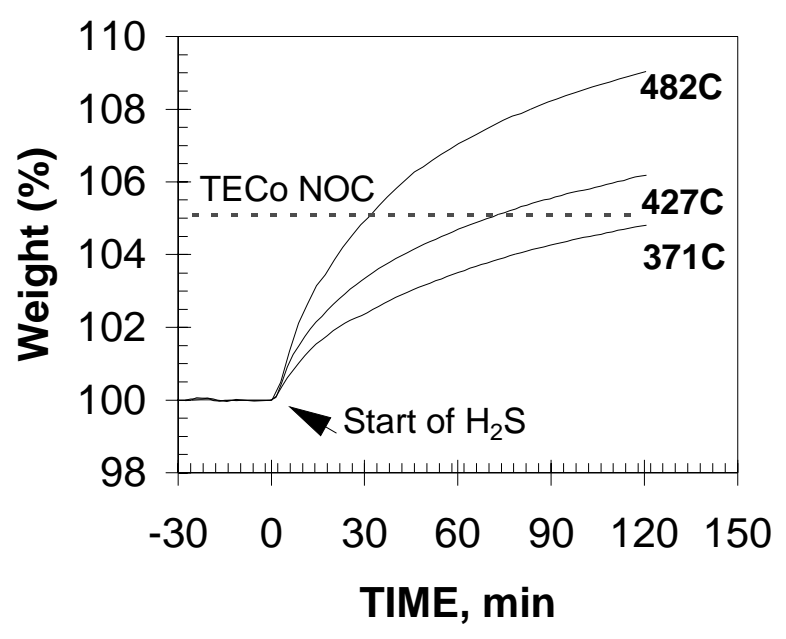

Figure 3-37. TGA reactivity of MZT-R1 zinc titanate as a function of temperature. 
It can be seen from Figure 3-37 that the sulfur loading at the TECo NOC (normal operating conditions) can be achieved with MZT-R1 by operation as low as approximately $371^{\circ} \mathrm{C}\left(700^{\circ} \mathrm{F}\right)$. This performance suggests a window of about $200^{\circ} \mathrm{F}$ below the NOC, albeit being considered off-design conditions. Other sorbent formulations were evaluated for operation at temperatures below $482{ }^{\circ} \mathrm{C}$, but their performance was not as good as that of MZT-R1.

\subsubsection{CRD bench reactor tests}

The evaluation of MZT's TGA chemical reactivity and mechanical durability in small amounts of fresh pellets was followed by bench-scale testing of five of the most promising formulations at GE-CRD. The bench tests provided information on the bed desulfurization performance and attrition resistance of the bed as a whole over multiple cycles of operation. These tests on MZT's were conducted under the optional Task 8 - Long-Term Testing.

The bench screening was performed using the $7-\mathrm{cm}$ (2.75 in.) inside diameter fixed-bed bench reactor at GE-CRD. The cross sectional area of the reactor was divided into four quadrants, and each quadrant was filled with a different sorbent formulation. In this way, all four formulations were exposed for the same period of time to the same flow rates, gas compositions, and baseline temperatures during the test.

Target conditions for desulfurization bench tests that apply to any sorbent under development are summarized in Table 3-14. As much as possible, these bench test conditions are expected to approximate the design steady-state operation of the TECo moving-bed demonstration plant. However, laboratory or bench reactor systems operating under fixed-bed configurations may not be able to satisfy simultaneously all the conditions of a large-scale moving-bed system. Two major exceptions were taken in the laboratory testing protocol: the outlet $\mathrm{H}_{2} \mathrm{~S}$ at TECo is expected to be less than $50 \mathrm{ppmv}$ at steady state rather than the $200 \mathrm{ppm}$ breakthrough level, and the absorption pressure at TECo will be $30 \mathrm{~atm}$ instead of $20 \mathrm{~atm}$.

Typical test conditions maintained during screening in the bench-scale reactor at CRD are presented in Table 3-15. At the end of the multiple cycles, typically five cycles of absorption and regeneration, the sorbent was removed from the reactor and the ASTM D-4058-81 attrition test performed on samples in each of the quadrants. By following this procedure, data were collected on the composite desulfurization performance (i.e., the $\mathrm{H}_{2} \mathrm{~S}$ breakthrough curves) and individual mechanical durability of each of the sorbents.

Table 3-14. Target test conditions during absorption in bench tests

\begin{tabular}{l|c}
\hline Parameter & Operating Condition \\
\hline Desired Sorbent Sulfur Loading & $96.2 \mathrm{~g} \mathrm{~S} /$ liter of bed $\left(6-7 \mathrm{lb} . \mathrm{S} / \mathrm{ft}^{3}\right.$ of bed $)$ \\
& at the gas inlet location \\
$\mathrm{H}_{2} \mathrm{~S}$ Breakthrough point & $200 \mathrm{ppm}$ \\
Gas space velocity & $\geq 2000 \mathrm{hr}^{-1}(\mathrm{STP})^{*}$ \\
Pressure & $20 \mathrm{~atm}$ \\
Temperature & $482^{\circ} \mathrm{C}\left(900{ }^{\circ} \mathrm{F}\right)$ \\
\hline
\end{tabular}

* STP (standard temperature and pressure) is defined at $20{ }^{\circ} \mathrm{C}$ and $1 \mathrm{~atm}$. 
The reactor bed typically accommodated up to 0.51 of sorbent. In the so-called quadrant tests, the bed volume was adjusted to obtain the desired gas space velocity, meet the requirement of sulfur loading at the gas inlet location, meet the $200 \mathrm{ppmv}$ breakthrough in a reasonable time $(<5 \mathrm{hr})$, and meet the current test schedule for screening. Test conditions during absorption (Table 3-15) followed the TECo guidelines for bench tests (Table 3-14), except for the reduced pressure (5 atm at CRD vs. 20 atm for preferred bench tests and $30 \mathrm{~atm}$ at TECo) and definition of breakthrough ( $200 \mathrm{ppmv}$ in bench tests vs. less than $50 \mathrm{ppmv}$ in the TECo plant). The chosen reduced pressure during absorption is a result of limitations in the existing GE-CRD bench hardware; a preferred condition for bench tests is $20 \mathrm{~atm}$ during absorption. The definition of breakthrough at $200 \mathrm{ppm}$ rather than at $50 \mathrm{ppm}$ was selected for ease of measurement and for historical comparisons. Regeneration was conducted at 5 atm and between $482^{\circ} \mathrm{C}$ and $760{ }^{\circ} \mathrm{C}$. The acceptable regeneration pressure range is 5 to $7 \mathrm{~atm}$.

Two quadrant bench tests, for a total of 8 formulations, were performed as presented in Table 3-16. In addition to the five new formulations prepared during 1997 at UCI, an old formulation from 1995, T$2565 \mathrm{M}$, was loaded in the quadrant test \#2 to be able to compare old and new methods of fabrication.

Figure 3-38 presents the composite $\mathrm{H}_{2} \mathrm{~S}$ breakthrough curves for four formulations in the quadrant bench test \#1 (formulations MZT-I1, MZT-G1, MZT-O1, and MZT-R1). The only potential difference in test conditions is that each sorbent may produce a different temperature rise above the baseline during regeneration, which would be characteristic to each sorbent; however, the exposure time was the same for all four sorbents in both absorption and regeneration modes.

Typical temperatures during regeneration during the first quadrant bench Test \#1 are presented in Figure 3-39. The three temperatures shown correspond to the gas inlet, middle section, and gas outlet locations of each of the quadrants in the reactor bed. At time zero the oxygen and $\mathrm{SO}_{2}$ were introduced to the bed. As the exothermic regeneration started and the temperatures rose by $28^{\circ} \mathrm{C}\left(50^{\circ} \mathrm{F}\right)$, the set point in the heating furnace was increased to $621^{\circ} \mathrm{C}\left(1150^{\circ} \mathrm{F}\right)$ to simulate the adiabatic operation of a

Table 3-15. Test conditions in the GE-CRD reactor system during quadrant bench tests

\begin{tabular}{|c|c|c|c|c|}
\hline Test Gas Composition & Absorption & $\begin{array}{c}\text { Reductive } \\
\text { Regeneration }\end{array}$ & $\begin{array}{c}\text { Oxidative } \\
\text { Regeneration }\end{array}$ & Nitrogen Purge \\
\hline $\mathrm{CO}$ & 38.6 & 39.0 & & \\
\hline $\mathrm{CO}_{2}$ & 5.7 & 5.7 & & \\
\hline $\mathrm{H}_{2}$ & 34.7 & 35.1 & & \\
\hline $\mathrm{H}_{2} \mathrm{O}$ & 20.0 & 20.2 & & \\
\hline $\mathrm{H}_{2} \mathrm{~S}$ & 1.0 & & & \\
\hline $\mathrm{O}_{2}$ & & & $2-5 \%$ & \\
\hline $\mathrm{SO}_{2}$ & & & $8 \%$ & \\
\hline $\mathrm{N}_{2}$ & & & balance & \\
\hline Pressure, atm & $5 \mathrm{~atm}$ & $5 \mathrm{~atm}$ & $5 \mathrm{~atm}$ & $1-5 \mathrm{~atm}$ \\
\hline Sorbent Bed & $482{ }^{\circ} \mathrm{C}$ & $482{ }^{\circ} \mathrm{C}$ & $482-704{ }^{\circ} \mathrm{C}$ & \\
\hline Temperature & & & & \\
\hline $\begin{array}{l}\text { Space velocity } \\
\left(\mathrm{STP}, 25^{\circ} \mathrm{C}, 1 \mathrm{~atm}\right)\end{array}$ & $2000 \mathrm{~h}^{-1}$ & $2000 \mathrm{~h}^{-1}$ & $1000 \mathrm{~h}^{-1}$ & $750 \mathrm{~h}^{-1}$ \\
\hline Reaction time, min & $120 \mathrm{~min}$ & $60 \mathrm{~min}$ & $180 \mathrm{~min}$ & \\
\hline
\end{tabular}


Table 3-16. Formulations loaded into bench quadrant tests at GE-CRD

\begin{tabular}{cc}
\hline Quadrant bench test \#1 & Quadrant bench test \#2 \\
\hline MZT-G1 & MZT-P1 \\
MZT-O1 & T-2564M \\
MZT-R1 & MZT-R1 \\
MZT-I1 & MZT-I1 \\
\hline
\end{tabular}

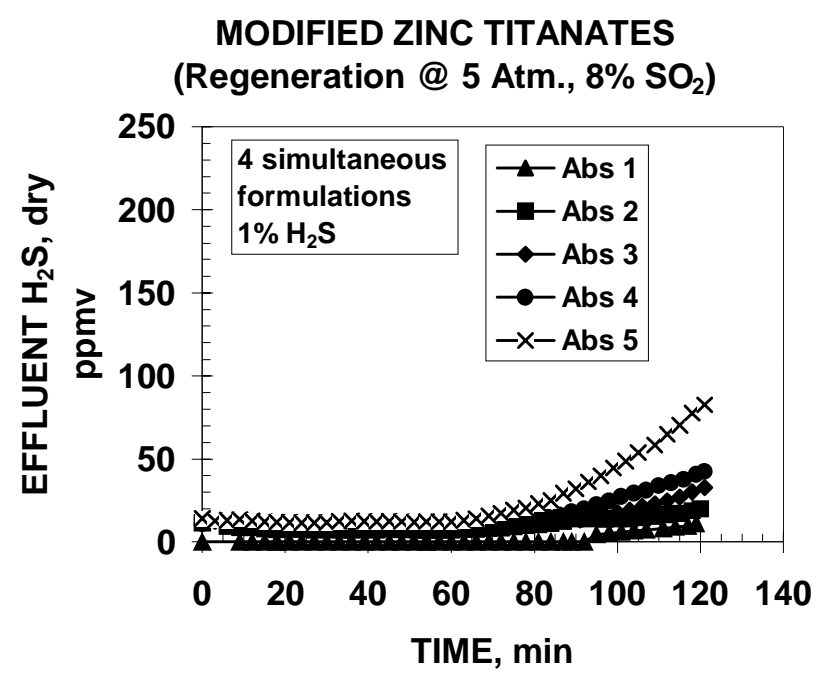

Figure 3-38. Breakthrough curves during absorption for the modified zinc titanate sorbents (Quadrant Bench Test \#1)

larger scale pilot plant system, where radiation towards the walls from the center of the bed is small due to the presence of the surrounding pellets that also undergo oxidation at the same time. Note that a temperature rise was observable at $482^{\circ} \mathrm{C}$ (gas inlet location). Because of the location of the heating elements in the bench furnace, the gas outlet location always runs cooler at about $462^{\circ} \mathrm{C}$. Most peak temperatures were maintained below $704^{\circ} \mathrm{C}\left(1300^{\circ} \mathrm{F}\right)$. As far as we can tell, there is no significant difference among the temperature profiles for each of the formulations from cycle 1 to cycle 5: all maximum temperatures were maintained below $704^{\circ} \mathrm{C}$. 

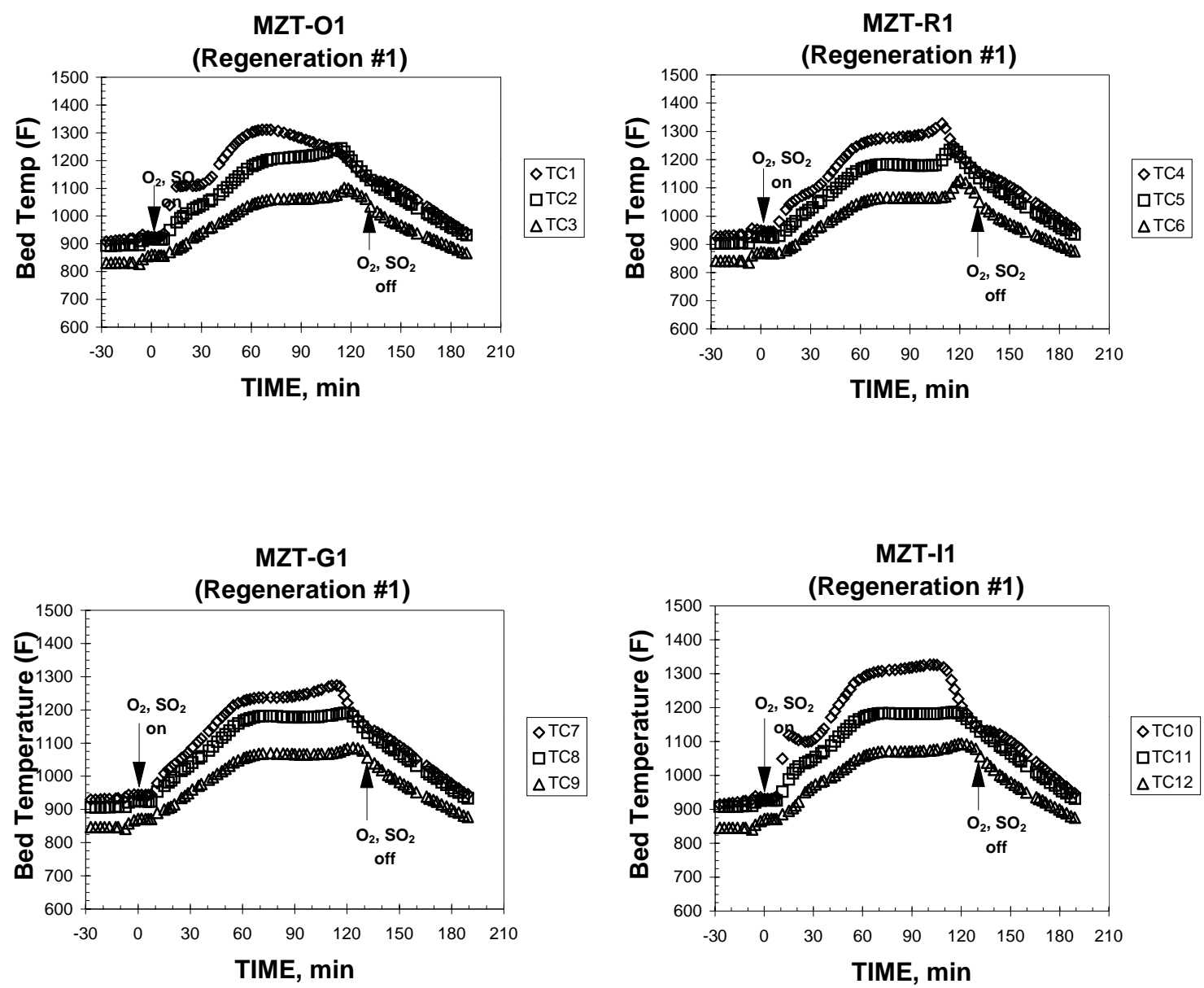

Figure 3-39. Temperatures profiles for the four sorbents tested under the Quadrant Bench Test \#1.

The corresponding temperature profiles for MZT-I1 and MZT-R1 for the quadrant bench test \#2 are shown in Figure 3-40 for the first (top) and fifth (bottom) regenerations. All regeneration profiles are similar in shape and suggest that the regeneration rates shown are within the requirements for regeneration of all formulations tested.

As a last issue on desulfurization performance of MZT's, we needed to compare the relative desulfurization rate of the modified zinc titanates (Figure 3-38) with respect to a prior baseline T-2594M zinc titanate formulation tested in the pilot plant (Figure 3-41). Figure 3-41 is the plot of corresponding breakthrough curves for the molybdenum-doped T-2594M zinc titanate at similar conditions of bench tests using $8 \% \mathrm{SO}_{2}$ in the regeneration. The breakthrough sulfur capacity of MZT's is higher than that of T-2594M, suggesting an improvement in the formulation performance. Figure 3-42 shows again the corresponding operation of the same T-2594M in the GE moving-bed pilot plant Test \#8 (September 1995 ) when the sorbent desulfurization performance (99\% sulfur removal) was satisfactory in both in bench tests and actual pilot plant operation. 
MZT-I1

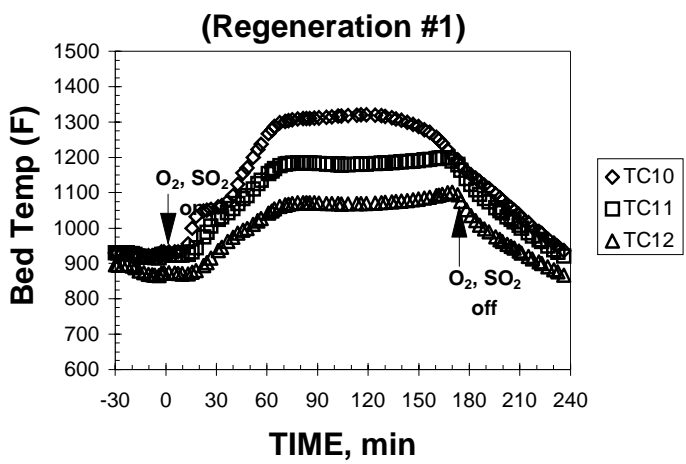

MZT-I1

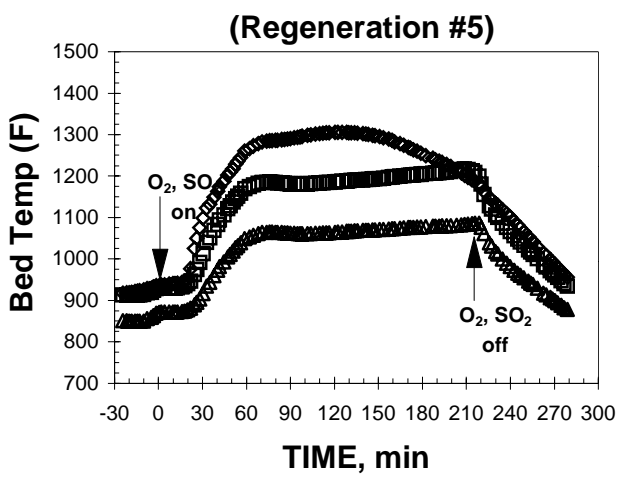

MZT-R1

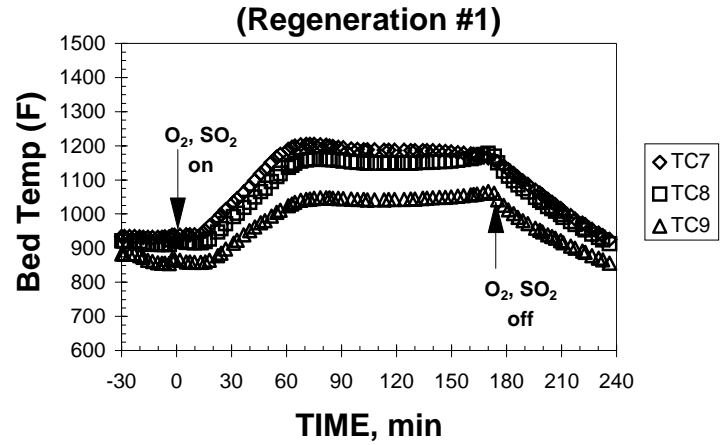

MZT-R1

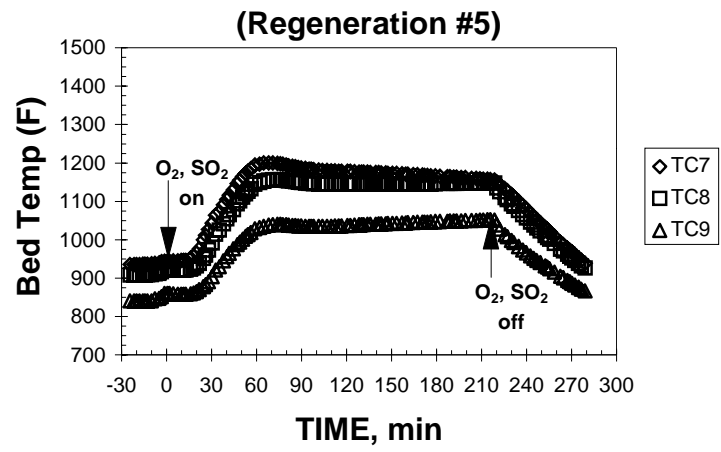

Figure 3-40. Temperatures profiles for the four sorbents tested under the Quadrant Bench Test \#1.

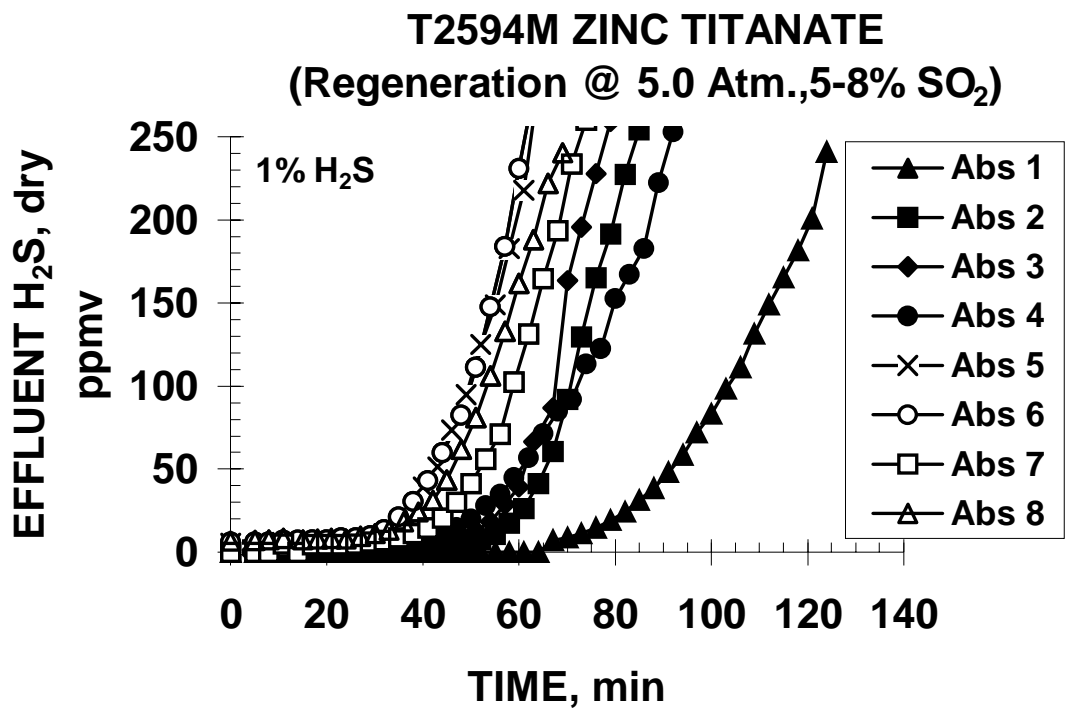

T2594r3.xls

Figure 3-41. Breakthrough curves for T-2594M zinc titanate with regeneration at $5 \mathrm{~atm}$ and $8 \% \mathrm{SO}_{2}$ in the regeneration gas 


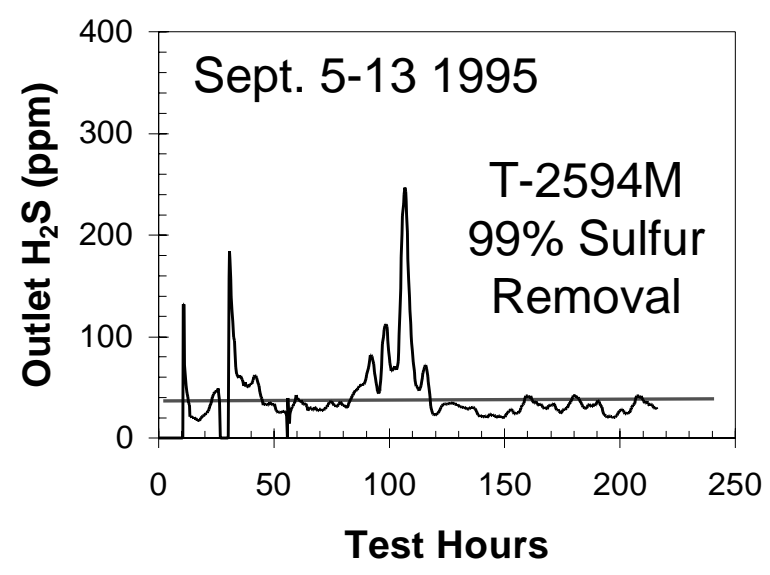

Figure 3-42. Outlet $\mathrm{H}_{2} \mathrm{~S}$ concentration from the pilot plant absorber using T-2594M during Test 8 (1995)

Since T-2594M had satisfactory desulfurization in the pilot plant absorber (99\% desulfurization efficiency, Figure 3-42), we can expect improved performance of the modified zinc titanates over T$2594 \mathrm{M}$ in pilot plant tests. The conclusion from the testing of pelletized MZT's is that an improvement in desulfurization kinetics was achieved in the laboratory over previous zinc titanates and this improvement could be expected to carry over to larger-scale systems.

\subsection{Mechanical durability of cycled formulations}

Table 3-17 presents the results of attrition and residual sulfide and sulfate on cycled sorbents after the $5^{\text {th }}$ regeneration for the four formulations tested in the quadrant bench test \#1 (formulations MZT-I1, MZT-G1, MZT-O1, and MZT-R1). Figure 3-43 presents the corresponding attrition results as attrition ratios. The attrition ratio is defined as the percent ASTM attrition loss in the final state $\left(5^{\text {th }}\right.$ regeneration) divided by the ASTM percent attrition loss in the fresh state. Samples were taken from the gas inlet location, where the highest sulfidation and regeneration levels are experienced by the sorbent. In addition, the corresponding attrition ratio for the baseline T-2594M is presented also. The attrition ratio was used in the chart to highlight the relative degradation of the pellets. For instance, an attrition ratio of 1.0 represents no degradation in the sorbent over the test duration. An attrition ratio less than 1 means that the sorbent became stronger in its final state while an attrition ratio greater than 1 means that the

Table 3-17. Attrition and sulfur results on 5th regeneration samples from quadrant bench test \#1

\begin{tabular}{ccccc}
\hline & MZT-O1 & MZT-R1 & MZT-G1 & MZT-I1 \\
\hline Attrition-Fresh & $0.91 \%$ & $2.0 \%$ & $2.5 \%$ & $1.96 \%$ \\
Attrition After 5 cycles & $1.53 \%$ & $2.0 \%$ & $2.74 \%$ & $1.83 \%$ \\
Sulfide Sulfur Content & $<0.1 \%$ & $<0.1 \%$ & $<0.1 \%$ & $<0.1 \%$ \\
Sulfate Sulfur Content & $2.90 \%$ & $0.22 \%$ & $3.80 \%$ & $0.23 \%$ \\
\hline
\end{tabular}




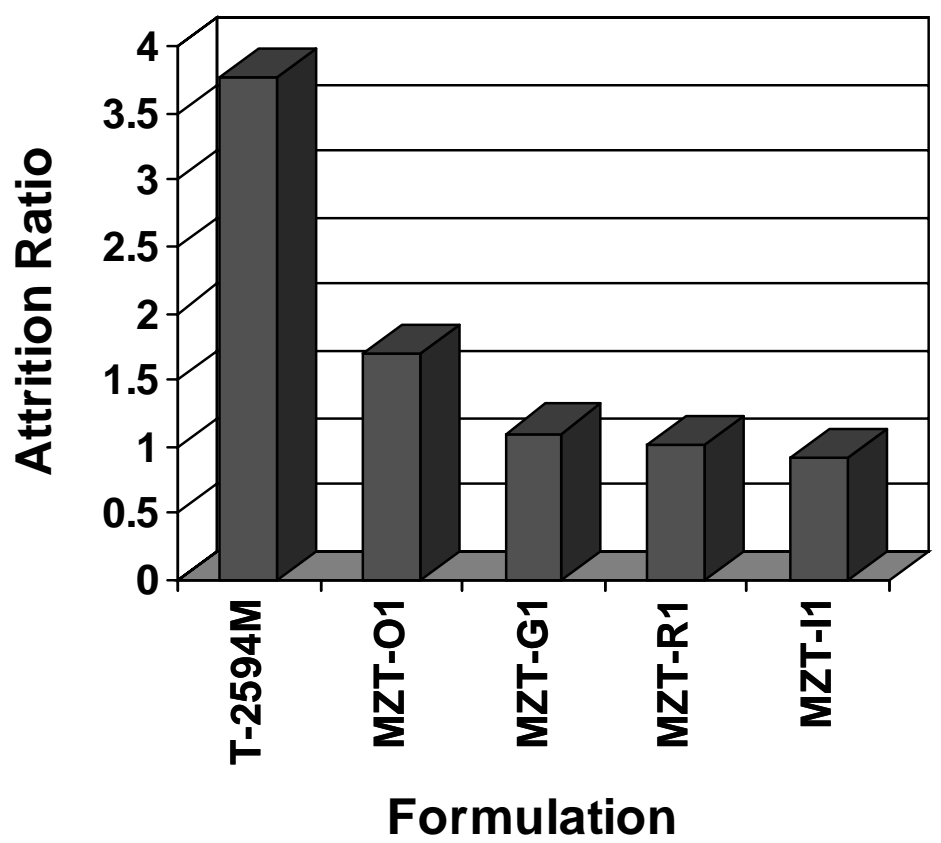

Figure 3-43. Attrition resistance ratios of zinc titanate formulations after 5 cycles of bench-scale testing (Quadrant Bench Test \#1)

sorbent experienced a degradation (i.e., weakening) in attrition resistance. The absolute values of the ASTM attrition losses were in the range 1 to $2.7 \%$.

A second quadrant bench test was also performed on a different batch of each of the formulation compositions MZT-I1 and MZT-R1 along with a sample of the baseline T-2594M zinc titanate and a zinc titanate without additives, MZT-P1 (Table 3-18). In addition to attrition measurements, sulfur measurements by TGA at GE and at Commercial Testing and Engineering (CTE) are presented in the same table. This second batch of MZT-I1 and MZT-R 1 behaved quite differently from the first batch tested in quadrant test\#1 (Table 3-17). Even though the attrition ratios of the MZTs were again lower than those of the base formulation T-2594M, the magnitude of the values for the batches used in the quadrant bench test \#2 was higher than those for batches in quadrant bench test\#1. A similar behavior was observed in the scaling up of fabrication of molybdenum-containing zinc titanates. After discussions with UCI, it was concluded that variations from batch to batch in the production process had repercussions in the sorbent's ability to maintain its mechanical strength during testing.

Table 3-18. Attrition and sulfur results on 5th regeneration samples from quadrant bench test \#2

\begin{tabular}{ccccc}
\hline & MZT-P1 & T2594M & MZT-R1 & MZT-I1 \\
\hline Attrition-Fresh & $1.0 \%$ & $0.46 \%$ & $2.0 \%$ & $2.0 \%$ \\
Attrition After 5 cycles & $5.23 \%$ & $2.64 \%$ & $7.08 \%$ & $8.19 \%$ \\
Sulfide Sulfur Content & $<0.1 \%$ & $2.74 \%$ & $1.54 \%$ & $0.45 \%$ \\
& & & $(1.45 \%$ CTE $)$ & $(0.93 \%$ CTE $)$ \\
Sulfate Sulfur Content & $4.95 \%$ & $2.66 \%$ & $4.35 \%$ & $4.0 \%$ \\
& & & $(4.85 \%$ CTE $)$ & $(4.33 \%$ CTE) \\
\hline
\end{tabular}


The main conclusion of the mechanical durability tests of MZT's is that the mechanical durability of the top formulations is approaching targets for commercial operation. However, fabrication variability from batch to batch of the same formulation suggests that more work is needed to understand the pelletization factors that contribute to sustainable durability over extended testing. The chemistry of desulfurization and regeneration is well understood, but the quality control of the pelletization process should still be improved. The best two formulations, MZT-R1 and MZT-I1, were considered for further testing in 25cycle bench tests at RTI as part of the qualification of sorbents for TECo's $2^{\text {nd }}$ sorbent fill.

\subsection{Bench-scale extended multicycle tests at GE-CRD}

Following the five-cycle quadrant tests at GE-CRD, 17 cycles of normal bench tests at GE-CRD were run on sorbent MZT-I1 in an attempt to determine best operating conditions for regeneration of the sorbent in the desired temperature range. These tests were performed after the results of the screening in quadrant tests were analyzed. Figure 3-44 and Figure 3-45 present the $\mathrm{H}_{2} \mathrm{~S}$ in the bed effluent as a function of time for 17 cycles on MZT-I1, and Table 3-19 shows the corresponding history of the sorbent operating conditions for absorption and regeneration. Given that it is somewhat difficult to see the trends in $\mathrm{H}_{2} \mathrm{~S}$ from cycle to cycle, the results are also plotted as the envelope of the $\mathrm{H}_{2} \mathrm{~S}$ concentrations at $2 \mathrm{hr}$ (120 min) of operation in Figure 3-46. Note that absorptions 7, 9, and 11 were very low in effluent $\mathrm{H}_{2} \mathrm{~S}$, suggesting a reversal of the upward trend seen in other cycles. This reversal is a result of the higher temperature of operation, $732^{\circ} \mathrm{C}\left(1350^{\circ} \mathrm{F}\right)$, in the previous regeneration (Table 3-19). As mentioned above, there is a very strong correlation in the maximum average temperature of regeneration $\left(732^{\circ} \mathrm{C}\right.$ ) and the subsequent $\mathrm{H}_{2} \mathrm{~S}$ concentration at 120 minutes of absorption. Each of the three regenerations where the bed temperature was allowed to rise and stay at $732{ }^{\circ} \mathrm{C}$ resulted in a lower $\mathrm{H}_{2} \mathrm{~S}$ in the following absorption.

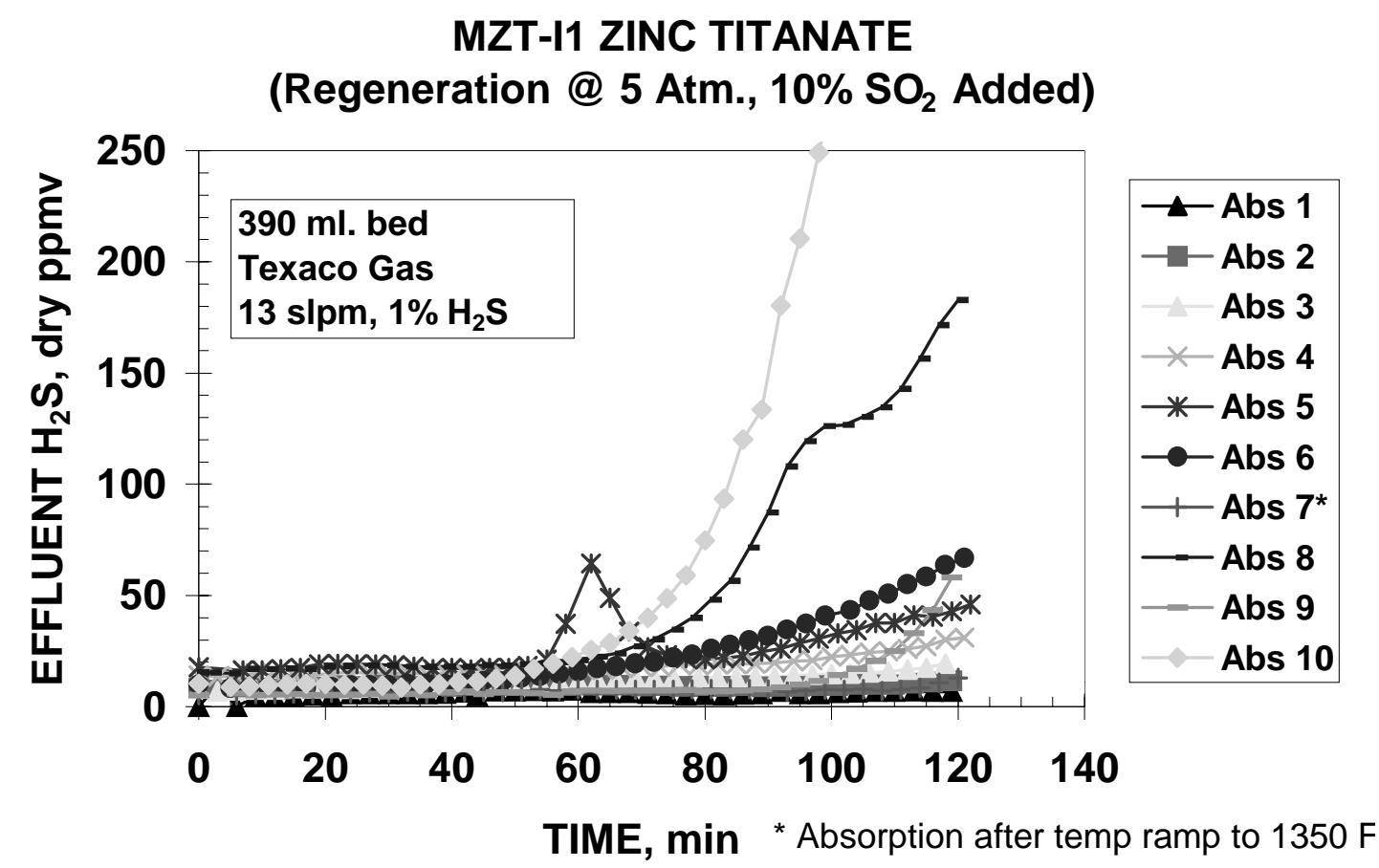

Figure 3-44. Breakthrough curves of MZT-I1 for the first 10 cycles of screening 


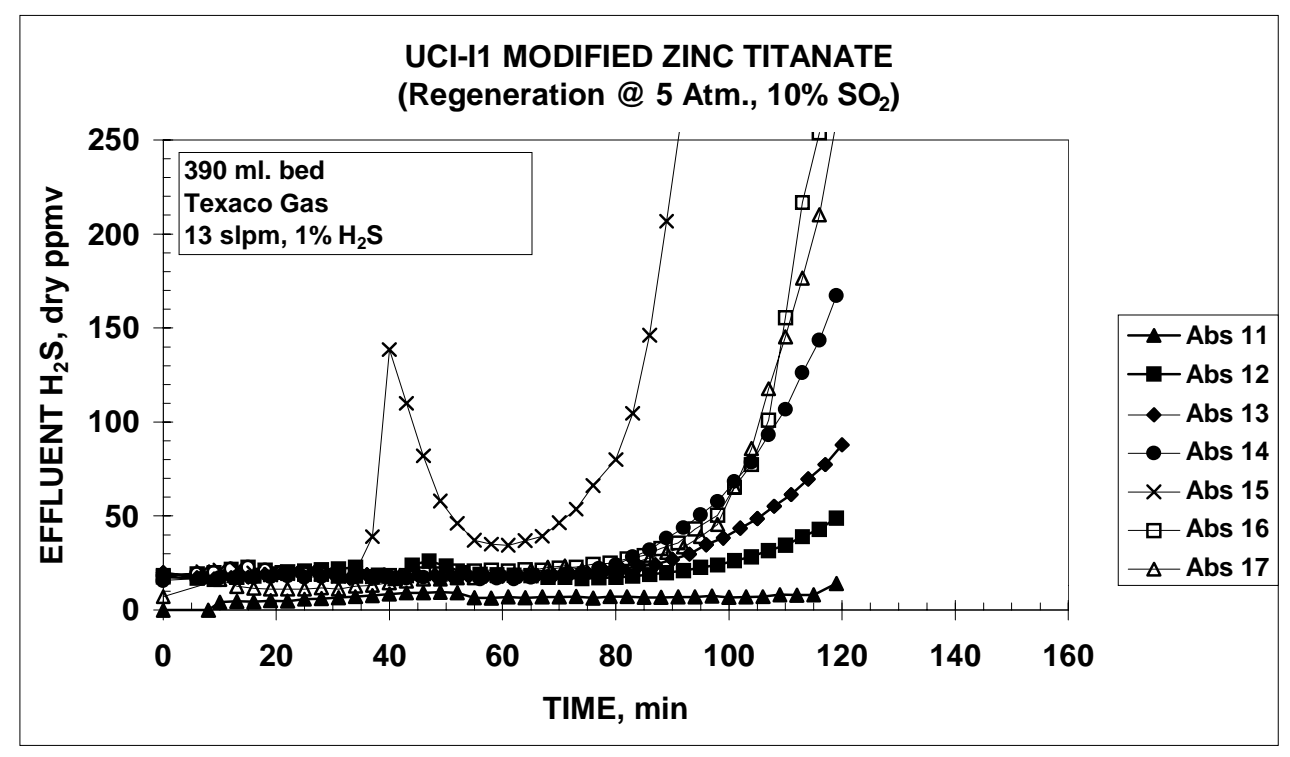

Figure 3-45. Breakthrough curves of MZT-I1 after the first 10 cycles of screening

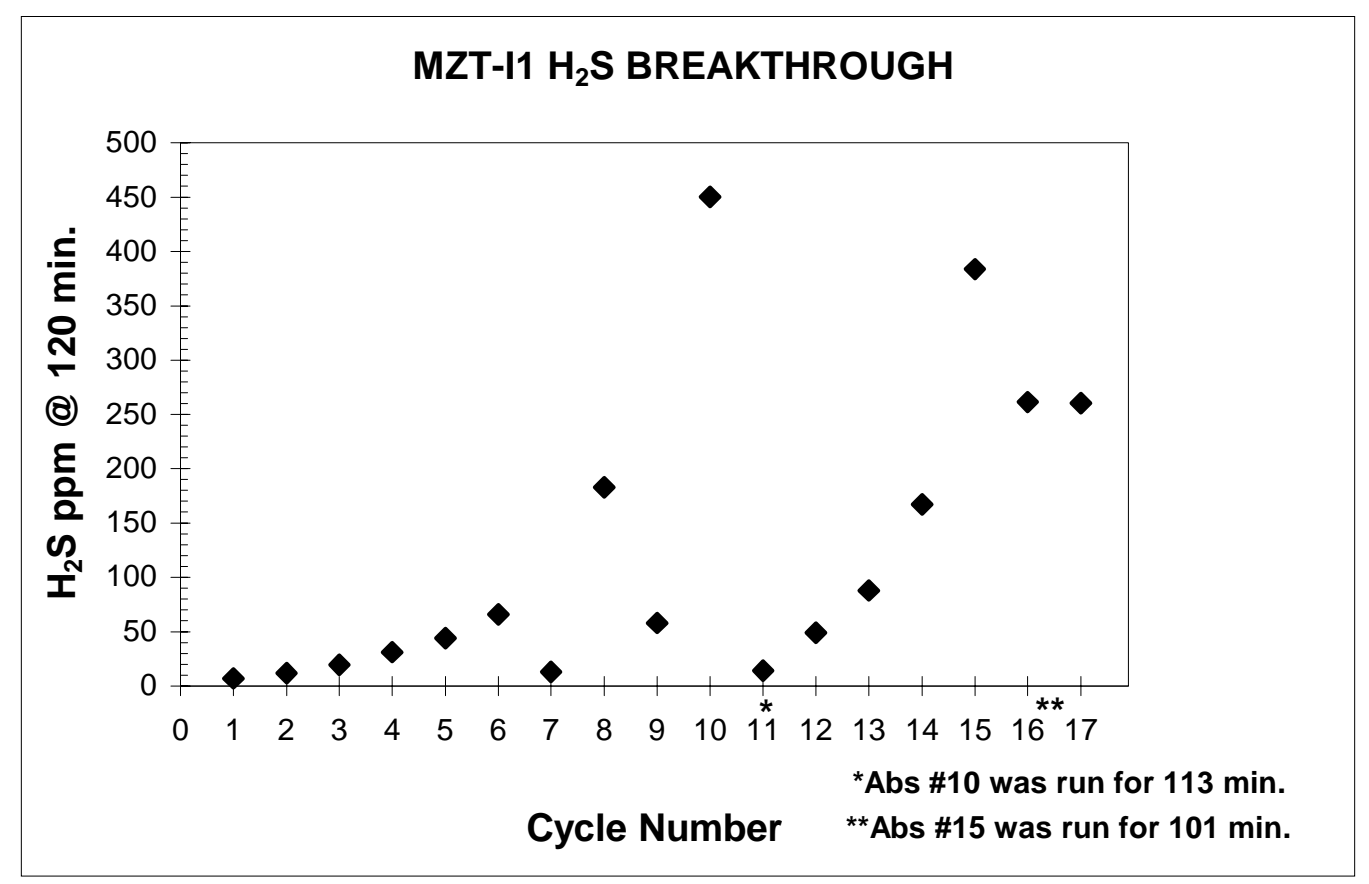

Figure 3-46. Envelope of the breakthrough curves at $120 \mathrm{~min}$ of absorption for MZT-I1 
Table 3-19. Bench-scale extended testing of MZT-I1

\begin{tabular}{|l|c|c|c|c|c|c|}
\hline \multicolumn{1}{|c|}{ Cycle } & $\mathbf{1}$ & $\mathbf{2}$ & $\mathbf{3}$ & $\mathbf{4}$ & $\mathbf{5}$ & $\mathbf{6}$ \\
\hline SULFIDATION & & & & & & \\
\hline $\begin{array}{l}\text { Reductive Regeneration } \\
\text { Duration (min.) }\end{array}$ & 26 & 60 & 60 & 60 & 60 & 60 \\
\hline Temperature $\left({ }^{\circ} \mathrm{C}\right)$ & & & & & & \\
\hline Pressure (atm) & 482 & 482 & 482 & 482 & 482 & 482 \\
\hline Space Velocity $\left(\mathrm{hr}^{-1}\right)$ & 5 & 5 & 5 & 5 & 5 & 5 \\
\hline Inlet $\mathrm{H}_{2}$ S Concentration (ppmv) & 2,000 & 2,000 & 2,000 & 2,000 & 2,000 & 2,000 \\
\hline $\mathrm{H}_{2}$ S Exposure Time (min.) & 10,000 & 10,000 & 10,000 & 10,000 & 10,000 & 10,000 \\
\hline REGENERATION & 120 & 120 & 120 & 120 & 120 & 120 \\
\hline Temperature $\left({ }^{\circ} \mathrm{C}\right)$ & & & & & & \\
& $482-$ & $482-$ & $482-$ & $482-$ & $482-$ & $482-$ \\
\hline Time of Regeneration(min.) & 621 & 621 & 621 & 635 & 649 & 649 \\
\hline Temp Ramp to $732{ }^{\circ} \mathrm{C}$ & 172 & 232 & 245 & 253 & 259 & 230 \\
\hline Pressure $($ atm) & no & no & no & no & no & yes \\
\hline Space Velocity (hr $\left.{ }^{-1}\right)$ & 1,000 & 1,000 & 1,000 & 1,000 & 1,000 & 1,000 \\
\hline $\mathrm{O}_{2}$ Concentration $($ vol\%) in Feed & $5-2.5$ & $5-2.5$ & $5-2.5$ & $5-2.5$ & $5-2.0$ & $5-2.0$ \\
\hline SO $_{2}$ concentration (vol\%) in Feed & 10 & 10 & 10 & 10 & 10 & 10 \\
\hline
\end{tabular}

\begin{tabular}{|l|c|c|c|c|}
\hline \multicolumn{1}{|c|}{ Cycle } & $\mathbf{7}$ & $\mathbf{8}$ & $\mathbf{9}$ & $\mathbf{1 0}$ \\
\hline SULFIDATION & & & & \\
\hline $\begin{array}{l}\text { Reductive Regeneration } \\
\text { Duration (min.) }\end{array}$ & 66 & 117 & 48 & 60 \\
\hline Temperature ( $\left.{ }^{\circ} \mathrm{C}\right)$ & & & & \\
\hline Pressure (atm) & 482 & 482 & 482 & 482 \\
\hline Space Velocity $\left(\mathrm{hr}^{-1}\right)$ & 5 & 5 & 5 & 5 \\
\hline Inlet $\mathrm{H}_{2}$ S Concentration (ppmv) & 2,000 & 2,000 & 2,000 & 2,000 \\
\hline $\mathrm{H}_{2} \mathrm{~S}$ Exposure Time (min.) & 10,000 & 10,000 & 10,000 & 10,000 \\
\hline REGENERATION & 120 & 120 & 120 & 113 \\
\hline Temperature $\left({ }^{\circ} \mathrm{C}\right)$ & $482-538$ & $482-649$ & $482-649$ & $482-649$ \\
\hline Time of Regeneration (min.) & 158 & 210 & 210 & 210 \\
\hline Temp Ramp to 732 ${ }^{\circ} \mathrm{C}$ & no & yes & no & no \\
\hline Pressure (psig) $^{-1}$ ) & 59 & 59 & 59 & 59 \\
\hline $\left.\mathrm{Space} \mathrm{Velocity} \mathrm{(hr}^{-1}\right)$ & 1,000 & 1,000 & 1,000 & 1,000 \\
\hline $\mathrm{O}_{2}$ Concentration (vol\%) in Feed & $5-2.5$ & $5-2.0$ & $5-2.0$ & $5-2.0$ \\
\hline $\mathrm{SO}_{2}$ concentration (vol\%) in Feed & 10 & 10 & 10 & 10 \\
\hline
\end{tabular}

\begin{tabular}{|l|c|c|c|c|c|}
\hline \multicolumn{1}{|c|}{ Cycle } & $\mathbf{1 3}$ & $\mathbf{1 4}$ & $\mathbf{1 5}$ & $\mathbf{1 6}$ & $\mathbf{1 7}$ \\
\hline SULFIDATION & & & & & 60 \\
\hline $\begin{array}{l}\text { Reductive Regeneration } \\
\text { Duration (min.) }\end{array}$ & 60 & 60 & 60 & 60 & 682 \\
\hline Temperature $\left({ }^{\circ} \mathrm{C}\right)$ & 482 & 482 & 482 & 482 & 482 \\
\hline Pressure(atm) & 5 & 5 & 5 & 5 & 5 \\
\hline Space Velocity $\left(\mathrm{hr}^{-1}\right)$ & 2,000 & 2,000 & 2,000 & 2,000 & 2,000 \\
\hline $\begin{array}{l}\text { Inlet } \mathrm{H}_{2} \mathrm{~S} \text { Concentration } \\
\text { ppmv) }\end{array}$ & 10,000 & 10,000 & 10,000 & 10,000 & 10,000 \\
\hline $\mathrm{H}_{2}$ S Exposure Time (min.) & 120 & 120 & 120 & 120 & 120 \\
\hline REGENERATION & & & & & \\
\hline Temperature $\left({ }^{\circ} \mathrm{C}\right)$ & $482-621$ & $482-621$ & $482-649$ & $482-649$ & $607-732$ \\
\hline Time of Regeneration(min.) & 145 & 232 & 245 & 253 & 259 \\
\hline Temp Ramp to 732 ${ }^{\circ} \mathrm{C}$ & no & no & no & no & no \\
\hline Pressure (psig) & 59 & 59 & 59 & 59 & 59 \\
\hline Space Velocity (hr $^{-1}$ ) & 2,000 & 1,000 & 1,000 & 1,000 & 1,000 \\
\hline $\begin{array}{l}\mathrm{O}_{2} \text { Concentration (vol\%) in } \\
\text { Feed }\end{array}$ & $3-1.5$ & $5-3.0$ & $3-2.0$ & $3-2.0$ & $5-2.0$ \\
\hline $\begin{array}{l}\text { SO } \\
\text { Feed concentration (vol\%) in }\end{array}$ & 10 & 10 & 10 & 10 & 10 \\
\hline
\end{tabular}


These results of bench-scale testing of MZT-I1 were used as a basis for planning screening tests at Research Triangle Institute facilities to be discussed later. These screening tests were performed at higher pressure (20 atm) absorption and the same (5-7 atm) pressure regeneration as those performed at GE-CRD. Current hardware at GE-CRD precludes testing at pressures above 7 atm, so testing at RTI approximated more closely the absorption step at TECo at $30 \mathrm{~atm}$.

Before proceeding with the results of the extended testing at RTI, the data on desulfurization and regeneration of sorbents at lower temperatures near $370^{\circ} \mathrm{C}\left(700^{\circ} \mathrm{F}\right)$ will be presented next.

\subsection{Desulfurization and regeneration performance at $371{ }^{\circ} \mathrm{C}\left(700{ }^{\circ} \mathrm{F}\right)$ temperatures}

Part of the analysis of the long-term data for bench testing required data on operation at lower temperatures, namely absorption and regeneration as low as $371^{\circ} \mathrm{C}\left(700^{\circ} \mathrm{F}\right)$. To satisfy this requirement, a series of tests were performed where the absorption of $\mathrm{H}_{2} \mathrm{~S}$ and the regeneration of the sorbent were initiated at $371{ }^{\circ} \mathrm{C}$, simulating the startup operation of the TECO system. This simulation of low gas and sorbent temperature represents the case of cold startup at the large TECO system, where the temperatures of the piping and the temperatures of both the gas and the sorbent flowing into the reaction vessels may be lower than the design case of $900^{\circ} \mathrm{F}\left(482^{\circ} \mathrm{C}\right)$ and currently running at about $371^{\circ} \mathrm{C}\left(700^{\circ} \mathrm{F}\right)$. If proven, the inability of a sorbent to desulfurize and regenerate properly from the very first cycle at low temperatures would be a stumbling block for its consideration in the TECO HGCU system. In addition, any preconditioning necessary on a sorbent would cause significant difficulties to implement in large scale. Figure 3-47 shows the $\mathrm{H}_{2} \mathrm{~S}$ breakthrough curves at $700^{\circ} \mathrm{F}$ for the first and second absorptions of MZT-R1 sorbent. As the porosity of the sorbent increases after the first cycle, so does the reactivity of the sorbent bed. This behavior is common in many sorbents and is desirable for startup operations.

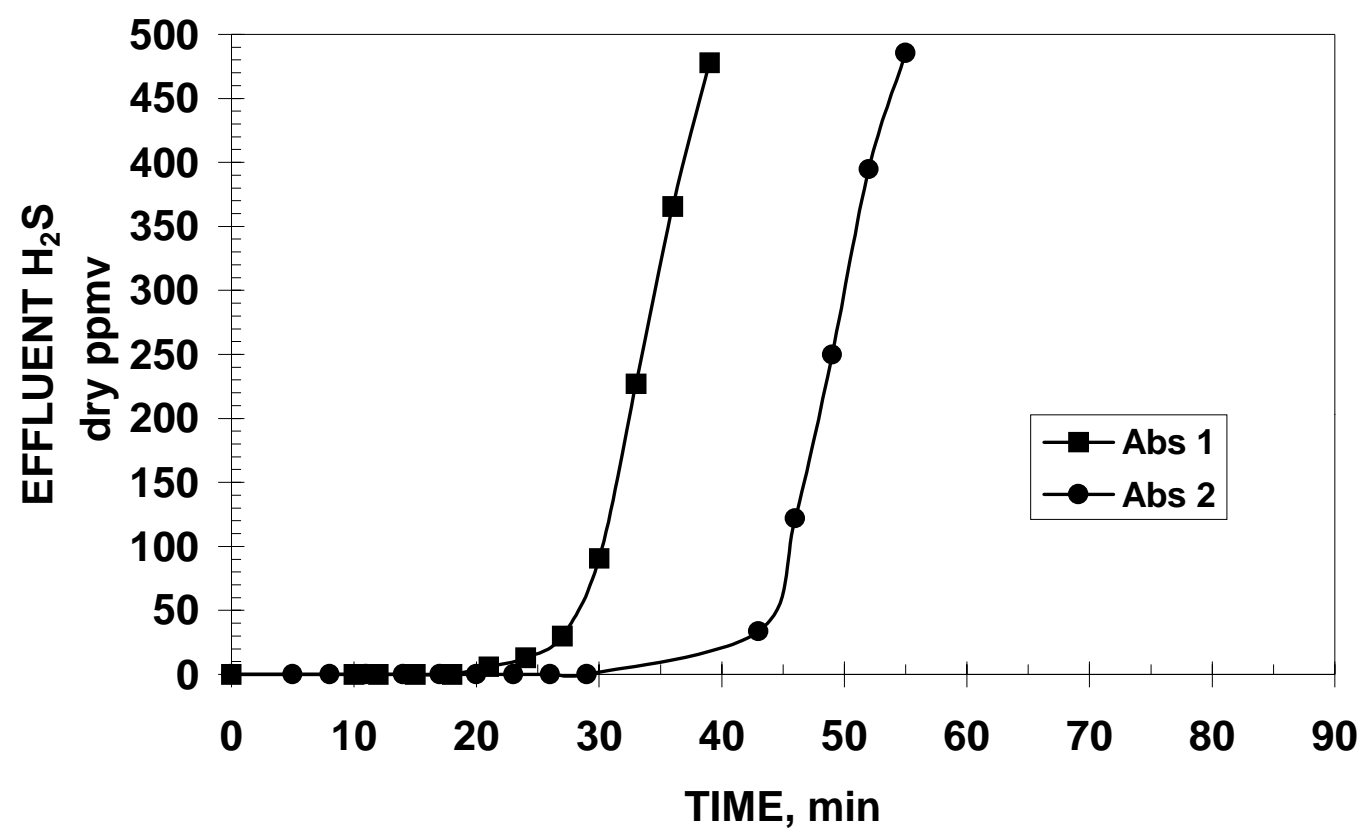

Figure 3-47. $\mathrm{H}_{2} \mathrm{~S}$ breakthrough curves for absorption by MZT-R1 at $371{ }^{\circ} \mathrm{C}\left(700{ }^{\circ} \mathrm{F}\right)$ 
When conducting absorption at $371^{\circ} \mathrm{C}\left(700^{\circ} \mathrm{F}\right)$, the bed reactivity is $1 / 2$ of that at $900{ }^{\circ} \mathrm{F}$ under the same conditions. The bed sulfur capacity is still the same. This means that operation with coal gas at 371 ${ }^{\circ} \mathrm{C}\left(70{ }^{\circ} \mathrm{F}\right)$ will require taking a lower flow of coal gas or moving sorbent at higher sorbent transfer rate to keep the outlet $\mathrm{H}_{2} \mathrm{~S}$ below acceptable limits. In practice, a combination of both techniques could be used to temporarily operate during startup and transient conditions.

Figure 3-48 shows the temperature profile of the first regeneration of MZT-R1 sorbent at $371{ }^{\circ} \mathrm{C}(700$ ${ }^{\circ} \mathrm{F}$ ) when the regenerant gas does not contain any recycled $\mathrm{SO}_{2}$. This condition of zero sulfur dioxide in the gas would be typical to the very early stages of startup, when the recycled gas has zero $\mathrm{SO}_{2}$ from the oxidation of zinc sulfide. Twenty minutes after the oxygen is added, the rate of reaction is high enough to produce an exotherm from $371^{\circ} \mathrm{C}\left(700^{\circ} \mathrm{F}\right)$ to about $593^{\circ} \mathrm{C}\left(1100^{\circ} \mathrm{F}\right)$. This exotherm of $222^{\circ} \mathrm{C}$ is sufficient to initiate the heating of the bed in the moving-bed system. In these laboratory tests, where there is no sorbent movement, the reaction exotherm starts to die out after 50 minutes. When added heat to the bed via the external heating furnace is provided, a second exotherm appears with a maximum temperature close to $805^{\circ} \mathrm{C}\left(1480^{\circ} \mathrm{F}\right)$. The observed regeneration rates in Figure 3-48 are sufficient to move a large-scale operation from startup at $371^{\circ} \mathrm{C}$ to steady-state operation at controlled temperature conditions in the range of $480-790^{\circ} \mathrm{C}$.

Figure 3-49 shows the equivalent regeneration temperature data for MZT-R1 for the case where 10\% $\mathrm{SO}_{2}$ was present in the regenerant gas and both the gas and sorbent temperatures were initially at 371 ${ }^{\circ} \mathrm{C}\left(700{ }^{\circ} \mathrm{F}\right)$. This condition of $10 \% \mathrm{SO}_{2}$ is representative of a transient operation when a temporary shutdown has allowed the gases and sorbent to cool off but the recycle gas continues to be circulated around the loop. Again, there is an initial exotherm where the sorbent rises in temperature from $371{ }^{\circ} \mathrm{C}$ $\left(700^{\circ} \mathrm{F}\right)$ to around $593^{\circ} \mathrm{C}\left(1100^{\circ} \mathrm{F}\right)$. This time, however, there is a slight delay in the onset of the first exotherm, and some temperatures in the middle of the bed (TC4) are still rising after 70 minutes.

Both cases show that this sorbent is capable of cold startup conditions at $371{ }^{\circ} \mathrm{C}\left(700^{\circ} \mathrm{F}\right)$ even in the presence of $10 \% \mathrm{SO}_{2}$ during regeneration. The actual reactor internal diameter is 2-7/8 in. instead of the standard $2 \mathrm{in}$. reactors used under other DOE tests, so that the actual linear velocity of the gas is $1 / 2$ of that in a standard bench reactor. The implication is that lower space velocities may be required during startup and transient operation of the regenerator to produce an exotherm and bring the system towards the higher temperature steady-state operation. Current large-scale systems like TECo do not have a lower limit constraint on the flow of gases to the regenerator so that the tests performed here can be translated directly to the larger systems.

Overall, cold startup of a large-scale system like TECo is possible using modified zinc titanates and lower space velocities to prevent premature breakthrough in the absorber and to maintain a temperature exotherm in the regenerator so that the system can be brought up to higher $\left(482^{\circ} \mathrm{C}\right)$ steady-state baseline operation. Sorbent MZT-R1 is particularly suited for lower temperature operation down to at least $371^{\circ} \mathrm{C}$. 


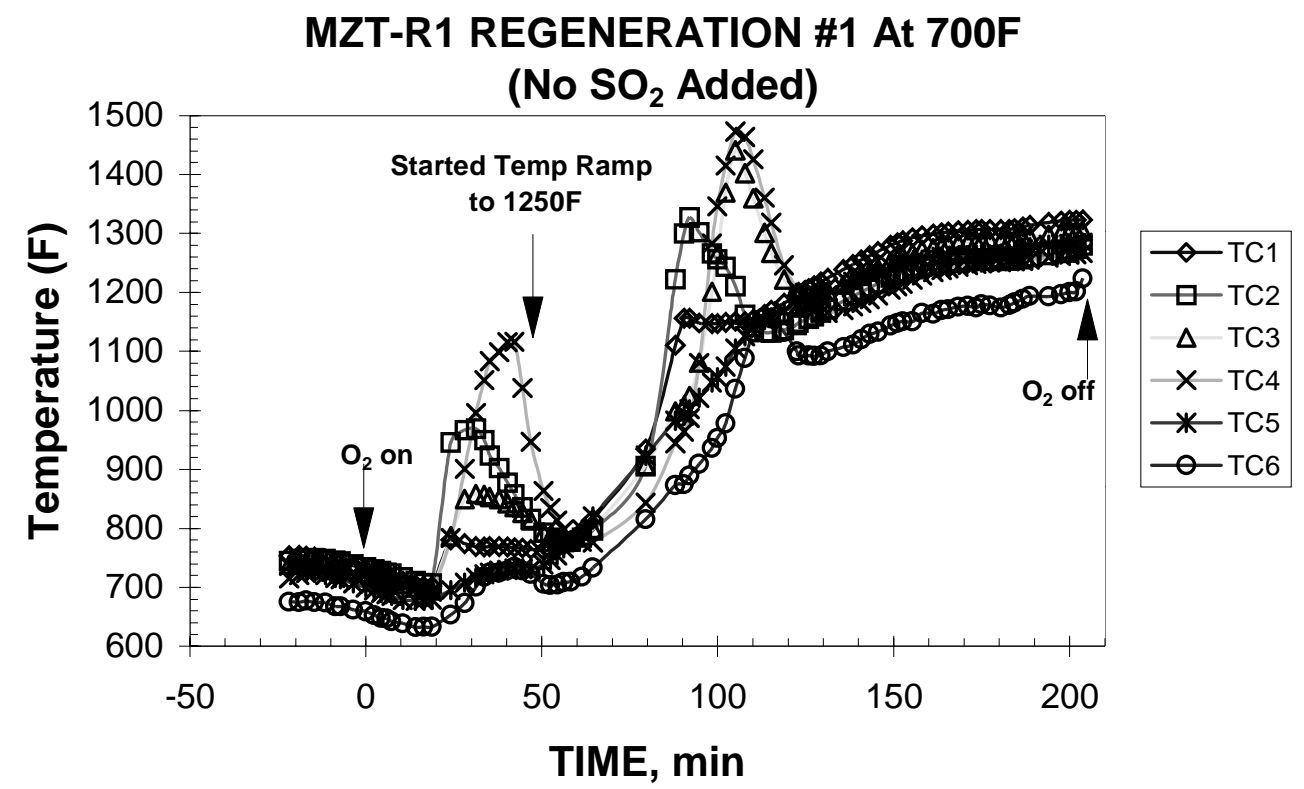

Figure 3-48. Temperature profiles during regeneration of MZT-R1 at $371{ }^{\circ} \mathrm{C}\left(700{ }^{\circ} \mathrm{F}\right)$ without any $\mathrm{SO}_{2}$

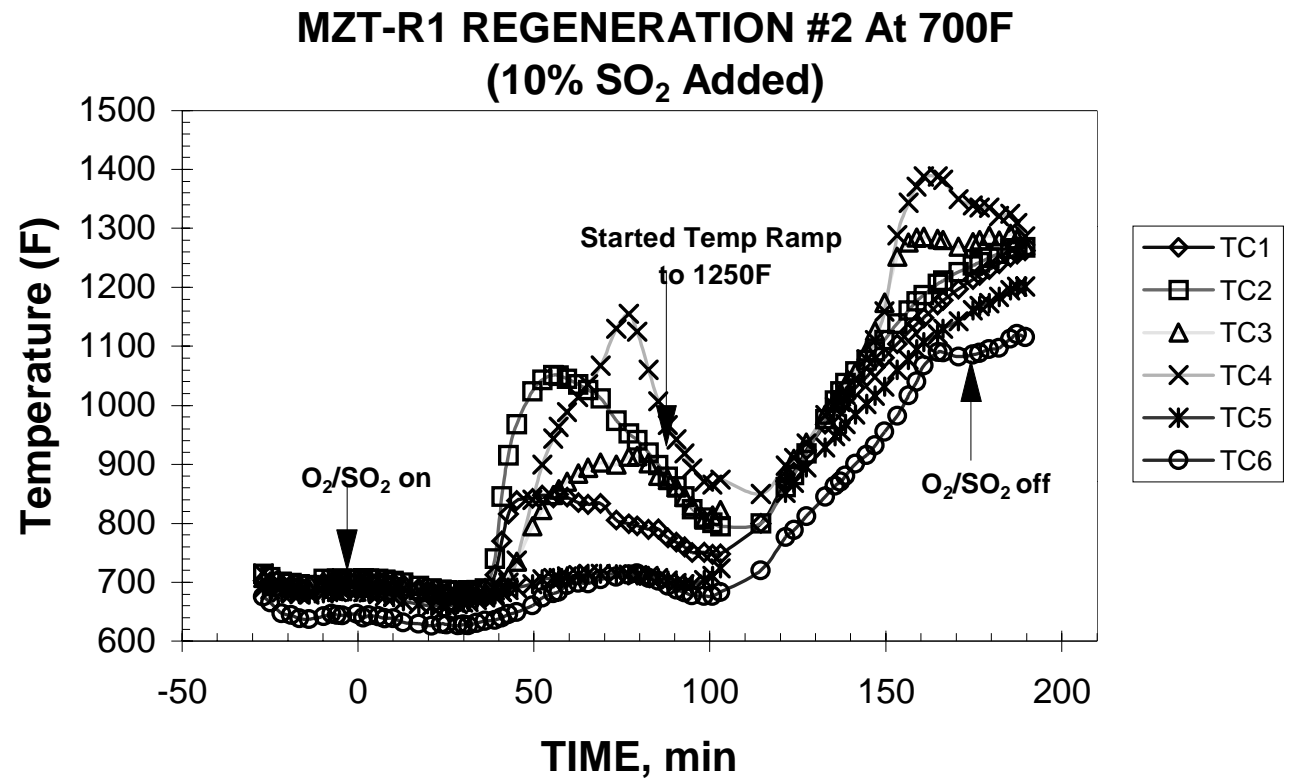

Figure 3-49. Temperature profiles during regeneration of MZT-R1 at $371{ }^{\circ} \mathrm{C}\left(700{ }^{\circ} \mathrm{F}\right)$ with $10 \% \mathrm{SO}_{2}$ added 


\subsubsection{RTI's Independent Bench Evaluation}

Given the satisfactory performance of two of the modified zinc titanate formulations, MZT-R1 and MZT-I1, during the screening process at GE-CRD, the two formulations were further screened in independent bench tests at Research Triangle Institute (RTI). One of them (MZT-R1) was further tested through 13 cycles of absorption and regeneration. Tests at RTI were under a separate DOE-sponsored program. Since the funding for the independent testing at RTI was not disbursed from this program but rather directly from DOE, only a summary of the major results will be given in this report.

By August 1997, MZT-R1 had undergone a preliminary 5-cycle screening test at RTI to check various operating conditions for the future long-term testing. Figure 3-50 presents the $\mathrm{H}_{2} \mathrm{~S}$ breakthrough curves during absorption at $20 \mathrm{~atm}$ for MZT-R1.

Figure 3-51 shows the corresponding curves for MZT-I1. Both sets of curves at 20 atm are comparable to those obtained at GE-CRD at 5-atm absorption during preliminary multiple cycle tests. Table 320 presents the results during the bench screening at RTI. MZT-I1 is a sorbent formulation that does not have additives for operation at lower temperatures around $371^{\circ} \mathrm{C}$. On the other hand, it exhibited higher mechanical strength. These preliminary results suggest that the modified zinc titanate formulations MZT-R1 and MZT-I1 are potential candidates for further evaluation in long-term tests. Both formulations were considered initially for screening tests at $382^{\circ} \mathrm{C}$. However, given that MZT-R1 showed better regenerability in screening tests at $371^{\circ} \mathrm{C}\left(700^{\circ} \mathrm{F}\right)$ at GE-CRD (Figure 3-49) and at RTI's preliminary scouting tests, MZT-R1 was chosen to test operation up to 25 cycles of bench testing.

A new larger batch sample was obtained from UCI for the tests at RTI. Reproducibility of the fabrication of MZT-R1 was somewhat questionable because the same formulation prepared under two small batches several months apart yielded results of $0.7 \%$ and $2.0 \%$ in ASTM attrition resistance. The batch-to-batch variability is significant compared to the typical range of attrition resistance measured in good fresh sorbents, about 1 to $4 \%$ attrition resistance.

Figure 3-52 shows the $\mathrm{H}_{2} \mathrm{~S}$ breakthrough curves for the 13 cycles performed at RTI. Testing was stopped at 13 cycles instead of 25 cycles to inspect the pellets and collect pellet samples. Even though the reactivity of the sorbent was still acceptable, some visual degradation of the mechanical properties was measured. Hairline cracks were observed in some of the pellets. Attrition resistance was over 10\% in some samples extracted from the bed, and hence, it was decided to discontinue testing until further analyses were available. The loss in mechanical durability was ascribed to these major areas:

- Batch-to-batch variability observed in the pelletization, as explained in the paragraphs above. In addition, variability within the batch also has an impact in the overall batch performance, particularly when attrition losses of about $1 \%$ are considered significant.

- The level of sulfate formation/decomposition during the testing. RTI's testing at $5 \mathrm{~atm}$ during regeneration is a more severe requirement on a sorbent than regeneration at lower pressures. Pore structure of the sorbent must be optimized to accommodate changes in the crystal structure between sulfidation and regeneration.

Overall, the testing at RTI showed that the two sorbents considered can desulfurize and regenerate at conditions resembling those to be encountered at the TECO plant, namely, desulfurization in the range $373-482^{\circ} \mathrm{C}\left(700-900^{\circ} \mathrm{F}\right)$ and regeneration up to $760^{\circ} \mathrm{C}\left(1400^{\circ} \mathrm{F}\right)$. Nonetheless, more work is 
MZT-R1 Scoping Test at RTI

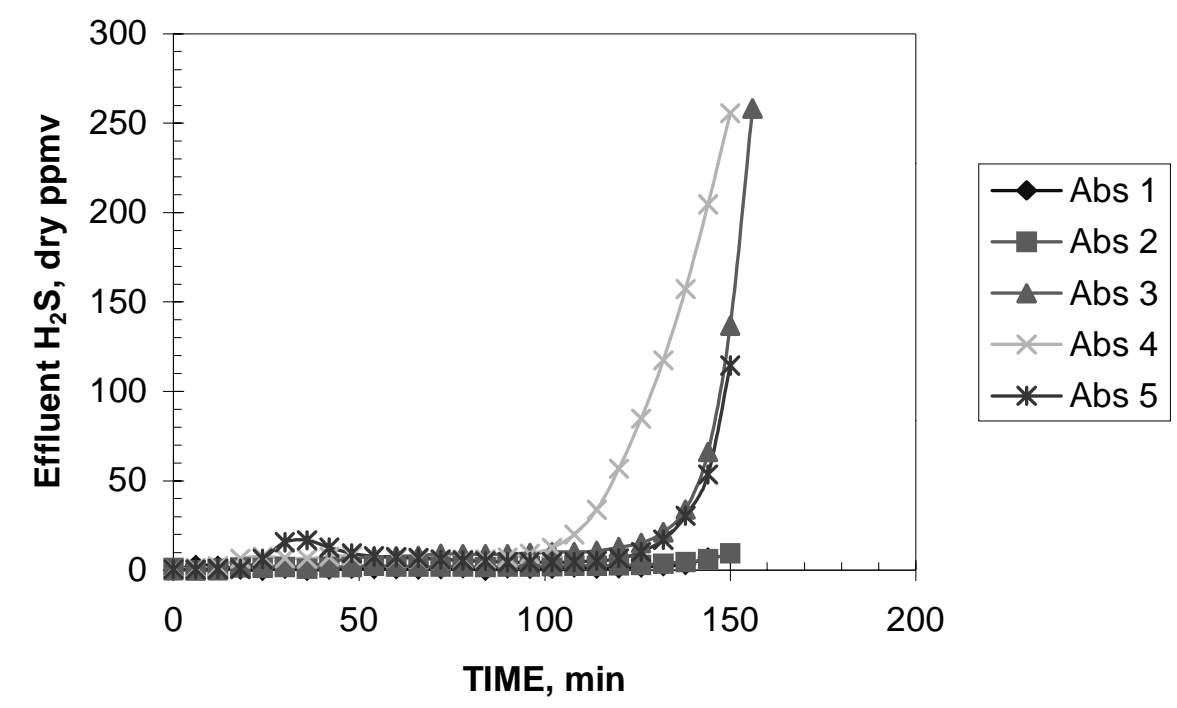

Figure 3-50. Breakthrough curves for MZT-R1 sorbent for 5 cycles in screening bench tests performed at RTI.

\section{MZT-I1 Scoping Test at RTI}

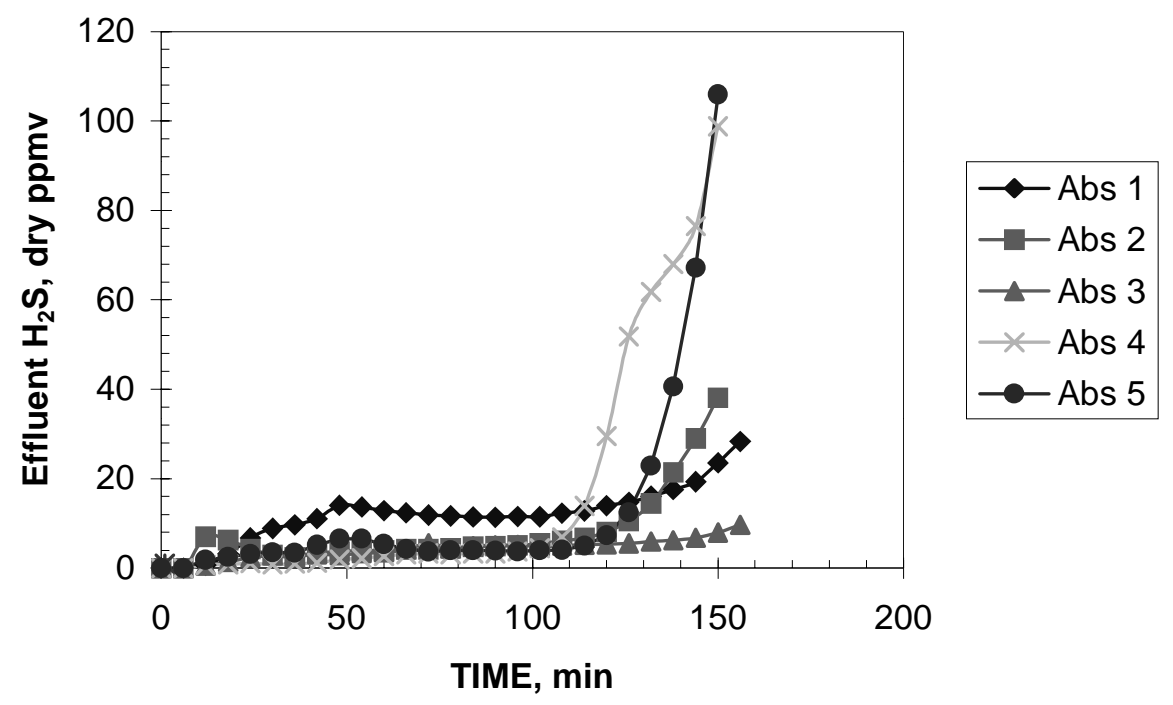

Figure 3-51. Breakthrough curves for MZT-I1 sorbent for 5 cycles in screening bench tests performed at RTI. 
Table 3-20. Preliminary results of screening tests at RTI on MZT-R1

\begin{tabular}{lcc}
\hline Parameter & 25-Cycle Bench Test Targets & Results after 5 cycles \\
\hline Absorption Temperature & $482{ }^{\circ} \mathrm{C}\left(900^{\circ} \mathrm{F}\right)$ & $482{ }^{\circ} \mathrm{C}\left(900^{\circ} \mathrm{F}\right)$ \\
Base Regeneration Temp. & $343-538^{\circ} \mathrm{C}$ & $482{ }^{\circ} \mathrm{C}\left(900^{\circ} \mathrm{F}\right)$ \\
& $\left(650-1000^{\circ} \mathrm{F}\right)$ & and $371{ }^{\circ} \mathrm{C}\left(700^{\circ} \mathrm{F}\right)$ \\
Reg. Pressure & $5-7 \mathrm{~atm}$ & $5 \mathrm{~atm}$ \\
Fresh ASTM attrition loss & $<4 \%$ & $2 \%$ \\
25-cycle ASTM attrition loss & $<5 \%$ & $\mathrm{~N} / \mathrm{A}$ \\
Net Sulfur Loading & $>0.11 \mathrm{~g} \mathrm{~S} / \mathrm{cc} \mathrm{bed}$ & $0.11 \mathrm{~g} \mathrm{~S} / \mathrm{cc}$ bed \\
& $\left(6.7 \mathrm{lb} . \mathrm{S} / \mathrm{ft}^{3} \mathrm{bed}\right)$ & $\left(6.7 \mathrm{lb} . \mathrm{S} / \mathrm{ft}^{3} \mathrm{bed}\right)$ \\
\hline
\end{tabular}

Breakthrough Curves for MZT-R1 Sorbent

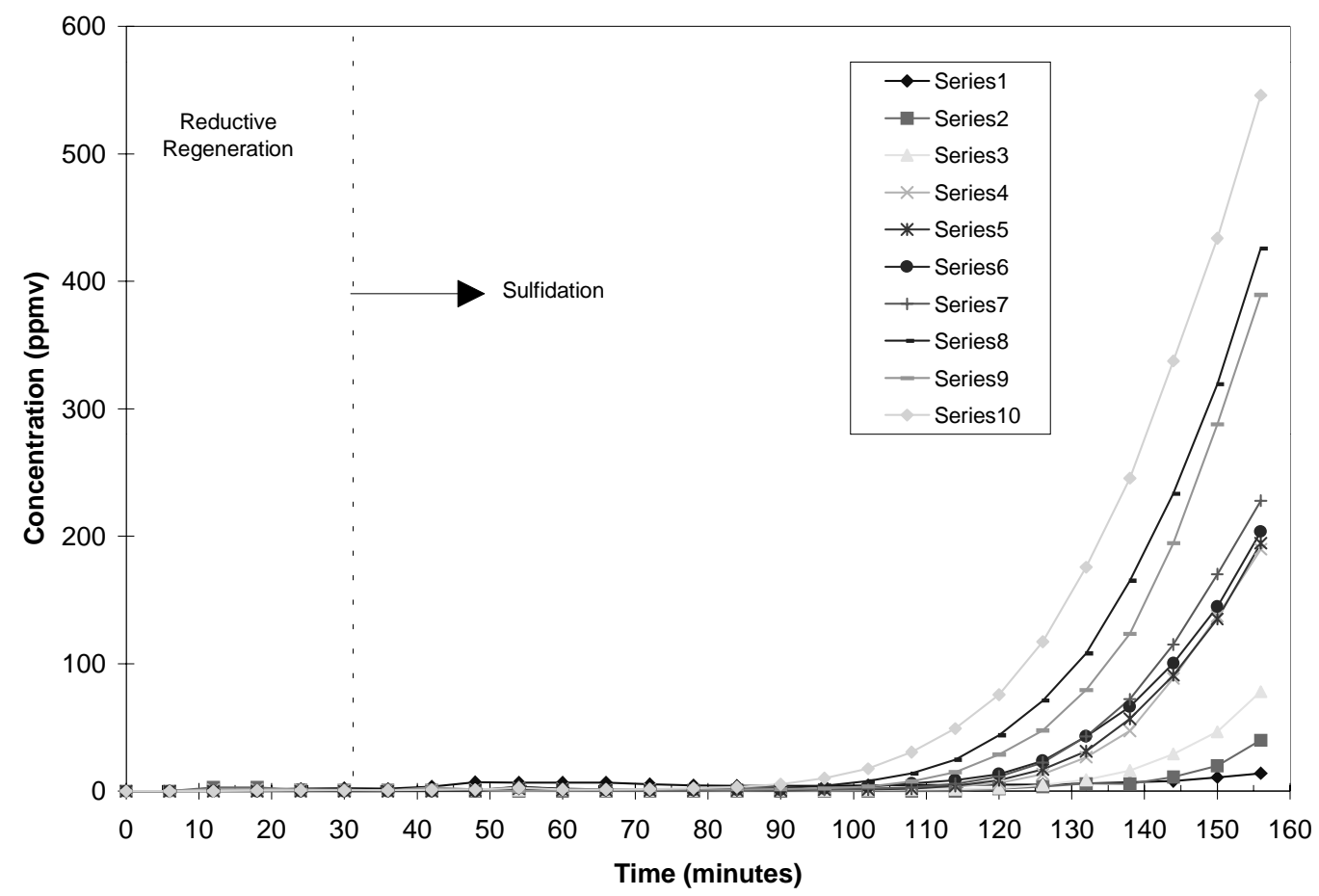

Figure 3-52. Breakthrough curves for MZT-I1 sorbent for 13 cycles in screening bench tests performed at RTI.

needed to control the batch to batch variability and to circumvent the impending degradation of the pellets over a higher number of cycles.

A more complete study is needed jointly with the sorbent manufacturers to control pelletization variability before resuming long-term testing of MZTs. 


\subsubsection{Evaluation of Chemetals' Manganese Oxide Sorbents}

Several formulations of zinc oxide/manganese oxide sorbents provided by Chemetals (Baltimore, Maryland) were evaluated at GE-CRD for mechanical durability (attrition and crush strength) and chemical reactivity. Our interest in manganese-based sorbents is in their potential use in high-temperature desulfurization of coal gases where a sorbent of higher strength properties is desired. Figure 3-53 shows the mechanical durability of three sorbents provided by Chemetals. CST-939 is a pure manganous oxide sorbent which exhibits a high crush strength and low ASTM attrition. The other two sorbents contain various amounts of zinc oxide; unfortunately, the ASTM attrition loss increases and the crush strength decreases with respect to the pure manganous oxide sorbents. The drive for adding zinc oxide is to circumvent the limitations of manganese oxides, namely, higher equilibrium values of $\mathrm{H}_{2} \mathrm{~S}$ during desulfurization and higher propensity to form sulfates. For our sorbent procurement specifications, attrition losses less than $4 \%$ and crush strength greater than $10 \mathrm{lb} /$ pellet $(4.5 \mathrm{~kg} / \mathrm{pellet})$ are acceptable for consideration in pilot scale tests.

Before testing desulfurization and regeneration of manganese oxide sorbent pellets, we tested powders of the pelletized sorbents to accelerate the sulfur uptake and regeneration characteristics in the absence of pore diffusion rate limitations. A first sulfidation on powder using a thermogravimetric analyzer (TGA) was performed, and a $12.6 \%$ weight gain over 2 hours of exposure to sulfidation gases (3\% $\mathrm{H}_{2} \mathrm{~S}, 482^{\circ} \mathrm{C}, 1 \mathrm{~atm}$ ) was measured that showed similar desulfurization characteristics to previous sorbents (Figure 3-54). The first 40 minutes were exposure to reducing gases, which then were followed by addition of $\mathrm{H}_{2} \mathrm{~S}$ to measure the weight gain during sulfidation. If we consider that the sorbent as received is mostly $\mathrm{Mn}_{2} \mathrm{O}_{3}$, then there may be two reactions taking place in the system:

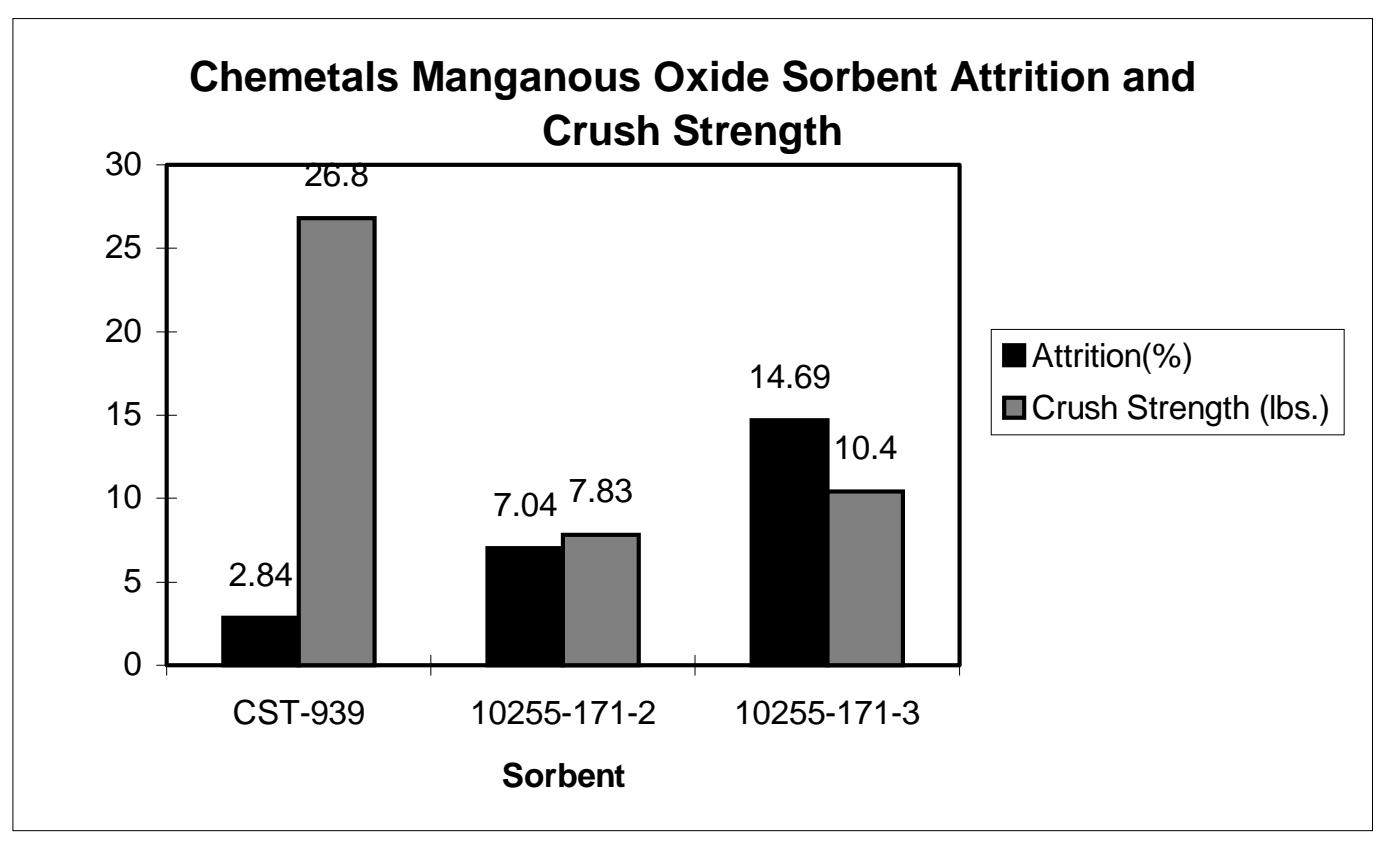

Figure 3-53. Mechanical strength of chemetals sorbents 


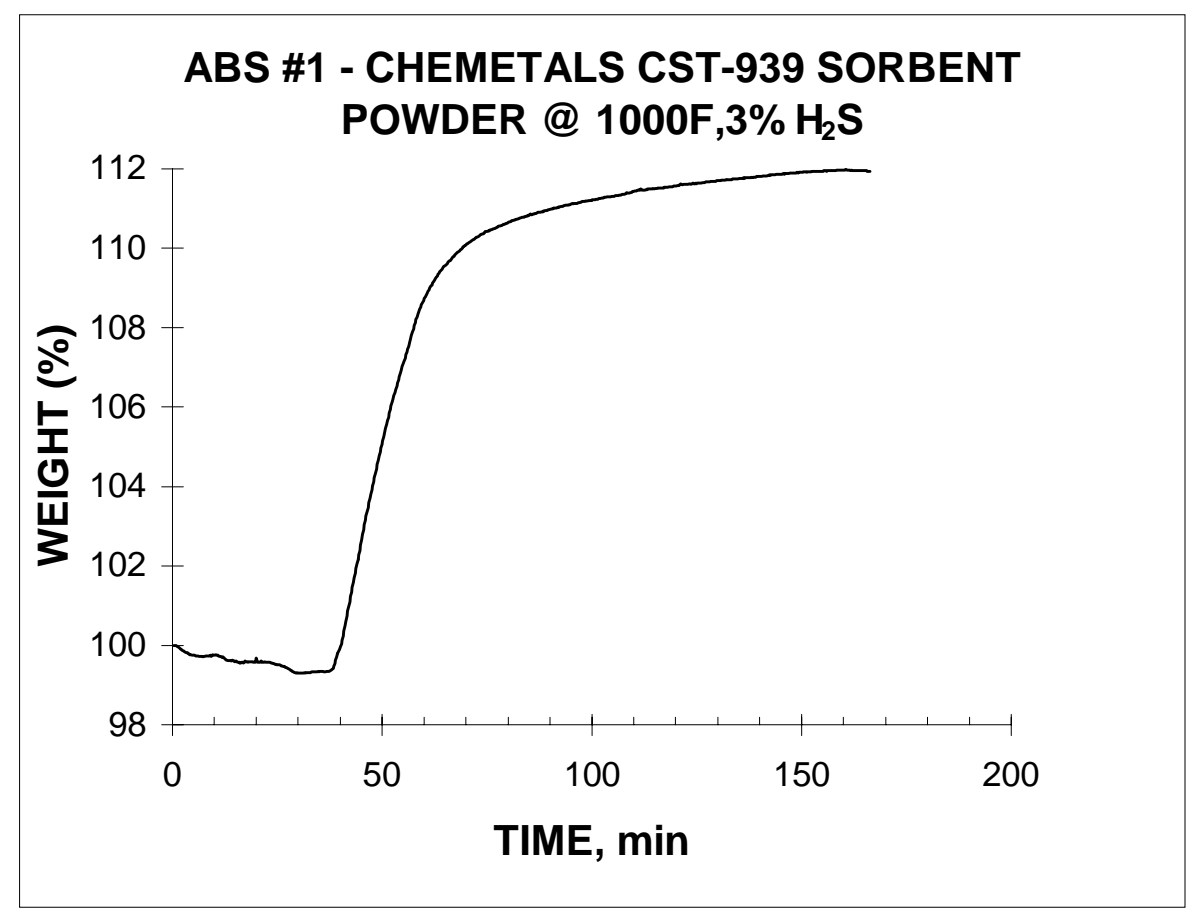

Figure 3-54. First sulfidation on CST 939 manganese oxide sorbent in a TGA

$$
\begin{array}{lr}
\mathrm{Mn}_{2} \mathrm{O}_{3}+\mathrm{H}_{2} \rightarrow 2 \mathrm{MnO}+\mathrm{H}_{2} \mathrm{O} & \Delta \mathrm{W}=-10.2 \% \\
\mathrm{MnO}+\mathrm{H}_{2} \mathrm{~S} \rightarrow \mathrm{MnS}+\mathrm{H}_{2} \mathrm{O} & \Delta \mathrm{W}=+22.6 \% \\
\hline \mathrm{Mn}_{2} \mathrm{O}_{3}+2 \mathrm{H}_{2} \mathrm{~S}+\mathrm{H}_{2} \rightarrow 2 \mathrm{MnS}+3 \mathrm{H}_{2} \mathrm{O} & \Delta \mathrm{W}=+10.3 \%
\end{array}
$$

One reaction is the reduction of the oxide Equation (1), the other is the sulfidation of $\mathrm{MnO}$, Equation (2). The net weight gain, $\Delta \mathrm{W}$, is $+11.3 \%$ in the overall reaction, Equation (3). This weight gain was measured and is shown in Figure 3-54, supporting our supposition of simultaneous oxide reduction by $\mathrm{H}_{2}$ and sulfidation by $\mathrm{H}_{2} \mathrm{~S}$.

Figure 3-55 shows the regeneration profile of Chemetals CST-939 sorbent powder at $732{ }^{\circ} \mathrm{C}(1350$ ${ }^{\circ} \mathrm{F}$ ) and $2 \% \mathrm{O}_{2}$. In principle, the sample weight should have decreased during regeneration, but instead, the weight first decreases and then increases. The observed behavior is suspected to be a result of first oxidation from sulfide to manganous oxide (which corresponds to a weight loss) followed by further oxidation from manganous oxide to manganic oxide (which corresponds to a weight gain).

Table 3-21 presents the major crystalline phases in the CST939 sorbent after the first sulfidation and regeneration reactions. These transformations by themselves have no direct negative effect on the sorbent operation, as long as the mechanical properties of the sorbent are not negatively impacted. 


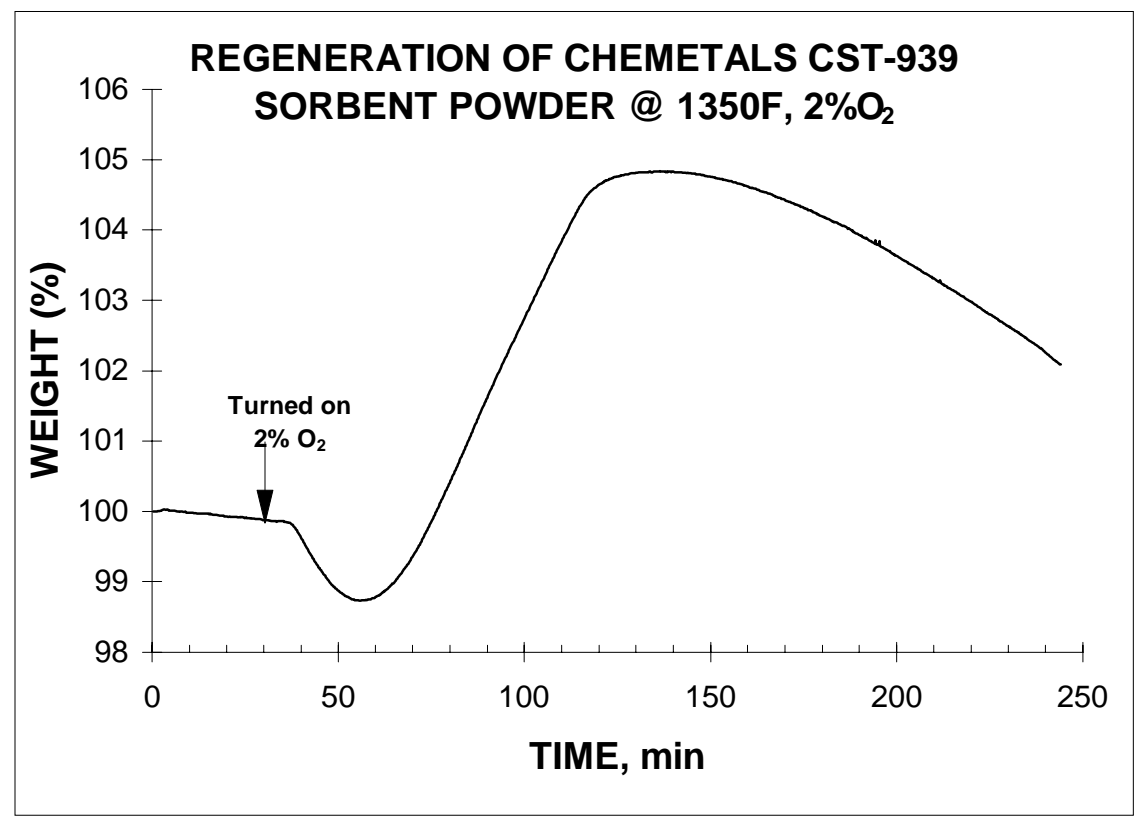

Figure 3-55. TGA regeneration profile of CST-939 sorbent powder at $1350{ }^{\circ} \mathrm{F}$ and $2 \% \mathrm{O}_{2}$

Table 3-21. XRD Analysis of CST939 sorbent

\begin{tabular}{ll}
\hline Sorbent sample & XRD Phases detected \\
\hline Fresh & $\mathrm{MnO}$ \\
After First Absorption & $\mathrm{MnS}, \mathrm{MnO}$ \\
After First Regeneration & $\mathrm{MnO}$ (major), $\mathrm{Mn}_{3} \mathrm{O}_{4}$ (major), \\
& $\mathrm{MnOS}$ (minor) \\
\hline
\end{tabular}

Further analyses were performed to rule out if a significant formation of sulfur species could have remained or formed, which would also produce a weight gain. The amount of MnOS was found to be between 1 and $2 \%$ after the first regeneration, based on XRD analysis, and it is unlikely to account for the approximately $5 \%$ to $6 \% \mathrm{wt}$ gain observed in Figure 3-55. We are uncertain if any molybdenum sulfate was formed, but manganese sulfate is a thermodynamically stable species at these conditions of regeneration. Figure 3-56 shows the phase stability diagram for the system $\mathrm{Mn}-\mathrm{S}-\mathrm{O}$ at $500{ }^{\circ} \mathrm{C}$, and the approximate point of operation during thermogravimetric analysis (TGA) tests is marked with an X. Sulfate concentrations of typically less than $1 \%$ are necessary in zinc oxide sorbents to avoid sorbent spalling or pore plugging due to sulfate formation. At this point, it is not known what the sulfate limit is for manganese oxide-based sorbents.

After the first regeneration under $\mathrm{O}_{2}$ was performed, a second sulfidation was carried out. Figure 3-57 presents the second sulfidation of CST-939. Fifty minutes of exposure to $\mathrm{N}_{2}$ were first done to obtain a steady horizontal baseline. The reducing gases $\left(\mathrm{CO}, \mathrm{H}_{2}\right)$ and other simulated coal gas components 


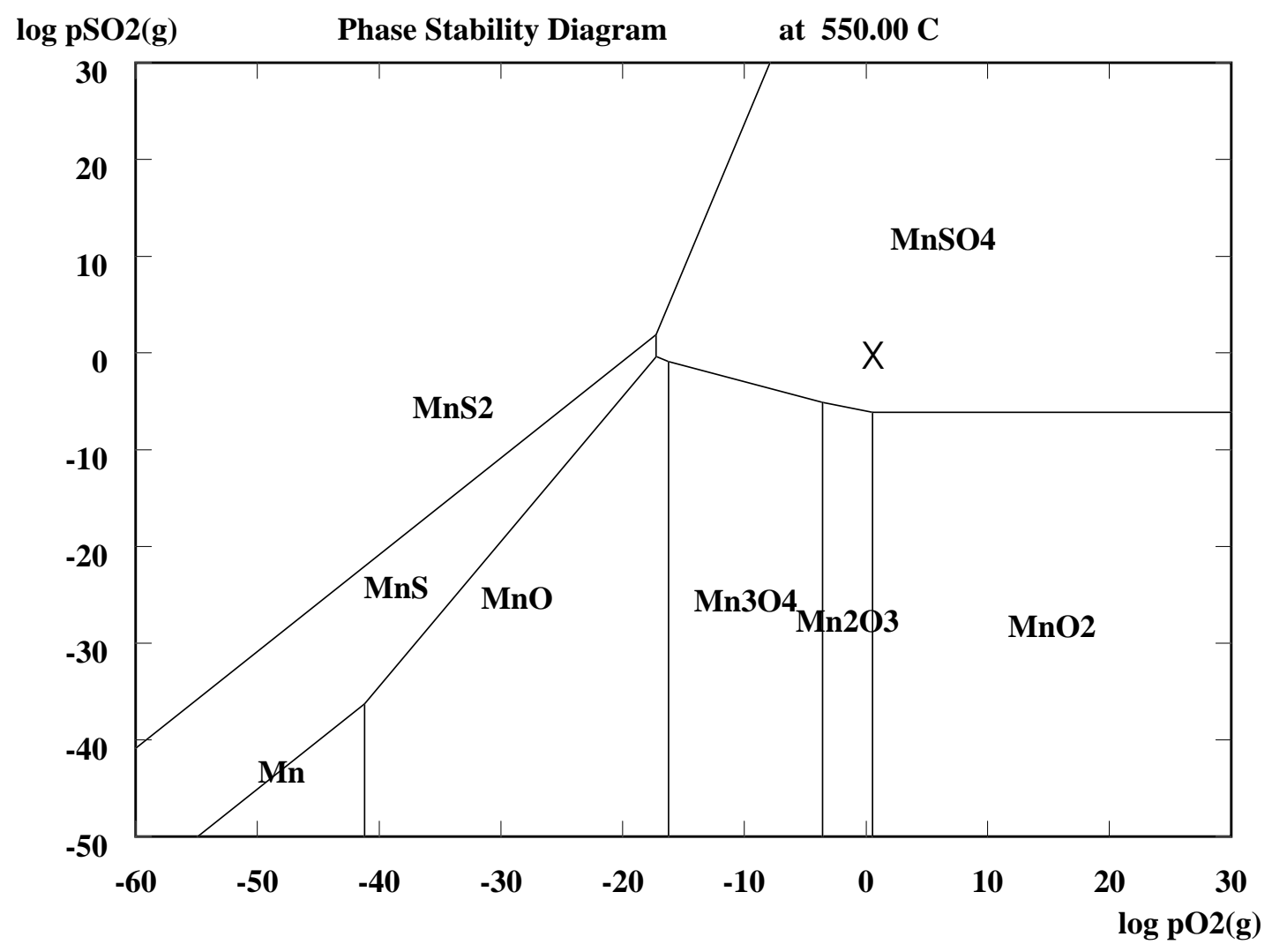

Figure 3-56. Equilibrium diagram for the system $\mathrm{Mn}-\mathrm{O}-\mathrm{S}$ at $550{ }^{\circ} \mathrm{C}\left(1022{ }^{\circ} \mathrm{F}\right)$

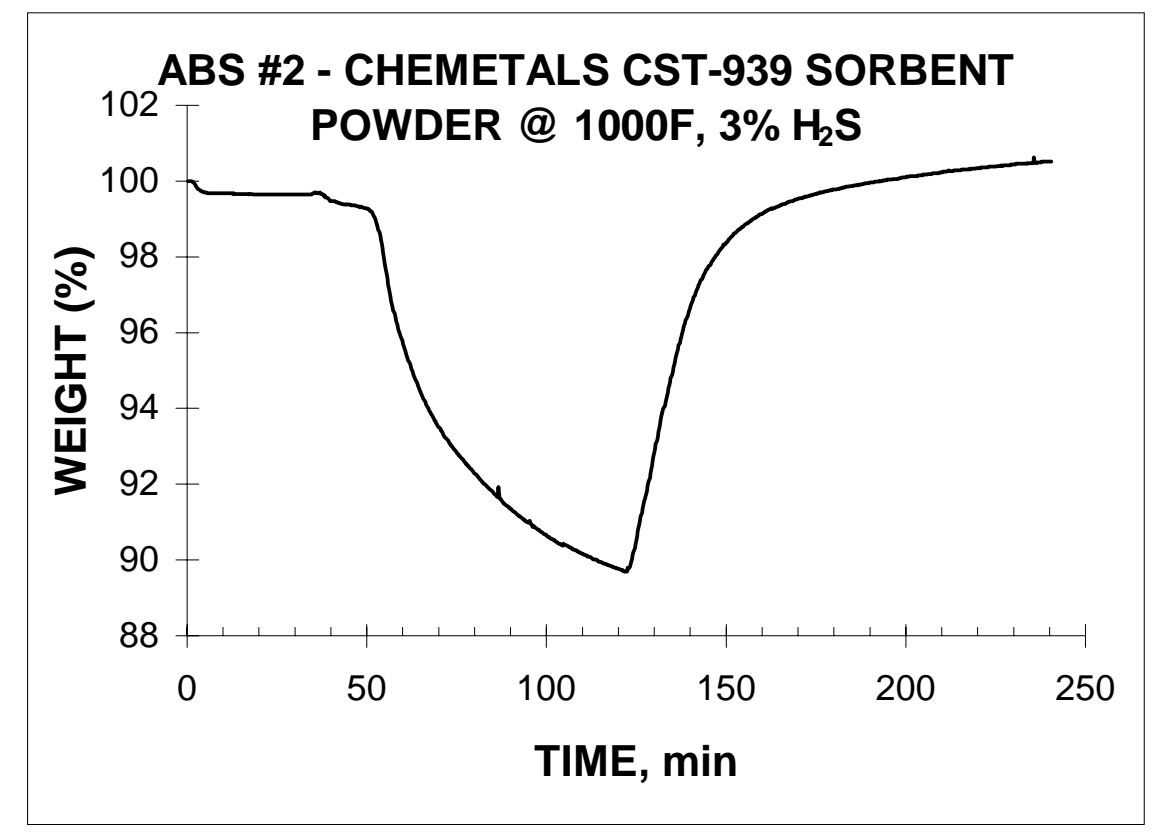

Figure 3-57. Second TGA absorption of CST-939 sorbent powder at $1000{ }^{\circ} \mathrm{F}$ and $3 \% \mathrm{H}_{2} \mathrm{~S}$. Reductive regeneration started at $\sim 50 \mathrm{~min}$. $\mathrm{H}_{2} \mathrm{~S}$ introduced at 125 minutes 
were introduced, and a $10 \%$ weight loss was measured. This weight loss is ascribed to the reaction $\mathrm{Mn}_{2} \mathrm{O}_{3}->\mathrm{MnO}$ (theoretical weight loss of 11.3\%). After a total time of 125 minutes, the $\mathrm{H}_{2} \mathrm{~S}$ was introduced to carry out the sulfidation reaction. A weight gain of $10.8 \%$ was obtained, which is slightly less than the $12.6 \%$ weight gain during the first sulfidation.

Having checked the reactivity of powder samples, tests were continued on whole pellets instead of powders. The first absorption of CST-939 pellets exhibited a standard weight gain curve upon sulfidation. The weight gain was again $12.6 \%$, which is acceptable.

The observed performance of CST-939, containing manganous oxide but no zinc, is acceptable for desulfurization. However, thermodynamic calculations predict that manganese oxides will have an equilibrium $\mathrm{H}_{2} \mathrm{~S}$ concentration that may be as high as 100 times that of zinc oxide at $450-500{ }^{\circ} \mathrm{C}$. Consequently the level of desulfurization of coal gases that can be achieved with manganese sorbents may not be as favorable. Addition of zinc oxide to the manganese obviates this limitation, but the loss in mechanical strength may represent a problem for keeping sorbent losses due to attrition low. If tests of manganese sorbents with zinc oxide showed lower attrition, they would be highly promising for larger scale use.

Figure 3-58 shows the first absorption of CST 10255-171-3 sorbent containing approximately 6\% zinc oxide in its structure. The weight gained during sulfidation is comparable to that of the pure manganese oxide, suggesting there are not negative interactions between zinc and manganese oxides as far as desulfurization reactivity is concerned. Further tests, of course, would be needed to determine if regeneration is affected.

Pure manganese oxide by itself cannot be used for our moving-bed application at TECO because manganese oxide requires regeneration above $816^{\circ} \mathrm{C}\left(1500^{\circ} \mathrm{F}\right)$, which is outside of the allowable temperature window for safe operation at the TECO HGCU demonstration plant, as dictated by the ASTM standards for the materials of construction. Also, pure manganese components will not remove

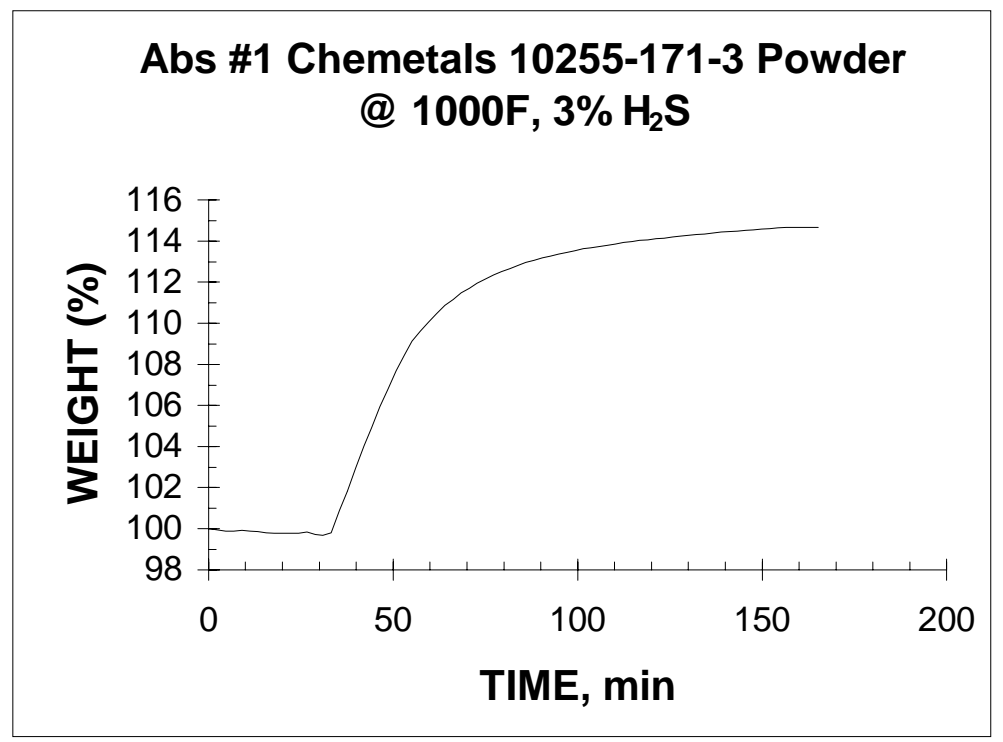

Figure 3-58. First absorption of CST 10255-171-3 sorbent 
$\mathrm{H}_{2} \mathrm{~S}$ in coal gas to low levels comparable to zinc-based sorbents as predicted by the thermodynamic calculations described earlier. At about $500{ }^{\circ} \mathrm{C}$, the equilibrium vapor pressure of $\mathrm{H}_{2} \mathrm{~S}$ in coal gas over $\mathrm{ZnO}$ is $0.1 \mathrm{ppm}$; the corresponding vapor pressure over manganese compounds is about $10 \mathrm{ppm}$, or a factor of 100 higher than that for zinc oxide. This higher equilibrium vapor pressure is somewhat of a limitation for large-scale operations, where $\mathrm{H}_{2} \mathrm{~S}$ equilibrium levels are generally not achievable over long-term operation. As mentioned before, combination of zinc oxide/manganese oxide, with proper attrition resistance, could be a viable avenue for regeneration and operation below $816^{\circ} \mathrm{C}$.

Chemetals manganous oxide sorbent CST-939 was tested in the bench-scale reactor using the procedure described below.

Test Procedure: The sorbent was subjected to 3 cycles of absorption and regeneration. The parameters for each step in a cycle are shown in Table 3-22. The test procedure was as follows:

Cycle 1:

(a) The sorbent was exposed to reductive regeneration conditions for 30 minutes to verify that the $\mathrm{H}_{2} \mathrm{~S}$ baseline was 0 ppm.

(b) The sorbent was exposed to absorption gas conditions until 200 ppmv (dry) $\mathrm{H}_{2} \mathrm{~S}$ was detected in the reactor effluent gas.

(c) The sorbent was exposed to regeneration gas conditions until the $\mathrm{O}_{2}$ concentration in the reactor effluent gas reached approximately $4 \%$. ( $\mathrm{No} \mathrm{SO}_{2}$ was added to the regeneration gas during Cycle 1).

(d) The $\mathrm{O}_{2}$ was turned off and the sorbent bed temperature was ramped to $700{ }^{\circ} \mathrm{C}$ and held there for 1 hour (Temperature Ramp conditions).

Cycle 2:

(a) The sorbent was exposed to reductive regeneration conditions for 2 hours (Reductive Regeneration \#1).

(b) The sorbent was exposed to absorption gas conditions until 200 ppmv (dry) $\mathrm{H}_{2} \mathrm{~S}$ was detected in the reactor effluent gas.

(c) The sorbent was exposed to regeneration gas conditions until the $\mathrm{O}_{2}$ concentration in the reactor effluent gas reached approximately $4 \%$. During this cycle, $8 \% \mathrm{SO}_{2}$ was added to the regeneration gas.

(d) The $\mathrm{O}_{2}$ and $\mathrm{SO}_{2}$ were turned off and the sorbent bed temperature was ramped to $1300^{\circ} \mathrm{F}$ and held there for 1 hour (Temperature Ramp conditions).

Cycle 3:

(a) The sorbent was exposed to reductive regeneration conditions for $21 / 2$ hours (Reductive Regeneration \#2).

(b) The sorbent was exposed to absorption gas conditions until $200 \mathrm{ppmv}$ (dry) $\mathrm{H}_{2} \mathrm{~S}$ was detected in the reactor effluent gas. 
Table 3-22. Bench-scale test parameters for Chemetals CST-939 sorbent

\begin{tabular}{|c|c|c|c|c|c|}
\hline \multirow[b]{2}{*}{ Test gas composition } & Absorption & $\begin{array}{c}\text { Reductive } \\
\text { Regeneration }\end{array}$ & $\begin{array}{c}\text { Regeneration } \\
\text { Cycle } 1\end{array}$ & $\begin{array}{c}\text { Regeneration } \\
\text { Cycles 2\&3 }\end{array}$ & $\begin{array}{c}\text { Temperature } \\
\text { Ramp }\end{array}$ \\
\hline & \multirow{3}{*}{$\begin{array}{c}38.6 \% \\
57 \%\end{array}$} & \multirow[b]{2}{*}{$39.0 \%$} & \multirow[t]{2}{*}{ s } & \multirow[t]{2}{*}{ ce } & \multirow[t]{2}{*}{ 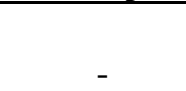 } \\
\hline $\mathrm{CO}$ & & & & & \\
\hline $\mathrm{CO}_{2}$ & & $5.7 \%$ & - & - & - \\
\hline $\mathrm{H}_{2}$ & $34.7 \%$ & $35.1 \%$ & - & - & - \\
\hline $\mathrm{H}_{2} \mathrm{O}$ & $20.0 \%$ & $20.2 \%$ & - & - & - \\
\hline $\mathrm{H}_{2} \mathrm{~S}$ & $1.0 \%$ & $0 \%$ & - & - & - \\
\hline $\mathrm{O}_{2}$ & - & - & $2 \%-5 \%$ & $2 \%-5 \%$ & - \\
\hline $\mathrm{SO}_{2}$ & - & - & $0 \%$ & $8 \%$ & - \\
\hline $\mathrm{N}_{2}$ & - & - & balance & balance & $100 \%$ \\
\hline Pressure (absolute) & $5 \mathrm{~atm}$. & $5 \mathrm{~atm}$. & $1.5 \mathrm{~atm}$ & $1.5 \mathrm{~atm}$ & $1.5 \mathrm{~atm}$. \\
\hline $\begin{array}{l}\text { Sorbent Bed } \\
\text { Temperature }\end{array}$ & $482^{\circ} \mathrm{C}$ & $482^{\circ} \mathrm{C}$ & $482^{\circ} \mathrm{C}-718^{\circ} \mathrm{C}$ & $482^{\circ} \mathrm{C}-718^{\circ} \mathrm{C}$ & $704^{\circ} \mathrm{C}$ \\
\hline Flow Rate & 13 slpm & $12.8 \mathrm{slpm}$ & 5 slpm & 5 slpm & 5 slpm \\
\hline Space Velocity & $1950 \mathrm{hr}^{-1}$ & $1920 \mathrm{hr}^{-1}$ & $750 \mathrm{hr}^{-1}$ & $750 \mathrm{hr}^{-1}$ & $750 \mathrm{hr}^{-1}$ \\
\hline \multicolumn{6}{|c|}{ Sorbent Bed Volume } \\
\hline
\end{tabular}

(c) The sorbent was exposed to regeneration gas conditions until the $\mathrm{O}_{2}$ concentration in the reactor effluent gas reached approximately $4 \%$. During this cycle, $8 \% \mathrm{SO}_{2}$ was added to the regeneration gas.

(d) The $\mathrm{O}_{2}$ and $\mathrm{SO}_{2}$ were turned off and the sorbent bed temperature was ramped to $700{ }^{\circ} \mathrm{C}$ and held there for 1 hour (Temperature Ramp conditions).

Results

Figure 3-59 shows the $\mathrm{H}_{2} \mathrm{~S}$ breakthrough curves for the three absorption cycles. While the sulfidation capacity of the sorbent is high (demonstrated by the relatively high breakthrough times), the sorbent has a high residual sulfur content after being regenerated. This is indicated by the high baseline $\mathrm{H}_{2} \mathrm{~S}$ before absorptions 2 and 3 (19 ppm and 48 ppm respectively) and the amount of each sulfur species evolved during the reductive regeneration of the sorbent (Figure 3-60 and Figure 3-61). The addition of 8\% $\mathrm{SO}_{2}$ during regeneration resulted in a significant increase in residual sulfur after regeneration.

Analysis for residual sulfur in CST-939 indicated that regeneration at the chosen conditions was not sufficient to oxidize the sulfur from the sorbent (Table 3-23).

Table 3-23. Sulfur analysis of Chemetals CST-939 sorbent after regeneration 3

\begin{tabular}{llc}
\hline & Fresh & After $3^{\text {rd }}$. Regeneration \\
\hline$\%$ Total Sulfur - Gas inlet & 0.15 & 4.68 \\
$\%$ Total Sulfur - Gas outlet & 0.15 & 1.70 \\
$\%$ Sulfate Sulfur - Gas inlet & 0.05 & 0.39 \\
\% Sulfate Sulfur - Gas outlet & 0.05 & 1.63 \\
\hline
\end{tabular}




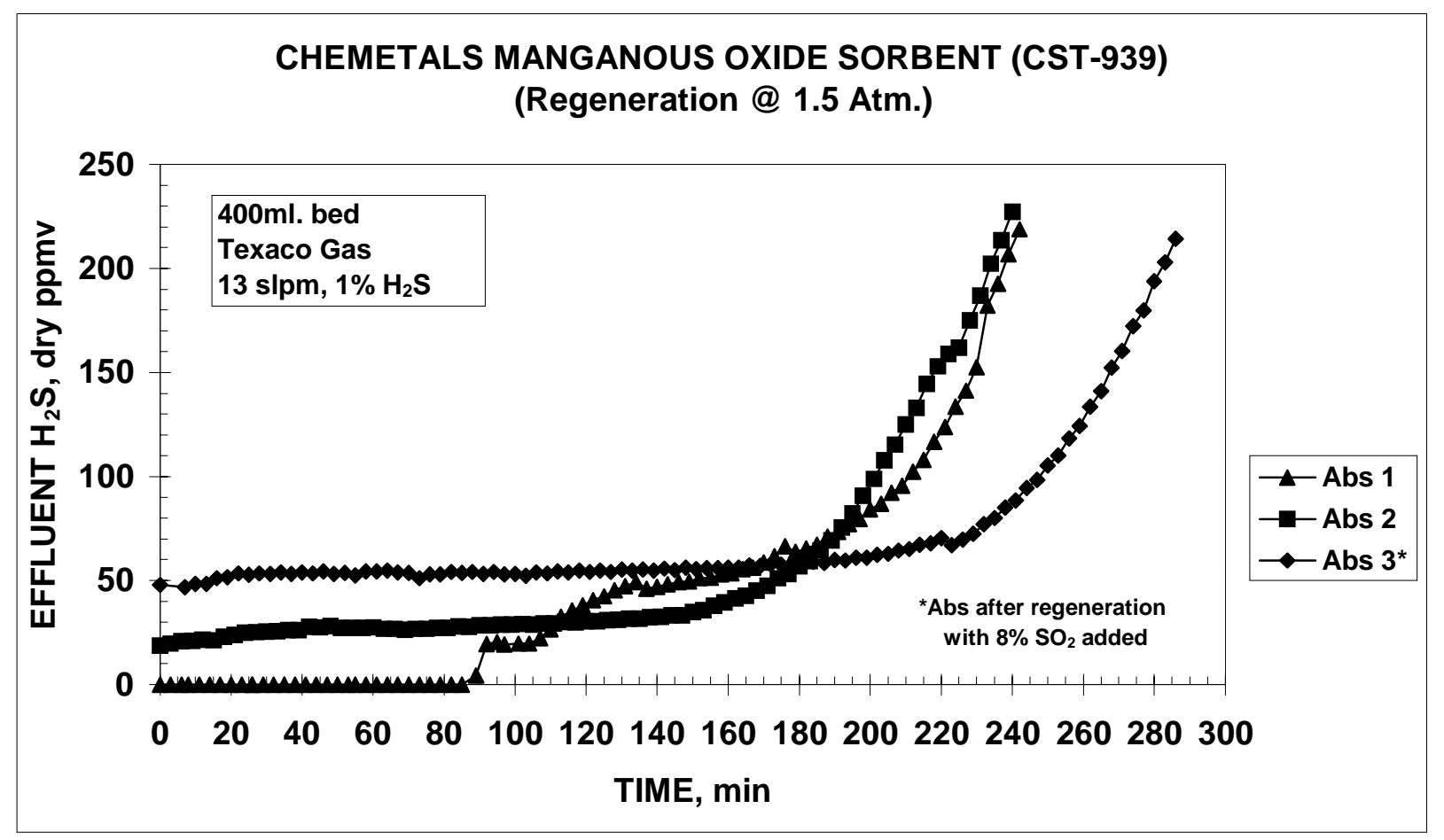

Figure 3-59. Chemetals CST-939 breakthrough curves

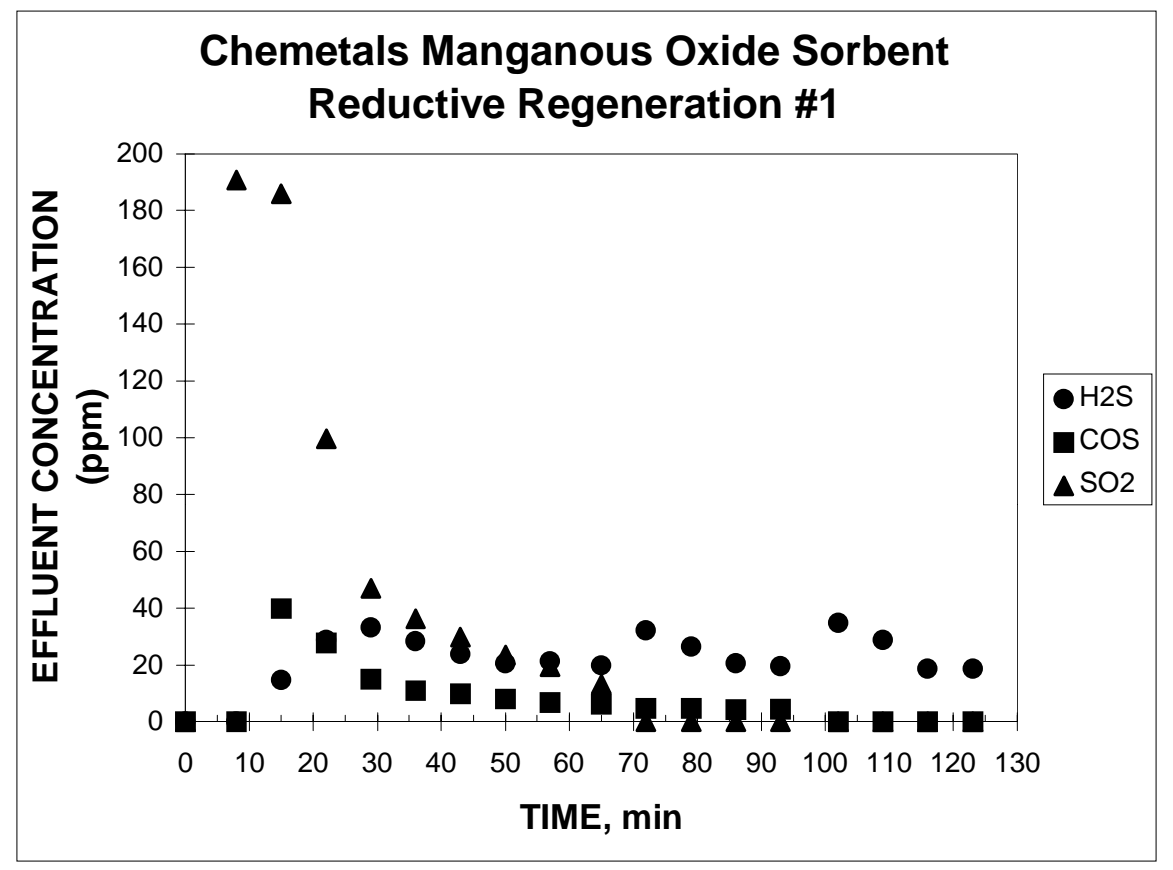

Figure 3-60. Sulfur species evolved during Reductive Regeneration \#1. 


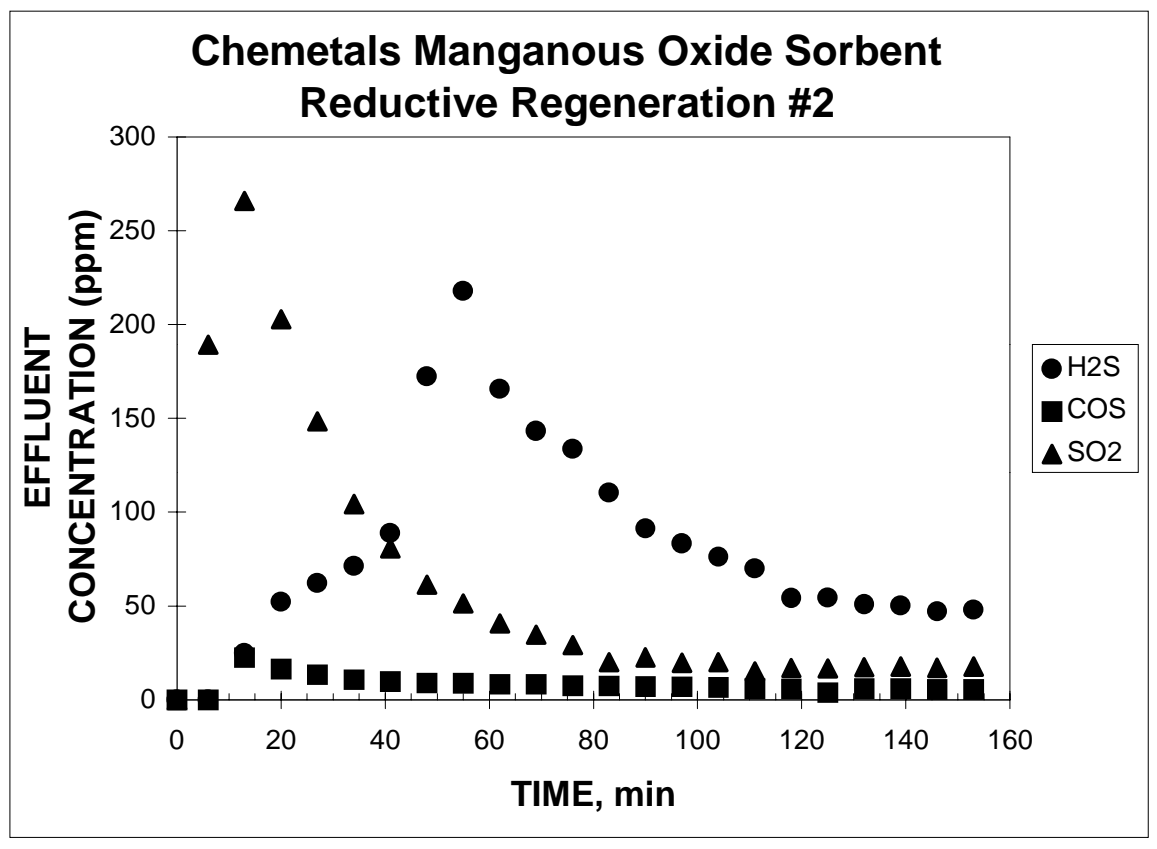

Figure 3-61. Sulfur species evolved during Reductive Regeneration \#2.

Evaluation of manganese-containing sorbents suggested that improvements in mechanical strength can be brought about by the manganese component of the sorbent. Given that manganese by itself cannot remove $\mathrm{H}_{2} \mathrm{~S}$ to as low levels as zinc-based sorbents can, the combination of the two may give a synergistic advantage. However, improvements in the attrition resistance of the manganese-zinc pellets are necessary to compete against other zinc-containing sorbents in durability.

\subsubsection{Evaluation of ICCI-2C Zinc Titanate Sorbent}

Testing of the Illinois Clean Coal Institute's ICCI2-C sorbent, as provided by Dr. J. Swisher from Southern Illinois University (SIU), was completed during 1996 as a parallel effort in the testing of proprietary sorbents. The zinc titanate-based sorbent was found to be acceptable for pilot plant testing (where regeneration is performed at a lower pressure of $1.5 \mathrm{~atm}$ ). A summary of the results for lowpressure regeneration, simulating pilot plant regeneration, is presented below.

Testing of ICCI-2C was carried out at GE-CRD under the bench-scale conditions of absorption at 5.0 atm and regeneration at 1.5 atm with $0 \%, 1 \%$, and $10 \% \mathrm{SO}_{2}$. Activation is defined as the process of treating the sorbent to a procedure of time, temperature, and gas composition so that its reactivity towards desulfurization increases to an acceptable level for large-scale use. The sulfur capacity of ICCI-2C is lower than other fully active sorbents, because of its lower zinc content (i.e., around 15\% $\mathrm{ZnO}$ ), and the reactivity is somewhat lower also, presumably because of its lower accessible surface area or porosity. Nonetheless, these two limitations can be circumvented in the moving-bed system by adjusting upwards the sorbent movement rate so that the sulfur removal per unit time remains constant. 
Figure 3-62 shows the $\mathrm{H}_{2} \mathrm{~S}$ breakthrough curves for the three test periods of regeneration with $0 \% \mathrm{SO}_{2}$ (cycles 1-5), $1 \% \mathrm{SO}_{2}$ (cycles 7-10), and 10\% $\mathrm{SO}_{2}$ (cycles 11-13) in the regeneration gas. There is a gradual activation of the sorbent after the third cycle that becomes complete by the fifth cycle. As with any other sorbent, some of the reactivity is decreased in the presence of $\mathrm{SO}_{2}$ regeneration. Absorptions were conducted at $482{ }^{\circ} \mathrm{C}, 5 \mathrm{~atm}$, and $1 \% \mathrm{H}_{2} \mathrm{~S}$ in the inlet gas. The gas composition simulated that of an oxygen-blown gasifier (i.e., high $\mathrm{CO}, \mathrm{H}_{2}$ concentration).

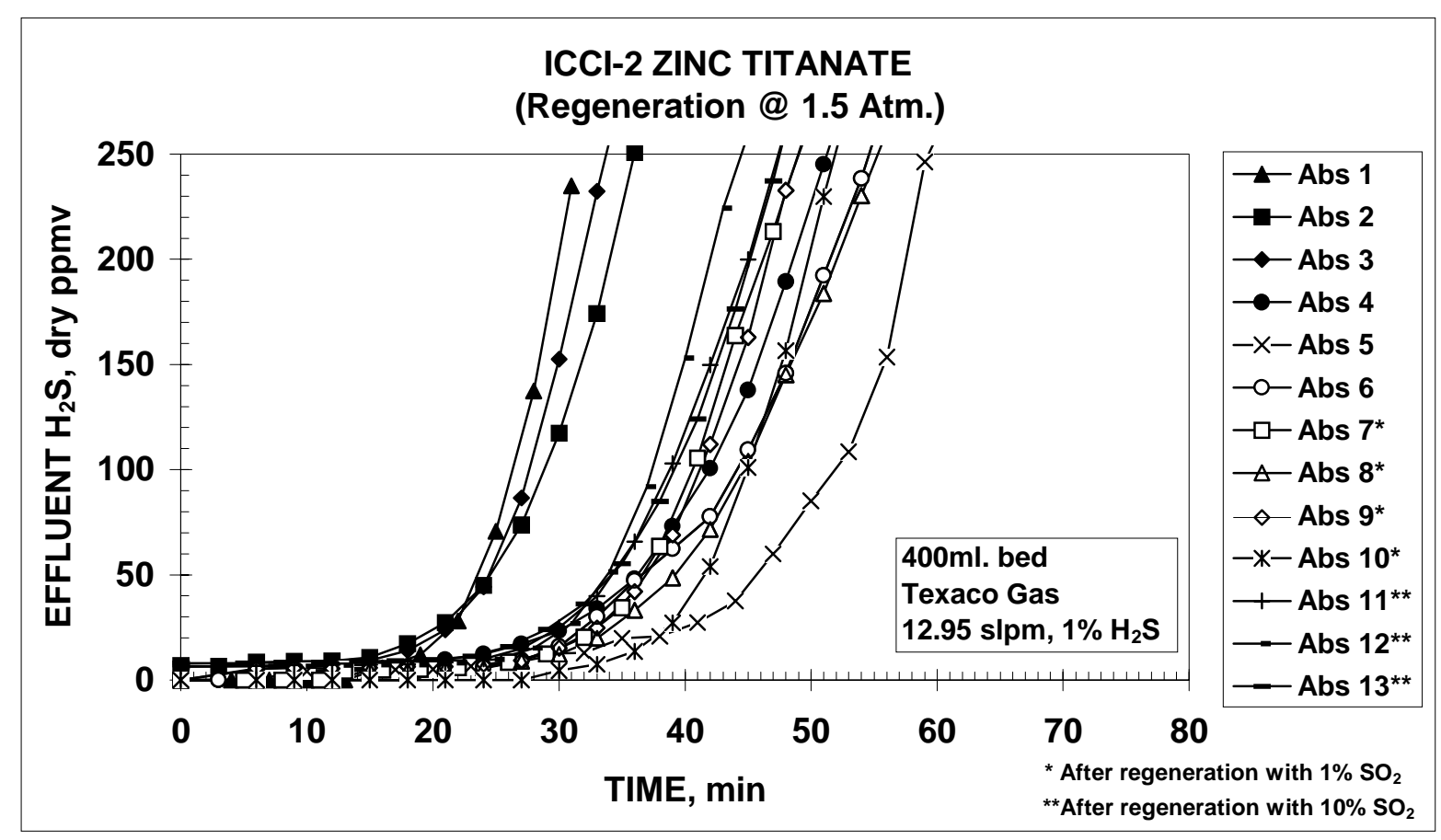

Figure 3-62. Breakthrough curves of ICCI-2C during bench testing at GE-CRD

Since it is sometimes somewhat difficult to see the trend in breakthrough times for multiple cycles shown in the same plot, an alternate approach to present the results is by plotting the "envelope" curve of the breakthrough curves versus cycle number. For each breakthrough curve, we take the time taken to reach $200 \mathrm{ppmv}_{2} \mathrm{~S}$ in the outlet gas for a given absorption and plot that time versus cycle number. Presentation of the data in this form is usually much easier when trying to determine how fast a sorbent is losing reactivity.

Figure 3-63 shows the envelope of the breakthrough curves from Figure 3-62, taken at the $200 \mathrm{ppm}$ $\mathrm{H}_{2} \mathrm{~S}$ point. You can see more clearly that the sorbent was very active by cycle 5 , and upon introduction of $\mathrm{SO}_{2}$, it slightly decreases in reactivity, and stabilizes at about $80 \%$ of its highest activity for $1 \% \mathrm{SO}_{2}$ and slightly lower for $10 \% \mathrm{SO}_{2}$. 


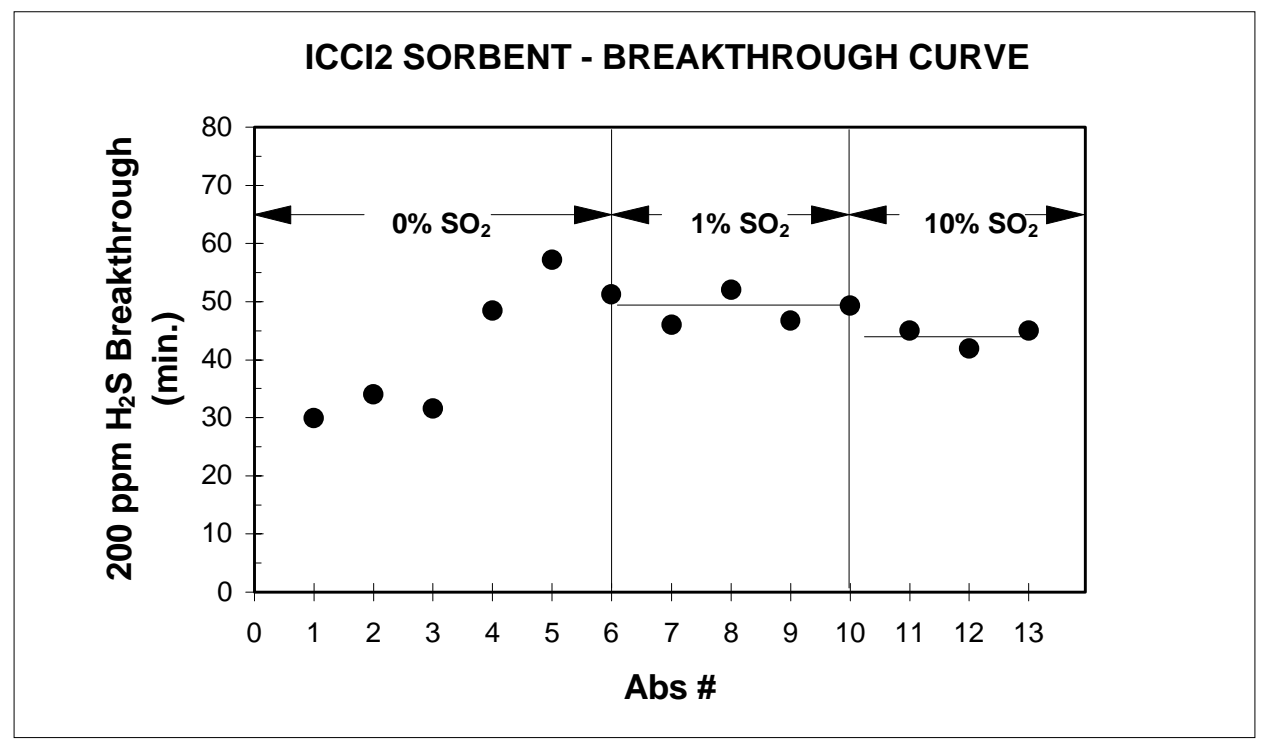

Figure 3-63. Envelope of the breakthrough curves for bench testing of ICCI-2C at GE-CRD

Figure 3-64 and Figure 3-65 show the TGA curves of samples extracted after the highest activation point (cycle 5) and after cycles with $10 \% \mathrm{SO}_{2}$ (cycle 13). The effect of $\mathrm{SO}_{2}$ on sorbent reactivity is small and not a major barrier. The weight gain due to sulfur loading is about 3-3.5\% wt or about 6 to $7 \%$ wt sulfur loading on the sorbent over 2 hours of exposure to $\mathrm{H}_{2} \mathrm{~S}$. For comparison, this amount is lower than other sorbents, which typically exhibit a $10-15 \%$ wt sulfur loading in the same time interval at full activation. Because the moving-bed absorber maintains performance by adjusting the sorbent movement rate, the lower reactivity of ICCI- $2 \mathrm{C}$ can be compensated by moving sorbent faster at the expense of (perhaps) higher sorbent mass loss per unit time of operation due to attrition.

Regeneration was started at $482{ }^{\circ} \mathrm{C}, 5 \% \mathrm{O}_{2}, 1000 \mathrm{~h}^{-1}$ space velocity. The main objective of this bench testing was to show the ability of the sorbent to regenerate when the inlet gas temperature is $482{ }^{\circ} \mathrm{C}$ as in pilot plant operation. As the temperature of the bed rose to $700^{\circ} \mathrm{C}$, the $\mathrm{O}_{2}$ concentration was reduced to $4 \% \mathrm{O}_{2}$ and the furnace temperature increased to $620^{\circ} \mathrm{C}$ to simulate the movement of the sorbent in a moving-bed system from the inlet location to a location further down the bed, where the gas temperature is higher. Once the temperatures in the bed decreased from $700^{\circ} \mathrm{C}$ to about $650{ }^{\circ} \mathrm{C}$, the oxygen concentration was adjusted again to maintain the temperatures high (this time simulating the second stage of regeneration in the pilot plant). When $\mathrm{O}_{2}$ breakthrough at the gas outlet was measured, the $\mathrm{O}_{2}$ and $\mathrm{SO}_{2}$ (if any) were shut off in the inlet gas and the nitrogen purge at $700{ }^{\circ} \mathrm{C}$ started for 1 hour.

Figure 3-66 presents the bed temperatures versus time as a function of bed location for the first regeneration. Odd numbered temperatures are measured along the center line of the bed. TC1 is the gas inlet location while TC7 is the gas outlet location at the center location. Even numbered temperatures represent wall temperatures at the same plane as the center temperatures. 


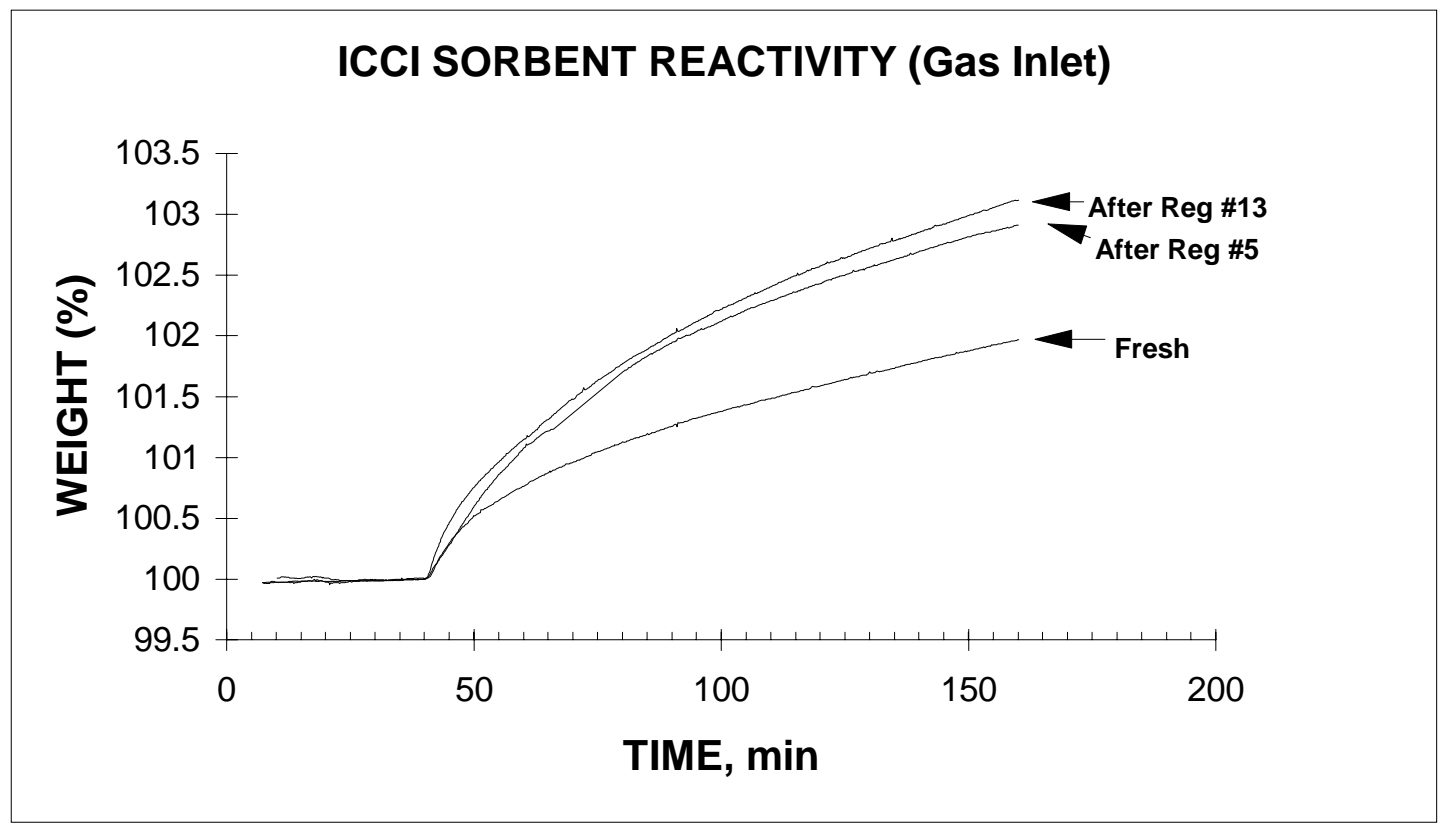

Figure 3-64. TGA Reactivity of ICCI-2C samples from the gas inlet location

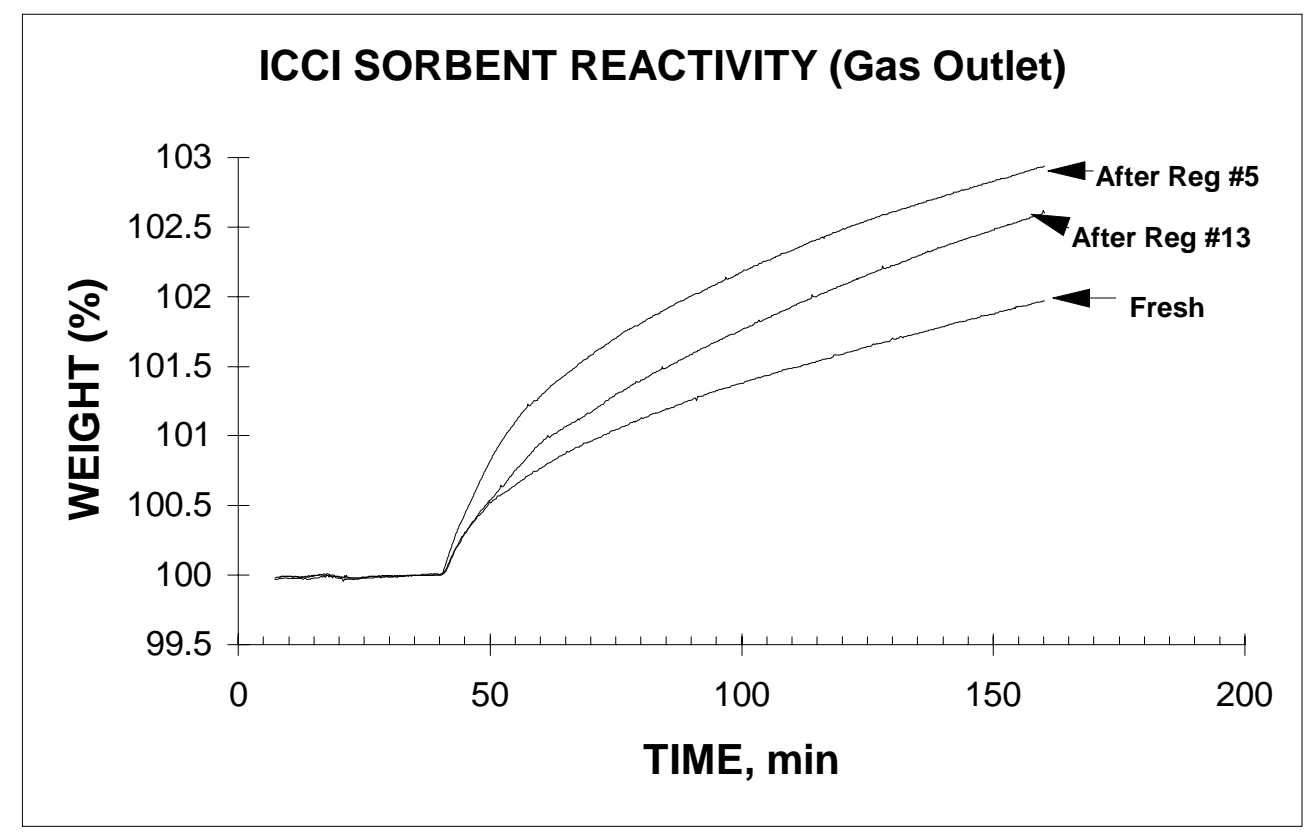

Figure 3-65. TGA Reactivity of ICCI-2C samples from the gas outlet location 


\section{Bench Screening Test of ICCl-2C Bed Temperatures}

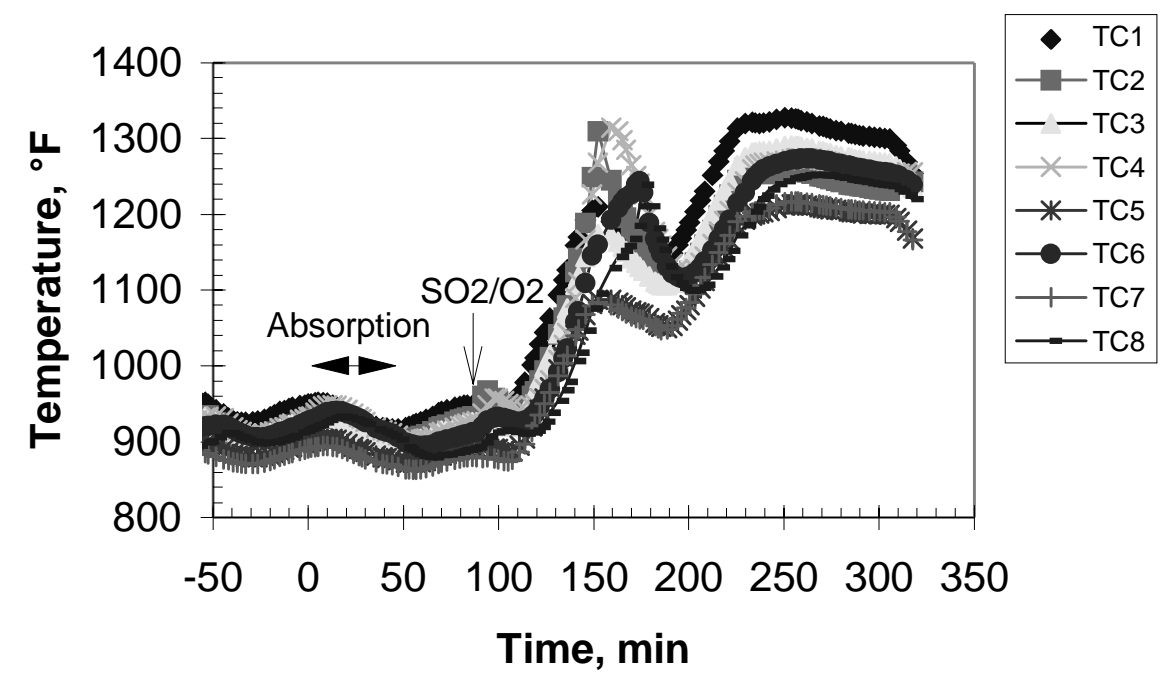

Figure 3-66. Temperature history of ICCI-2C during bench-scale absorptions and regenerations

Table 3-23 below shows the residual total sulfur and sulfate at both gas inlet and gas outlet locations for samples after the 5th regeneration and after the 13th regeneration. The amounts of residual sulfate and residual total sulfur are very minimal (values below $0.5 \%$ is acceptable). As expected, the presence of $\mathrm{SO}_{2}$ slows down the rate of regeneration, as given by the higher amounts of residual total sulfur in the sample. All sulfur analyses of the sorbents are acceptable for operation.

Table 3-23. Residual sulfur of ICCI-2C samples after bench-scale testing at GE-CRD

\begin{tabular}{c|c|c|c|}
\hline \multicolumn{4}{c|}{ ICCI2 SORBENT - Bench-Scale Test } \\
\hline & Fresh & After 5th Regeneration & After 13th Regeneration \\
\hline \% Total Sulfur & & & .66 \\
Gas Inlet & .08 & .16 & .26 \\
Gas Outlet & .08 & .16 & .16 \\
\hline \% Sulfate Sulfur & & & .04 \\
Gas Inlet & .05 & .14 & .14 \\
Gas Outlet & .05 & & \\
\hline
\end{tabular}


Finally, the attrition of the samples was also measured, as given below:

ASTM attrition:

- Fresh Sorbent: $2.16 \%$

- Gas inlet location, 13 th regeneration: $1.89 \%$

- Gas outlet location, 13th regeneration: $2.09 \%$

For comparison, other sorbents exhibit ASTM attrition values of around 0.7 to $1 \%$ for fresh sorbent. ICCI-2C's attrition is approximately double. However, the advantage of one material over the other for TECO operation (i.e., where regeneration is done under $\mathrm{SO}_{2}$ at 5-7 atm) can only be given by the more extensive testing protocol, i.e., the 25 cycle test under pressurized conditions of regeneration in the presence of $\mathrm{SO}_{2}$. ICCI-2C is capable of operating under pilot plant conditions (1.5-atm regeneration) provided an activation step for three to five cycles in the absence of $\mathrm{SO}_{2}$ during regeneration is carried out. Evaluation at higher generation pressures (i.e., $7 \mathrm{~atm}$ ), as in the TECO demonstration plant, will require additional laboratory testing before confirming the suitability of the sorbent for those conditions. 


\subsection{TASK 5 - SORBENT COST ASSESSMENT}

In the process of screening formulations for sorbent development, it is important not only to analyze the sorbent performance from a technical standpoint (desulfurization and regeneration characteristics) but also from the point of view of the potential cost associated with the operation of a commercial hot gas cleanup system using a moving-bed sorbent. The important cost areas in determining the total operating cost associated with the sorbent itself are:

- purchase of the sorbent

- replacement or makeup during operation

- disposal of the spent material

The cost assessment was initiated early in the program and concurrently in the cost assessment with the thermodynamic equilibrium calculations of Task 2 -Sorbent Preparation. The first item in the cost assessment is the purchase cost of the sorbent, which includes the price of raw materials and the fabrication cost at a vendor. We looked at the order-of-magnitude purchase price of raw metal oxides for sorbent fabrication in commercial quantities (i.e., more than 100,000 lb/year). Table 3-24 shows the relative costs of the metal oxides identified under Task 2 as being potentially usable for sorbent fabrication. If a sorbent is to be fabricated inexpensively and be competitive in price with either a straight zinc titanate (with no additives) or a supported zinc oxide on an inert substrate, the cost of raw materials cannot exceed $\$ 2-3 / \mathrm{lb}$.

From Table 3-24 we can see that major desulfurization components, i.e., those oxides that will perform the bulk of the desulfurization duty, must be in the lower categories of the cost scale, namely, less than $\$ 2 / \mathrm{lb}$. Zinc oxide can be obtained from about $\$ 0.50 / \mathrm{lb}$ for relatively low purity up to about $\$ 2 / \mathrm{lb}$ for high purity/high surface area grades. Manganese oxides and copper oxides can be purchased in large quantities for about $\$ 2 / \mathrm{lb}$, so they also can be used as starting materials for bulk desulfurization. Oxides in the medium-to-high price range such as zirconium oxide can be used as strengthening materials (since the desulfurization activity is practically zero) but in smaller quantities, less than $50 \%$ of the composition, in order to keep raw material prices down.

In addition, raw metal oxides that cost $\$ 7-10 / 1 b$ can only be used as additives in small amounts $(<10 \%)$ to a major desulfurization component, so that the price increases by less than $\$ 1 / \mathrm{lb}$ only. Because target

Table 3-24. Relative cost of metal oxides for sorbent fabrication

\begin{tabular}{|l|c|c|}
\hline$<\mathbf{\$ 1 / l b}$ & $\mathbf{\$ 2 - \$ 6 / l b ~}$ & $\mathbf{\$ 7 - \$ 1 0 / l b}$ \\
\hline $\mathrm{ZnO} \rightarrow$ & $\leftarrow \mathrm{ZnO}$ & $\mathrm{V}_{2} \mathrm{O}_{5}$ \\
$\mathrm{TiO}_{2}$ & $\mathrm{NiO}$ & $\mathrm{MoO}_{3}$ \\
& $\mathrm{MnO}_{2}$ & $\mathrm{Cr}_{2} \mathrm{O}_{3}$ \\
& $\mathrm{CuO}$ & $\mathrm{CoO}$ \\
& & $\mathrm{CeO}_{2}$ \\
& & $\leftarrow \mathrm{ZrO}_{2} \rightarrow$ \\
\hline
\end{tabular}


prices for commercial quantities of moving-bed sorbents are in the range of $\$ 3-5 / \mathrm{lb}$, the expensive metal oxides like molybdenum seem to be viable only as secondary additives. For instance, current zinc titanate with molybdenum additive uses two to three percent molybdenum in order to keep target costs within reach.

The second item in the initial purchase cost is the fabrication cost. From discussions with various sorbent suppliers, the cost of converting the raw materials into a formed (pelletized) sorbent formulation adds about $\$ 1 / \mathrm{lb}$ for the current fabrication techniques. These pelletization techniques are considered proprietary or trade secrets so no details are available in the public domain.

After the initial purchase cost, the second category in the total operating cost assessment of sorbents included the cost associated with the replacement or makeup cost of the sorbent. The sorbent makeup is dictated by the necessary removal of the sorbent from the moving-bed system either because of fines production (by attrition or pellet degradation that increases the pressure drop across the bed) or a loss in chemical reactivity of the sorbent (that requires faster sorbent movement across the absorber to maintain a given level of desulfurization performance). The removal of sorbent fines is done after each cycle through a vibrating screen at the bottom of the regenerator.

The basis for calculating the replacement or makeup cost for a moving-bed system is the current TECo Polk Power Station I configuration for the entire plant:

- $250 \mathrm{MW}$ (net) electricity production

- 2000 ton (dry)/day of coal with $2.45 \%$ sulfur and $4.5 \%$ moisture in the coal

- $7 \%$ sulfur loading per pound of sorbent and $100 \%$ sulfur removal from the coal fuel

Figure 3-67 presents the sorbent makeup cost, in cents per kWh versus the percent sorbent makeup as a function of purchase cost. Since the sorbent moves continuously in a loop between the absorber and the regenerator vessels in the moving-bed system, the sorbent makeup is defined as the percentage of

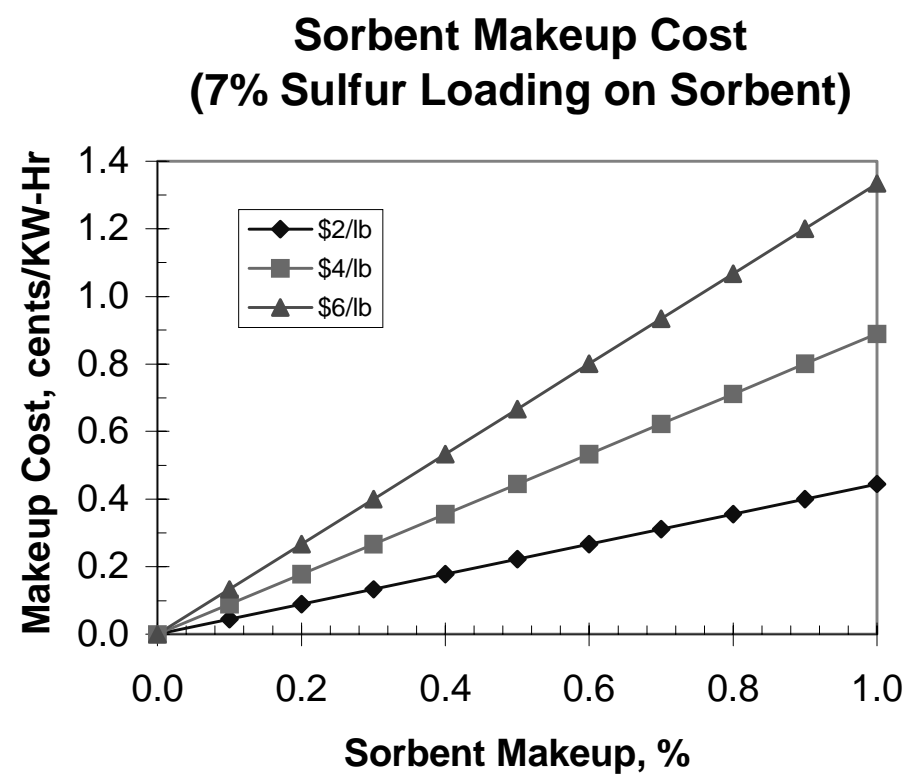

Figure 3-67. Sorbent makeup cost versus percent sorbent makeup. 
the total material circulated in pounds divided by the amount removed through the vibrating screen, also in pounds. Therefore, if the sorbent makeup cost that a utility company is willing to accept is defined and the purchase cost per pound is available from a sorbent supplier, then the allowable sorbent makeup rate (as a percentage of the circulated amount) is defined. For instance, if the utility company will accept a makeup cost of 0.1 to 0.2 cents/ $\mathrm{kWh}$ and the sorbent supplier quotes a selling price range of $\$ 3-\$ 5 /$ $\mathrm{lb}$, then a makeup rate of 0.16 to $0.2 \%$ is acceptable to make the system economically viable at the commercial scale.

Acceptable sorbent candidate formulations for moving beds have an initial ASTM attrition loss of 1-2\% or less. The ASTM attrition loss measured in laboratory tests has been observed to be up to 10 times higher than the actual makeup rates measured in the pilot plant. If this ratio holds for commercial-scale systems, the actual makeup rate will be about $0.1-0.2 \%$ for fresh material, which is in agreement with the sample calculation of 0.16 to $0.2 \%$ presented above using Figure 3-67. Market conditions will eventually determine the target ASTM attrition rates for acceptability of a given sorbent formulation.

The third category in the total operating cost assessment of sorbents includes the disposal cost of the spent sorbent. The cost of disposal will be directly related to whether or not the material can be classified as non-hazardous and suitable for landfilling. Past samples of sorbents from the GE-CRD pilot plant have been analyzed and passed landfill requirements as non-hazardous materials under RCRA requirements.

Various reclaimers have been contacted by GE-CRD in the past under the pilot plant program, and various arrangements have been made for disposal of relatively small quantities of zinc titanates and zinc-based sorbents. For larger shipments (about 30,000 lb), the reclaimer has paid \$20/ton for the spent sorbent material. For large commercial quantities (greater than 100,000 lb), it is expected that a positive revenue can be realized by the utility for selling the material to the metal ore reclaimer. The chemical composition will influence strongly the selling price. For the purpose of estimation of the operating costs for this task, no credit is given for the sale of the spent sorbent material since geographic market conditions vary widely across the U.S.

Consequently, for a sorbent development program for moving-bed applications, the general guidelines to keep the sorbent costs low and aim at meeting commercial operation targets should be:

- Bulk desulfurization components should be less than $\$ 2 / \mathrm{lb}$.

- Sorbent makeup rates should be about $0.1-0.2 \%$ in commercial systems when the purchase price range is $\$ 3-5 / 1 b$ and the acceptable operating cost for the utility company is in the range of 0.1-0.2 cents/kWh.

- A positive revenue stream is expected if the spent sorbent can be sold as non-hazardous, landfillable material under RCRA guidelines. 


\subsection{TASK 6 - TOPICAL REPORT}

This topical report includes a summary of all the technical information generated during the course of the contract from September 1994 to date. In addition to the monthly technical reports, the following annual technical reports were submitted to DOE to summarize the annual technical progress of the project:

- 1994 Annual Technical Report (September 1994-November 1994)

- 1995 Annual Technical Report (December 1994 to November 1995)

- 1996 Annual Technical Report (December 1995 to November 1996)

- 1997 Annual Technical Report (December 1996 to November 1997) 


\subsection{TASK 7 - MARKET PLAN}

The market plan for the development of moving-bed sorbents was centered around potential sorbent suppliers for three formulations:

1. modified zinc titanates (MZT's)

2. ICCI-2C sorbent

3. zinc-manganese oxide sorbents

Fabrication of modified zinc titanates was conducted at UCI in the performance of this contract program. To develop technical formulations that could be manufactured in commercial quantities (greater than 100,000 lb/yr), UCI committed to provide technical support in the development of the large-scale technique for extruding and forming MZT's at their facilities in Louisville, Kentucky. Fabrication of zinc titanate compositions is protected in part by previous patent positions at GE developed during the course of the years in sorbent development. The know-how of pelletization and forming comes from UCI's industrial experience in the granulation, pelletization, and forming of commercial catalysts and specialty chemicals. A secrecy agreement was signed between GE and UCI and is in place to protect UCI's industrial experience in the market place. This relationship of patented zinc titanate compositions and proprietary fabrication techniques is in place to move forward quickly in response to market conditions that require manufacture of large quantities of sorbents.

As the testing at TECo's Polk Station proceeds with the current sorbent formulations, and if a request is received from DOE and TECo's project management, UCI and GE are in a position to consider fabrication of 100,000 lb. of zinc titanate sorbents. Market conditions, scheduling of production, raw materials costs, and other external factors will determine the timing and final cost of the delivered product, but it is anticipated that the target sorbent cost of $\$ 3-5 / \mathrm{lb}$ can be met. A potential market development risk for commercialization of moving-bed sorbents in the future is the uncertainty about the size of the near-term market for coal-based IGCC power generation in the U.S. Several alternate sorbent manufacturers had been polled by GE over the years for upgrading of their facilities to prepare for demonstration- and commercial-scale production of desulfurization sorbents, and a recurring question revolves around the certainty in the predicted near-future market for coal-based IGCC in the US.

Several other sorbent manufacturers are interested in forming partnerships to market moving-bed sorbents, but, because of their smaller current production size, response to a sudden opening in the IGCC/HGCU market would take several years for them to upgrade their production facilities and respond to market requests for new sorbents.

In parallel to the position of modified zinc titanates, E\&A Associates has also developed a proprietary position with UCI to offer ICCI-2C sorbent in support of moving-bed sorbents at TECo. As actual process conditions for steady-state desulfurization in the demonstration-scale TECo plant develop, ICCI-2C is an alternate sorbent path for moving-bed sorbent development towards commercial systems.

With respect to the evaluation of manganese-based sorbents, it is believed that a feasible program plan could be implemented where Chemetals optimizes the chemical composition and mechanical strength of manganese-zinc based sorbents and GE focuses on the kinetic characteristics of the desulfurization performance. Potential applications of the manganese-based sorbents for moving-bed systems would be 
a third-generation sorbent fill for the Clean Coal Technology Demonstration Plants. A development plan would still be necessary for the marketing of commercial quantities of zinc-manganese sorbents.

Evaluation of manganese-containing sorbents suggested that improvements in mechanical strength can be brought about by the manganese component of the sorbent. Given that manganese by itself cannot remove $\mathrm{H}_{2} \mathrm{~S}$ to as low levels as zinc-based sorbents can, the combination of both zinc and manganese oxides may give a synergistic advantage that either of the two metals taken alone cannot provide. However, improvements in the attrition resistance of the manganese-zinc pellets in larger scale production are necessary to compete in durability against other zinc-containing sorbents.

\section{REFERENCES: CHAPTER 3}

1 Gal, E.1991 System for Removal of Sulfur Compounds from Gases and for Regenerating Spent Sorbents, U.S. patent 5,026,528, June 25, 1991. Also U.S. patent 4,857,285, August 1989.

2 Ayala, R.E. and E. Gal. 1995. Process and Apparatus for Generating Elemental Sulfur and Reusable Metal Oxide from Spent Metal Sulfide Sorbents, U.S. patent 5,401,475, March 28, 1995.

3 Ayala, R.E. Molybdenum-Based Additives to Mixed-Metal Oxides for Use in Hot Gas Cleanup Sorbents for the Catalytic Decomposition of Ammonia in Coal Gases. U.S. Patent 5,188,811. Feb. 23, 1993.

4 Ayala, R.E.; T.L. Chuck; and V.S. Venkataramani. Hot Coal Gas Desulfurization. US Patent 5,753,198. May 19, 1998.

5 Furman, A.H., R. Ayala, A. Feitelberg, M. Lacey, and S. Bevan. 1998. Integrated Operation of a Pressurized Fixed-Bed Gasifier and Hot Gas Desulfurization System. CD ROM. Final Report to the U.S. Department of Energy/Federal Energy Technology Center, Morgantown, WV, under contract DE-AC21-87MC23170. March 1998. 


\section{Chapter 4}

\section{CONCLUSIONS AND RECOMMENDATIONS}

\subsection{CONCLUSIONS}

The following conclusions can be drawn from the evaluation of metal oxides from thermodynamic and kinetic principles in order to identify sorbent formulations suitable for fabrication and laboratory evaluation:

- A literature review of past work and screening thermodynamic calculations of metal oxides identified twenty metal oxides that had the potential for use in hot gas desulfurization systems in the temperature range of 343 to $538^{\circ} \mathrm{C}$. These were considered for evaluation.

- Thermodynamic equilibrium diagrams of $\mathrm{H}_{2} \mathrm{~S}_{(\mathrm{g})}$ over metal oxides were constructed as a function of temperature to determine the maximum sulfur removal possible at the given temperature range. Two coal gas fuel compositions were chosen: oxygen-blown, entrained-flow gasifier and air-blown, fluidized-bed gasifier. Of the twenty metal oxides initially considered, manganese, molybdenum, cobalt, zinc, and copper oxides were identified as having the low equilibrium $\mathrm{H}_{2} \mathrm{~S}$ and the required kinetic rates to desulfurize coal gas to the target of less than $25 \mathrm{ppm} \mathrm{H}_{2} \mathrm{~S}$.

- Corresponding phase stability diagrams of the metal sulfides in oxidative regeneration gases were also constructed to identify the regeneration capabilities of the promising desulfurization metal oxides. Zinc, copper, iron and molybdenum among others were the metals that thermodynamically and kinetically exhibited promising characteristics for regeneration at temperatures compatible with the desulfurization range chosen. Manganese required a higher temperature of regeneration than the others but still could be considered for evaluation.

- Three categories of metal oxides were considered for evaluation: (1) main components for desulfurization, (2) secondary components for desulfurization, chemical stability additives, or porosity modifiers, and (3) structural components to maintain mechanical durability of the pellets.

- Table 4-1 summarizes the metal oxides that were identified in each of the three categories as potential candidates for laboratory fabrication and evaluation.

The following conclusions can be drawn from the sorbent fabrication and experimental evaluation of UCI-GE zinc titanates:

Table 4-1. List of metal components for sorbent screening.

\begin{tabular}{ccc}
\hline Main Component & Secondary Component & Structural Component \\
\hline $\mathrm{Zn}$ & $\mathrm{Fe}, \mathrm{Cu}, \mathrm{Mo}, \mathrm{Co}$ & $\mathrm{Ti}, \mathrm{Zr}, \mathrm{Ce}$ \\
$\mathrm{Fe}$ & $\mathrm{Cu}$ & $\mathrm{Ti}, \mathrm{Zr}$ \\
$\mathrm{Ce}$ & $\mathrm{Mo}$ & $\mathrm{Ti}, \mathrm{Zr}$ \\
$\mathrm{Cu}$ & $\mathrm{Mn}$ & $\mathrm{Ti}, \mathrm{Zr}$ \\
\hline
\end{tabular}


- Molybdenum-containing zinc titanate (at 2\% equivalent molybdenum oxide) exhibited a good combination of chemical and mechanical properties during laboratory testing at GE-CRD. Further testing at RTI's facilities during 1996 showed that requirements at that time for chemical reactivity and sulfur loading were exceeded at the target levels of $50 \%$ of theoretical. The mechanical ASTM attrition loss was well below the target level for the fresh material ( $0.7 \% \mathrm{vs.} 4 \%$ target) although the same ASTM attrition loss after 50 cycles was higher at $7.4 \%$ versus the target of $5 \%$. Higher levels of attrition resistance would be required ultimately for this sorbent to be economically viable in commercial systems.

- The same molybdenum-containing formulation studied in the laboratory facilities was also tested for 200 hours of continuous operation in the GE-CRD pilot plant under Test 8 in September 1995 to determine the correspondence in performance between bench-scale conditions in the laboratory and pilot plant operation. The pilot plant makeup losses were measured at 1.7 and $0.3 \%$ for the 200-hr cycled sorbent under conditions of two different mesh sizes of the vibrating screen that removes the sorbent fines. These results compare favorably with the 7.4\% ASTM attrition loss measured after 50 cycles in the laboratory, indicating that the large-scale operation is less severe and the cost of sorbent replacement or makeup in the pilot plant is less than predicted from ASTM tests. With respect to desulfurization performance in the GE-CRD pilot plant, close to $99 \%$ sulfur removal (30-40 ppm dry $\mathrm{H}_{2} \mathrm{~S}$ in the clean gas) was obtained while simultaneously achieving the target sulfur loading on the sorbent for TECo and steady $\mathrm{SO}_{2}$ production during regeneration. The results at the three levels of testing indicate that the flow of information and technology transfer from laboratory to pilot plant is technically consistent and prediction of larger pilot-plant scale operation is possible from laboratory and bench test results.

- Several formulations of modified zinc titanates (MZT's) were pelletized to aim at improvements in mechanical durability over the previously tested molybdenum-containing zinc titanate formulations. Two rounds of formulations containing additives were prepared. Although the first round of formulations was disappointingly weak in mechanical strength, the second round of pelletization included two formulations, MZT-I1 and MZT-R1, which exhibited improved characteristics. Both presented better mechanical durability with negligible degradation with respect to the fresh formulation, but only MZT-R1 was capable of meeting the requirements of sulfur loading of $0.11 \mathrm{~g}$ of sulfur $/ \mathrm{cm}^{3}$ of bed $\left(6.7 \mathrm{lb} / \mathrm{ft}^{3}\right)$ at the low temperatures of operation $\left(370^{\circ} \mathrm{C}, 700{ }^{\circ} \mathrm{F}\right)$.

- Batch-to-batch repeatability in the fabrication of MZT's, however, is still an issue. ASTM attrition loss of different batches of fresh MZT-R1 prepared for testing at GE-CRD and RTI ranged from 0.7 to $2.0 \%$. This batch-to-batch variability in the attrition resistance of fresh samples is large compared to the corresponding changes in attrition loss, typically less than $1 \%$, that occur over repetitive testing. Further refinements to the formulation of MZT compositions will require better control in the pelletization procedures.

- Testing at RTI for 13 cycles at bench-scale conditions showed that the two MZT sorbents considered (MZT-R1 and MZT-I1) can desulfurize and regenerate at conditions resembling those to be encountered at the TECo plant, namely, desulfurization in the range $373-482^{\circ} \mathrm{C}\left(700-900{ }^{\circ} \mathrm{F}\right)$ and regeneration up to $760^{\circ} \mathrm{C}\left(1400^{\circ} \mathrm{F}\right)$. In spite of these positive results, more work is needed to circumvent the impending degradation of the pellets over a higher number of cycles. 
The following conclusions can be drawn from the testing of proprietary sorbents in the GE-CRD pressurized bench-scale reactor system:

- Several formulations of zinc oxide/manganese oxide sorbents provided by Chemetals (Baltimore, Maryland) were evaluated at GE-CRD for mechanical durability (attrition and crush strength) and chemical reactivity.

- Evaluation of Chemetals manganese-containing zinc-based sorbents suggested that improvements in mechanical strength can be brought about by the manganese component to the sorbent. Given that manganese by itself cannot remove $\mathrm{H}_{2} \mathrm{~S}$ to as low levels as zinc-based sorbents can, the combination gives a synergistic advantage of deep desulfurization and added mechanical strength. However, improvements in the fabrication procedures aimed at increasing attrition resistance of the manganese-zinc pellets are necessary to compete against other zinc-containing sorbents in durability.

- Evaluation of ICCI-2C sorbent was carried out at GE-CRD with the purpose of evaluating the reactivity and durability of the sorbent in pelletized forms. ASTM attrition losses after 13 cycles of bench testing (range 1.89-2.09\%) were comparable to that of the fresh sorbent (2.16\%), suggesting that this sorbent is a potential candidate for long-term use. All testing was performed at $482{ }^{\circ} \mathrm{C}$ for absorption and regeneration; evaluation at lower temperatures is still needed to confirm suitability for low-temperature operation down to $343^{\circ} \mathrm{C}$.

- ICCI-2C is capable of operating under pilot plant conditions (1.5-atm regeneration) provided an activation step of three to five cycles is carried out in the absence of $\mathrm{SO}_{2}$ during regeneration. Evaluation at higher generation pressures (i.e., $7 \mathrm{~atm}$ ), as in the TECO demonstration plant, will require additional bench-scale testing before confirming the suitability of the sorbent for those conditions.

- With respect to the economics of operating a moving-bed HGCU system, a reasonable target for the sorbent operating cost to a utility company is 0.1 to 0.2 cents $/ \mathrm{kWh}$. To operate below this target and be commercially viable, the sorbent makeup rate must be less than 0.16 to $0.2 \%$ at a sorbent purchase price of $\$ 3-5 / \mathrm{lb}$ to make the moving-bed HGCU systems feasible. Higher sorbent prices or higher make-up rates make the HGCU system commercially less attractive. Currently, sorbent manufacturers consider these sorbent prices achievable in commercial quantities. 


\subsection{RECOMMENDATIONS}

The development of zinc titanates, whether in the form of molybdenum-added formulations or modified zinc titanates (MZT's), has reached a level of understanding that makes them suitable for commercial applications. Evaluation of desulfurization reactivity at the laboratory, bench-scale, and pilot-plant facilities has shown that zinc titanates and proprietary sorbents can easily meet the target levels of $99 \%$ desulfurization of coal gases in the temperature range of 343 to $538^{\circ} \mathrm{C}$.

A significant issue that still remains with the use of zinc titanates is the capability to control the fabrication procedures that result in predictable sorbent mechanical properties, particularly the ASTM attrition resistance. To date, variations from batch to batch have a spread that is comparable to the changes observed during testing over five to fifteen cycles. It is recommended that a program be undertaken with commercial sorbent suppliers aimed at understanding and minimizing the variability in the physical morphology and mechanical properties of the pelletized sorbents.

For the case of Chemetals manganese-zinc sorbents, given that addition of zinc oxide decreased the attrition resistance of the pure manganese sorbents, a study of the production methods and mixing variability is also needed.

For the case of ICCI-2C sorbents, a study is needed on the operability of the sorbent at temperatures in the range 343 to $482^{\circ} \mathrm{C}$ to determine if the chemical reactivity is sufficient to operate a commercial system at the desired sulfur loadings on the sorbent. In addition, methods should be investigated that decrease the level of conditioning or activation that is currently required over the first three to five cycles.

Overall the technology of manufacturing pelletized sorbents for desulfurization in moving-bed applications has reached a maturity that makes it possible to assess current sorbent performance in laboratory and bench-scale systems and correlate with pilot-scale performance. Extrapolation of these performance parameters is still necessary when going to commercial scale systems, since no data have been generated at those scales. Future advances in moving-bed technology will require data on the mechanical and chemical performance of TECo's Polk Station hot gas cleanup demonstration plant. 